Anne Caroline Negrão

Modelagem hidrodinâmica unidimensional da passagem de onda de cheia em um córrego urbano considerando escoamento transcrítico

VERSÃO CORRIGIDA

São Carlos - SP

2015 

Anne Caroline Negrão

\title{
Modelagem hidrodinâmica unidimensional da passagem de onda de cheia em um córrego urbano considerando escoamento transcrítico
}

\author{
Dissertação apresentada à Escola de \\ Engenharia de São Carlos da Universidade \\ de São Paulo, como parte dos requisitos para \\ a obtenção do título de Mestre em Ciências: \\ Engenharia Hidráulica e Saneamento. \\ Universidade de São Paulo - USP \\ Escola de Engenharia de São Carlos - EESC \\ Programa de Pós-Graduação em Engenharia Hidráulica e Saneamento
}

Orientadora: Profa. Tit. Luisa Fernanda Ribeiro Reis

VERSÃO CORRIGIDA

São Carlos - SP

2015 
AUTORIZO A REPRODUÇÃO TOTAL OU PARCIAL DESTE TRABALHO, POR QUALQUER MEIO CONVENCIONAL OU ELETRÔNICO, PARA FINS DE ESTUDO E PESQUISA, DESDE QUE CITADA A FONTE.

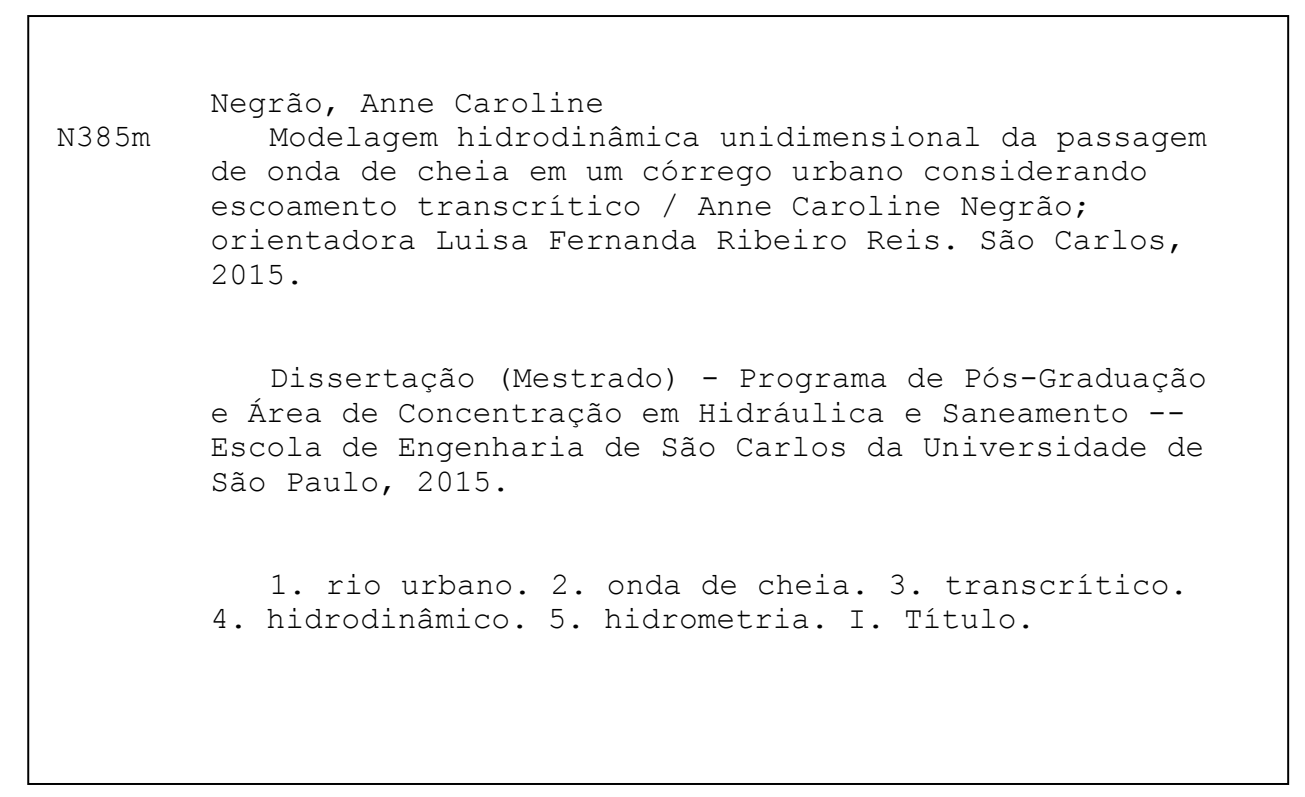




\section{FOLHA DE JULGAMENTO}

Candidata: Engenheira ANNE CAROLINE NEGRÃO.

Título da dissertação: "Modelagem hidrodinâmica unidimensional da passagem de onda de cheia em um córrego urbano considerando escoamento transcrítico".

Data da defesa: 09/10/2015

\section{Comissão Julgadora:}

Profa. Titular Luisa Fernanda Ribeiro Reis

(Orientador)

(Escola de Engenharia de São Carlos/EESC)

Prof. Dr. Klebber Teodomiro Martins Formiga

(Universidade Federal de Goiós/UFG)

Prof. Dr. Edevar Luvizotto Junior

(Universidade Estadual de Campinas/UNICAMP)
Resultado:

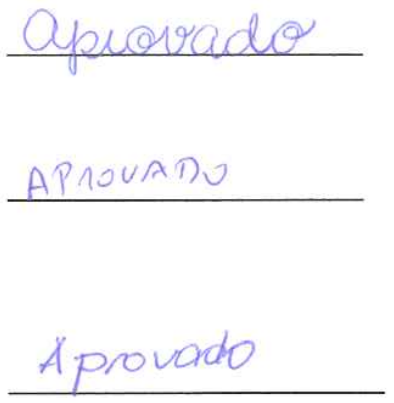

Coordenadora do Programa de Pós-Graduação em Engenharia Hidráulica e Saneamento:

Profa. Associada Maria Bernadete A. Varesche Silva

Presidente da Comissão de Pós-Graduação:

Prof. Associado Paulo César Lima Segantine 

Aos engenheiros ambientais que continuam lutando pelo o que acreditam. 



\section{Agradecimentos}

A Deus, por me dar saúde e disposição para encarar os desafios da vida!

À minha família, meu pai Sergio, minha mãe Maris e meus irmãos Sergio e Leozel. Apesar dos desentendimentos familiares, sei que vocês acreditaram em mim e que estariam presentes para me levantar independente da altura da queda. Isso me fortaleceu para seguir em frente e mudar de vida sem medo.

Agradeço à você, meu pai, que me apoiou não só com a contribuição financeira tendo ainda que auxiliar uma baita filha, já formada e com 26 anos na cara - mas também com a paciência de que um dia eu iria me estabilizar profissionalmente, com a motivação que não me deixou desistir quando as dúvidas apareceram, com a atenção e o cuidado em saber se faltava alguma coisa e se tudo corria bem.

Agradeço à você, minha mãe, mesmo com a nossa separação eu sentia no fundo do coração seu amor. A distância me fez dar mais valor a todo o carinho que você sempre dedicou a mim e meus irmãos. Sou o que sou, boa parte, graças a você, obrigada!

À minha orientadora Professora Luisa Fernanda Ribeiro Reis, que foi muito presente, resolvendo do meu lado, passo a passo, todos os problemas que encontrávamos. Se não fossem a sua persistência e dedicação nunca teríamos alcançado o que alcançamos. Muito obrigada!

Aos Professores João Luiz Boccia Brandão e Rodrigo de Melo Porto. Desde o início do projeto detiveram atenção especial ao nosso trabalho e sempre nos aconselharam.

Ao Professor Fazal Hussain Chaudhry pela ideia do suporte de fundo e à Oficina Mecânica da EESC-USP pela confecção.

Aos técnicos Miro, Bérgamo e Marcelo, que ajudaram, com toda a disposição, na instalação da Rede de Hidrometria e nas tentativas de medição de vazão. Suas ideias foram geniais pela simplicidade e lógica! Obrigada por compartilharem a vasta experiência que vocês possuem!

Às amigas e colegas de campo, Daysy, Taís e Dani. Vocês se mostraram mulheres incríveis e corajosas. Quase não dá para acreditar nessas mulheres descendo os canais da cidade com botas de borracha, carregando escada, parafusadeira, computador, martelo, chave de grifo, etc e ainda mantendo todo o charme. Admiro muito vocês!

Agradeço também à Maria Gamboa, que sempre esteve disponível quando precisássemos e algumas vezes foi conosco para campo com toda a paciência para esperar chover. Os seus conselhos sobre o andamento do meu trabalho também foram muito importantes. 
Agradeço especialmente à Daysy, com quem pude contar sem receios nas atividades de campo, pois sempre esteve um passo a frente na organização das atividades e fazia tudo acontecer. Obrigada pelas conversas e conselhos quando tive dúvidas, pela ajuda na correção da minha qualificação, pela companhia em eventos. Obrigada também pelo trabalhoso processamento dos dados de precipitação, graças ao seu esforço pude utilizalos no meu trabalho. Sei que você dará continuidade a esse trabalho com excelência! Foi um grande prazer em trabalhar contigo! Aproveito para agradecer ao Martins, que acompanhou o trabalho de campo de perto e sempre contribuiu com ótimas ideias.

Ao Rodrigo, que compartilhou a experiência do seu trabalho, cujo mesmo dei continuidade, sempre muito atencioso e disposto a ajudar, se interessou pela evolução do trabalho e deu várias dicas de campo.

Além dos já mencionados, gostaria também de agradecer ao Marcão, Leandro e Jairo, que também ajudaram muito nas atividades de campo. O apoio de todos vocês foi fundamental para este trabalho.

Aos amigos e colegas do LabSin. Além dos já mencionados, incluo o Narumi, Renata, Loide, Rafael, Heider, Ana e Fred. Adorava a companhia de vocês no dia a dia, nos bolos de fim de tarde, nas comemorações de aniversário, no cafezinho, nas reuniões, no bandex. Cada um de vocês me ajudou de alguma forma, obrigada! Foi um prazer trabalhar com vocês!

Agradecimento especial ao Narumi, por sempre, sempre mesmo, me ajudar com qualquer coisa e em qualquer momento, e fazer tudo sorrindo. Obrigada por me ajudar a resolver pepinos computacionais indecifráveis, fazer desenhos no Corel Draw para a apresentação da minha qualificação, dar conselhos, me motivar a seguir em frente e acreditar na minha capacidade. Muito obrigada! Estarei sempre te devendo... e te pedindo ajuda!

À república Partido Away, minha família em São Carlos: Julia, Leandro, Sadao, Carla, Nara, Leo, Antonio, Vitória, Loide. Com quem dividi muitos momentos de risadas, almoços super elaborados de fim de semana, discussões sem pé nem cabeça... Vocês me acolheram quando cheguei em São Carlos sem conhecer ninguém e desdo começo foram ótimos amigos, guardarei boas lembranças de cada um! Obrigada por me adotarem!

Aos amigos conquistados em São Carlos. Além dos já mencionados, também gostaria de agradecer à Maria Clara, Gustavo, Altair, Thiago, Ju, Mari, Char, Inaê, Poty, Txe, Alecrim, aos amigos da república XB e agregados: Monstro, Bel, Teta, Quixera, Kiemi, Dico, Bobo, Nay, Zé, Pauleta, Cebola e Seu Jorge. Obrigada pelos vários momentos de alegria, da cerveja nossa de cada semana, dos Tuscas, dos churras do SHS... Vocês tornaram São Carlos realmente especial! 
Agradeço especialmente ao Monstro (Gui), que conquistou meu coração e tornou os meus dias ainda mais felizes. Meu companheiro infalível na diversão, no trabalho, nos estudos, na cozinha, nas viagens e até nas horas difíceis. Obrigada por sempre estar disposto a ajudar, por discutir comigo os problemas do meu trabalho, por me acompanhar algumas vezes no campo, por me acalmar nos momentos de desespero e relembrar o meu potencial. Obrigada pela paciência em ler por completo e ainda revisar meu texto. Seu apoio foi muito importante nessa fase da minha vida! Te amo!

À equipe de vôlei, pelos treinos e campeonatos. Com vocês aprendi um pouco mais sobre competição, companheirismo e raça! Raça CAASO!!!

À São Carlos, a Terra do Nunca, que se mostrou uma cidade acolhedora, rica na programação cultural e nas festas universitárias, nas quais me sentia com 15 anos novamente.

À USP e ao Departamento de Hidráulica e Saneamento por toda e estrutura oferecida aos alunos.

À Coordenação de Aperfeiçoamento de Pessoal de Nível Superior (CAPES), e ao Conselho Nacional de Desenvolvimento Científico e Tecnológico do Brasil (CNPq), pela bolsa de mestrado concedida. 

"Se tens que lidar com água, consulta primeiro a experiência, depois a razão." Leonardo Da Vinci 



\section{Resumo}

NEGRÃO, A. C. (2015) Modelagem hidrodinâmica unidimensional da passagem de onda de cheia em um córrego urbano considerando escoamento transcrítico. Dissertação (Mestrado) - Escola de Engenharia de São Carlos, Universidade de São Paulo, São Carlos, 2015.

A compreensão, monitoramento e simulação da dinâmica da rede de drenagem de um centro urbano, inclusive os rios, podem auxiliar a análise de risco e o desenvolvimento e correção de projetos de rede de drenagem urbana. Entretanto, a simulação de rios urbanos é um grande desafio, devido a rápida variação das condições de escoamento (nível d'água e velocidade) durante a passagem de onda de cheia, trazendo dificuldades tanto no monitoramento como na modelagem. Por se tratar de escoamentos não permanentes com significativo efeito de histerese da relação nível-vazão, torna-se necessária a utilização de modelos hidrodinâmicos. Além disso, a possível ocorrência de escoamento transcrítico aumenta a complexidade de representação do problema. Neste trabalho, um modelo hidrodinâmico capaz de resolver escoamentos transcríticos foi desenvolvido com o objetivo de simular eventos de passagem de onda de cheia em rios urbanos. O modelo, implementado na linguagem Fortran, foi baseado nas equações unidimensionais completas de Saint-Venant e utiliza o esquema de resolução de Preissmann adaptado por um redutor dos termos de inércia. Isso permitiu a resolução de escoamentos transcríticos, conforme comprovado em problemas teóricos padrões. Na aplicação prática do modelo, eventos de onda de cheia foram monitorados em um trecho do canal do córrego do Gregório na cidade de São Carlos, São Paulo, e simulações foram realizadas considerando apenas dados de níveis. Os resultados obtidos foram satisfatórios (Eficiência de Nash-Sutcliffe acima de 0,7) e permitiram a utilização das vazões estimadas para a proposição de uma curva-chave para o córrego. A metodologia aplicada neste trabalho se mostrou promissora para a definição de curva-chave de rios urbanos que apresentam dificuldades de medição de vazão.

Palavras-chave: rio urbano, onda de cheia, escoamento transcrítico, modelagem hidrodinâmica, hidrometria. 



\section{Abstract}

NEGRÃO, A. C. (2015) One-dimensional hydrodynamic modeling of flood wave passage in an urban stream considering transcritical flow. Dissertação (Mestrado)

- Escola de Engenharia de São Carlos, Universidade de São Paulo, São Carlos, 2015.

The recognition, monitoring and simulation of the drainage system's dynamics of an urban center, including rivers, can assist in the risk assessment and the development and correction of urban drainage network projects. However, the simulation of urban rivers is a great challenge, due to the rapid variation of the flow conditions (water level and velocity) during the passing of flood waves, and poses difficulties for their monitoring and modeling. The use of a hydrodynamic model becomes necessary, as the flow is unsteady and produces a hysteresis effect of stage-discharge relation. Furthermore, the possible occurrence of transcritical flow increases the complexity of the problem representation even more. This manuscript addresses the development of a hydrodynamic model that solves transcritical flows and simulates flood wave events in urban rivers. The model, implemented in the Fortran programming language, was based on the one-dimensional complete equations of Saint Venant and uses the Preissmann scheme of resolution adapted by a reduction factor of the inertial terms. Such features enabled the resolution of transcritical flows, as evidenced in standard theoretical problems. In a practical application of the model, flood wave events were monitored in the Gregório creek in São Carlos, São Paulo, and simulations were performed only with level data. The results were satisfactory (NashSutcliffe efficiency above 0.7 ) and enabled the use of the flows estimated for the proposal of a rating curve for the creek. The methodology applied has shown promising for the definition of a rating curve for urban rivers of difficult flow measurements.

Key-words: urban rivers, flood wave, transcritical flow, hydrodynamic model, hydrometry. 



\section{Lista de ilustrações}

Figura 1 - Ilustração das variáveis (Adaptado de Aricó e Tucciarelli (2007)). . . 36

Figura 2 - Curva-chave em forma de loop (Adaptado de Chaudhry (1993)). . . . . 37

Figura 3 - Malha computacional para o esquema generalizado de Preissmann (Adaptado de Djordjević (2002)). . . . . . . . . . . . . . . 38

Figura 4 - Diagrama de Energia Específica para Vazão Constante (AKAN, 2006). 42

Figura 5 - Condições de contorno (CC) necessárias para escoamento trascrítico, sendo Fr o número de Froude: (a) uma condição de contorno à montante $(1+0)$; (b) uma condição de contorno à montante e outra à jusante $(1+1)$; e (c) duas condições de contorno à montante e uma à jusante (2+1) (Adaptado de Meselhe, Sotiropoulos e Holly Jr. (1997)). . . . . . 43

Figura 6 - Variação do filtro LPI (Adaptado de Fread, Jin e Lewis (1996)). . . . . 46

Figura 7 - Variação do coeficiente redutor utilizado por Djordjević, Prodanović e

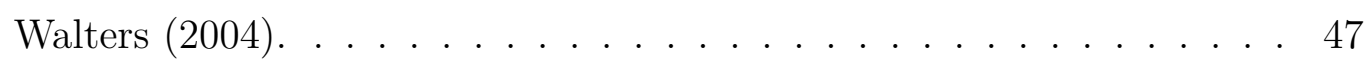

Figura 8 - Mapa de Localização da Bacia do Gregório. . . . . . . . . . . . . . . 57

Figura 9 - Localização (Adaptado do Google Earth). . . . . . . . . . . . . . 58

Figura 10 - Foto do trecho simulado. . . . . . . . . . . . . . . . . . 59

Figura 11 - Suporte de fundo para medição de profundidade d'água com levelogger:

(a) vista superior; (b) vista inferior; (c) instalação em campo. . . . . . 61

Figura 12 - ADP RiverSurveyor S5 acoplado em prancha (SONTEK, 2009). . . . . 64

Figura 13 - Seção de canal trapezoidal. . . . . . . . . . . . . . . . 65

Figura 14 - Representação gráfica (a) do nível d'água e fundo do canal e (b) da profundidade d'água e declividade de fundo do problema teste (Reproduzido de MacDonald et al. (1997)). . . . . . . . . . . . . . . . 71

Figura 15 - Suavização do registro através de média móvel de 5 dados para o evento do dia 25/03/2013. . . . . . . . . . . . . . . . . . . 73

Figura 16 - Aproximação da seção de montante obtida pela topografia para uma seção retangular. . . . . . . . . . . . . . . . . . . . . . . 74

Figura 17 - Aproximação do perfil do fundo do canal. . . . . . . . . . . . . 74

Figura 18 - Detalhe da aproximação de $\Delta x$ para os degraus. . . . . . . . . . . . . 74

Figura 19 - Linha d'água inicial para o evento do dia 25/03/2013 (a) antes e (b) depois do aquecimento no modelo hidrodinâmico. . . . . . . . . . 76

Figura 20 - Fluxograma do modelo. . . . . . . . . . . . . . . . 78

Figura 21 - Falha da simulação sem aplicação de filtro, considerando a discretização espacial de $\Delta x=10 \mathrm{~m}$. . . . . . . . . . . . . . . . . . . . . . . . . 87

Figura 22 - Análise da influência do filtro LPI na solução e determinação do máximo valor de $m$, considerando $\Delta x=1 \mathrm{~m}$. . . . . . . . . . . 88 
Figura 23 - Evolução da simulação com filtro LPI de $m=14$ e $\Delta x=1$ m. . . . . . 89

Figura 24 - Solução estabilizada para o filtro de $m=14$. . . . . . . . . . . . . . . 90

Figura 25 - Perda de informação na seleção de eventos registrados pela instalação em tubos. Os dados registrados que coincidem com as faixas cinzas, mesmo que consistentes, não participam da simulação. . . . . . . . . . 91

Figura 26 - Evolução dos limnigramas, com o passar das seções, simulados para o evento do dia 19/12/2014 21h para (a) fundo simples e (b) fundo com degraus. . . . . . . . . . . . . . . . . . 94

Figura 27 - Evolução da linha d'água simulada para o evento do dia 19/12/2014 para (a) fundo simples e (b) fundo com degraus. . . . . . . . . . . . . . 94

Figura 28 - Profundidade d'água simulada para o evento do dia 19/12/2014 para (a) fundo simples e (b) fundo com degraus. . . . . . . . . . . . . . . . 95

Figura 29 - Comparação dos hidrogramas simulados utilizando (a) fundo simples e (c) fundo com degraus com os hidrogramas obtidos pela Equação de Manning utilizando as declividades (b) do fundo simples e (d) do fundo com degraus. . . . . . . . . . . . . . . . . . . . . . . . . 996

Figura 30 - Comparação dos hidrogramas simulados com o hidrograma obtido pela Equação de Manning considerando a geometria do fundo simples a montante. . . . . . . . . . . . . . . . . . 996

Figura 31 - Intervalo de variação da velocidade simulada considerando todos os eventos para (a) fundo simples e (b) fundo com degraus. . . . . . . . . 97

Figura 32 - Variação da velocidade simulada para o evento do dia 19/12/2014 . . . 97

Figura 33 - Intervalo de variação do número de Froude considerando todos os eventos para (a) fundo simples e (b) fundo com degraus. . . . . . . . . . . . 98

Figura 34 - Variação do número de Froude para a simulação do evento do dia 19/12/2014 21h para (a) fundo simples e (b) fundo com degraus.. . . . 99

Figura 35 - Relações profundidade-vazão obtidas para a simulação do evento do dia 19/12/2014 para a aproximação de (a) fundo simples e (b) fundo com degraus. . . . . . . . . . . . . . . . . . . . . . . . 100

Figura 36 - Nuvem de pontos que relaciona profundidade-vazão para as seções (a) de montante, (b) intermediária e (c) de jusante, considerando fundo simples, e para a seção (d) de montante, (e) intermediária e (f) de jusante, considerando fundo com degraus. . . . . . . . . . . . . . . . . 100

Figura 37 - Ajuste de curva-chave considerando a relação profundidade-vazão para as seções (a) de montante, (b) intermediária e (c) de jusante, considerando fundo simples, e para a seção (d) de montante, (e) intermediária e (f) de jusante, considerando fundo com degraus. . . . . . . . . . . . . 101 
Figura 38 - Comparação entre as curvas-chave ajustada e a Equação de Manning calculada considerando as declividades das seções (a) de montante, (b) intermediária e (c) de jusante, considerando fundo simples, e das seções (d) de montante, (e) intermediária e (f) de jusante, considerando fundo com degraus. . . . . . . . . . . . . . . . . . . . 102

Figura 39 - Evolução da simulação com filtro LPI de $m=5$ e $\Delta x=10$ m. . . . . 145

Figura 40 - Solução estabilizada para o filtro de $m=5$ e $\Delta x=10 \mathrm{~m}$. . . . . . . 146 



\section{Lista de tabelas}

Tabela 1 - Os termos da equação de momento e as possíveis simplificações das equações de Saint Venant (Adaptado de Chow, Maidment e Mays (1988) p. 281). . . . . . . . . . . . . . . . . . 36

Tabela 2 - Pontos de medição e identificação dos equipamentos. . . . . . . . . . . 60

Tabela 3 - Evolução da configuração das instalações dos sensores. . . . . . . . . . 62

Tabela 4 - Distâncias dos sensores ao fundo do canal. . . . . . . . . . . . . . 72

Tabela 5 - Intervalos de desempenho de um modelo mensal, considerando o Coeficiente de Eficiência de Nash-Sutcliffe $(E N S)$, proposto por Moriasi et al. (2007). . . . . . . . . . . . . . . . . . . 79

Tabela 6 - Eventos significativos registrados pela instalação em tubos. . . . . . . . 83

Tabela 7 - Eventos significativos registrados pela instalação em suporte de fundo. $\quad 84$

Tabela 8 - Coeficiente de Eficiência de Nash-Sutcliffe (ENS) resultantes das simulações dos eventos registrados com a instalação em tubos. . . . . . . . . 92

Tabela 9 - Coeficiente de Eficiência de Nash-Sutcliffe (ENS) resultantes das simulações dos eventos registrados com a instalação em suportes de fundo. . 93

Tabela 10 - Coeficientes de Eficiência de Nash-Sutcliffe (ENS) resultantes das simulações dos eventos registrados com a instalação em tubos para diferentes valores de rugosidade de Manning. . . . . . . . . . . . . . 103

Tabela 11 - Coeficientes de Eficiência de Nash-Sutcliffe (ENS) resultantes das simulações dos eventos registrados com a instalação em suportes de fundo para diferentes valores de rugosidade de Manning. . . . . . . . . . . . . 104

Tabela 12 - Medidas obtidas a partir da topografia. . . . . . . . . . . . . . 117

Tabela 13 - Discretização espacial utilizada na aproximação de fundo simples. . . . 117

Tabela 14 - Discretização espacial utilizada na aproximação de fundo com degraus. 118 



\section{Lista de abreviaturas e siglas}

\begin{tabular}{|c|c|}
\hline $\mathrm{ADCP}$ & Acoustic Doppler Current Profilers \\
\hline ADP & Acoustic Doppler Profilers \\
\hline CCHE2D & Center for Computational Hydroscience and Engeneering $2 D$ Model \\
\hline EESC & Escola de Engenharia de São Carlos \\
\hline FINEP & Financiadora de Estudos e Projetos para Inovação e Pesquisa \\
\hline HEC-RAS & Hydrologic Engineering Centers River Analysis System \\
\hline ICFM & International Conference on Flood Management \\
\hline LabSin & Laboratório de Simulação Numérica \\
\hline LPI & Local Partial Inertial \\
\hline MAPLU-2 & Manejo de Águas Pluviais 2 \\
\hline MAST & Marching in space and time \\
\hline SHS & Departamento de Hidráulica e Saneamento \\
\hline SWIM & Soil and Water Integrated Model \\
\hline VPMS & Variable Parameter Muskingum Stage \\
\hline UGRH & Unidade de Gerenciamento de Recursos Hídricos \\
\hline USP & Universidade de São Paulo \\
\hline $1 \mathrm{D}$ & Unidimensional \\
\hline $2 \mathrm{D}$ & Bidimensional \\
\hline
\end{tabular}





\section{Lista de símbolos}

$\alpha$

$\Delta h$ e $\Delta Q \quad$ Correção das variáveis $h$ e $Q$

$\Delta t \quad$ Intervalo de tempo

$\Delta x \quad$ Distância entre as seções

d Derivada parcial

A Área da seção transversal

$A, C$ e $D \quad$ Matrizes $2 \times 2$ que representam as diagonais da matriz $M$

$a, b, c$ e $d \quad$ Coeficientes da equação

B Largura da superfície d'água ou equações de condição de contorno

$C$ e $M \quad$ Diferenças finitas da equação da continuidade e da quantidade de movimento

D $\quad$ Profundidade hidráulica

E $\quad$ Energia específica

ENS Coeficiente de eficiência de Nash-Sutcliffe

$e, f, E$ e $F \quad$ Variáveis auxiliares do Método da Dupla Varretura

Fr Número de Froude

f $\quad$ Função qualquer

g Aceleração da gravidade

$h \quad$ Cota da superfície d'água

j $\quad$ Contador espacial 


\begin{tabular}{|c|c|}
\hline$j j$ & Número total de seções \\
\hline$M$ & Matriz dos coeficientes \\
\hline$m$ & Constante utilizada pelo filtro LPI \\
\hline$N$ & Número de seções \\
\hline$n$ & Coeficiente de rugosidade de Manning ou contador de instante de tempo \\
\hline$n n$ & Número total de instantes de tempo \\
\hline$P$ & Perímetro molhado \\
\hline$Q$ & Vazão \\
\hline$q$ & Vazão de contribuição lateral por unidade de comprimento \\
\hline$r B, r C$ e $r M$ & Resíduos das equações \\
\hline$S_{0}$ & Inclinação longitudinal de fundo \\
\hline$S_{f}$ & Inclinação da linha de energia \\
\hline$t$ & Tempo \\
\hline tol & Tolerância \\
\hline$v$ & Velocidade média da seção \\
\hline$x$ & Distância na direção do fluxo principal \\
\hline$y$ & Profundidade d'água \\
\hline$y^{\prime}$ & Derivada de $y$ \\
\hline$Z$ & Matriz dos resíduos \\
\hline$z$ & Cota do fundo do canal ou variável dependente \\
\hline$W$ & Matriz das correções \\
\hline
\end{tabular}




\section{Sumário}

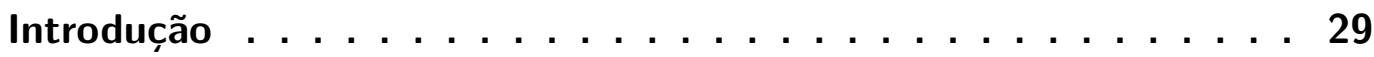

Objetivos $\ldots \ldots \ldots \ldots \ldots \ldots \ldots \ldots \ldots \ldots \ldots$

MODELAGEM 1D DE CANAIS ABERTOS - AS EQUAÇÕES DE SAINT VENANT $\ldots \ldots \ldots \ldots \ldots \ldots \ldots \ldots$

1.1 Resolução Numérica - Esquema de Preissmann Clássico . . . . . . 37

1.2 Escoamento Transcrítico e a Falha do Esquema de Preissmann . . . 41

1.3 Propostas de Soluções do Escoamento Transcrítico . . . . . . . . . . 44

2 MONITORAMENTO DA PASSAGEM DE ONDA DE CHEIA . . 49

II METODOLOGIA E MATERIAIS 55

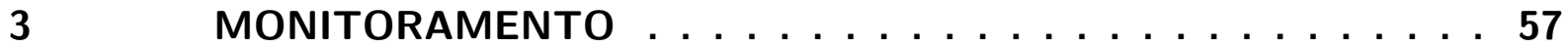

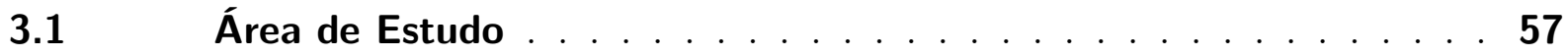

$3.2 \quad$ Monitoramento Limnimétrico . . . . . . . . . . . . . . 59

$3.3 \quad$ Medição de Velocidade . . . . . . . . . . . . . . 63

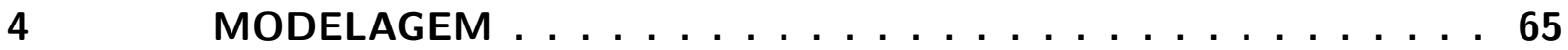

4.1 Desenvolvimento do Modelo Hidrodinâmico 1D . . . . . . . . 65

$4.1 .1 \quad$ Implementação . . . . . . . . . . . . . . . . . 65

4.1.2 Resolução do Sistema de Equações Linearizado . . . . . . . . . . . . . . 68

$4.2 \quad$ Problema Teste . . . . . . . . . . . . . . . . 70

4.3 Aplicação ao Trecho do Córrego do Gregório . . . . . . . . . . . 71

4.3.1 Processamento dos Eventos . . . . . . . . . . . . . . . 71

4.3.2 Aproximações da Geometria do Canal . . . . . . . . . . . . . . 73

4.3.3 Definição dos Parâmetros de Simulação . . . . . . . . . . . . . . . . 75

4.3.4 Aquecimento das Condições Iniciais e Definição das Condições de Contorno 75

4.3.5 Simulação dos Eventos e Análise dos Resultados . . . . . . . . . . . . 77

III RESULTADOS E DISCUSSÃO 81

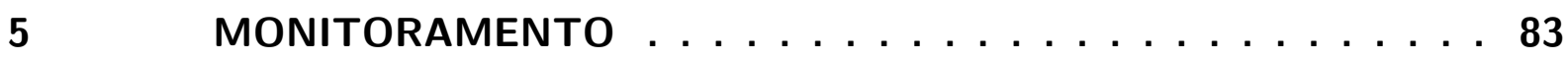




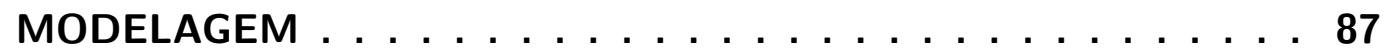

6.1 Resolução do Problema Teste . . . . . . . . . . . . . . 87

6.2 Simulação do Trecho do Córrego do Gregório . . . . . . . . . . 90

6.3 Observações em Relação à Escolha do Coeficiente de Rugosidade

de Manning . . . . . . . . . . . . . . . . . . 102

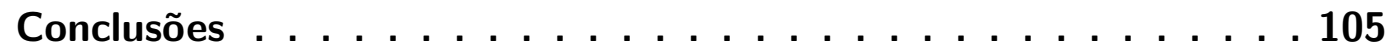

Referências . . . . . . . . . . . . . 109

APÊNDICES

APÊNDICE A - DISCRETIZAÇÃO ESPACIAL DO TRECHO DO CÓRREGO DO GRE

APÊNDICE B - CÓDIGO DO MODELO HIDRODINÂMICO 1D . 119

APÊNDICE C - LIMNIGRAMAS OBTIDOS COM A INSTALAÇÃO EM TUBOS . . . . . . . . . . . 133

APÊNDICE D - LIMNIGRAMAS OBTIDOS COM A INSTALAÇÃO EM SUPORTES DE FUNDO . . . . . . 137

APÊNDICE E - RESULTADOS DO PROBLEMA TESTE PARA A DISCRETEIZAÇÃO DE $\Delta x=10 \mathrm{M} \ldots \ldots 145$

APÊNDICE F - LIMNIGRAMAS SIMULADOS DOS EVENTOS OBTIDOS COM A INSTALAÇÃO EM TUBOS . 147

APÊNDICE G - LIMNIGRAMAS SIMULADOS DOS EVENTOS OBTIDOS COM A INSTALAÇÃO EM SUPORTES DE FUNDO . . . . . . . . . . 151

APÊNDICE H - HIDROGRAMAS SIMULADOS DOS EVENTOS OBTIDOS COM A INSTALAÇÃO EM TUBOS . 159

APÊNDICE I - HIDROGRAMAS SIMULADOS DOS EVENTOS OBTIDOS COM A INSTALAÇÃO EM SUPORTES DE FUNDO . . . . . . . . . . 163

ANEXO A - REDE DE HIDROMETRIA . . . . . . . 173 


\section{Introdução}

O processo de urbanização acelerado e desordenado vem gerando uma densa população em centros urbanos, com infra-estrutura inadequada e impactos significativos sobre os recursos hídricos. As inundações estão entre as principais consequências negativas da urbanização desenfreada, fazendo com que a população conviva com perdas humanas, sociais e econômicas cada vez mais frequentes.

Nesse cenário, a modelagem hidráulica-hidrológica se apresenta como uma ferramenta poderosa para a representação da drenagem de uma cidade, auxiliando no seu planejamento e na tomada de decisão. Entretanto, devido a impermeabilização do solo e a canalização dos rios, o escoamento superficial durante um evento chuvoso atinge velocidades e níveis muito maiores que o normal. Essas características, combinadas com o carreamento de material flutuante proveniente de resíduos sólidos urbano, dificultam sobremaneira o monitoramento de nível e de vazão. Além disso, essa rápida mudança de condições de escoamento somente ocorre durante precipitações intensas. Dessa forma, a medição de velocidades deve ser realizada durante o evento de precipitação, o que expõe a equipe de trabalho à situações de risco.

A cidade de São Carlos-SP está entre as cidades que sofrem com os problemas das inundações. A parte mais densamente povoada da cidade está inserida na Bacia do Gregório, cujo córrego representa um dos principais afluentes do Rio Monjolinho, que por sua vez pertencente à Bacia Jacaré-Guaçu. O córrego do Gregório foi modificado inúmeras vezes (CDCC, 1999) sem o devido planejamento, fato esse que, aliado à crescente urbanização, vem resultando em graves problemas de inundação em alguns pontos da cidade. Na região do Mercado Municipal, o Gregório teve sua planície de inundação aterrada e seu traçado retificado. Além disso, o córrego foi tamponado na região central da cidade. Essas mudanças, combinadas com a impermeabilização da bacia, tornaram a região mais suscetível às inundações. O aumento da velocidade de escoamento e dos picos de vazão encontram restrição logo após a confluência do córrego do Gregório com o rio Monjolinho, na região da rotatória do Shopping Iguatemi. Tal restrição se deve à passagem obrigatória do córrego do Monjolinho pelo canal existente sob a linha férrea, que vem propiciando inundações frequentes na região. Muitos estudos sobre o sistema de drenagem da cidade de São Carlos (BARBASSA, 1991; BORGES, 2006; MENDES; MENDIONDO, 2006; DECINA, 2012; MAROTTI et al., 2014) e projetos de alteração já foram desenvolvidos, sem que se pudesse contar com curvas-chave de pontos notáveis da rede de córregos que atravessam a cidade.

Um estudo anteriormente realizado teve como objetivo relacionar níveis a vazões para o córrego do Gregório através da resolução de um modelo hidrodinâmico (ALMEIDA, 2013). Entretanto, deparou-se com o problema da ocorrência de escoamento transcrítico, 
para o qual as equações de Saint Venant em sua forma original não se mostram adequadas. Assim, o presente trabalho tem como objetivo investigar a proposição de uma curva-chave para o córrego do Gregório, através da modelagem hidrodinâmica unidimensional que considera a transição de regime de escoamento e utiliza dados de nível somente. Este trabalho foi desenvolvido no âmbito do projeto Manejo de Águas Pluviais 2 (MAPLU-2), financiado pela FINEP.

Mesmo com uma diversidade de software comerciais de modelagem hidrodinâmica disponíveis, tais como o HEC-RAS (US ARMY CORPS OF ENGINEERS, 2010), o CCHE2D (NATIONAL CENTER FOR COMPUTATIONAL HYDROSCIENCE AND ENGINEERING, 2005) e o SWIM (POTSDAM INSTITUTE FOR CLIMATE IMPACT RESEARCH, 2000), decidiu-se em desenvolver o próprio modelo baseando-se nos seguintes argumentos: (1) nem sempre se tem disponíveis todas as informações exigidas pelos modelos comerciais; (2) os modelos comerciais podem não serem capazes de resolver problemas mais específicos ou não permitem certas adaptações e testes, ou até a inclusão de ferramentas diferenciadas de otimização; (3) as equações e os procedimentos utilizados no modelo próprio são conhecidos profundamente e dominados, dessa forma, as adaptações tornam-se mais fáceis e flexíveis (NIEMI, 2010). Portanto, o modelo próprio pode ser desenvolvido conforme uma preferência do pesquisador, objetivos e necessidades correntes, podendo ser mais ou menos complexos. 


\section{Objetivos}

Esta pesquisa tem como objetivo principal realizar a modelagem hidrodinâmica unidimensional de um córrego urbano durante a passagem de onda de cheia visando a determinação de sua curva-chave.

Os objetivos específicos do trabalho incluem:

- Desenvolver um modelo hidrodinâmico unidimensional utilizando as equações completas de Saint Venant e uma adaptação do método de Preissmann para resolver escoamentos trancríticos;

- Realizar testes do modelo através de problemas teóricos padrões;

- Realizar o monitoramento de nível d'água e velocidade de um trecho do canal do córrego do Gregório, São Carlos, SP;

- Aplicar o modelo desenvolvido aos eventos de onda de cheia monitorados, dando como entradas apenas informaçãoes de nível para obter estimativas de vazão;

- Relacionar nível-vazão através da proposição de uma curva-chave. 



\section{Parte I}

Revisão de Literatura 



\section{Modelagem 1D de Canais Abertos - As Equações de Saint Venant}

Durante um evento chuvoso, as condições de escoamento ao longo da rede de macrodrenagem urbana variam de forma significativa e rápida. Dessa forma, para um estudo mais detalhado da passagem de onda de cheia através de um canal, torna-se necessária uma abordagem não permanente (AKAN, 2006).

As Equações de Saint Venant, também conhecidas como equações de águas rasas, são amplamente utilizadas na modelagem de canais abertos considerando escoamento não permanente. Elas são obtidas a partir dos princípios da conservação da massa e da quantidade de movimento, na sua versão unidimensional, e consideram as seguintes hipóteses: (1) distribuição de pressão hidrostática; (2) inclinação média do canal suave, podendo-se considerar que a medição vertical da profundidade é equivalente à medição perpendicular; (3) velocidade uniformemente distribuída pelo canal, ou seja, a velocidade e o nível variam apenas na direção longitudinal do canal; (4) canal prismático; (5) fluxo homogêneo e incompressível (CHAUDHRY, 1993; CHOW; MAIDMENT; MAYS, 1988). A forma diferenciável e conservativa das Equações de Saint Venant podem ser expressas como:

$$
\begin{aligned}
\frac{\partial A}{\partial t}+\frac{\partial Q}{\partial x} & =q \\
\frac{\partial Q}{\partial t}+\frac{\partial}{\partial x}\left(\frac{\beta Q^{2}}{A}\right)+g A \frac{\partial y}{\partial x}+g A\left(S_{f}-S_{0}\right) & =0
\end{aligned}
$$

sendo $A\left(\mathrm{~m}^{2}\right)$ a área da seção transversal, $t(\mathrm{~s})$ o tempo, $Q\left(\mathrm{~m}^{3} / \mathrm{s}\right)$ a vazão, $x(\mathrm{~m})$ a distância na direção do fluxo principal, $q\left(\mathrm{~m}^{2} / \mathrm{s}\right)$ a vazão de contribuição lateral por unidade de comprimento, $g\left(\mathrm{~m} / \mathrm{s}^{2}\right)$ a aceleração da gravidade, $y(\mathrm{~m})$ a profundidade da água, $\beta$ o fator de correção de momento, $S_{f}(\mathrm{~m} / \mathrm{m})$ a inclinação da linha de energia, $S_{0}$ $(\mathrm{m} / \mathrm{m})$ a inclinação longitudinal de fundo. Nesta dissertação $z(\mathrm{~m})$ representa a cota do fundo do canal e $h(\mathrm{~m})$ a cota da superfície da água, assim, $h=y+z$ conforme indicação da Figura 1.

A inclinação da linha de energia pode ser obtida pelas leis de resistência, como a fórmula de Chézy ou de Manning. Considerando a equação de Manning, pode-se estabelecer que:

$$
S_{f}=\frac{n^{2} P^{4 / 3} Q|Q|}{A^{10 / 3}}
$$

sendo $n\left(\mathrm{~s} / \mathrm{m}^{1 / 3}\right)$ o coeficiente de rugosidade de Manning e $P(\mathrm{~m})$ o perímetro molhado. 


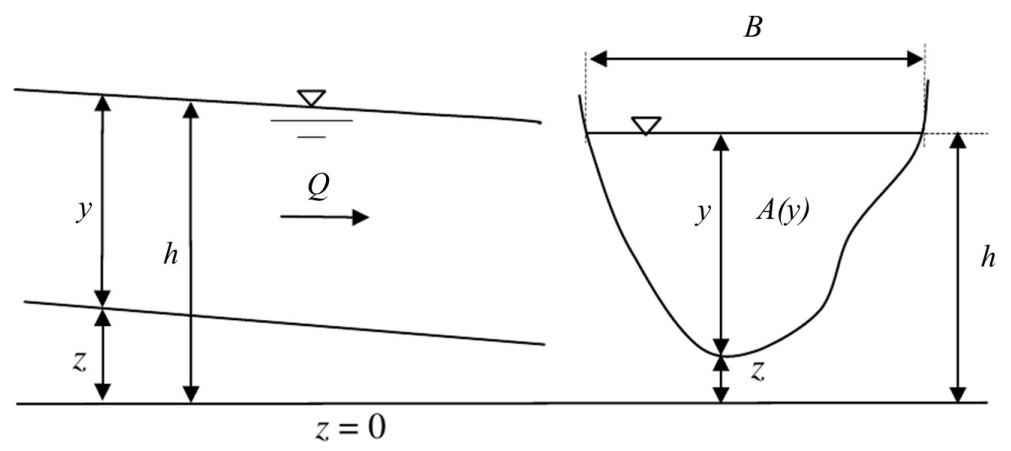

Figura 1 - Ilustração das variáveis (Adaptado de Aricó e Tucciarelli (2007)).

Dependendo das necessidades do problema a ser analisado, as Equações de Saint Venant podem ser representadas de diversas formas. Em alguns casos as simplificações da Equação 1.2, representadas na Tabela 1, são suficientes na resolução de diversos problemas.

Tabela 1 - Os termos da equação de momento e as possíveis simplificações das equações de Saint Venant (Adaptado de Chow, Maidment e Mays (1988) p. 281).

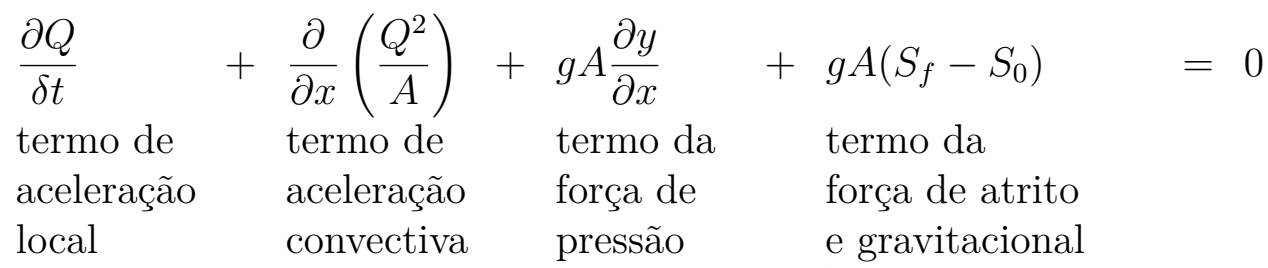

onda cinemática

onda difusiva

onda dinâmica

A escolha do tipo de modelo depende do grau de importância relativo de cada termo da equação de momento. Em casos de alta declividade de fundo, os termos de inércia, que são os termos de aceleração local e de aceleração convectiva, possuem ordem de grandeza muito menor do que os demais termos. Nesse caso, a omissão dos termos de inércia diminui a dificuldade matemática e numérica na resolução dos problemas sem grandes perdas de precisão. Esse tipo de modelo é conhecido como modelo de onda difusiva e é utilizado em situações em que a velocidade não possui grande variação no espaço e no tempo (CUNGE; HOLLY JR.; VERWEY, 1980; PORTO, 2006).

Se, além dos termos de inércia, também for omitido o termo da força de pressão, obtém-se a forma mais simplificada possível das Equações de Saint Venant, que é conhecida como modelo de onda cinemática e pode ser resolvido utilizando-se apenas a equação de Manning. Essa simplificação é bastante utilizada para propagar ao longo das bacias hidrográficas os hidrogamas estimados por modelos hidrológicos de chuva-vazão (TUCCI, 1998). 
O modelo que admite as equações completas é denominado modelo de onda dinâmica, ou modelo hidrodinâmico, e proporciona uma descrição mais precisa do escoamento. Entretanto, a dificuldade numérica aumenta consideravelmente, sendo necessário aplicar métodos numéricos robustos e obter informações mais detalhadas sobre o canal de estudo.

No caso da análise da passagem de uma onda de cheia, o detalhamento das Equações de Saint Venant torna-se importante devido às características fortemente nãopermanentes do escoamento. Nesse tipo de escoamento, a relação cota e vazão não pode mais ser representada por uma relação unívoca, como no caso permanente, ou seja, uma mesma vazão pode estar relacionada à profundidades diferentes, dependendo se o escoamento está ascendendo ou descendendo. Esse efeito é conhecido como histerese da curva-chave e se manifesta em forma de loop como representado na Figura 2 (FREAD, 1975).

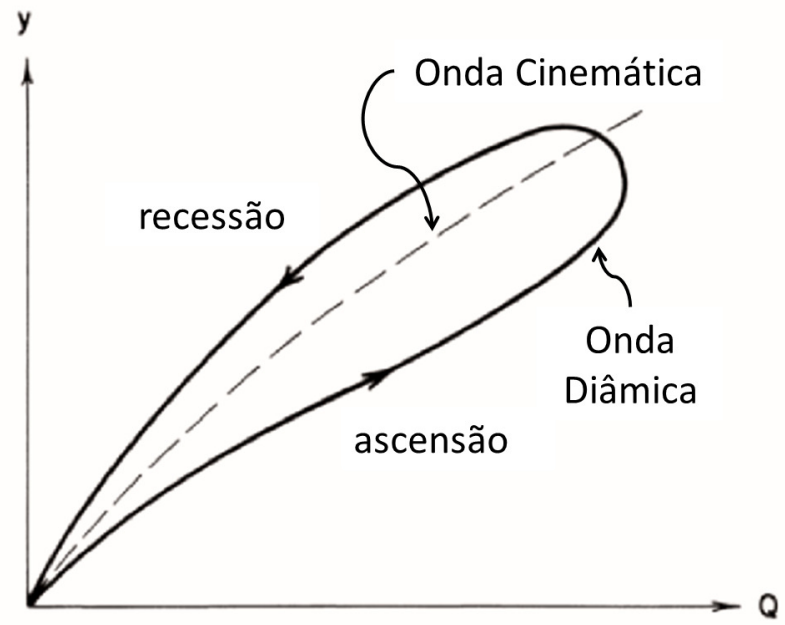

Figura 2 - Curva-chave em forma de loop (Adaptado de Chaudhry (1993)).

Durante a subida da onda de cheia, a vazão normalmente é maior do que seria para o mesmo nível em condições permanentes. O mesmo vale para a descida da onda, em que a vazão normalmente é menor do que a observada na situação permanente (HERSCHY, 1995).

\subsection{Resolução Numérica - Esquema de Preissmann Clássico}

As equações completas de Saint Venant são equações diferenciais parciais do tipo hiperbólico com solução analítica apenas em casos muito específicos. Por isso, recorre-se a métodos numéricos de resolução. Entre eles, destacam-se na literatura: o método das características, o método das diferenças finitas, o método de elementos finitos e, mais recentemente, o método de volumes finitos.

O método de resolução de Preissmann, também conhecido como esquema de quatro pontos, é um método de diferenças finitas largamente utilizado na resolução de pro- 
blemas unidimensionais de águas rasas devido à sua conformação implícita robusta e incondicionalmente estável (SILVA; MASCARENHAS; MIGUEZ, 2003; AKAN, 2006). A discretização generalizada de Preissmann considera uma grade computacional retangular representada na Figura 3. As equações de aproximação por diferenças finitas utilizadas pelo esquema são apresentadas a seguir:

$$
\begin{aligned}
f & \approx \theta\left[\psi f_{j+1}^{n+1}+(1-\psi) f_{j}^{n+1}\right]+(1-\theta)\left[\psi f_{j+1}^{n}+(1-\psi) f_{j}^{n}\right] \\
\frac{\partial f}{\partial t} & \approx \psi\left(\frac{f_{j+1}^{n+1}-f_{j+1}^{n}}{\Delta t}\right)+(1-\psi)\left(\frac{f_{j}^{n+1}-f_{j}^{n}}{\Delta t}\right) \\
\frac{\partial f}{\partial x} & \approx \theta\left(\frac{f_{j+1}^{n+1}-f_{j}^{n+1}}{\Delta x}\right)+(1-\theta)\left(\frac{f_{j+1}^{n}-f_{j}^{n}}{\Delta x}\right) \\
\phi \frac{\partial f}{\partial x} & \approx \theta\left[\psi \phi_{j+1}^{n+1}+(1-\psi) \phi_{j}^{n+1}\right]\left(\frac{f_{j+1}^{n+1}-f_{j}^{n+1}}{\Delta x}\right) \\
& +(1-\theta)\left[\psi \phi_{j+1}^{n}+(1-\psi) \phi_{j}^{n}\right]\left(\frac{f_{j+1}^{n}-f_{j}^{n}}{\Delta x}\right)
\end{aligned}
$$

sendo que $f$ representa qualquer função, $\psi$ e $\theta$ são os coeficientes de ponderação espacial e temporal, respectivamente, $\Delta t$ é o intervalo de tempo entre os instantes $n$ e $n+1$ e $\Delta x$ é a distância entre as seções $j$ e $j+1$ (DJORDJEVIĆ; PRODANOVIĆ; WALTERS, 2004).

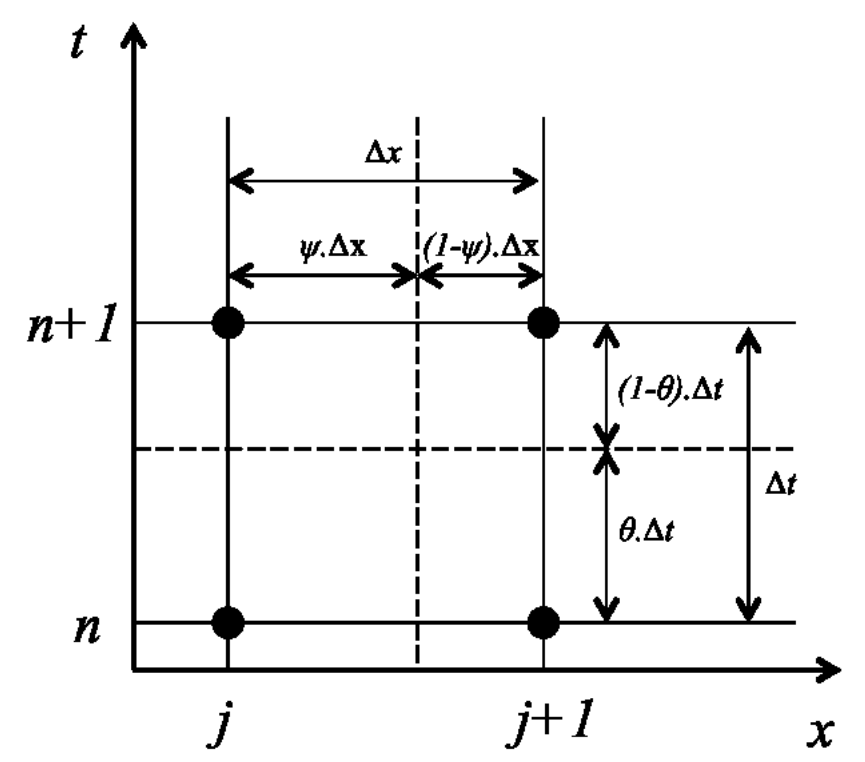

Figura 3 - Malha computacional para o esquema generalizado de Preissmann (Adaptado de Djordjević (2002)).

Os coeficientes de ponderação temporal $(\theta)$ e espacial $(\psi)$ permitem o uso de grade irregular, podendo ser ajustada conforme o problema. Quando $\theta=1$ o esquema é completamente implícito, quando $\theta=0$ o esquema é completamente explícito e quando $\theta=1 / 2$ o esquema é conhecido como Box Scheme (AKAN, 2006). Fread (1974) faz uma 
análise da estabilidade e convergência do esquema implícito de quatro pontos através do método Von Neumann e do erro de truncamento, considerando diferentes valores de $\theta$, e constatou que o esquema é incondicionalmente estável para $0,5 \leq \theta \leq 1$ e que a acurácia é reduzida conforme $\theta$ se aproxima de 1 . Fread (1974) também recomenda utilizar valores próximos de $\theta=0.55$ para evitar pseudo-instabilidade. O coeficiente espacial $(\psi)$, na grande maioria das aplicações, é igual a 0,5 (AKAN, 2006; CHAUDHRY, 1993; DJORDJEVIĆ; PRODANOVIĆ; WALTERS, 2004; FREITAG, 2003; LOPES, 2011).

Shamaa e Karkur (2011) verificaram a estabilidade dos esquemas de Preissman inverso e explícito inverso com a variação dos coeficientes de ponderação. Os esquemas inversos consistem em iniciar o cálculo a partir do último instante de tempo e retroceder ao primeiro instante de tempo. Esses esquemas são bastante utilizados em canais de irrigação para estimar a demanda de água a montante de forma a atingir um hidrograma desejado a jusante. Os autores observaram que para o caso implícito a variação dos coeficientes de ponderação pouco influenciavam os resultados. Já o caso explícito se apresentou estável somente para valores específicos desses coeficientes. Segundo Cunge, Holly Jr. e Verwey (1980), para evitar oscilações indesejadas na solução, considera-se $\psi=0,5$ e $0,6<\theta<1$.

Aplicando-se as Equações 1.5 - 1.7 aos termos das Equações 1.1 e 1.2, obtém-se um sistema de $2 N$ equações - considerando que $N$ seja o número de seções - e $2 N+2$ incógnitas. As outras duas equações necessárias para a resolução do sistema são obtidas através das condições de contorno, de montante ou montante e jusante, de acordo com o tipo de escoamento que se tem. Com essas equações e as condições iniciais o sistema pode ser resolvido.

A cada passo de tempo as equações são resolvidas por métodos de iteração nãolineares que buscam zerar os resíduos da solução. O mais utilizado é o Método de Iteração de Newton Generalizado (AKAN, 2006).

O sistema de equações é representado por uma matriz esparsa e pode ser resolvido de diversas formas, a mais intuitiva é por inversão de matriz, como o Método de Eliminação de Gauss. Entretanto, formas mais robustas e rápidas estão ganhando espaço, como o Método da Dupla Varredura utilizada por Jhonson, Baines e Sweby (2002), Freitag e Morton (2007), Niemi (2010) e também neste trabalho.

Segundo o Método da Dupla Varredura, também conhecido como método de Thomas, as matrizes esparsas podem ser representadas por pontos computacionais conectados apenas aos seus pontos adjacentes, não mais a todos os outros pontos (CUNGE; HOLLY JR.; VERWEY, 1980). Dessa forma, o número de operações diminui para uma proporção de $N$, sendo $N$ o número de grades computacionais, contra $N^{3}$ dos métodos convencionais (FREITAG, 2003). 
Acompanhando a dedução realizada por Cunge, Holly Jr. e Verwey (1980), considerase o sistema de equações:

$$
a_{j} z_{j-1}+b_{j} z_{j}+c_{j} z_{j+1}=d_{j}
$$

que é representado por uma matriz tri-diagonal:

$$
\left[\begin{array}{ccccccc}
b_{1} & c_{1} & \ldots & \ldots & \ldots & \ldots & \ldots \\
a_{2} & b_{2} & c_{2} & \ldots & \ldots & \ldots & \ldots \\
\ldots & a_{3} & b_{3} & c_{3} & \ldots & \ldots & \ldots \\
\ddots & \ddots & \ddots & \ddots & \ddots & \ddots & \ddots \\
\ldots & \ldots & \ldots & \ldots & a_{j j-1} & b_{j j-1} & c_{j j-1} \\
\ldots & \ldots & \ldots & \ldots & \ldots & a_{j j} & b_{j j}
\end{array}\right]\left[\begin{array}{c}
z_{1} \\
z_{2} \\
z_{3} \\
\vdots \\
z_{j j-1} \\
z_{j j}
\end{array}\right]=\left[\begin{array}{c}
d_{1} \\
d_{2} \\
d_{3} \\
\vdots \\
d_{j j-1} \\
d_{j j}
\end{array}\right]
$$

em que $a, b, c$ e $d$ são os coeficientes da equação e $z$ é a variável dependente.

Aplicando a relação auxiliar:

$$
z_{j-1}=e_{j} z_{j}+f_{j}
$$

e substituindo na equação 1.8 , pode-se obter a relação entre $z_{j}$ e $z_{j+1}$ :

$$
z_{j}=\frac{-c_{j} z_{j+1}+\left(d_{j}-a_{j} f_{j}\right)}{b_{j}+a_{j} e_{j}}
$$

Comparando as Equações 1.10 e 1.11, verifica-se que:

$$
\begin{aligned}
e_{j+1} & =\frac{-c_{j}}{b_{j}+a_{j} e_{j}} \\
f_{j+1} & =\frac{d_{j}-a_{j} f_{j}}{b_{j}+a_{j} e_{j}}
\end{aligned}
$$

Para iniciar a varredura forward, os valores de $e_{1}$ e $f_{1}$ devem ser conhecidos. Para $j=1$, tem-se o seguinte sistema de duas equações:

$$
\begin{aligned}
z_{1} & =e_{1} z_{2}+f_{2} \\
a_{1} z_{1}+b_{1} z_{2} & =d_{1}
\end{aligned}
$$

ou melhor: 


$$
\begin{aligned}
& z_{1}=e_{1} z_{2}+f_{2} \\
& z_{1}=\frac{-b_{1} z_{2}+d_{1}}{a_{1}}
\end{aligned}
$$

assim:

$$
\begin{aligned}
& e_{1}=\frac{-b_{1}}{a_{1}} \\
& f_{1}=\frac{d_{1}}{a_{1}}
\end{aligned}
$$

Os valores $a_{1}, b_{1}$ e $d_{1}$ são conhecidos, pois correspondem à condição de contorno de montante. Logo, é possível obter $e_{1}$ e $f_{1}$ e dar continuidade ao cálculo através das equações 1.12 e 1.13 para $j=2,3, \ldots, j j$.

Considerando agora $j=j j$, obtém-se o sistema:

$$
\begin{aligned}
z_{j j-1} & =e_{j j} z_{j j}+f_{j j} \\
b_{j j} z_{j j-1}+c_{j j} z_{j j} & =d_{j j}
\end{aligned}
$$

eliminando $z_{j j-1}$ :

$$
z_{j j}=\frac{d_{j j}-b_{j j} f_{j j}}{c_{j j}-b_{j j} e_{j j}}
$$

Os valores $b_{j j}, c_{j j}$ e $d_{j j}$ correspondem à condição de contorno de jusante e $z_{j j}$ pode ser calculado. A partir da Equação 1.10, faz-se a varredura backward para $j=j j-1, \ldots, 1$ obtendo-se todos os valores da variável dependente $z_{j}$.

\subsection{Escoamento Transcrítico e a Falha do Esquema de Preissmann}

O número de Froude é o parâmetro adimensional utilizado na identificação do tipo de regime de um escoamento. Ele representa a razão entre as forças de inércia e gravitacional:

$$
F r=\frac{v}{\sqrt{g D}}
$$

sendo Fr o número de Froude; $v$ a velocidade média da seção; $g$ a aceleração da gravidade e $D$ a profundidade hidráulica, que no caso de uma seção retangular é a própria profundidade d'água $y$. Se $F r<1$ o escoamento é subcrítico ou fluvial, se $F r>1$ o escoamento é supercrítico ou torrencial e se $F r=1$ o escoamento é crítico. 
O tipo de regime de escoamento está muito ligado à energia envolvida, sendo interessante analisar um diagrama clássico nos estudos de canais abertos como o Diagrama de Energia Específica para Vazão Constante (Figura 4).

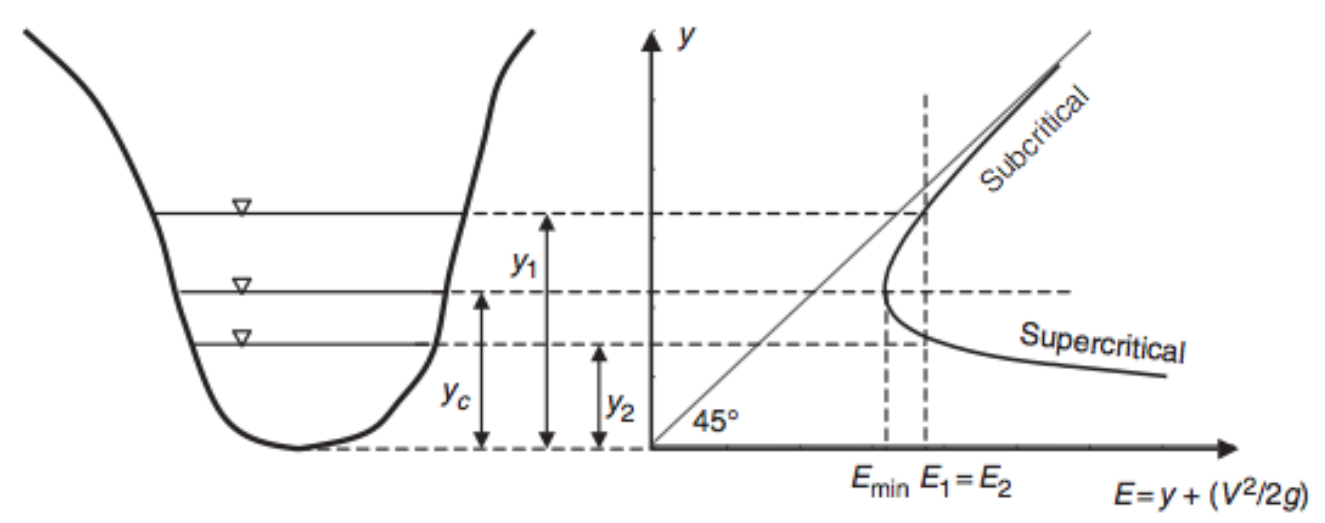

Figura 4 - Diagrama de Energia Específica para Vazão Constante (AKAN, 2006).

Na Figura $4, y_{c}$ é a profundidade crítica, cuja energia específica é a mínima $\left(E_{m i n}\right)$, $y_{1}$ é a profundidade d'água para o caso subcrítico cuja energia específica é $E_{1}$ e $y_{2}$ é a profundidade d'água para o caso supercrítico cuja energia específica é $E_{2}$, que é igual a $E_{1}$. As profundidades $y_{1}$ e $y_{2}$ são chamadas de profundidades alternadas, ou seja, são as duas profundidades correspondentes a uma mesma energia específica (AKAN, 2006).

Observando tal diagrama, Porto (2006) destaca que, próximo da ponta da curva, na região cujo número de Froude é próximo de um, uma pequena variação na energia específica leva a uma grande variação na profundidade d'água. Assim, um intervalo considerável de profundidades pode estar relacionado a praticamente uma mesma energia. Consequentemente, o escoamento com valores de $\mathrm{Fr}$ muito próximos de um possuem instabilidades que se manifestam por ondulações na superfície d'água de difícil reprodução nos modelos.

A partir do diagrama e comparando as profundidades alternadas pode-se inferir que, para uma mesma vazão, o escoamento subcrítico apresenta maior profundidade que o escoamento supercrítico $\left(y_{1}>y_{2}\right)$ e consequentemente menor velocidade $\left(v_{1}<v_{2}\right)$. Tais características ficam mais evidentes quando o escoamento recebe alguma interferência. Por exemplo, se um escoamento supercrítico é perturbado, a velocidade relativa de propagação da onda resultante, conhecida como celeridade, não possui magnitude suficiente para vencer a velocidade do escoamento torrencial e se propagar contra corrente. Logo, no escoamento supercrítico, os efeitos da perturbação "correm" para jusante sem causar efeitos significativos a montante. Já no caso subcrítico, a menor velocidade do escoamento permite que a celeridade tenha também interferência a montante da perturbação.

Essa propriedade dos escoamentos deve ser levada em conta na definição das condições de contorno durante a simulação de um problema. Escoamentos subcríticos, por 
propagar perturbações nos dois sentidos, exigem uma condição de contorno a montante e outra a jusante (estrutura 1+1). Já escoamentos supercríticos, por desconsiderar o que ocorre a jusante, exigem duas condições de contorno a montante e nenhuma a jusante (estrutura $2+0$ )

Quando são observados dois regimes de escoamento dentro de um domínio de análise, diz-se que tal escoamento é transcrítico. A transição pode ocorrer do subcrítico para o supercrítico, conhecida como choque ou ressalto hidráulico, ou do supercrítico para o subcrítico, conhecida como ponto sônico. Neste último caso, a transição ocorre de forma suave e sua localização é de difícil definição (FREITAG, 2003). Normalmente, o escoamento transcrítico ocorre em canais com inclinações íngremes, fortes contrações ou elevações locais do fundo, em canais de irrigação e em ondas de rompimento de barragem (MESELHE; SOTIROPOULOS; HOLLY JR., 1997).

A diferença entre as estruturas de condições de contorno dos regimes subcríticos e supercríticos e a grande instabilidade da transição entre escoamentos são os principais motivos da dificuldade algébrica e computacional da modelagem de escoamentos transcríticos (ABEDINI; HASHEMI, 2006).

Meselhe e Holly Jr. (1997) alertam que o esquema de Preissmann, aplicado em sua forma padrão, não é capaz de resolver escoamentos transcríticos. O principal motivo dessa "falha" é a definição das condições de contorno. O esquema de Preissmann exige exatamente duas condições de contorno, nem mais nem menos. Entretanto, o número de condições de contorno no escoamento transcrítico pode variar de uma a três condições dependendo das características do trecho (MESELHE; HOLLY JR., 1997). A Figura 5 representa três situações de escoamento transcrítico e as condições de contorno necessárias para cada caso.

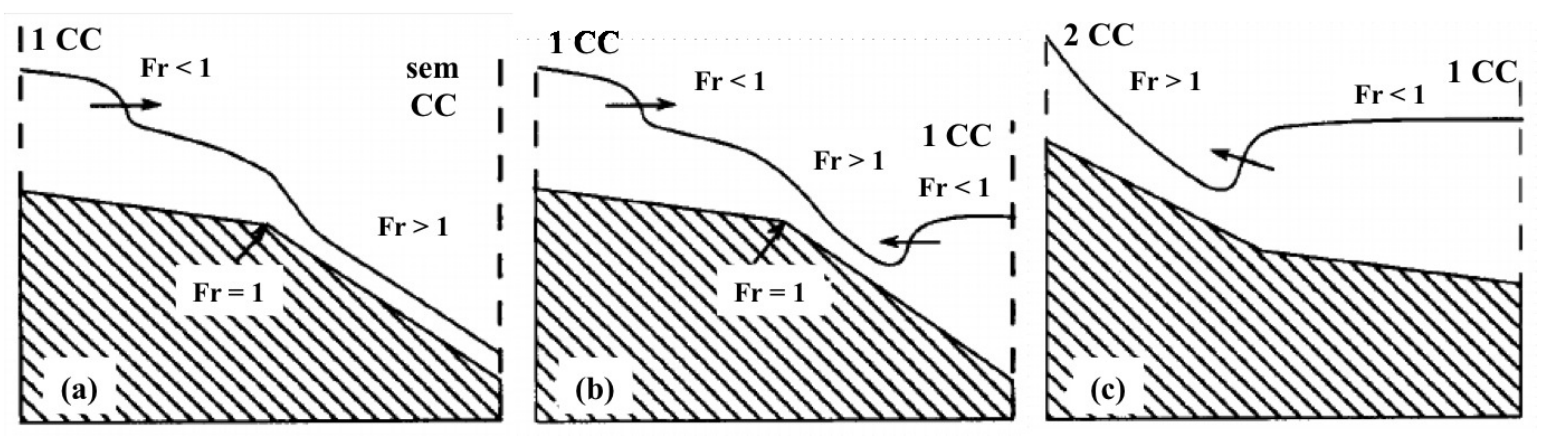

Figura 5 - Condições de contorno (CC) necessárias para escoamento trascrítico, sendo Fr o número de Froude: (a) uma condição de contorno à montante $(1+0)$; (b) uma condição de contorno à montante e outra à jusante $(1+1)$; e (c) duas condições de contorno à montante e uma à jusante $(2+1)$ (Adaptado de Meselhe, Sotiropoulos e Holly Jr. (1997)).

Na Figura 5(a) o escoamento se inicia subcrítico, logo são necessárias uma condição a montante e outra a jusante. Devido ao aumento da inclinação do fundo do canal, o 
escoamento passa a ser supercrítico, sendo necessárias duas condições de contorno a montante. A combinação subcrítico-supercrítico utiliza a montante uma única condição de contorno exigida pelo escoamento subcrítico e nenhuma condição de contorno a jusante do escoamento supercrítico resultando em uma estrutura 1+0. Assim, na aplicação do esquema de Preissmann, o sistema de equação é representado por uma equação a menos tornando-se indeterminado (MESELHE; HOLLY JR., 1997). Apesar de dentro do domínio analisado a condição $F r=1$ ser atingida, para a mesma ser utilizada como a segunda condição de contorno, torna-se necessário localizar a posição exata da sua ocorrência e alterar a estrutura de resolução para permitir a inclusão de um contorno interno. Essa metodologia, conhecida como captura de choque, foi adotada por alguns pesquisadores e será discutida na próxima seção.

Na Figura 5(b) a estrutura das condições de contorno é 1+1 e pode ser representada pelo esquema de Preissmann. Entretanto, o comportamento subcrítico-supercríticosubcrítico transita por valores em torno de $F r=1$, fazendo com que o esquema de Preissmann perca sua estabilidade incondicional Abedini e Hashemi (2006), Freitag (2003). No caso supercrítico-subcrítico da Figura 5(c), adotam-se as duas condições de contorno a montante do escoamento supercrítico adicionada à uma condição de contorno a jusante do escoamento subcrítico formando uma estrutura $2+1$. Dessa forma, o sistema de equações torna-se superdeterminado, ou seja, com mais equações do que incógnitas (MESELHE; HOLLY JR., 1997). Nesse caso, pode-se excluir uma das equações? Qual delas? Qual será o efeito? As propostas de como lidar com essas peculiaridades do escoamento transcrítico serão apresentadas na próxima seção.

\subsection{Propostas de Soluções do Escoamento Transcrítico}

Duas frentes de trabalho vêm ganhando destaque na resolução de escoamentos transcríticos: (1) os esquemas de captura de choque - desenvolvidos na aerodinâmica e adaptados para escoamento em canais abertos - e (2) a redução da influência dos termos inerciais da equação de momento.

Na primeira frente, Meselhe, Sotiropoulos e Holly Jr. (1997) apresentam o MESH como um esquema de resolução promissor para transições suaves, como as que ocorrem em canais de irrigação. O esquema é um procedimento preditor-corretor inspirado em uma resolução das equações de Euler para escoamentos compressíveis (CASIER; DECONINCK; HIRSCH, 1984 apud MESELHE; SOTIROPOULOS; HOLLY JR., 1997) . Já Jhonson, Baines e Sweby (2002) adotaram os conceitos de distribuição de resíduos em escoamentos transônicos, apresentados por Morton, Rudgyard e Shaw (1993), para escoamentos transcríticos em canais abertos e adaptaram ao próprio método de Preissmann. Freitag e

1 CASIER, F.; DECONINCK, H.; HIRSCH, C. A class of bidiagonal schemes for solving the Euler equations. AIAA Journal, v. 22, n. 11, p. 1556-1563, 1984. 
Morton (2007) seguem os mesmos conceitos, entretanto resolvem o sistema de equações por Simples e Dupla Varredura mantendo o clássico Método de Iteração de Newton. Além disso, o método proposto por estes autores - bem detalhado em Freitag (2003) - utiliza o número de Froude para identificar o tipo de escoamento ao longo do domínio e a posição das transições para poder aplicar um tratamento diferenciado em cada região. Seguindo a mesma linha, Sart et al. (2010) também identificam zonas transcríticas através do número de Froude e aplicam contornos internos para solucioná-las localmente.

Os esquemas de captura de choque normalmente são baseados em volumes finitos e trabalham com estruturas algébricas mais complicadas. Logo, por serem mais robustos, exigem maior desempenho computacional, como discutido por Djordjević, Prodanović e Walters (2004).

A segunda vertente surgiu a partir da constatação de que, quando ocorre a transição entre regimes ou quando o escoamento é muito próximo do crítico, os termos de inércia da equação dinâmica tornam-se muito instáveis. Visando reduzir esse efeito, alguns pesquisadores (KUTIJA, 1993; FREAD; JIN; LEWIS, 1996; DJORDJEVIĆ; PRODANOVIĆ; WALTERS, 2004) vislumbraram como uma solução simples e direta a aplicação de redutores dos termos de inércia. Assim, podia-se combinar a precisão da equação dinâmica juntamente com a estabilidade da equação difusiva (FREAD; JIN; LEWIS, 1996).

O precursor dessa ideia foi Havno e Brorsen (1985 apud KUTIJA; MESELHE; HOLLY JR.; DJORDJEVIĆ; PRODANOVIĆ; WALTERS, 1993, 1997, 2004) ${ }^{2}$ que, através da introdução de um coeficiente, reduziam gradualmente o termo de inércia da equação de momento conforme o fluxo se aproxima do escoamento supercrítico. Isso permite o uso de um único algoritmo para resolver qualquer tipo de escoamento, tendo como base os contornos do escoamento subcrítico, ou seja, um contorno de montante e um de jusante (estrutura 1+1). Kutija (1993) analisou os efeitos da supressão do termo convectivo e destacou que sob condições supercríticas a profundidade d'água é superestimada e os picos são atrasados. Abedini e Hashemi (2006) também discutiram os efeitos dessa redução nos escoamentos transcríticos e apoiaram o uso de métodos que evitem esse tipo de abordagem.

Apesar dos problemas apontados, Kutija e Hewett (2002) continuaram suas pesquisas na segunda vertente e desenvolveram o NewC. O principal argumento é o grande uso das diferenças finitas e do método implícito na maior parte dos software comerciais de engenharia e a facilidade de incluir nesses tipos de software a metodologia sem grandes mudanças na estrutura principal dos modelos.

Djordjević, Prodanović e Walters (2004) também analisam as consequências da aplicação do método de redução dos termos inerciais, referido no trabalho com aproximação de Havno. Os pesquisadores destacam que o erro conceitual das condições de contorno

2 HAVNO, K.; BRORSEN, M. Generalized mathematical modeling system for flood analysis and flood control design. In: BRITISH HYDRODYNAMICS RESEARCH ASSOC. International Conference on Hydraulics of Floods and Floods Control. Stevenage, UK, 1985. 
embutido pela aproximação de Havno pode ser significativo para canais com grandes declividades de fundo, nos quais o número de Froude tende a ser muito maior do que um. Entretanto, tal erro é tolerável para escoamentos mais próximos do fluvial e com números de Froude próximos de um. Os autores também destacam que, quando próximo de $F r=1$, o termo redutor transforma a equação completa de momento em uma equação difusiva incapaz de resolver a descontinuidade através de um ressalto hidráulico. Por outro lado, o método é capaz de superar as oscilações numéricas dessas descontinuidades sem a necessidade de inclusão de uma viscosidade artificial, que normalmente é necessária nos métodos de captura de choque.

Apesar de ser considerada fisicamente incorreta e poder não conservar adequadamente volumes - reduzindo-se deliberadamente sua confiabilidade (SART et al., 2010; DJORDJEVIĆ; PRODANOVIĆ; WALTERS, 2004; ABEDINI; HASHEMI, 2006) - a segunda vertente apresenta-se estável, simples, flexível e de notável conveniência (KUTIJA; HEWETT, 2002; DJORDJEVIĆ; PRODANOVIĆ; WALTERS, 2004) para o problema analisado neste trabalho, sendo assim, adotada.

Entre as metodologias de aplicação de coeficientes redutores estudadas, a de Fread, Jin e Lewis (1996) foi selecionada para apalicação no presente trabalho por se tratar de uma referência bem descrita e por ter sido também adaptada ao software HEC-RAS como uma opção de resolução de escoamentos mistos (ABEDINI; HASHEMI, 2006). Os autores aplicaram um filtro numérico como coeficiente redutor, chamado de Local Partial Inertial (LPI), ao modelo FLDWAV, desenvolvido pelo National Weather Service (NWS), que resolve as equações completas de Saint Venant seguindo o método de Preissmann. Isso permitiu a simulação de rupturas de barragens envolvendo transição de regimes ou escoamentos muito próximos do crítico.

O LPI é um filtro aplicado aos dois termos de inércia da equação de momento e é dependente do número de Froude local. A equação de momento (1.2) fica modificada da seguinte forma:

$$
\alpha\left[\frac{\partial Q}{\partial t}+\frac{\partial}{\partial x}\left(\frac{Q^{2}}{A}\right)\right]+g A \frac{\partial y}{\partial x}+g A\left(S_{f}-S_{0}\right)=0
$$

em que:

$$
\alpha=\left\{\begin{array}{lll}
1-F r^{m} & \text { se } & F r \leq 1 \\
0 & \text { se } & F r>1
\end{array}\right.
$$

sendo $m$ uma constante especificada pelo usuário.

A Figura 6 apresenta a variação do filtro em função do número de Froude para diferentes valores de $m$. Quanto menor o número de Froude, menor é a interferência o filtro sobre os termos de inércia. Quando o Froude se aproxima de um, a interferência do filtro tende a ser maior ou menor, dependendo do valor $m$ estipulado. Quanto maior o 
valor de $m$ menos efeito o filtro terá sobre os termos de inércia, o que proporciona maior precisão à simulação.

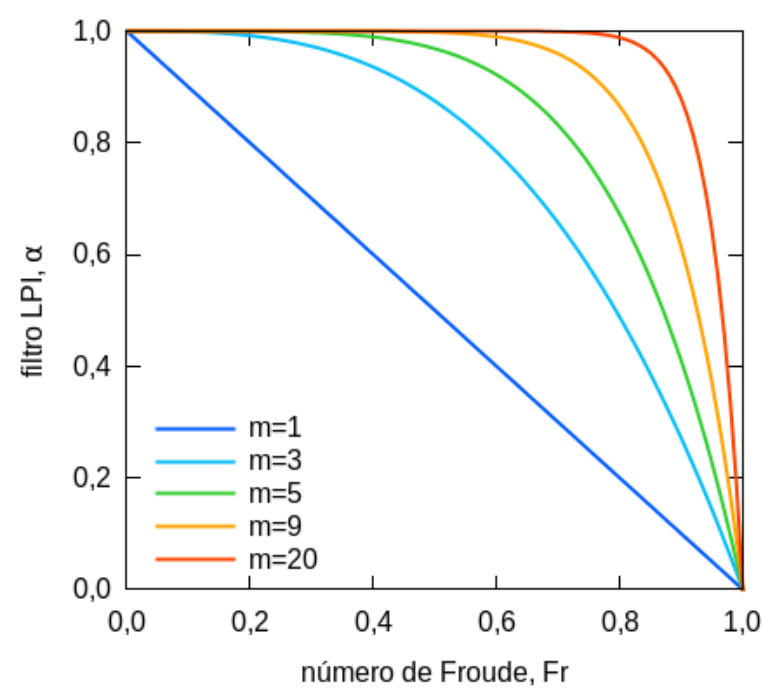

Figura 6 - Variação do filtro LPI (Adaptado de Fread, Jin e Lewis (1996)).

Fread, Jin e Lewis (1996) fizeram uma análise do erro consequente da omissão, total ou parcial, dos termos inerciais da equação de momento causada pelo filtro LPI. Os erros foram obtidos a partir da diferença entre os hidrogramas simulados com o filtro e os hidrogramas simulados sem o filtro. Segundo os autores essa diferença não passou de $6 \%$ até mesmo em simulações de ruptura de grandes barragens.

Outra metodologia analisada foi a de Djordjević, Prodanović e Walters (2004) cujo trabalho considera escoamentos em redes de drenagem em que, além da possibilidade de transição de regime, também existe a possibilidade de transição entre sistemas de superfície livre e sob pressão. Nesse trabalho, o termo redutor é aplicado apenas ao termo de aceleração convectiva das equações de momento. Além disso, o fator redutor atua apenas localmente e é dependente da média (ou máximo) local do número de Froude em quatro pontos computacionais. Assim, a equação de momento (1.2) é modificada da seguinte maneira:

$$
\frac{\partial Q}{\partial t}+\alpha\left[\frac{\partial}{\partial x}\left(\frac{Q^{2}}{A}\right)\right]+g A \frac{\partial y}{\partial x}+g A\left(S_{f}-S_{0}\right)=0
$$

sendo que:

$$
\alpha=\left\{\begin{array}{lll}
1 & \text { se } \overline{F r} \leq F r_{0} \\
\frac{F r_{1}-\overline{F r}^{\beta}}{F r_{1}-F r_{0}^{\beta}} & \text { se } \quad F r_{0}<\overline{F r}<F r_{1} \\
0 & \text { se } \overline{F r} \geq F r_{1}
\end{array}\right.
$$


sendo $\overline{F r}$ a média dos números de Froude em quatro pontos computacionais, $F r_{0}$ e $F r_{1}$ os limites inferior e superior, respectivamente, do intervalo no qual se deseja aplicar o termo redutor e $\beta$ um coeficiente definido pelo usuário.

Djordjević, Prodanović e Walters (2004) aplicam a metodologia aos problemas analíticos apresentados por MacDonald et al. (1997) e fazem análises para as seguintes combinações de valores: $F r_{0}=1$ e $F r_{1}=1,2 ; F r_{0}=0,9$ e $F r_{1}=1,1 ; F r_{0}=0,8$ e $F r_{1}=1 ; F r_{0}=0,7$ e $F r_{1}=0,9$, todos com $\beta=2$. Através da Figura 7 , analisou-se o efeito do termo redutor sobre o número de Froude e observou-se a possibilidade de ocorrência de valores negativos. Devido a dificuldade de compreender o efeito de valores negativos do coeficiente redutor essa metodologia não foi aplicada no presente trabalho.

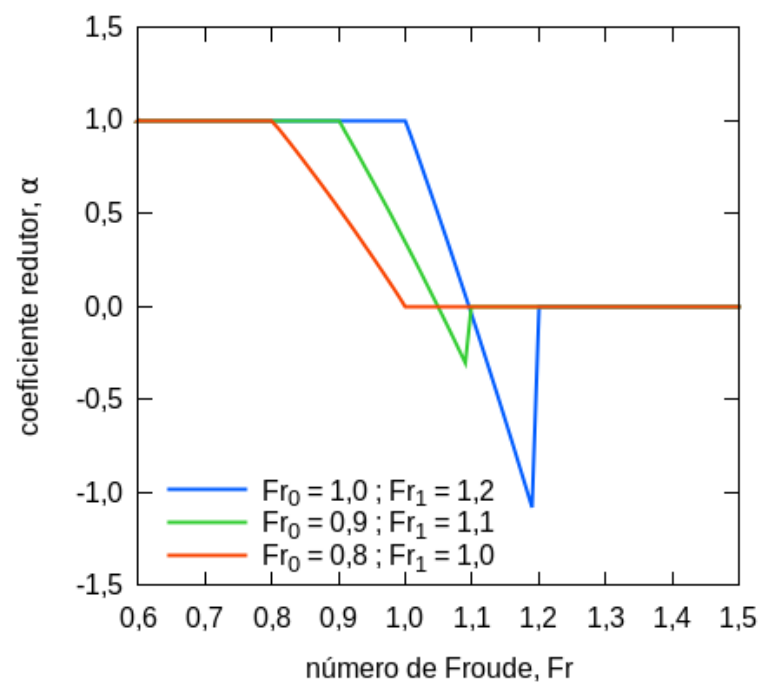

Figura 7 - Variação do coeficiente redutor utilizado por Djordjević, Prodanović e Walters (2004). 


\section{Monitoramento da Passagem de Onda de Cheia}

A qualidade e confiabilidade de modelos hidráulico-hidrológicos depende diretamente do primeiro passo de qualquer análise do ciclo hidrológico: a coleta de dados. Logo, a medição de variáveis hidrológicas em locais adequados, no intervalo de tempo certo e com boa qualidade são essenciais para o sucesso de qualquer simulação, tenha ela foco em inundações, disponibilidade de água, geração de energia ou irrigação (HERSCHY, 1995).

$\mathrm{Na}$ análise hidrodinâmica de rios urbanos, três variáveis são especialmente importantes: a geometria do leito do rio, o nível d'água e a vazão através das seções de interesse. As precipitações que dão origem às ondas de cheia podem também auxiliar a análise da transformação chuva-vazão e do tempo de resposta da bacia hidrográfica aos eventos chuvosos.

A escolha do local do monitoramento também é importante. Devem-se buscar locais com: boas condições de acesso; leito regular e estável; sem controles de jusante como, por exemplo, estreitamentos, comportas e confluência com outro rio; trecho reto; e, preferencialmente, sem contribuição lateral significativa.

Pode-se dizer que o nível d'água é a mais importante medida da hidrometria, pois normalmente é a variável com maior frequência de medição e é a base para a estimativa da vazão. Logo, a incerteza na medição de nível possui efeitos significativos na incerteza da vazão (HERSCHY, 1995).

Tendo como foco o monitoramento da passagem de onda de cheia em um rio urbano, a frequência de aquisição dos dados e a precisão dos mesmos merecem atenção especial. A rápida variação do nível d'água exige a utilização de limnígrafos capazes de registrar intervalos curtos de variação - entre 1 e 5 minutos segundo Lobo (2002), podendo até ser menor, dependendo das condições da bacia monitorada - com grande precisão para possibilitar a representação da ascensão, pico e recessão do limnigrama de cheia. Para atender às expectativas, os transdutores de pressão são uma alternativa que tem sido bastante explorada e indicada por serem de simples utilização e adaptável a diversas condições (SOLINST, 2013). Entretanto, a utilização de um equipamento mais preciso não dispensa a instalação da régua, que serve de referência à verificação dos registros realizados.

Devido as altas velocidades que atingem as ondas de cheia, deve-se atentar para a forma de instalação dos transdutores em campo. As forças dinâmicas do escoamento devem ser evitadas buscando-se posicionar a porta de medição de pressão do sensor paralelamente ao escoamento. Além disso, a instalação não pode interferir de forma significativa no escoamento do rio. As instalações por vasos comunicantes (stilling well) são uma solução 
engenhosa para a medição de nível em diversas aplicações. Bastante utilizadas em estações fluviométricas, elas protegem o sistema e evitam oscilações da linha d'água causadas pelo vento (HERSCHY, 1995). Entretanto, esse tipo de instalação em meio urbano nem sempre é viável. Por se tratar de uma construção (perfuração de poço e ligação por condutos) que irá interferir consideravelmente no meio, a falta de espaço, a burocracia para se obter permissão de instalação e a exposição ao vandalismo são alguns dos problemas encontrados.

No caso da medição de vazão, existem diversos métodos e a escolha depende das condições locais de escoamento, dos recursos disponíveis e do objetivo da medição. O método área-velocidade é vastamente utilizado na maioria dos rios. De acordo com esse método, a vazão é estimada considerando a relação $Q=v A$. Assim, mede-se a geometria da seção transversal para se obter a área $(A)$ e a velocidade de escoamento em alguns pontos dessa seção para se calcular a velocidade média $(v)$ (HERSCHY, 1995). Entre as formas de medição de velocidade em canais abertos, destacam-se o uso de molinetes hidrométricos, flutuadores e, atualmente, perfiladores acústicos.

O molinete hidrométrico é tradicionalmente utilizado na hidrometria e reconhecido mundialmente. Entretanto, diversos problemas são encontrados com a utilização dessa metodologia em rios urbanos (LOBO, 2002). A grande quantidade de material flutuante (resíduos sólidos diversos, tais como lixo domiciliar e galhos), presente em grande quantidade nos córregos urbanos, acabam se acumulando no molinete e dificultando, ou até impossibilitando, a medição. Esse material pode ser observado em maior quantidade nos primeiros instantes da onda de cheia, quando a chuva "lava" a superfície da bacia. Além disso, as altas velocidades, encontradas principalmente quando a onda de cheia atinge o seu pico, podem inviabilizar a imersão do molinete devido ao arrasto do equipamento pela água, mesmo com a utilização de lastros pesados (LOBO, 2002). A mudança rápida de nível durante a passagem das ondas de cheia, que inviabiliza a aplicação do método clássico de contabilização das vazões, é outro problema. Tal método consiste em obter as velocidades nas profundidades 0,2 e 0,8 ou 0,6 em várias verticais para que a vazão possa ser totalizada como a soma dos produtos entre as velocidades médias e as respectivas áreas de influência. Além disso, a medição em cada ponto e o deslocamento entre os pontos demanta tempo considerável.

Em casos de altas velocidades, o uso de flutuadores é mais indicado, apesar da aproximação da velocidade superficial do rio ser grosseira (HERSCHY, 1995). Além disso, torna-se bastante complicado monitorar a evolução da onda de cheia, pois é necessário acompanhar e cronometrar o lançamento de diversos flutuadores. Tudo isso exige uma equipe bem treinada de pelo menos 5 pessoas. Outra dificuldade é a recuperação dos flutuadores caso os mesmos não sejam degradáveis.

Atualmente, a utilização de ADCP (Acoustic Doppler Current Profilers) vem ganhando preferência na medição de vazão devido à sua maior resolução de velocidades, 
à redução no tempo necessário para realizar as medições e à facilidade de uso (MUELLER; WAGNER, 2009; ANA, 2012). A técnica é fundamentada no efeito doppler e estima a velocidade da água a partir da velocidade das partículas presentes na água, que são detectadas pelos sensores através da reflexão das ondas ultrassônicas. Entretanto, a aplicação de ADCP em córregos urbanos não é comum e também depara com os problemas das altas velocidades, acumulo de material suspenso e dificuldade de acesso.

Devido às dificuldades de medição de velocidades para obtenção de vazão, usualmente monitora-se apenas nível e a vazão é relacionada através de uma curva-chave, que é definida com base em medições simultâneas de nível e vazão durante alguns cenários hidrológicos representativos. Apesar de bastante comum, o uso de curva-chave envolve diversas fontes de incerteza (BALDASSARRE; MONTANARI, 2009).

A confiabilidade de uma curva-chave depende da disponibilidade de uma amostra representativa de velocidades. Porém, existe grande dificuldade em medir velocidades durante eventos extremos. Além deles não serem frequentes, é muito arriscado realizar medições em tais situações (CORATO; MORAMARCO; TUCCIARELLI, 2011). Dessa forma, para obtenção de altos valores de vazão, torna-se necessário extrapolar a curvachave, recaindo na sua principal fonte de incerteza (BALDASSARRE; MONTANARI, 2009).

Quando se está interessado na passagem de onda de cheia, acresce-se ainda mais uma dificuldade. Como discutido na Seção 1, em escoamento não permanente o efeito de histerese da curva-chave torna-se importante. Caso as forças cinemáticas do escoamento sejam dominantes, o que geralmente ocorre em rios com grandes inclinações $\left(>10^{-3}\right)$, a aproximação para uma curva-chave unívoca é satisfatória. Porém, em situações de inclinação suave, em que as forças inerciais e de pressão são significativas, a forma de loop da curva-chuva é mais larga e deve ser considerada (FREAD, 1975).

Dottori, Martina e Todini (2009) apresentam e comparam diversos métodos aplicados por diferentes autores para melhorar a estimativa da vazão em condições de escoamento não permanente. Também fazem críticas às limitações a que a maioria dos métodos estão sujeitos e à falta de transparência na descrição dos critérios de resolução, o que dificulta aplicações práticas. Os autores demonstraram que os métodos que utilizam dois pontos de medição de nível, para verificar a inclinação da linha da água, produziram melhores resultados e podem ser uma abordagem promissora.

Visto que existe grande dificuldade em medir velocidades em rios urbanos e é necessário considerar efeitos complexos de escoamento, alguns pesquisadores (FENTON, 1999; PERUMAL et al., 2007; ARICÓ; NASELLO; TUCCIARELLI, 2009) vêm investindo na resolução das equações de Saint Venant a partir de dados de nível somente. Perumal et al. (2007) estimaram vazão e desenvolveram uma curva-chave com informações apenas de nível através de um modelo de propagação de nível, que é uma extensão do método de Muskingum com parâmetros variáveis chamado de VPMS (PERUMAL; RAJU, 1998 
apud PERUMAL et al., 2007) ${ }^{1}$. Deve-se atentar para o fato de que este método não é aplicável a situações com declividade do trecho muito pequena e considerável contribuição lateral.

Para facilitar a resolução das equações completas de Saint Venant, Aricó e Tucciarelli (2007) separaram o sistema de equações diferenciais parciais (Equações 1.1 e 1.2) em dois sistemas de equações diferenciais ordinárias. O sistema de predição ou correção convectiva e o sistema de correção difusiva. Ambos são resolvidos pela técnica MAST (marching in space and time). O primeiro sistema é resolvido por aproximação Euleriana e utiliza uma discretização do tempo auto-ajustável. O sistema de correção difusiva é utilizado para resolver um sistema linear - representado por uma matriz esparsa, simétrica e bem condicionada - pelo método implícito das diferenças finitas.

Apesar dos modelos completos (hidrodinâmicos) serem mais robustos e confiáveis, as simplificações e hipóteses adotadas para a determinação das equações de Saint Venant podem não representar adequadamente situações mais particulares de escoamento (CORATO; MORAMARCO; TUCCIARELLI, 2011), sendo necessárias abordagens especificas às situações encontradas em campo e validação rigorosa de resultados.

A informação da vazão ganha grande valor na validação dos resultados de modelos ou, até mesmo, na calibração de parâmetros. Entretanto, a rápida subida do nível impede a perfilagem completa das velocidades da seção e a estimativa da vazão por métodos convencionais baseados na área-velocidade. Com isso, métodos de estimativa de vazão a partir de medidas de velocidade em apenas uma única vertical, de preferência a que contenha a velocidade máxima, vêm se tornando bastante populares (CHIU; HSU; TUNG, 2005; FULTON; OSTROWSKI, 2008; CORATO; MORAMARCO; TUCCIARELLI, 2011; CUI, 2011). Esse método foi proposto por Chiu (1987) e é sustentado pelo princípio da máxima entropia e da distribuição de probabilidades de velocidades.

Fulton e Ostrowski (2008) apresentaram novas tecnologias de medição instantânea de velocidades superficiais, como radares de mão (COSTA et al., 2006), acopladas aos métodos de estimativa de vazão baseados no conceito de probabilidades. A nova técnica, comparada com métodos convencionais, apresentou estimativas de vazões instantâneas consistentes e acuradas - diferenças de vazão de no máximo $11 \%$ para os rios analisados pelos pesquisadores. Entretanto, os autores destacam que o vento pode interferir significativamente na medição do fluxo principal do rio, especialmente em escoamentos com baixas velocidades.

Cui (2011), em sua tese, compara métodos baseados na entropia com métodos convencionais de estimativa da distribuição de velocidades, como a lei exponencial de velocidade e a Lei de Prandtl-von Karman. De acordo com esse trabalho, o método da entropia se apresentou mais acurado que os tradicionais.

$1 \quad$ PERUMAL, M.; RAJU, K. G. R. Variable-parameter stage-hydrograph routing method. i: Theory. ii: Evaluation. Journal of Hydrologic Engineering, v. 3, n. 2, p. 109-121, 1998. 
Para estimar a vazão de um rio durante eventos de inundações, Corato, Moramarco e Tucciarelli (2011) propuseram um procedimento que utiliza apenas dados de nível e medidas ocasionais de velocidade. Um modelo hidráulico difusivo unidimensional, desenvolvido por Aricó, Nasello e Tucciarelli (2009) com base no MAST, é utilizado para propagar os dados de nível de montante para jusante e a equação de difusão é igualada a zero no contorno de jusante. O coeficiente de rugosidade de Manning é calibrado com base em vazões instantâneas obtidas de um modelo de distribuição de velocidade. Também é feita uma investigação do comprimento mínimo do trecho para que os efeitos das condições de contorno a jusante não interfiram na vazão a montante.

Visto as dificuldades de medir vazão, o presente trabalho focou em resolver as equações unidimencionais completas de Saint Venant visando garantir a representação de efeitos de histerese e relacionar satisfatoriamente nível e vazão utilizando apenas dados observados de nível. Entretanto, medições de vazão continuam sendo necessárias para uma validação mais rigorosa das simulações. Portanto, a estimativa de vazão via método da entropia apresenta-se promissora para as dificuldades de medição em rios urbanos durante a passagem de ondas de cheia. 



\section{Parte II}

Metodologia e Materiais 



\section{Monitoramento}

\section{1 Área de Estudo}

Almeida (2013), visando modelar a passagem de onda de cheia em rios urbanos, buscou trechos de canais na área urbana da cidade de São Carlos que apresentassem as seguintes características: seção estável (canalizado), retilíneo e suficientemente longo, com pouca contribuição lateral e sem efeitos de remanso. Entre as possibilidades investigadas pelo pesquisador, foi selecionado um trecho no córrego do Gregório. Esse córrego possui $8,5 \mathrm{~km}$ de extensão, $15,6 \mathrm{~km}^{2}$ de área de drenagem e é um dos principais afluentes do rio Monjolinho (PMSC, 2007), que por sua vez pertencente à Unidade de Gerenciamento de Recursos Hídricos Tietê-Jacaré (Figura 8).

\section{Localização da Bacia do Córrego do Gregório}

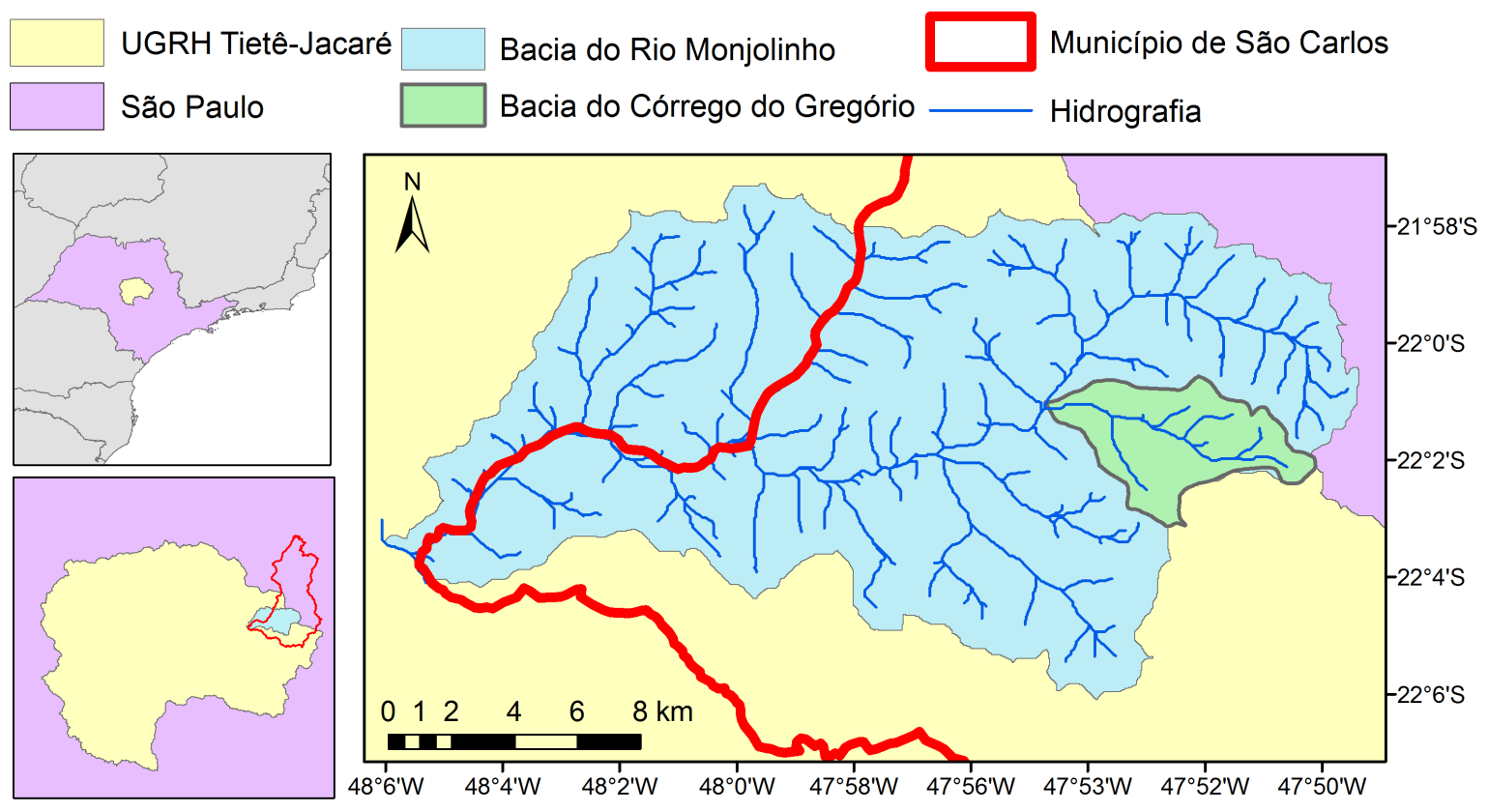

Figura 8 - Mapa de Localização da Bacia do Gregório. 
A parte mais densamente povoada da cidade de São Carlos está inserida na bacia do córrego do Gregório. Por isso, seu sistema de drenagem já passou por diversas modificações - como impermeabilização, canalização, retificação e aterramento - sem o planejamento adequado, resultando em sérios problemas de inundação em alguns pontos da cidade (CDCC, 1999). Visto a importância do córrego, o mesmo trecho selecionado por Almeida (2013) foi utilizado neste trabalho com o objetivo de relacionar níveis a vazões para o córrego do Gregório.

O trecho estudado tem 244,97 $\mathrm{m}$ de comprimento e dista aproximadamente 930 $\mathrm{m}$ da sua confluência com o rio do Monjolinho, drenando praticamente toda a bacia do Gregório. Esse trecho foi canalizado em 2012 com concreto pré-moldado de coeficiente de rugosidade de Manning de projeto de $0,016 \mathrm{~s} / \mathrm{m}^{1 / 3}$. Sua seção é praticamente retangular, com cerca de 4,30 $\mathrm{m}$ de profundidade e $8 \mathrm{~m}$ de largura em toda a extensão do trecho. A Figura 9 apresenta a localização e a Figura 10 uma foto do trecho selecionado. Como destacado por Almeida (2013), o trecho possui três pontos de pequena descarga da drenagem superficial - com diâmetro da tubulação de 16" e 32" - cuja contribuição lateral da vazão foi considerada desprezível no presente trabalho.

Optou-se por monitorar três seções do trecho. Dessa forma, durante a simulação, além de ser possível definir condições de contorno tanto de montante como de jusante, também foi possível aferir os resultados do modelo.

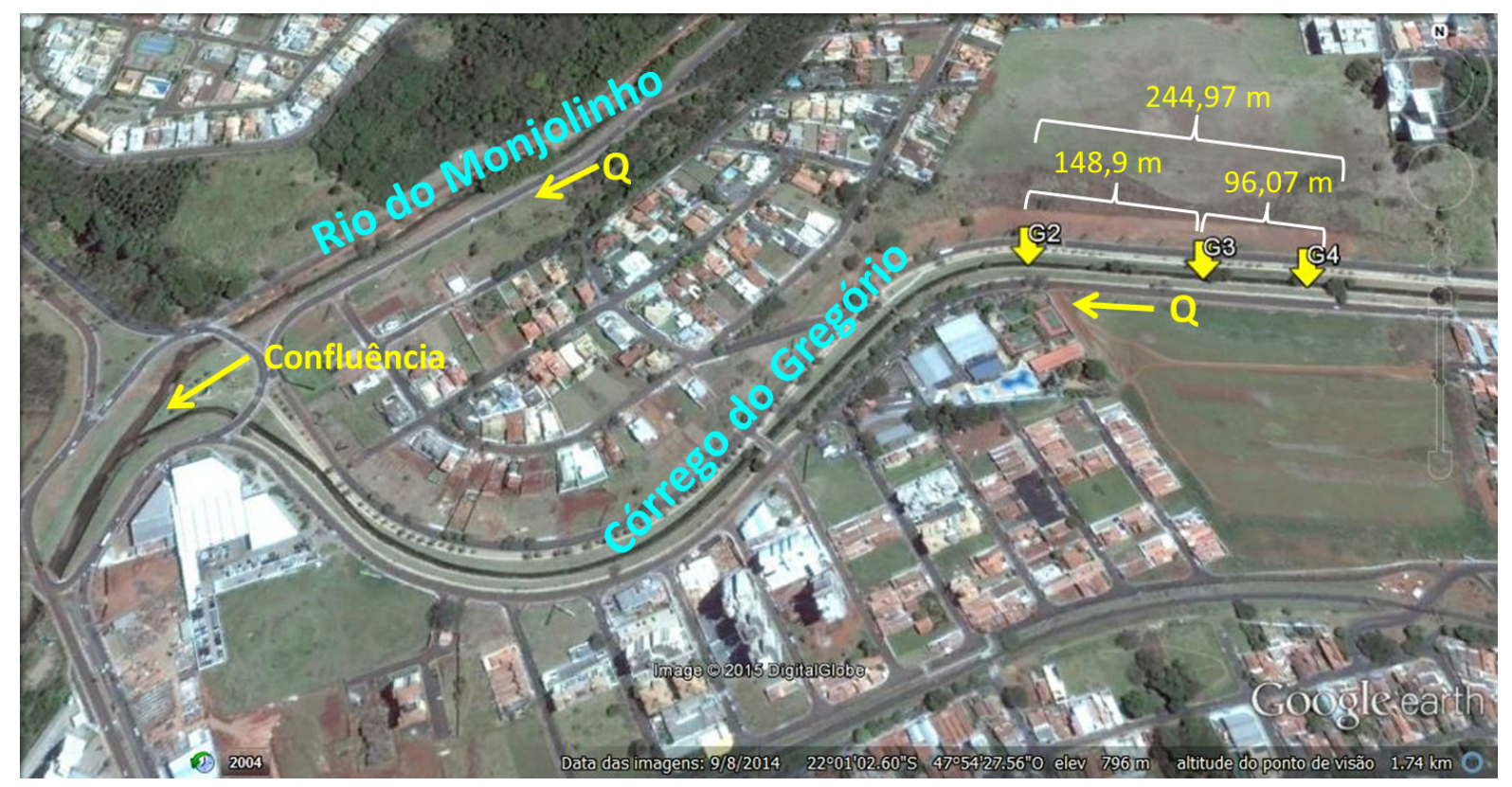

Figura 9 - Localização (Adaptado do Google Earth). 


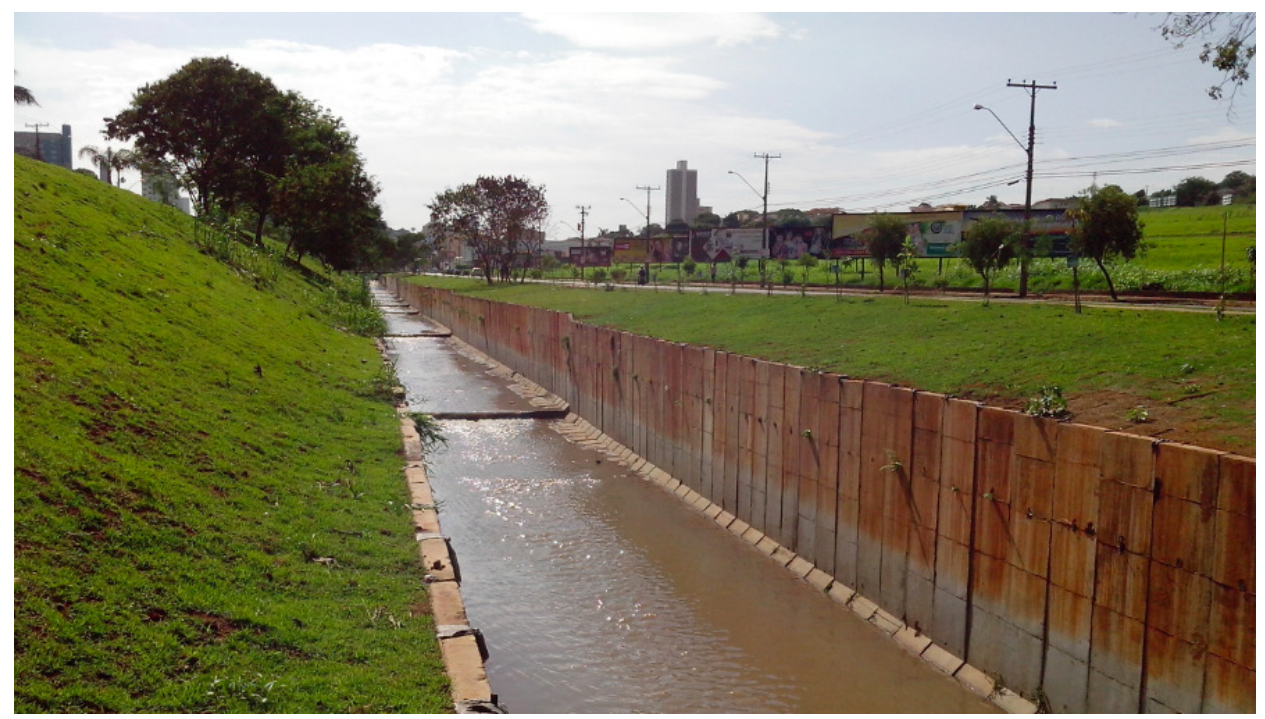

Figura 10 - Foto do trecho simulado.

\subsection{Monitoramento Limnimétrico}

Os três pontos de medição limnimétrica instalados em 2013 por Almeida (2013) no córrego do Gregório foram os primeiros da Rede de Hidrometria instalada, monitorada e mantida pela equipe do SHS do projeto MAPLU-2 (LABSIN, 2015). Atualmente a rede possui 16 pontos de monitoramento limnimétrico, 8 pluviômetros e 1 ponto de medição de vazão distribuídos pela cidade de São Carlos (Anexo A).

O monitoramento de nível d'água é realizado por transdutores de pressão da Solinst Ltd. Também foram instaladas réguas em todos os pontos de medição limnimétrica para verificação dos registros . Os transdutores de pressão da Solinst consistem em levelogger, que registram cargas de pressão absolutas, e barologger, que registram cargas de pressões atmosféricas. Ambos também registram temperaturas para realizar a compensação automática. A partir do Levelogger Series Software (Versão 4.0.3) é feita a transferência, a compensação barométrica para obter as medidas de altura da coluna d'água e a programação dos equipamentos. Segundo a Solinst (2013), as especificações técnicas dos equipamentos são:

- Modelo: Levelogger e Barologger Edge 3001 F15 M5;

- Fabricante: Solinst Canada Ltd;

- Capacidade de memória: 40.000 leituras ou até 120.000 no modo compactado;

- Dimensões: $22 \times 159 \mathrm{~mm}$;

- Intervalos de medição: de 0,125 segundos a 99 horas; 
- Exatidão do levelogger: \pm 0,5\% FS. Sendo FS a escala máxima (Full Scale), que para o modelo F15 M5 é de 5 m;

- Acurácia do levelogger: $\pm 0,3 \mathrm{~cm}$;

- Exatidão e acurácia do barologger: \pm 0,5 kPa;

- Alcance do barologger: até $30 \mathrm{~km}$ de raio e/ou a cada $300 \mathrm{~m}$ na mudança de altitude.

Os três pontos de medição de nível d'água localizados na área de estudo desse trabalho foram instalados de forma a permitir a modelagem hidráulico-hidrológica. Também foram utilizados dados de três pluviômetros influentes na bacia para verificar a sua resposta à precipitação em termos dos limnigramas resultantes. Na Tabela 2 são apresentadas as coordenadas desses pontos cuja localização na Rede de Hidrometria consta no Anexo A.

Tabela 2 - Pontos de medição e identificação dos equipamentos.

\begin{tabular}{|c|c|c|c|c|c|}
\hline Identificação & Posição & Latitude & Longitude & $\begin{array}{c}\text { Distância } \\
\text { do ponto de } \\
\text { jusante }(\mathrm{m})\end{array}$ & $\begin{array}{l}\text { Cota do } \\
\text { fundo do } \\
\text { canal }(\mathrm{m}) \\
\end{array}$ \\
\hline G2 & jusante & $22^{\circ} 00^{\prime} 58,38^{\prime \prime} \mathrm{S}$ & $47^{\circ} 54^{\prime} 19,08^{\prime \prime} \mathrm{W}$ & - & 773,650 \\
\hline G3 & intermediário & $22^{\circ} 00^{\prime} 58,92^{\prime \prime} \mathrm{S}$ & $47^{\circ} 54^{\prime} 13,68^{\prime \prime} \mathrm{W}$ & 148,90 & 774,767 \\
\hline G4 & montante & $22^{\circ} 00^{\prime} 59,22^{\prime \prime} \mathrm{S}$ & $47^{\circ} 54^{\prime} 10,50^{\prime \prime} \mathrm{W}$ & 244,97 & 775,784 \\
\hline $\mathrm{P} 1$ & USP Campus 1 & $22^{\circ} 01^{\prime} 12,78^{\prime \prime} \mathrm{S}$ & $47^{\circ} 53^{\prime} 59,82^{\prime \prime} \mathrm{W}$ & - & - \\
\hline $\mathrm{P} 4$ & SAAE Getúlio Vargas & $22^{\circ} 01^{\prime} 58,83^{\prime \prime} \mathrm{S}$ & $47^{\circ} 52^{\prime} 34,39^{\prime \prime} \mathrm{W}$ & - & - \\
\hline P5 & SAAE Cogeb & $22^{\circ} 00^{\prime} 46,42^{\prime \prime} \mathrm{S}$ & $47^{\circ} 52^{\prime} 57,63^{\prime \prime} \mathrm{W}$ & - & - \\
\hline
\end{tabular}

Os dados pluviométricos não foram utilizados nas simulações, eles apenas foram utilizados para analisar a quantidade de chuva capaz de gerar limnigramas significativos no canal e o tempo de resposta da bacia. Em 2013 apenas os dados de P4 estavam disponíveis e foram utilizados diretamente. A partir de 2014, também se tinham disponíveis os registros dos pontos P1 e P5. Assim, para estimar a precipitação na bacia, adotou-se o Método de Thiessen considerando os pluviômetros P1, P4 e P5 com fatores de influência de 0,042, 0,698 e 0,260, respectivamente. O pluviômetro P6, apesar de ser bastante influente na bacia do Gregório, não foi considerado pois no período analisado seus registros ainda estava em fase de consistência.

A primeira configuração das instalações dos sensores de pressão foi em tubos fixados na parede do canal, entre placas de concreto pré-moldadas. Após a instalação dos sensores, no dia 16/05/2013 foi realizado o levantamento topográfico do trecho. Essa primeira configuração é apresentada e discutida com detalhes por Almeida (2013).

Os levelogger instalados em tubos ficaram a aproximadamente $0,5 \mathrm{~m}$ acima do ponto de menor cota da seção, já que a seção do canal não é perfeitamente retangular. 
Com isso, apenas eventos muito significativos, ou seja, eventos que atingiram grandes valores de profundidade, eram registrados. Para contornar esse problema, uma nova forma de instalação dos sensores foi idealizada e desenvolvida pela equipe de pesquisa, visando medir menores profundidades d'água. O suporte de fundo (Figura 11) foi confeccionado pela Oficina Mecânica da EESC-USP utilizando chapas de aço inoxidável de $1 \mathrm{~mm}$ de espessura e placa de poliacetal de $10 \mathrm{~mm}$ de espessura. $\mathrm{O}$ seu formato hidrodinâmico e a posição dos furos buscam evitar a interferência no escoamento, efeitos de descolamento da lamina d'água e medição de pressão dinâmica. Ele pode ser instalado na parede do canal, mantendo o levelogger na posição vertical, ou no fundo do canal, com o levelogger na horizontal.

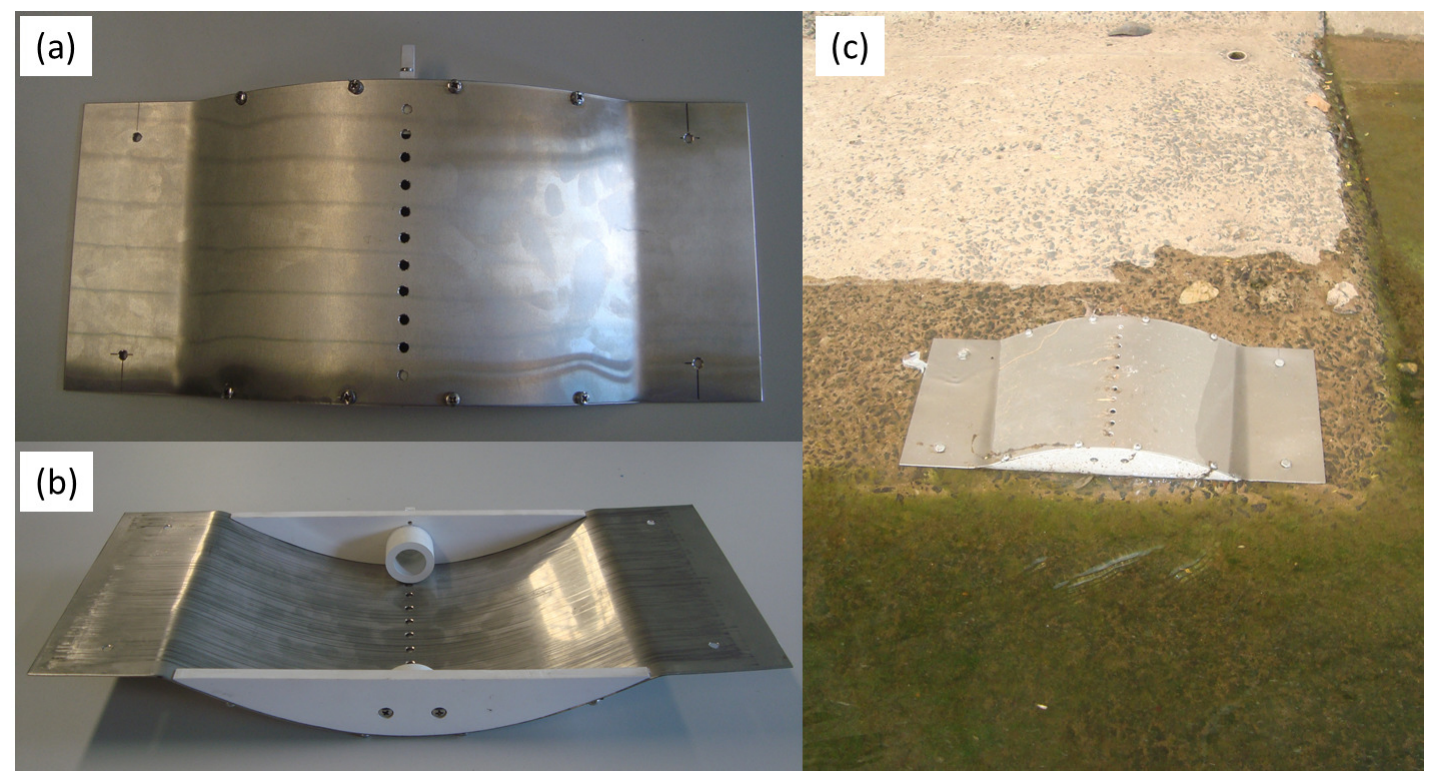

Figura 11 - Suporte de fundo para medição de profundidade d'água com levelogger: (a) vista superior; (b) vista inferior; (c) instalação em campo.

Os testes do suporte de fundo, realizados no Laboratório de Hidráulica da EESCUSP e no campo, apresentaram resultados coerentes. Inicialmente, ele foi instalado apenas no ponto de montante, para comparação de medidas. Atualmente, o suporte de fundo está instalado em toda a Rede de Hidrometria.

Em um primeiro momento, o intervalo de tempo entre cada registro foi configurado para 10 segundos. Mas essa configuração exigia a ida da equipe a campo a cada quatro dias para descarregar os dados (ALMEIDA, 2013). A observação de alguns eventos possibilitou a conclusão de que intervalos de 30 segundos seriam suficientes para acompanhar uma onda de cheia no trecho selecionado. Com isso e com o método de compressão dos dados oferecido pelo Software, o intervalo de coleta dos dados passou a ser mensal, juntamente com a manutenção das instalações.

A instalação dos barologger também passou por mudanças. A princípio, cada levelogger tinha o seu barologger instalado na mesma tubulação. Depois, passou-se a utilizar 
apenas um barologger para os três levelogger, visto que eles possuem um raio de ação de $30 \mathrm{~km}$ e a altitude da área monitorada não varia mais do que $300 \mathrm{~m}$. O barologger foi então instalado juntamente com um dos pluviômetros e utilizado para compensar todos os levelogger da Rede de Hidrometria. A Tabela 3 resume a evolução da configuração das instalações dos sensores.

Tabela 3 - Evolução da configuração das instalações dos sensores.

\begin{tabular}{lcl}
\hline \multicolumn{1}{c}{ Posição } & Sensor & \multicolumn{1}{c}{ Instalação } \\
\hline \multicolumn{2}{c}{ 01/03/2013 a $\mathbf{1 9 / 0 4 / 2 0 1 3 ~}$} \\
\hline montante & L2 e B2 & tubo de metal \\
intermediário & L3 e B3 & tubo de PVC \\
jusante & L1 e B1 & tubo de PVC \\
\hline
\end{tabular}

$19 / 04 / 2013$ a $13 / 01 / 2014$

\begin{tabular}{|c|c|c|}
\hline $\begin{array}{l}\text { montante } \\
\text { intermediário } \\
\text { jusante }\end{array}$ & $\begin{array}{c}\text { L3 } \\
\text { L2 e B2 } \\
\text { L1 }\end{array}$ & $\begin{array}{l}\text { tubo de metal } \\
\text { tubo de PVC } \\
\text { tubo de PVC }\end{array}$ \\
\hline \multicolumn{3}{|c|}{$13 / 01 / 2014$ a $19 / 02 / 2014$} \\
\hline montante & L3 & tubo de metal \\
\hline montante & $\mathrm{L} 4$ & suporte de fundo \\
\hline intermediário & L2 e B2 & tubo de PVC \\
\hline jusante & L1 & tubo de PVC \\
\hline
\end{tabular}

$19 / 02 / 2014$ a $21 / 07 / 2014$

\begin{tabular}{lcl}
\hline montante & L4 & suporte de fundo \\
jusante & L1 e B2 & tubo de PVC \\
\hline
\end{tabular}

$10 / 10 / 2014$ a $30 / 10 / 2014$

\begin{tabular}{lcl}
\hline montante & L8 & suporte de fundo \\
jusante & L9 e B1 & tubo de PVC \\
\hline
\end{tabular}

a partir de $30 / 10 / 2014$

\begin{tabular}{lcl}
\hline montante & L16 & suporte de fundo \\
intermediário & L15 & suporte de fundo \\
jusante & L14 & suporte de fundo \\
pluviômetro P1 & B3 & garrafa PET \\
\hline
\end{tabular}




\subsection{Medição de Velocidade}

Desejava-se confrontar as estimativas de vazão realizadas pelo modelo hidrodinâmico alimentado apenas com dados de nível. Por isso algumas tentativas de medição de vazão serão apresentadas a seguir.

Almeida (2013) utilizou laranjas como flutuadores e tempo de vídeo para estimar a velocidade no trecho do córrego do Gregório durante a passagem de uma onda de cheia no dia 23/03/2013. Devido à grande turbulência e turbidez da água, houve grande dificuldade em visualizar as laranjas e elas acabaram sendo perdidas. Entretanto, a grande quantidade de material carreado pelo rio possibilitou adotar como flutuadores outros objetos, como isopor, sacos plásticos, bolas, madeira e etc, que passavam pelo rio durante a filmagem. Apesar da estimativa da velocidade ser bastante imprecisa, chegou-se a valores médios de $5 \mathrm{~m} / \mathrm{s}$ a montante, e $4 \mathrm{~m} / \mathrm{s}$ a jusante. Deve-se destacar que o evento do dia 23/03/2013 não atingiu profundidades suficientes para serem adequadamente registradas pela instalação em tubos, visto que sua profundidade máxima foi inferior a 0,5 m a jusante. Apesar dessas velocidades já elevadas, é esperado que elas atinjam valores ainda maiores em eventos de maior intensidade.

Considerando a magnitude dessas velocidades e as características do canal, verificouse que, provavelmente, o escoamento possua número de Froude muito próximo de um, o que possibilita a ocorrência de ressalto hidráulico ondular, de difícil caracterização.

Para auxiliar a verificação do modelo, desejava-se acompanhar a evolução da vazão durante as diferentes fases da passagem da onda de cheia (subida, pico e descida). Diante da situação encontrada em campo, o aparelho ADCP foi considerado como a solução mais viável para a medição de velocidade.

O Projeto MAPLU-2 tem disponível para medição de velocidade d'água o Sistema SonTek RiverSurveyor S5, um Perfilador Acústico Doppler (Acoustic Doppler Profiler ADP) projetado para medir velocidades de fluxo, profundidade e batimetria e para estimar vazões fluviais. O sistema é composto pelo perfilador S5 - idealizado para águas rasas com um alcance máximo de $5 \mathrm{~m}$ para medição de velocidade e $15 \mathrm{~m}$ para estimativa de vazão - pelo suporte em prancha Hydroboard (Figura 12) e pelo software para processamento dos dados.

Como o canal é consideravelmente profundo (4 m) e largo ( $8 \mathrm{~m})$ e o nível d'água varia rapidamente durante a passagem de onda de cheia - em cerca de 15 min o nível chega a subir $1 \mathrm{~m}$ (ver eventos nos Apêndices C e D) - foi necessário adaptar o uso do ADP à realidade encontrada no campo. Além disso, a inexistência de ponte sobre o trecho analisado aumentava a dificuldade de movimentação do equipamento dentro do canal.

Diferentes suportes, medidas de segurança e procedimentos foram desenvolvidos e testados em campo pela equipe de pesquisa para permitir a medição de velocidade durante a passagem da onda de cheia. Buscou-se uma maneira da prancha acompanhar a rápida subida e descida do nível da água sem perder sua estabilidade. Constatou-se 
não ser viável realizar a travessia completa da prancha pela seção (procedimento exigido pelo software) devido a dificuldade de movimentação da prancha e a rápida mudança das condições de escoamento, ou seja, não se tinha tempo suficiente para finalizar as travessias e acompanhar a evolução do escoamento.

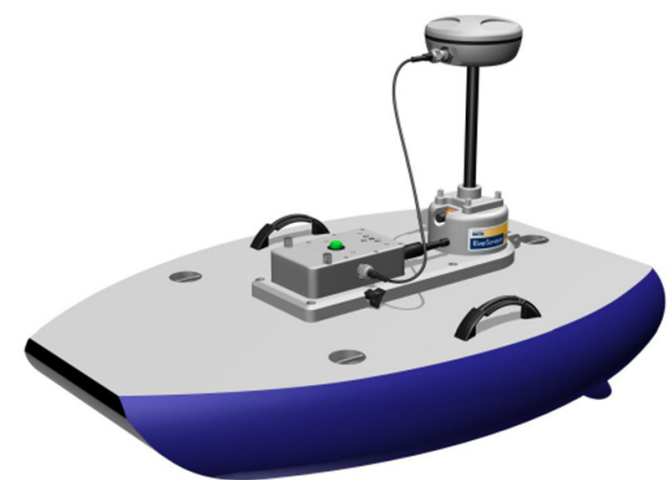

Figura 12 - ADP RiverSurveyor S5 acoplado em prancha (SONTEK, 2009).

Decidiu-se por manter o ADP parado no meio do canal realizando medições de velocidade em uma única vertical. A ideia era ignorar o cálculo da vazão feita pelo software, que exigia a travessia da prancha através da seção, e extrair os dados brutos de velocidade para serem interpretados e processados através de outros métodos de aproximação da vazão, como, por exemplo, o método da máxima entropia de Chiu (1987).

Infelizmente, essa etapa do trabalho não se viabilizou. Apesar de algumas tentativas, não foi possível realizar medições coerentes de velocidade durante um evento de passagem de onda de cheia. Além disso, as campanhas de medição foram interrompidas devido aos riscos aos quais a equipe se via exposta nessas ocasiões. Outras possibilidades de medição estão sendo analisadas para trabalhos futuros.

Os desafios e dificuldades encontrados e as soluções adotadas para o monitoramento de nível e estimativa da vazão em rio urbano foram apresentadas em forma de pôster e discutidos na $6^{\text {th }}$ International Conference on Flood Management - ICFM, em São Paulo (NEGRÃO et al., 2014). 


\section{Modelagem}

\subsection{Desenvolvimento do Modelo Hidrodinâmico 1D}

Para o desenvolvimento do modelo, adotou-se a formulação das equações de Saint Venant apresentada por Akan (2006) e a resolução do sistema segundo o método apresentado por Freitag (2003). Esses procedimentos serão detalhados nas próximas seções.

\subsubsection{Implementação}

A partir das equações 1.1 e 1.2 - tendo em consideração que (1) a contribuição lateral é desprezível, $\log q=0$; (2) o canal é prismático, $\log 0=1$; (3) $h=z+y$; (4) $S_{0}=-\partial z / \partial x$ e (5) aplicando-se o filtro LPI (FREAD; JIN; LEWIS, 1996) para resolver escoamento transcrítico - as Equações de Saint Venant podem ser representadas da seguinte forma:

$$
\begin{aligned}
\frac{\partial A}{\partial t}+\frac{\partial Q}{\partial x} & =0 \\
\alpha\left[\frac{\partial Q}{\partial t}+\frac{\partial}{\partial x}\left(\frac{Q^{2}}{A}\right)\right]+g A \frac{\partial h}{\partial x}+g A S_{f} & =0
\end{aligned}
$$

sendo $\alpha$ o filtro LPI que reduz os efeitos dos termos de inércia dependendo das condições de fluxo locais e é definido em função do número de Froude da seguinte forma:

$$
\alpha=\left\{\begin{array}{lll}
1-F r^{m} & \text { se } & F r \leq 1 \\
0 & \text { se } & F r>1
\end{array}\right.
$$

em que a constante $m \geq 1$.

O equacionamento também foi generalizado para canais trapezoidais (Figura 13). Com isso, a área, o perímetro e as suas derivadas são calculados do seguinte modo:

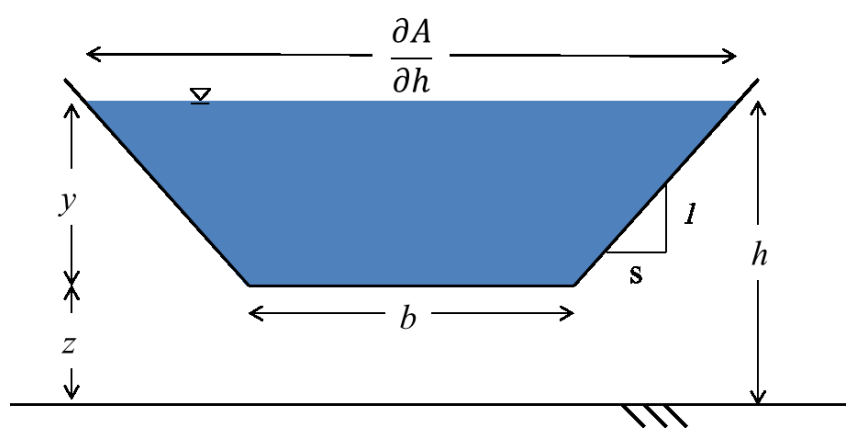

Figura 13 - Seção de canal trapezoidal. 


$$
\begin{aligned}
A & =(b+s y) y \\
P & =b+2 y \sqrt{1+s^{2}} \\
\frac{\partial A}{\partial h} & =b+2 s y \\
\frac{\partial P}{\partial h} & =2 \sqrt{1+s^{2}}
\end{aligned}
$$

As equações 4.1 e 4.2 foram discretizadas aplicando-se as equações do esquema de Preissmann (Equações 1.5 - 1.7) com $\psi=1 / 2$. Assim, foram obtidas as equações na forma de diferenças finitas (Equações 4.8 e 4.9) nas quais as incógnitas são as vazões e as cotas da superfície d'água no instante de tempo seguinte $\left(Q_{j}^{n+1}\right.$ e $\left.h_{j}^{n+1}\right)$.

$$
\begin{aligned}
& \frac{\left(A_{j+1}^{n+1}+A_{j}^{n+1}\right)-\left(A_{j+1}^{n}+A_{j}^{n}\right)}{2 \Delta t}+\frac{\theta\left(Q_{j+1}^{n+1}-Q_{j}^{n+1}\right)+(1-\theta)\left(Q_{j}^{n}+1-Q_{j}^{n}\right)}{\Delta x}=0 \\
& \alpha\left[\frac{\left(Q_{j+1}^{n+1}+Q_{j}^{n+1}\right)-\left(Q_{j+1}^{n}+Q_{j}^{n}\right)}{2 \Delta t}\right]+\frac{\alpha \theta}{\Delta x}\left[\frac{\left(Q_{j+1}^{n+1}\right)^{2}}{A_{j+1}^{n+1}}-\frac{\left(Q_{j}^{n+1}\right)^{2}}{A_{j}^{n+1}}\right] \\
& \quad+\frac{\alpha(1-\theta)}{\Delta x}\left[\frac{\left(Q_{j+1}^{n}\right)^{2}}{A_{j+1}^{n}}-\frac{\left(Q_{j}^{n}\right)^{2}}{A_{j}^{n}}\right]+g \theta \frac{\left(A_{j+1}^{n+1}+A_{j}^{n+1}\right)}{2} \frac{\left(h_{j+1}^{n+1}-h_{j}^{n+1}\right)}{\Delta x} \\
& \quad+g(1-\theta) \frac{\left(A_{j+1}^{n}+A_{j}^{n}\right)}{2} \frac{\left(h_{j+1}^{n}-h_{j}^{n}\right)}{\Delta x}+g \theta \frac{\left(A_{j+1}^{n+1}+A_{j}^{n+1}\right)}{2} \frac{\left(S_{f}\right)_{j+1}^{n+1}+\left(S_{f}\right)_{j}^{n+1}}{2} \\
& \quad+g(1-\theta) \frac{\left(A_{j+1}^{n}+A_{j}^{n}\right)}{2} \frac{\left(S_{f}\right)_{j+1}^{n}+\left(S_{f}\right)_{j}^{n}}{2}=0
\end{aligned}
$$

Fixando-se $n$ e variando $j=1,2, \ldots, j j$, sendo $j j$ o número de seções, as Equações 4.8 e 4.9 formam um sistema com $2 j j$ equações e $2 j j+2$ incógnitas. As outras duas equações necessárias para a resolução do sistema são obtidas através das condições de contorno do problema. De acordo com a representação de Akan (2006), as equações do sistema podem ser expressas pelas seguintes funções:

$$
\begin{aligned}
B_{1}\left[Q_{1}^{n+1}, h_{1}^{n+1}\right] & =0 \\
C_{j}\left[Q_{j}^{n+1}, h_{j}^{n+1}, Q_{j+1}^{n+1}, h_{j+1}^{n+1}\right] & =0 \\
M_{j}\left[Q_{j}^{n+1}, h_{j}^{n+1}, Q_{j+1}^{n+1}, h_{j+1}^{n+1}\right] & =0 \\
B_{N}\left[Q_{N}^{n+1}, h_{N}^{n+1}\right] & =0
\end{aligned}
$$

sendo que $C_{j}$ e $M_{j}$ representam as diferenças finitas da equação da continuidade e da quantidade de movimento, respectivamente e $B_{1}$ e $B_{N}$ são as equações de condição de contorno de montante e de jusante, respectivamente, representando o caso subcrítico (estrutura 1+1). 
Para a resolução do sistema não-linear foi utilizado o Método de Iteração de Newton Generalizado, que consiste em atribuir valores às incógnitas $Q_{j}^{n+1}$ e $h_{j}^{n+1}$ e corrigi-las iterativamente. Substituindo-se os valores estimados nas Equações 4.8 e 4.9 obtém-se os resíduos, que devem se aproximar de zero, considerando uma certa tolerância, durante o processo iterativo. Os valores de correção são obtidos igualando-se as derivadas das equações de contorno e das Equações 4.8 e 4.9 ao negativo dos resíduos:

$$
\begin{aligned}
\frac{\partial B_{1}}{\partial Q_{1}^{n+1}} \Delta Q_{1}+\frac{\partial B_{1}}{\partial h_{1}^{n+1}} \Delta h_{1} & =-r B_{1} \\
\frac{\partial C_{j}}{\partial Q_{j}^{n+1}} \Delta Q_{j}+\frac{\partial C_{j}}{\partial h_{j}^{n+1}} \Delta h_{j}+\frac{\partial C_{j}}{\partial Q_{j+1}^{n+1}} \Delta Q_{j+1}+\frac{\partial C_{j}}{\partial h_{j+1}^{n+1}} \Delta h_{j+1} & =-r C_{j} \\
\frac{\partial M_{j}}{\partial Q_{j}^{n+1}} \Delta Q_{j}+\frac{\partial M_{j}}{\partial h_{j}^{n+1}} \Delta h_{j}+\frac{\partial M_{j}}{\partial Q_{j+1}^{n+1}} \Delta Q_{j+1}+\frac{\partial M_{j}}{\partial h_{j+1}^{n+1}} \Delta h_{j+1} & =-r M_{j} \\
\frac{\partial B_{N}}{\partial Q_{N}^{n+1}} \Delta Q_{N}+\frac{\partial B_{N}}{\partial h_{N}^{n+1}} \Delta h_{N} & =-r B_{N}
\end{aligned}
$$

O sistema de equações (Equações 4.14 - 4.17) tem a seguinte representação matricial, em que os sobrescritos $n+1$ são omitidos por clareza:

$$
M W=Z
$$

em que:

$$
\begin{aligned}
& M=\left[\begin{array}{cccccccc}
\frac{\partial B_{1}}{\partial Q_{1}} & \frac{\partial B_{1}}{\partial h_{1}} & 0 & 0 & \ldots & \ldots & \ldots & \ldots \\
\frac{\partial C_{1}}{\partial Q_{1}} & \frac{\partial C_{1}}{\partial h_{1}} & \frac{\partial C_{1}}{\partial Q_{2}} & \frac{\partial C_{1}}{\partial h_{2}} & 0 & 0 & \ldots & \ldots \\
\frac{\partial M_{1}}{\partial Q_{1}} & \frac{\partial M_{1}}{\partial h_{1}} & \frac{\partial M_{1}}{\partial Q_{2}} & \frac{\partial M_{1}}{\partial h_{2}} & 0 & 0 & \ldots & \ldots \\
0 & 0 & \frac{\partial C_{2}}{\partial Q_{2}} & \frac{\partial C_{2}}{\partial h_{2}} & \frac{\partial C_{2}}{\partial Q_{3}} & \frac{\partial C_{2}}{\partial h_{3}} & \ldots & \ldots \\
0 & 0 & \frac{\partial M_{2}}{\partial Q_{2}} & \frac{\partial M_{2}}{\partial h_{2}} & \frac{\partial M_{2}}{\partial Q_{3}} & \frac{\partial M_{2}}{\partial h_{3}} & \ldots & \ldots \\
\ddots & \ddots & \ddots & \ddots & \ddots & \ddots & \ddots & \ddots \\
\ldots & \cdots & \ldots & 0 & \frac{\partial C_{N-1}}{\partial Q_{N-1}} & \frac{\partial C_{N-1}}{\partial h_{N-1}} & \frac{\partial C_{N-1}}{\partial Q_{N}} & \frac{\partial C_{N-1}}{\partial h_{N}} \\
\ldots & \ldots & \ldots & 0 & \frac{\partial M_{N-1}}{\partial Q_{N-1}} & \frac{\partial M_{N-1}}{\partial h_{N-1}} & \frac{\partial M_{N-1}}{\partial Q_{N}} & \frac{\partial M_{N-1}}{\partial h_{N}} \\
\ldots & \ldots & \ldots & \ldots & 0 & 0 & \frac{\partial B_{N}}{\partial Q_{N}} & \frac{\partial B_{N}}{\partial h_{N}}
\end{array}\right] \\
& W=\left[\begin{array}{lllllll}
\Delta Q_{1} & \Delta h_{1} & \Delta Q_{2} & \Delta h_{2} & \ldots & \Delta Q_{N} & \Delta h_{N}
\end{array}\right]^{T} \\
& Z=\left[\begin{array}{lllllll}
-r B_{1} & -r C_{1} & -r M_{1} & \ldots & -r C_{N-1} & -r M_{N-1} & -r B_{N}
\end{array}\right]^{T}
\end{aligned}
$$


As derivadas parciais de cada termo das equações discretizadas são:

$$
\begin{aligned}
\frac{\partial C_{j}}{\partial Q_{j}} & =-\frac{\theta}{\Delta x} \\
\frac{\partial C_{j}}{\partial h_{j}} & =\frac{1}{2 \Delta t} \frac{\partial A_{j}}{\partial h_{j}} \\
\frac{\partial C_{j}}{\partial Q_{j+1}} & =\frac{\theta}{\Delta x} \\
\frac{\partial C_{j}}{\partial h_{j+1}} & =\frac{1}{2 \Delta t} \frac{\partial A_{j+1}}{\partial h_{j+1}} \\
\frac{\partial M_{j}}{\partial Q_{j}} & =\frac{\alpha_{j}^{n}}{2 \Delta t}-\alpha_{j}^{n} \frac{2 \theta}{\Delta x} \frac{Q_{j}}{A_{j}}+g \theta \frac{\left(A_{j+1}+A_{j}\right)}{4} \frac{\partial\left(S_{f}\right)_{j}}{\partial Q_{j}} \\
\frac{\partial M_{j}}{\partial h_{j}} & =\alpha_{j}^{n} \frac{\theta}{\Delta x} \frac{\left(Q_{j}\right)^{2}}{\left(A_{j}\right)^{2}} \frac{\partial A_{j}}{\partial h_{j}}-g \theta \frac{\left(A_{j+1}+A_{j}\right)}{2 \Delta x}+g \theta \frac{\left(h_{j+1}-h_{j}\right)}{2 \Delta x} \frac{\partial A_{j}}{\partial h_{j}} \\
& +g \theta \frac{\left(A_{j+1}+A_{j}\right)}{4} \frac{\partial\left(S_{f}\right)_{j}}{\partial h_{j}}+g \theta \frac{\left(S_{f}\right)_{j+1}+\left(S_{f}\right)_{j}}{4} \frac{\partial A_{j}}{\partial h_{j}} \\
\frac{\partial M_{j}}{\partial Q_{j+1}} & =\frac{\alpha_{j}^{n}}{2 \Delta t}+\alpha_{j}^{n} \frac{2 \theta}{\Delta x} \frac{Q_{j+1}}{A_{j+1}}+g \theta \frac{\left(A_{j+1}+A_{j}\right)}{4} \frac{\partial\left(S_{f}\right)_{j+1}}{\partial Q_{j+1}} \\
\frac{\partial M_{j}}{\partial h_{j+1}} & =-\alpha_{j}^{n} \frac{\theta}{\Delta x}\left(\frac{Q_{j+1}}{A_{j+1}}\right)^{2} \frac{\partial A_{j+1}}{\partial h_{j+1}}+g \theta \frac{\left(A_{j+1}+A_{j}\right)}{2 \Delta x}+g \theta \frac{\left(h_{j+1}-h_{j}\right)}{2 \Delta x} \frac{\partial A_{j+1}}{\partial h_{j+1}} \\
& +g \theta \frac{\left(A_{j+1}+A_{j}\right)}{4} \frac{\partial\left(S_{f}\right)_{j+1}}{\partial h_{j+1}}+g \theta \frac{\left(S_{f}\right)_{j+1}+\left(S_{f}\right)_{j}}{4 A_{j+1}} \frac{\partial h_{j+1}}{4}
\end{aligned}
$$

A solução desse sistema linearizado fornece a correção dos valores estimados $Q_{j}^{n+1}$ e $h_{j}^{n+1}$ para a próxima iteração. Assim, as estimativas são atualizadas:

$$
\begin{aligned}
\left(Q_{j}^{n+1}\right)_{k+1} & =\left(Q_{j}^{n+1}\right)_{k}+\left(\Delta Q_{j}\right)_{k} \\
\left(h_{j}^{n+1}\right)_{k+1} & =\left(h_{j}^{n+1}\right)_{k}+\left(\Delta h_{j}\right)_{k}
\end{aligned}
$$

sendo $k$ os ciclos de iteração.

O processo de iteração é finalizado quando todos os resíduos atingem um valor tolerável $\left(\left|r B_{1}\right|\right.$ e $\left|r C_{j}\right|$ e $\left|r M_{j}\right|$ e $\left|r B_{N}\right| \leq t o l$, sendo que tol é um valor positivo muito pequeno) ou quando o número máximo de iterações é atingido. Confirmado o critério de parada, passa-se para o próximo instante de tempo.

\subsubsection{Resolução do Sistema de Equações Linearizado}

Como descrito na seção anterior, para cada iteração é necessário resolver um sistema de equações linearizado pelo Método de Newton Generalizado. As matrizes resultantes são esparsas e podem assumir grandes dimensões, de acordo com o número de seções em que o trecho de canal for subdividido. Assim, para a resolução do sistema matricial 
(Equação 4.18), utilizou-se o algoritmo de Thomas, também conhecido como o Método da Dupla Varredura, conforme descrito por Freitag (2003).

O algoritmo de Thomas resolve sistemas representados por matrizes tri-diagonais. Entretanto, a matriz $M$ é penta-diagonal. Para poder aplicar o algoritmo, $M$ foi agrupada em sub-matrizes $2 \times 2$ formando uma matriz tridiagonal em blocos. Com esse método, ao invés de se resolver diretamente o sistema 4.18, que envolve a inversão de uma matriz muito grande e complicada, resolve-se um grupo de sistemas (Equação 4.32) mais simples e com menos operações (FREITAG, 2003). Além das vantagens computacionais e simplificação algébrica, visando uma futura adequação do modelo, o Método da Dupla Varredura foi escolhido por ser compatível aos métodos de captura de choque, que são procedimentos mais robustos de resolução de escoamento transcrítico, como apresentado na Seção 1.3.

$$
A_{j} W_{j-1}+D_{j} W_{j}+C_{j} W_{j+1}=Z_{j}
$$

onde $D_{j}, A_{j}$ e $C_{j}$ são matrizes $2 \times 2$ que representam a diagonal principal, a diagonal inferior e a diagonal superior da matriz tridiagonal em blocos, respectivamente e $W_{j}=$ $\left[\Delta Q_{j}, \Delta h_{j}\right]^{T}$. Assim, tem-se:

$$
\begin{gathered}
D_{1}=\left[\begin{array}{ll}
\frac{\partial B_{1}}{\partial Q_{1}} & \frac{\partial B_{1}}{\partial h_{1}} \\
\frac{\partial C_{1}}{\partial Q_{1}} & \frac{\partial C_{1}}{\partial h_{1}}
\end{array}\right] \quad, \quad D_{N}=\left[\begin{array}{ll}
\frac{\partial M_{N-1}}{\partial Q_{N}} & \frac{\partial M_{N-1}}{\partial h_{N}} \\
\frac{\partial B_{N}}{\partial Q_{N}} & \frac{\partial B_{N}}{\partial h_{N}}
\end{array}\right] \quad \text { e } \\
D_{j}=\left[\begin{array}{ll}
\frac{\partial M_{j-1}}{\partial Q_{j}} & \frac{\partial M_{j-1}}{\partial h_{j}} \\
\frac{\partial C_{j}}{\partial Q_{j}} & \frac{\partial C_{j}}{\partial h_{j}}
\end{array}\right] \quad \text { para } j=2, \ldots, N-1 \\
A_{1}=0 \quad \text { e } A_{j}=\left[\begin{array}{cc}
\frac{\partial M_{j-1}}{\partial Q_{j-1}} & \frac{\partial M_{j-1}}{\partial h_{j-1}} \\
0 & 0
\end{array}\right] \quad \text { para } j=2, \ldots, N \\
C_{N}=0 \quad \mathrm{e} \quad C_{j}=\left[\begin{array}{cc}
0 & 0 \\
\frac{\partial C_{j}}{\partial Q_{j+1}} & \frac{\partial C_{j}}{\partial h_{j+1}}
\end{array}\right] \text { para } j=1, \ldots, N-1
\end{gathered}
$$

Em um primeiro momento, o cálculo matricial é feito progressivamente (forward) obtendo-se $E_{j}$ e $F_{j}$ :

$$
\begin{aligned}
& E_{1}=-D_{1}^{-1} C_{1} \quad \text { e } \quad E_{j}=-\left(D_{j}+A_{j} E_{j-1}\right)^{-1} C_{j} \quad \text { para } \quad j=2, \ldots, N \\
& F_{1}=-D_{1}^{-1} Z_{1} \quad \text { e } \quad F_{j}=\left(D_{j}+A_{j} E_{j-1}\right)^{-1}\left(Z_{j}-A_{j} F_{j-1}\right) \quad \text { para } \quad j=2, \ldots, N
\end{aligned}
$$

Tendo $E_{j}$ e $F_{j}$, calcula-se de forma regressiva (backward) o $W_{j}$ :

$$
W_{N}=F_{N} \quad \text { e } \quad W_{j}=E_{j} W_{j+1}+F_{j} \quad \text { para } \quad j=N-1, \ldots, 1
$$


Obtendo-se $W_{j}$ tem-se $\Delta Q_{j}$ e $\Delta h_{j}$ necessários para atualizar as estimativas da próxima iteração.

\subsection{Problema Teste}

Durante o desenvolvimento do modelo, problemas com soluções conhecidas foram utilizados para a verificação dos algoritmos. Na fase inicial, reproduziu-se os problemas 8.1, 8.2 e 8.3 apresentados por Akan (2006). Por serem problemas bem detalhados e simples (com poucas seções), foi possível acompanhar passo a passo a resolução e identificar problemas no código e as diferenças entre as diversas versões do modelo desenvolvido.

Posteriormente, o algoritmo foi aplicado a um problema analítico apresentado por MacDonald et al. (1997), que simula um escoamento transcrítico envolvendo ressalto hidráulico. Esse mesmo problema também foi utilizado como teste por Freitag (2003) e Djordjević, Prodanović e Walters (2004).

O trecho de canal simulado possui seção trapezoidal com inclinação dos taludes de $1: 1(s=1), 1 \mathrm{~km}$ de comprimento e coeficiente de rugosidade de Manning de 0,02. Manteve-se constante a vazão de entrada em $20 \mathrm{~m}^{3} / \mathrm{s}$ e a profundidade da água de saída em 1,349963 m. A declividade do fundo do canal é obtida pela Equação 4.39 (MACDONALD et al., 1997):

$$
S_{0}=\left[1-\frac{400(10+2 y)}{g(10+y)^{3} y^{3}}\right] y^{\prime}+0.16 \frac{(10+2 y \sqrt{2})^{4 / 3}}{(10+y)^{10 / 3} y^{10 / 3}}
$$

em que:

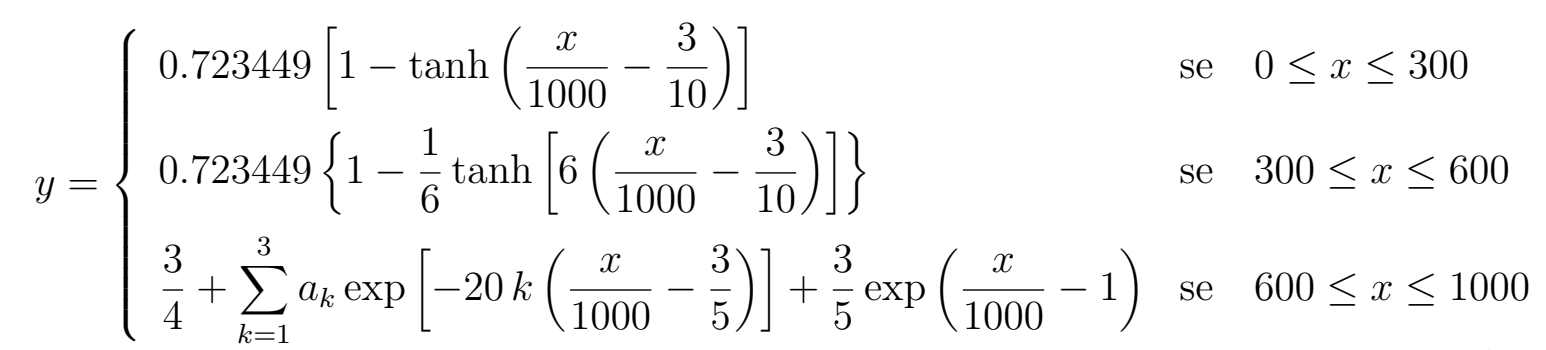

$$
y^{\prime}= \begin{cases}-0.723449 \times 10^{-3} \operatorname{sech}^{2}\left(\frac{x}{1000}-\frac{3}{10}\right) & \text { se } \quad 0 \leq x \leq 300 \\ -0.723449 \times 10^{-3} \operatorname{sech}^{2}\left[6\left(\frac{x}{1000}-\frac{3}{10}\right)\right] & \text { se } \quad 300 \leq x \leq 600 \\ -\frac{1}{50} \sum_{k=1}^{3} k a_{k} \exp \left[-20 k\left(\frac{x}{1000}-\frac{3}{5}\right)\right]+\frac{3}{5000} \exp \left(\frac{x}{1000}-1\right) & \text { se } \quad 600 \leq x \leq 1000\end{cases}
$$

sendo $a_{1}=-0,111051, a_{2}=0,026876$ e $a_{3}=-0,217567$. 
O fundo do canal é obtido por:

$$
z(x)=-\int_{x}^{L} S_{0}(x) d x
$$

Visto que $S_{0}$ envolve uma combinação de funções ( $y$ e $\left.y^{\prime}\right)$ cuja integral é de difícil resolução analítica, $z$ foi calculado considerando $S_{0}=-\Delta z / \Delta x$. Dependendo da discretização $\Delta x$ adotada, o resultado varia próximo da descontinuidade. Alguns efeitos da discretização serão discutidos na Seção 6.1.

Nas representações gráficas do problema (Figura 14), pode-se observar o comportamento da linha d'água e a mudança de regimes subcrítico-supercrítico-subcrítico, caracterizando um escoamento transcrítico.
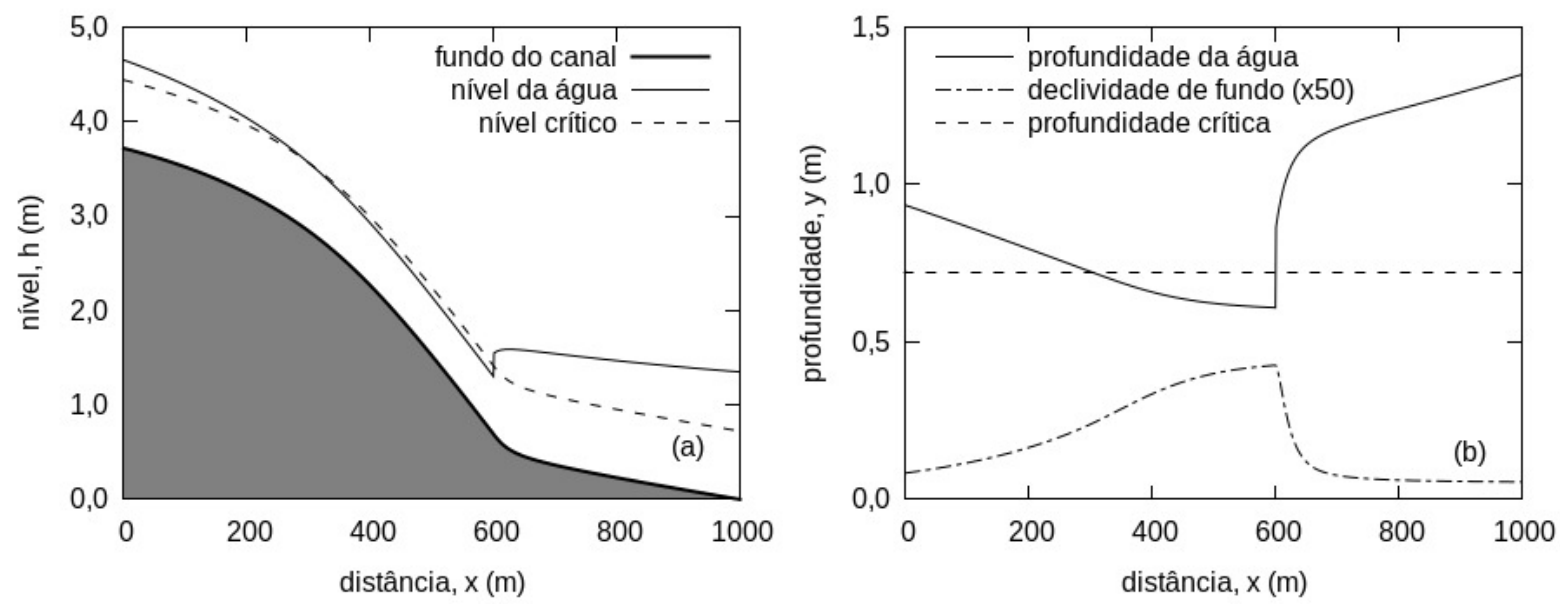

Figura 14 - Representação gráfica (a) do nível d'água e fundo do canal e (b) da profundidade d'água e declividade de fundo do problema teste (Reproduzido de MacDonald et al. (1997)).

\subsection{Aplicação ao Trecho do Córrego do Gregório}

\subsubsection{Processamento dos Eventos}

Para nenhuma das configurações, tubo ou suporte de fundo, foi possível instalar sensores exatamente na menor cota das seções do canal. Por isso, foi necessário adicionar aos dados registrados as distâncias verticais entre a posição dos sensores e a menor cota de fundo do canal.

Durante o levantamento topográfico do trecho, as posições dos sensores dentro dos tubos também foram cotadas e as distâncias verticais entre os sensores e o fundo do canal foram obtidas a partir da topografia. Vale destacar que, para essa configuração, pode ter ocorrido a movimentação vertical dos tubos com o passar do tempo e os valores topográficos levantados podem não representar precisamente a real posição dos tubos para todos os eventos. 
Após instalados os suportes de fundo, foram realizadas medições do posicionamento dos sensores com uma trena. Com essas medidas e com a topografia foi possível obter as distâncias verticais dos sensores ao fundo do canal. Como o suporte é fixo, tem-se maior garantia de que essas distâncias não se alteram com o passar do tempo.

As distâncias dos sensores ao fundo do canal obtidas para cada configuração e seção (Tabela 4) foram somadas aos dados brutos de nível para a determinação das profundidades d'água em relação à menor cota da seção. Vale destacar que, com a instalação do suporte de fundo, foi obtido um ganho de cerca de $40 \mathrm{~cm}$ de profundidade que passou a ser monitorada.

Tabela 4 - Distâncias dos sensores ao fundo do canal.

\begin{tabular}{ccc}
\hline Posição & $\begin{array}{c}\text { Instalação } \\
\text { em tubo }\end{array}$ & $\begin{array}{c}\text { Instalação em } \\
\text { suporte de fundo }\end{array}$ \\
\hline Montante & $0.486 \mathrm{~m}$ & $0.103 \mathrm{~m}$ \\
Intermediário & $0.521 \mathrm{~m}$ & $0.096 \mathrm{~m}$ \\
Jusante & $0.464 \mathrm{~m}$ & $0.086 \mathrm{~m}$ \\
\hline
\end{tabular}

Para a seleção dos eventos, inicialmente eram plotados todos os dados monitorados dos três pontos de medição e visualmente os eventos eram selecionados, se os mesmos atingissem grandes profundidades e tivessem os limnigramas bem representados nas três seções monitoradas. Com a observação de vários eventos foi possível definir critérios de seleção. Para os dados obtidos pela instalação em tubo, considerou-se como evento apenas os valores acima $0,6 \mathrm{~m}$, já que os sensores encontravam-se a cerca de $0,4 \mathrm{~m}$ do fundo do canal e as medições próximas de zero (seco) chegavam a variar até $0,2 \mathrm{~m}$. Além disso, também foram considerados apenas eventos cujo nível máximo de montante fosse maior que 0,7 m, pois apenas eventos com picos maiores que esse valor apresentavam limnigramas de montante com ascensão, pico e resseção bem delimitados. Por causa dessas restrições rigorosas, apenas eventos muito intensos eram considerados e uma parte considerável das medições de profundidade de inicio de ascensão e final de resseção do limnigrama eram perdidas (ver eventos no Apêndice C).

Os dados obtidos pelas instalações com suporte de fundo tiveram restrições menos rigorosas, sendo possível selecionar eventos menores e mais completos. Adotaram-se como critérios níveis acima de $0,2 \mathrm{~m}$ e picos de montante acima de 0,35 m.

Selecionados os eventos, aplicou-se uma média móvel aos dados limnimétricos para minimizar os ruídos da medição. Vale destacar que, mesmo havendo algumas medições a cada 10 segundos, padronizou-se o uso de registros a cada 30 segundos somente, visto que não representou uma perda significativa de informação, como discutido na Seção 3.2. Definiu-se o tamanho da janela de média móvel - ou seja, o número de dados aos quais se aplica a média - visualmente, buscando reduzir o ruído e evitar perdas de informações nos 
picos e no começo das subidas rápidas dos limnigramas. Assim, a janela de 5 medições mostrava-se satisfatória. A Figura 15 apresenta a suavização de um dos eventos como exemplo.

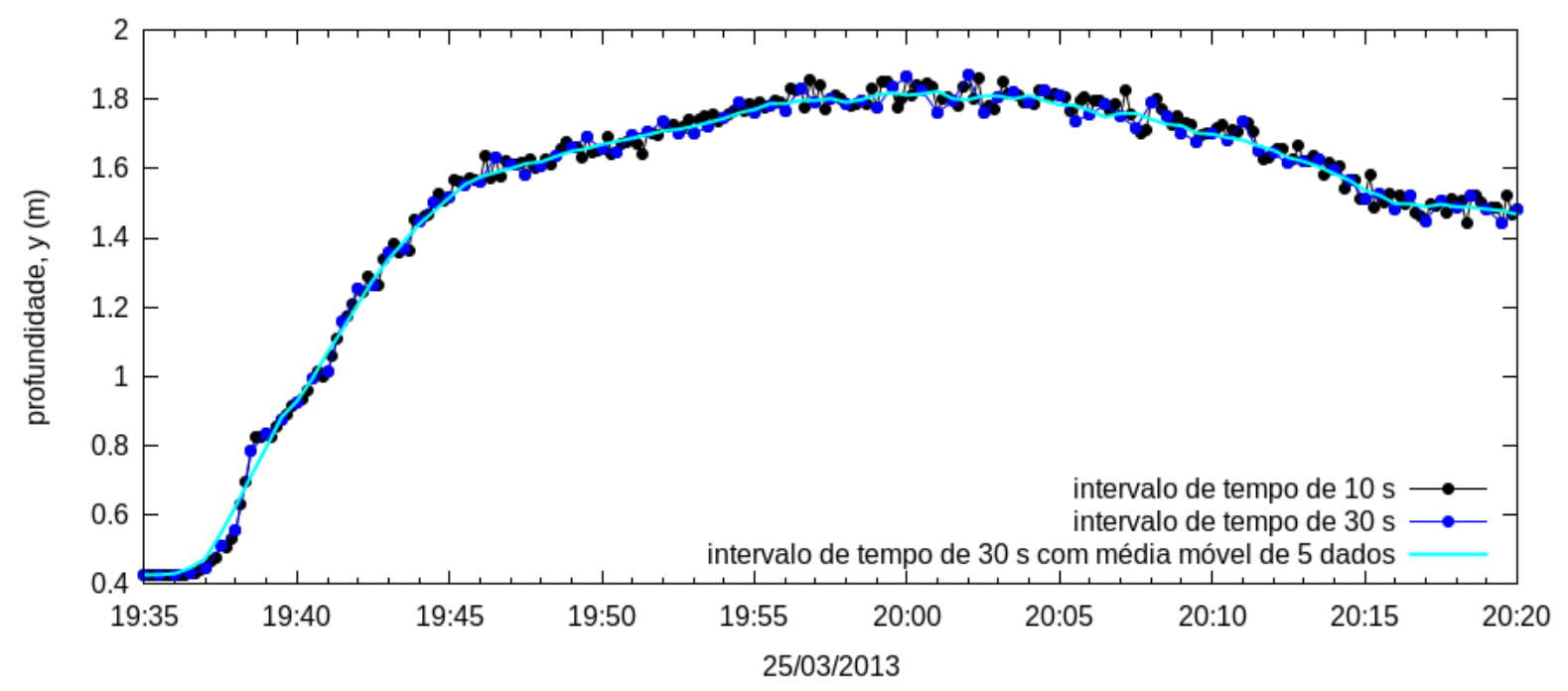

Figura 15 - Suavização do registro através de média móvel de 5 dados para o evento do dia 25/03/2013.

\subsubsection{Aproximações da Geometria do Canal}

O trecho selecionado possui seções próximas de uma seção retangular, com pequenos "chanfros" nas paredes e ligeira inclinação no fundo. Apesar da semelhança das seções em todo o trecho, as cotas mais baixas não estão localizadas exatamente no meio do canal, elas variam de uma seção para outra.

Visando à simplificação da aplicação do modelo desenvolvido, todas as seções foram consideradas retangulares com $8 \mathrm{~m}$ de largura com fundo localizado na menor cota da seção. A Figura 16 apresenta a aproximação adotada utilizando como exemplo a seção de montante. Essa mesma aproximação foi considerada para todas as seções modeladas.

No caso do perfil do trecho, para facilitar a discretização e a análise dos resultados, as distâncias entre cada ponto de medição e entre os degraus foram arredondados para valores inteiros. Além disso, também foram consideradas duas aproximações do fundo do canal: (1) fundo simplificado em dois trechos com declividades de fundo diferentes, porém constantes, referido nesse trabalho como fundo simples, e (2) perfil de fundo aproximado ao obtido pela topografia, referido como fundo com degraus. Na Figura 17 são representas tais aproximações.

Para a aproximação denominada fundo simples, a mudança de declividade ocorre no meio do terceiro degrau de montante para jusante. Esse ponto foi escolhido porque a partir dele muda-se o padrão das distâncias entre os degraus. Para a aproximação denominada fundo com degraus, considerou-se que a variação de cota nos degraus ocorre dentro de 0,1 m de distância, como ilustrado na Figura 18. Essas aproximações e o arren- 
dondamento para valores inteiros permitiu uma discretização mais simples da distância, ficando definido $\Delta x$ como $1 \mathrm{~m}$, variando para $0,9 \mathrm{~m}$ e $0,1 \mathrm{~m}$ apenas nas ocorrências dos degraus. A discretização do perfil está relacionada com a cota de fundo de cada seção para os dois tipos de fundo no Apêndice A, no qual também se encontra as medições obtidas pela topografia.

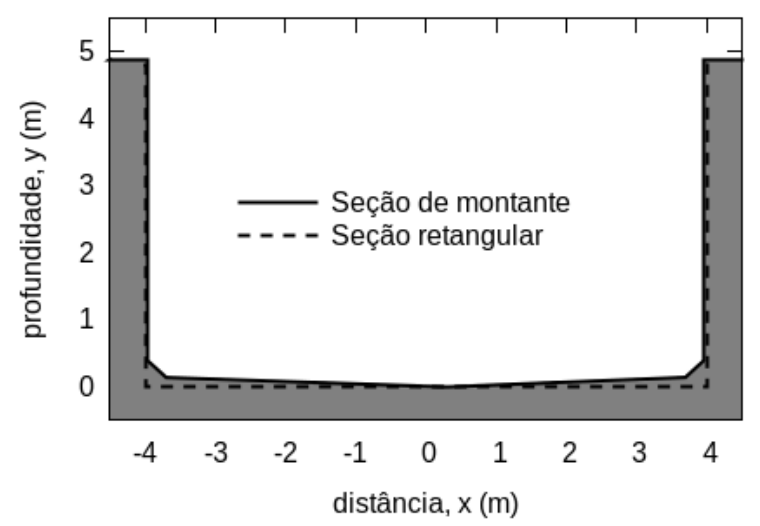

Figura 16 - Aproximação da seção de montante obtida pela topografia para uma seção retangular.

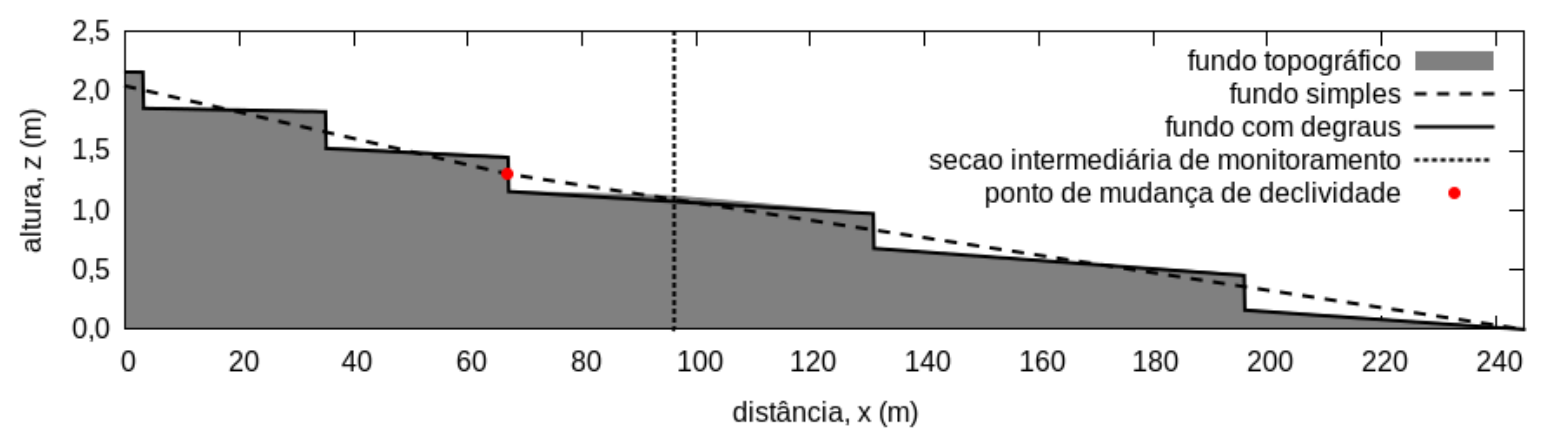

Figura 17 - Aproximação do perfil do fundo do canal.

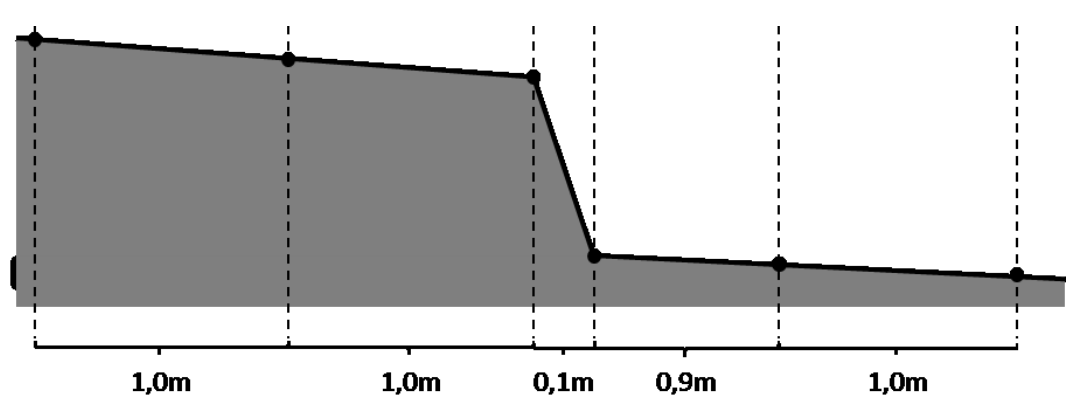

Figura 18 - Detalhe da aproximação de $\Delta x$ para os degraus. 


\subsubsection{Definição dos Parâmetros de Simulação}

Os parâmetros referentes à geometria do canal seguiram as aproximações apresentadas na Seção 4.3.2, que são: comprimento do trecho $L=245 \mathrm{~m}$; largura da seção $B=8$ $\mathrm{m}$; canal retangular, ou seja, declividade dos taludes $s=0$. Foram realizadas simulações para os dois tipos de fundo do canal: fundo simples e fundo com degraus. Adotou-se $\Delta x$ variável, o que permitiu a simulação do fundo do canal com degraus sem precisar refinar muito a malha espacial. Dessa forma, na ocorrência do degrau $\Delta x=0,1$ e $\Delta x=0,9 \mathrm{~m}$ e nos demais casos $\Delta x=1 \mathrm{~m}$, como apresentado pela Figura 18. A discretização do tempo ficou definida como o intervalo de tempo entre os dados processados como descrito na Seção 4.3.1, ou seja, $\Delta t=30 \mathrm{~s}$ para todos os eventos.

Verificou-se com as simulações que, mesmo com um número grande de iterações (em torno de 100), os resíduos não chegavam a valores menores do que $10^{-6}$. Além disso, a convergência ocorria logo nas primeiras iterações. Portanto, adotou-se número máximo de iterações igual a 10 e tolerância igual a $10^{-5}$.

O coeficiente de rugosidade de Manning foi fixado em $n=0,020 \mathrm{~s} / \mathrm{m}^{1 / 3}$. Entretanto, foram feitas análises para os valores 0,016 e $0,023 \mathrm{~s} / \mathrm{m}^{1 / 3}$ e não foram observadas grandes diferenças nos resultados, como será discutido na Seção 6.3. Seguindo a recomendação da bibliografia, adotou-se $\theta=0,6$.

Como não foi possível realizar a simulação sem a utilização do filtro, valores para o fator $m$ do filtro LPI que permitissem a simulação de todos os eventos foram testados. Para o fundo simples, o valor máximo de $m$ encontrado foi $m=10$ e para o fundo com degraus $m=3$.

\subsubsection{Aquecimento das Condições Iniciais e Definição das Condições de Contorno}

Como a medição de níveis não é realizada exatamente no fundo do canal (Tabela 4), não se tem disponíveis as profundidades do escoamento de base para serem utilizados como condições iniciais. Além disso, mesmo utilizando um escoamento de base hipotético, quando o nível é muito baixo, a largura da superfície da água não é mais constante e a simplificação para canal retangular perde sentido.

Dessa forma, considerou-se o início da simulação do evento como o início de medidas de profundidade d'água consistentes nas três seções monitoradas. Consequentemente, inicia-se a simulação quando a passagem da onda de cheia já está ocorrendo, ou seja, o escoamento já é variável (unsteady). Reforçando, as profundidades de referência para o desenho da linha d'água inicial foram aquelas do instante de tempo cujas profundidades das três seções já eram medições válidas, ou seja, seguiam os critérios descritos na Seção 4.3.1.

A princípio e utilizando apenas o fundo simples, a linha d'água inicial era otimizada por Algoritmos Genéticos considerando o escoamento gradualmente variado resolvido pelo 
método de Runge-Kutta de quarta ordem. O parâmetro otimizado era a vazão e buscavase minimizar a diferença ao quadrado entre o nível simulado e o nível medido. O nível de referência podia ser de jusante ou de montante dependendo se o escoamento fosse subcrítico ou supercrítico, respectivamente. Também evitavam-se vazões que causassem a transição de escoamento dentro do trecho simulado.

Definida a linha d'água inicial e a vazão otimizada, buscou-se aquecer a condição inicial no próprio modelo hidrodinâmico. Para isso, como condições de contorno, mantiveram-se constantes as profundidades iniciais de jusante e de montante. Os demais parâmetros são os mesmos utilizados na simulação e descritos na Seção 4.3.3. O "aquecimento" do modelo consistiu em realizar a simulação até se atingir a estabilidade das variáveis, que ocorria em torno de 300 intervalos de tempo.

Esse procedimento não pode ser aplicado ao fundo com degraus devido à variação brusca das cotas de fundo na região dos degraus, o que impede a obtenção de linhas d'água condinzentes considerando o escoamento gradualmente variado. Desta forma, adotou-se como linha d'água inicial uma reta que ligava o nível inicial de montante com o de jusante e calculava-se a vazão inicial considerando a profundidade a montante como a profundidade normal. Essa abordagem é muito mais simples e se apresentou suficiente até mesmo para o fundo simples, visto que não se observou diferenças das condições iniciais após o seu "aquecimento", como exemplificado na Figura 19.
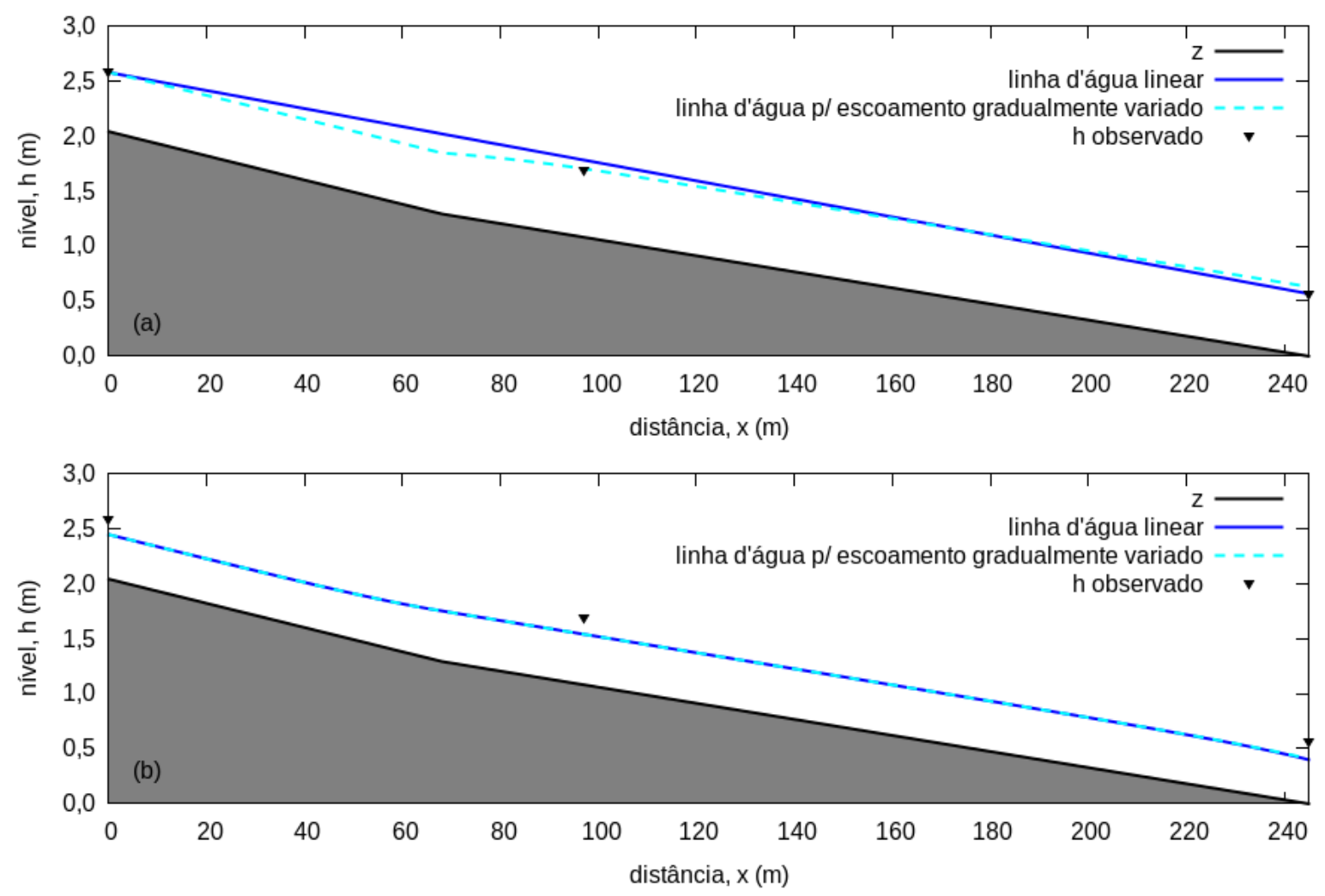

Figura 19 - Linha d'água inicial para o evento do dia 25/03/2013 (a) antes e (b) depois do aquecimento no modelo hidrodinâmico. 
Na ausência de dados de vazão e seções de controle, as condições de contorno basearam-se apenas em níveis. Também foi fixada a configuração 1+1 (subcrítico), como exigido pelo método de redução dos termos inerciais aplicado neste trabalho. Assim, como condições de contorno, foram utilizados os limnigramas observados a jusante e a montante do trecho (Equações 4.43 e 4.44). Esses dados foram "recortados" e suavização por média móvel, como descrito na Seção 4.3.1, para serem utilizados como entradas do modelo.

$$
\begin{aligned}
& h_{1}^{n}=h_{\text {montante }}^{n} \\
& h_{j j}^{n}=h_{\text {jusante }}^{n}
\end{aligned}
$$

sendo $h_{\text {montante }}^{n}$ o nível d'água a montante e $h_{\text {jusante }}^{n}$ o nível d'água a jusante.

\subsubsection{Simulação dos Eventos e Análise dos Resultados}

Definidas as entradas, os parâmetros, as condições iniciais (aquecidas) e as condições de contorno, as simulações foram realizadas para todos os eventos selecionados. A Figura 20 apresenta um fluxograma do modelo hidrodinâmico 1D informando as entradas necessárias e a ordem dos procedimentos. O código em FORTRAN utilizado para realizar as simulações está disponível no Apêndice 4.1.

Os resultados foram representados por gráficos de vazão/profundidade no tempo e no espaço. Para facilitar a interpretação e comparação dos resultados, foi utilizado o Coeficiente de Eficiência de Nash-Sutcliffe aplicado às profundidades d'água na seção intermediária (Equação 4.45).

$$
E N S=1-\frac{\sum\left(y_{o b s}-y_{s i m}\right)^{2}}{\sum\left(y_{o b s}-\bar{y}_{o b s}\right)^{2}}
$$

sendo $y_{o b s}$ o nível da água observado e $y_{\text {sim }}$ o nível da água simulado e $\bar{y}_{\text {obs }}$ a média do nível da água observado.

O Coeficiente de Eficiência de Nash-Sutcliffe (ENS) (NASH; SUTCLIFFE, 1970) é um dos coeficientes mais utilizado na verificação e contabilização da performace de modelos hidrológicos (KRAUSE; BOYLE; BASE, 2005). Ele corresponte ao erro da previsão ao quadrado normalizado pela variância das observações. Devido ao erro ao quadrado, o coeficiente tem maior peso para valores maiores, ou seja, os picos são muito mais importantes do que o escoamento de base. Para esse trabalho, essa característica é vantajosa, visto que se deseja simular os picos da passagem de onda de cheia. ENS varia entre 1, perfeitamente ajustado, e $-\infty$. Eficiência negativa significa que a média é uma estimativa melhor que a própria previsão.

Moriasi et al. (2007) fizeram um levantamento de metodologias de quantificação de qualidade de modelos relacionados à recursos hídricos, entre eles desca-se o Coeficiente de Eficiência de Nash-Sutcliffe para a análise de escoamento fluvial. Analisando diversos 
trabalhos, os autores, considerando intervalos de tempo mensais de simulação, propuseram uma classificação do desempenho do modelo a partir de intervalos de ENS (Tabela 5).

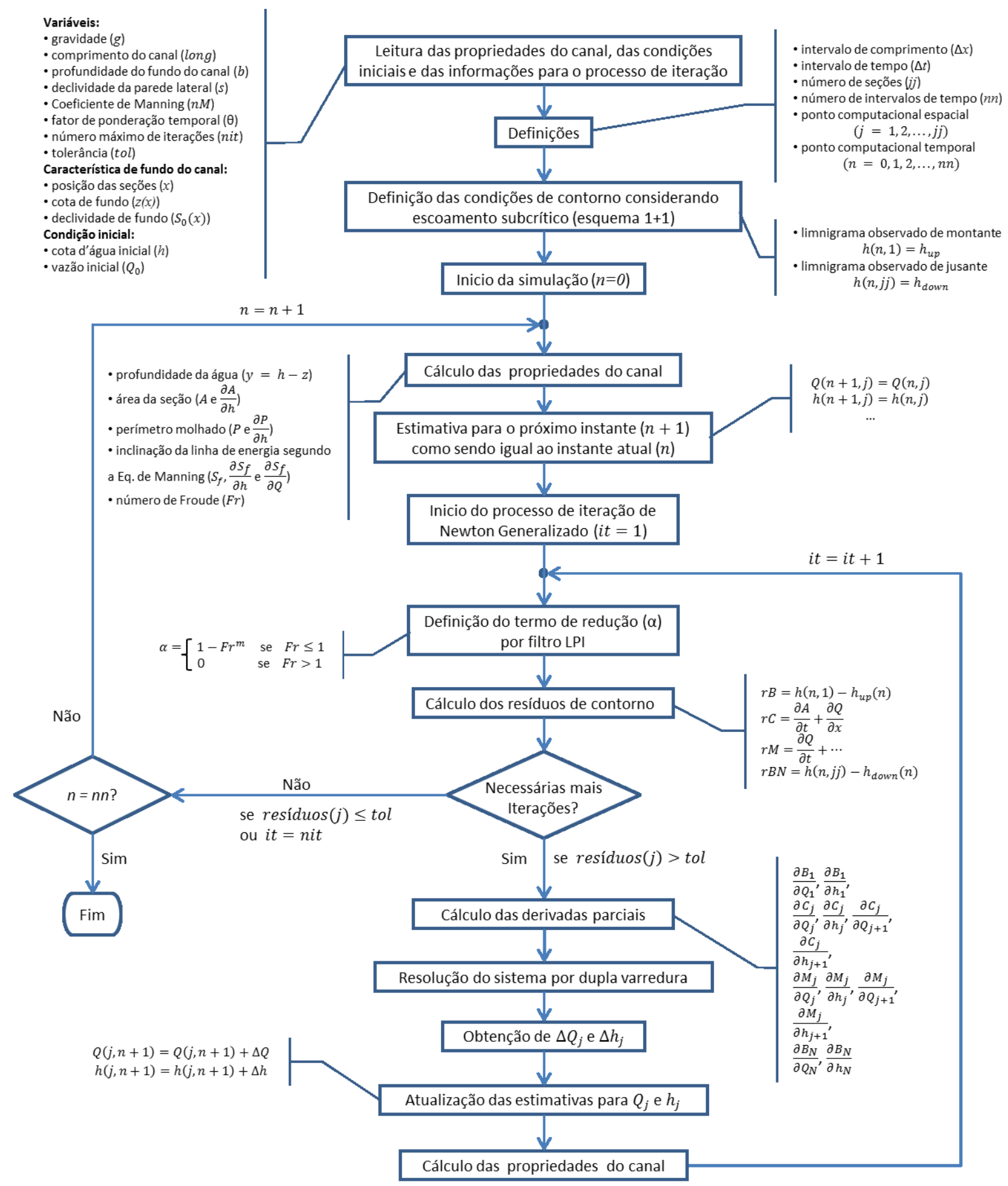

Figura 20 - Fluxograma do modelo.

Moriasi et al. (2007) também destacaram que modelos diários tendem a apresentar valores maiores de ENS. Neste trabalho o intervalo de tempo das simulações está na ordem de segundos, logo as informações são mais detalhadas. Com isso e com a análise visual dos resultados, adotou-se um critério mais rigoroso de seleção de eventos, que considera que a simulação produzui bons resultados quando $E N S>0,7$. 
Tabela 5 - Intervalos de desempenho de um modelo mensal, considerando o Coeficiente de Eficiência de Nash-Sutcliffe (ENS), proposto por Moriasi et al. (2007).

\begin{tabular}{cc}
\hline Desempenho & ENS \\
\hline Muito bom & $0,75<E N S<1,00$ \\
Bom & $0,65<E N S<0,75$ \\
Satisfatório & $0,50<E N S<0,65$ \\
Insatisfatório & $E N S<0,50$ \\
\hline
\end{tabular}





\section{Parte III}

\section{Resultados e Discussão}





\section{Monitoramento}

No total foram selecionados 60 eventos significativos entre 2013 e inicio de 2015 . Todos eles estão resumidos e separados por tipo de instalação dos sensores nas Tabelas 6 e 7 e os limnigramas, juntamente com os hietogramas, encontram-se nos Apêndices $\mathrm{C}$ e D. Os dados de nível d'água monitorados de fevereiro de 2013 até maio de 2013 também foram analisados por Almeida (2013).

Tabela 6 - Eventos significativos registrados pela instalação em tubos.

\begin{tabular}{|c|c|c|c|c|}
\hline \multirow[b]{2}{*}{ Data } & \multicolumn{3}{|c|}{ Profundidade máxima (m) } & \multirow{2}{*}{$\begin{array}{l}\text { Precipitação acumulada } \\
\text { (mm/evento })\end{array}$} \\
\hline & Montante & Intermediário & Jusante & \\
\hline $27 / 02 / 201312 \mathrm{~h}$ & 0,84 & 1,16 & 1,32 & $*$ \\
\hline $28 / 02 / 201318 \mathrm{~h}$ & 0,80 & 1,18 & 1,23 & $*$ \\
\hline 09/03/2013 17h & 1,07 & 1,70 & 1,70 & 52,0 \\
\hline 09/03/2013 20h & 0,79 & 0,94 & 1,04 & 10,6 \\
\hline $10 / 03 / 201319 \mathrm{~h}$ & 1,25 & 1,62 & 1,60 & 29,4 \\
\hline $25 / 03 / 201319 \mathrm{~h}$ & 1,09 & 1,83 & 1,87 & 46,6 \\
\hline 02/04/2013 13h & 0,77 & 1,24 & 1,27 & 29,4 \\
\hline $02 / 04 / 201315 \mathrm{~h}$ & 1,06 & 1,64 & 1,63 & 25,4 \\
\hline $28 / 05 / 201310 \mathrm{~h}$ & 1,12 & 1,64 & 1,65 & 34,0 \\
\hline $04 / 10 / 201302 \mathrm{~h}$ & 1,02 & 1,61 & 1,77 & 48,4 \\
\hline 04/11/2013 13h & 1,03 & 1,64 & 1,80 & 45,4 \\
\hline $16 / 11 / 201316 \mathrm{~h}$ & 0,78 & 1,22 & 1,42 & 16,4 \\
\hline $17 / 11 / 201316 \mathrm{~h}$ & 0,97 & 1,45 & 1,61 & 22,2 \\
\hline $29 / 11 / 201323 \mathrm{~h}$ & 1,04 & 1,66 & 1,81 & 34,6 \\
\hline
\end{tabular}

* Os dados de precipitação da Rede de Hidrometria ainda não estavam disponíveis.

Antes de iniciar a análise geral dos eventos, é importante alertar que o limnigrama do evento do dia 09/03/2013 às 17h apresentou comportamento incomum para a seção de montante. Alguns registros em torno do pico do limnigrama ficaram cerca de 0,2 $\mathrm{m}$ acima dos vizinhos. Isso foi interpretado como um erro de medição e corrigido com a subtração desses $0,2 \mathrm{~m}$.

Observando os limnigramas dos Apêndices C e D, verifica-se que as durações de todos os eventos estão dentro de em uma janela de 3h (olhar as escalas temporais dos limnigramas), sendo a duração de aproximadamente $2 \mathrm{~h}$ para aqueles com os maiores picos. Ademais, a subida do limnigrama é muito rápida, cerca de 15 min nos evento mais intensos.

Uma característica da bacia bem representada pelos eventos é o rápido tempo de resposta. Logo que se inicia a precipitação o limnigrama começa a subir em questão de poucos minutos, o que é justificado por se tratar de uma bacia urbana e relativamente pequena, entre 15 e 30 min após o início da precipitação o limnigrama já atinge seu pico. 
Tabela 7 - Eventos significativos registrados pela instalação em suporte de fundo.

\begin{tabular}{|c|c|c|c|c|}
\hline \multirow[b]{2}{*}{ Data } & \multicolumn{3}{|c|}{ Porfundidade máxima (m) } & \multirow{2}{*}{$\begin{array}{c}\text { Precipitação acumulada } \\
\text { (mm/evento) }\end{array}$} \\
\hline & Montante & Intermediário & Jusante & \\
\hline 01/11/2014 23h & 0,51 & 0,73 & 0,82 & 3,9 \\
\hline $02 / 11 / 201418 \mathrm{~h}$ & 0,68 & 0,70 & 0,76 & 16,8 \\
\hline $04 / 11 / 201401 \mathrm{~h}$ & 0,73 & 0,79 & 0,82 & 25,9 \\
\hline $04 / 11 / 201416 \mathrm{~h}$ & 0,74 & 0,82 & 0,81 & 16,8 \\
\hline $07 / 11 / 201423 \mathrm{~h}$ & 0,92 & 1,02 & 1,13 & 35,1 \\
\hline $14 / 11 / 201404 \mathrm{~h}$ & 0,58 & 0,74 & 0,91 & 9,4 \\
\hline $26 / 11 / 201416 \mathrm{~h}$ & 0,42 & 0,58 & 0,59 & 6,2 \\
\hline 09/12/2014 17h & 0,60 & 0,64 & 0,71 & 18,7 \\
\hline $12 / 12 / 201416 \mathrm{~h}$ & 1,20 & 1,36 & 1,35 & 33,8 \\
\hline $14 / 12 / 201415 \mathrm{~h}$ & 0,40 & 0,55 & 0,61 & 2,0 \\
\hline 19/12/2014 21h & 1,16 & 1,36 & 1,47 & 38,4 \\
\hline $21 / 12 / 201414 \mathrm{~h}$ & 0,50 & 0,67 & 0,76 & 6,6 \\
\hline $22 / 12 / 201422 \mathrm{~h}$ & 0,64 & 0,74 & 0,69 & 15,2 \\
\hline $23 / 12 / 201415 \mathrm{~h}$ & 0,71 & 0,82 & 0,69 & 25,1 \\
\hline $28 / 12 / 201417 \mathrm{~h}$ & 0,71 & 1,02 & 1,18 & 5,9 \\
\hline $28 / 12 / 201419 \mathrm{~h}$ & 0,69 & 0,82 & 1,03 & 12,7 \\
\hline $30 / 12 / 201417 \mathrm{~h}$ & 0,76 & 0,86 & 0,93 & 27,8 \\
\hline $30 / 12 / 201422 \mathrm{~h}$ & 0,47 & 0,66 & 0,74 & 5,1 \\
\hline $01 / 01 / 201518 \mathrm{~h}$ & 0,52 & 0,73 & 0,82 & 14,2 \\
\hline $03 / 01 / 201520 \mathrm{~h}$ & 0,54 & 0,88 & 0,91 & 5,7 \\
\hline $05 / 01 / 201515 \mathrm{~h}$ & 0,89 & 1,03 & 1,24 & 21,3 \\
\hline $08 / 01 / 201517 \mathrm{~h}$ & 0,50 & 0,76 & 0,83 & 6,0 \\
\hline $08 / 01 / 201519 \mathrm{~h}$ & 0,52 & 0,76 & 0,81 & 6,7 \\
\hline $10 / 01 / 201517 \mathrm{~h}$ & 0,66 & 0,86 & 1,04 & 13,8 \\
\hline $11 / 01 / 201516 \mathrm{~h}$ & 0,73 & 0,82 & 0,85 & 8,9 \\
\hline $14 / 01 / 201517 \mathrm{~h}$ & 0,54 & 0,78 & 0,85 & 8,9 \\
\hline $20 / 01 / 201523 \mathrm{~h}$ & 0,40 & 0,69 & 0,71 & 4,7 \\
\hline $22 / 01 / 201516 \mathrm{~h}$ & 0,62 & 0,82 & 0,96 & 12,2 \\
\hline $26 / 01 / 201519 \mathrm{~h}$ & 0,46 & 0,70 & 0,76 & 10,5 \\
\hline $29 / 01 / 201503 \mathrm{~h}$ & 0,49 & 0,75 & 0,80 & 9,1 \\
\hline $31 / 01 / 201517 \mathrm{~h}$ & 0,39 & 0,59 & 0,63 & 3,2 \\
\hline $01 / 02 / 201516 \mathrm{~h}$ & 0,59 & 0,82 & 0,92 & 7,4 \\
\hline $03 / 02 / 201515 \mathrm{~h}$ & 0,40 & 0,60 & 0,64 & 3,7 \\
\hline $04 / 02 / 201506 \mathrm{~h}$ & 0,49 & 0,74 & 0,79 & 5,9 \\
\hline $05 / 02 / 201516 \mathrm{~h}$ & 0,51 & 0,78 & 0,81 & 5,8 \\
\hline $10 / 02 / 201514 \mathrm{~h}$ & 0,45 & 0,69 & 0,74 & 7,6 \\
\hline $10 / 02 / 201521 \mathrm{~h}$ & 0,37 & 0,56 & 0,58 & 3,9 \\
\hline $15 / 03 / 201519 \mathrm{~h}$ & 0,80 & 0,92 & 1,02 & 9,1 \\
\hline $16 / 03 / 201516 \mathrm{~h}$ & 1,14 & 1,30 & 1,46 & 10,1 \\
\hline $21 / 03 / 201515 \mathrm{~h}$ & 0,74 & 0,83 & 0,87 & 0,4 \\
\hline $27 / 03 / 201518 \mathrm{~h}$ & 0,84 & 0,94 & 1,11 & $*$ \\
\hline $28 / 03 / 201518 \mathrm{~h}$ & 0,51 & 0,65 & 0,74 & $*$ \\
\hline $29 / 03 / 201518 \mathrm{~h}$ & 0,82 & 0,93 & 1,04 & $*$ \\
\hline $30 / 03 / 201512 \mathrm{~h}$ & 0,51 & 0,65 & 0,72 & $*$ \\
\hline $05 / 04 / 201515 \mathrm{~h}$ & 0,62 & 0,74 & 0,93 & * \\
\hline $05 / 04 / 201519 \mathrm{~h}$ & 0,39 & 0,59 & 0,62 & $*$ \\
\hline
\end{tabular}

* Não foram registradas pela Rede de Hidrometria precipitações representativas. 
Vale destacar aqui que, esse comportamento exige muito preparo e paciência da equipe de medição de vazão. Pois, os colaboradores e equipamentos deviam estar preparados e em posição de medição antes do início da chuva. Como se dependia da previsão de precipitação, houve casos em que se perdiam eventos por falta de previsão ou por desconfiança das mesmas - especialmente por se tratar de chuvas de verão (localizadas e de difícil previsão) - e casos em que se preparava tudo no campo e não ocorria precipitação.

Voltando à análise dos eventos, a mudança na forma de medição da profundidade d'água para os suportes de fundo permitiu o registro de eventos com profundidades menores do que as consideradas com a medição em tubos. Na instalação com os tubos, os menores níveis foram o do dia 09/03/2013 às 20h, que também tem o menor acumulado de precipitação $(10,6 \mathrm{~mm})$, e do dia 02/04/2013 às $13 \mathrm{~h}$ com a menor profundidade de montante, ambos com valores de pico em torno de $1 \mathrm{~m}$. Já na medição com os suportes de fundo, foi possível considerar eventos com profundidades de pico em torno de 0,5 m, assim como grande parte dos eventos de 2015. Além disso, os eventos resultantes de acumulados de precipitação menores do que $10 \mathrm{~mm}$, que provavelmente não seriam medidos com os tubos, foram satisfatoriamente registrados e puderam participar da simulação.

Outra observação é que, com o suporte de fundo, foi possível verificar eventos resultantes de chuvas mais distribuídas no tempo e com limnigramas amortecidos, que mesmo com uma lâmina de precipitação acumulada considerável não gerou níveis muito altos, como, por exemplo, os eventos dos dias 04/11/2014, 07/11/2014, 26/11/2014 e $13 / 12 / 2014$.

Coincidentemente os anos de 2014 e 2015 apresentaram eventos menores do que os observados em 2013, porém, devido às instalações dos suportes de fundo, foi possível coletar uma amostra significativa de eventos apesar do período de seca.

O período de seca é perceptível nos limnigramas e nos acumulados de precipitação. Somente em 2013, nove eventos apresentaram profundidades maiores do que a maior profundidade registrada em 2014 e 2015 (1,47 m). De modo geral, o evento que registrou as maiores profundidades ocorreu no dia 25/03/2013 com 1,87 m a jusante. O evento do dia 09/03/2013 também merece destaque por apresentar o maior acumulado de precipitação registrada.

Comparando os limnigramas de cada evento, pode-se observar que as profundidades d'água da seção intermediária são mais próximas das profundidades de jusante em praticamente todos os eventos, apesar da seção intermediária estar a menor distância da seção de montante. Isso leva a crer que o comportamento do escoamento intermediário é semelhante ao escoamento de jusante e que alguma mudança ocorre entre a seção de montante e a seção intermediária. Como a geometria do canal, a direção do fluxo e a rugosidade do trecho não mudam significativamente, espera-se que haja a transição do regime de escoamento causado pela leve suavização da inclinação do fundo do canal e que o escoamento se assemelhe ao apresentado na Figura 5(c). 



\section{Modelagem}

\subsection{Resolução do Problema Teste}

Alguns problemas testes foram utilizados visando a verificação da qualidade do modelo desenvolvido. A presente seção apresenta os resultados produzidos para o problema transcrítico proposto por MacDonald et al. (1997) e apresentado na Seção 4.2, seguindo os procedimentos descritos na Seção 4.1.

Como condição de contorno, a vazão de montante e o nível de jusante foram mantidos constantes durante toda a simulação. A linha d'água da solução analítica apresentada por MacDonald et al. (1997) foi adotada como condição inicial. Os demais parâmetros ficaram definidos como: $\theta=2 / 3$ e tolerância de $10^{-6}$, sendo 10 o número máximo de iterações. Foram feitos testes com $\Delta x=10 \mathrm{~m}(j j=101)$, como indicado por Freitag (2003), e $\Delta x=1 \mathrm{~m}(j j=1001)$. Como intervalo de tempo, utilizou-se $\Delta t=1 \mathrm{~s}$, também indicado por Freitag (2003).

Utilizando o modelo desenvolvido sem a aplicação de nenhum filtro, ou seja, $\alpha=1$, não foi possível resolver o problema. Para $\Delta x=1 \mathrm{~m}$, a maioria dos valores obtidos tendeu a infinito. Realizando a simulação com um intervalo de $\Delta x=10 \mathrm{~m}$, foi possível observar que as oscilações ocorrem imediatamente antes da descontinuidade (Figura 21). Esse comportamento já é observado no primeiro instante de tempo e se mantém igual com o passar do tempo.
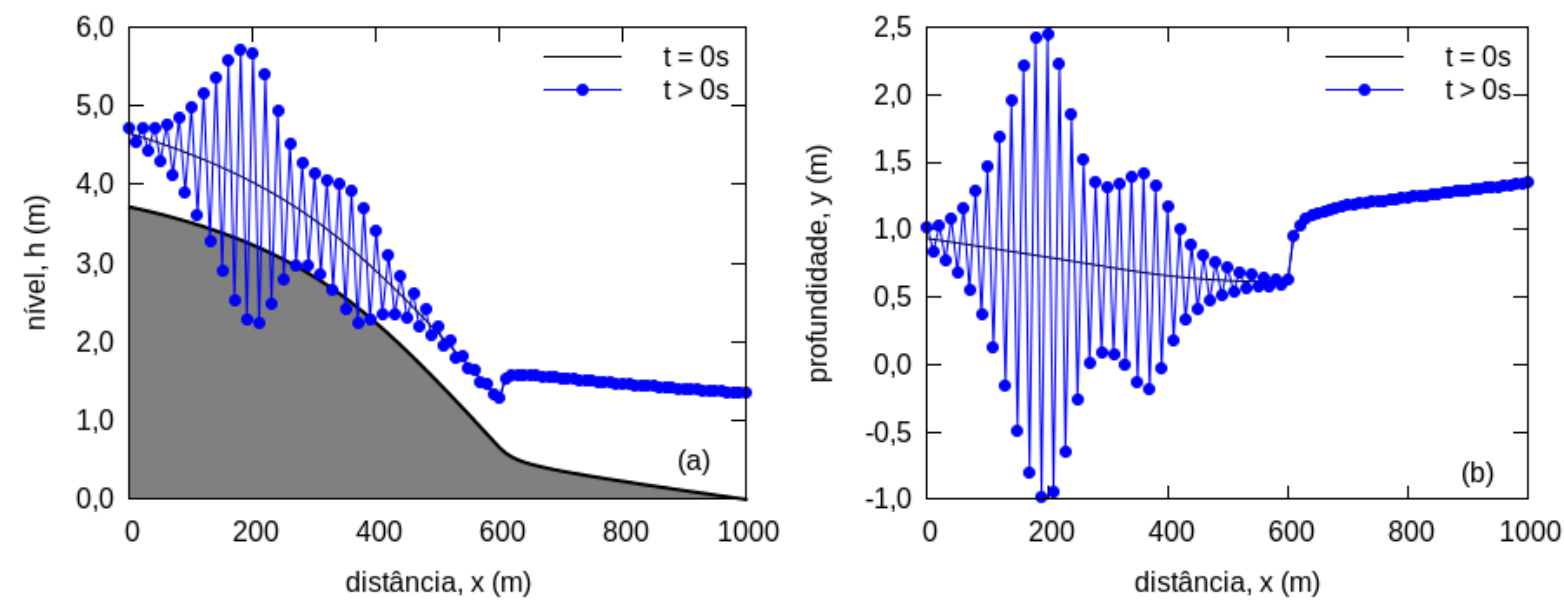

Figura 21 - Falha da simulação sem aplicação de filtro, considerando a discretização espacial de $\Delta x=10 \mathrm{~m}$.

Aplicando-se o filtro LPI às equações de Saint Venant, como descrito na Seção 4.1, foi possível realizar a simulação do problema teste. Para definir o parâmetro $m$ do filtro LPI, realizou-se uma análise da estabilidade das soluções para diferentes valores 
de $m$, tanto para $\Delta x=10 \mathrm{~m}$ como para $\Delta x=1 \mathrm{~m}$. Para tal, vários valores de $m$ foram testados e buscou-se o seu valor máximo para garantir maior peso das equações dinâmicas na resolução do problema. Observou-se que, utilizando $\Delta x=10 \mathrm{~m}$, a linha d'água apresentava-se mais instável, exigindo valores pequenos de $m(m=5$ foi o valor máximo obtido para garantir a estabilidade da solução ao longo do tempo). Os resultados obtidos considerando $\Delta x=10 \mathrm{~m}$ estão disponíveis no Apêndice E. Aqui serão discutidos apenas os resultados obtidos considerando $\Delta x=1 \mathrm{~m}$, que demonstrou maior estabilidade nas soluções.

A Figura 22 possibilita a análise do comportamento das soluções dependendo da escolha do valor de $m$ do filtro LPI. O valor máximo de $m$ que permitiu a estabilidade da solução ao longo do tempo para $\Delta x=1 \mathrm{~m}$ foi $m=14$. O valor de $m$ imediatamente depois do $m$ máximo $(m=15)$ começa a apresentar oscilações a partir do instante de tempo $n=11$, essas oscilações ficam mais evidentes com o aumento de $m$ e ocorrem nas regiões de transição do escoamento.

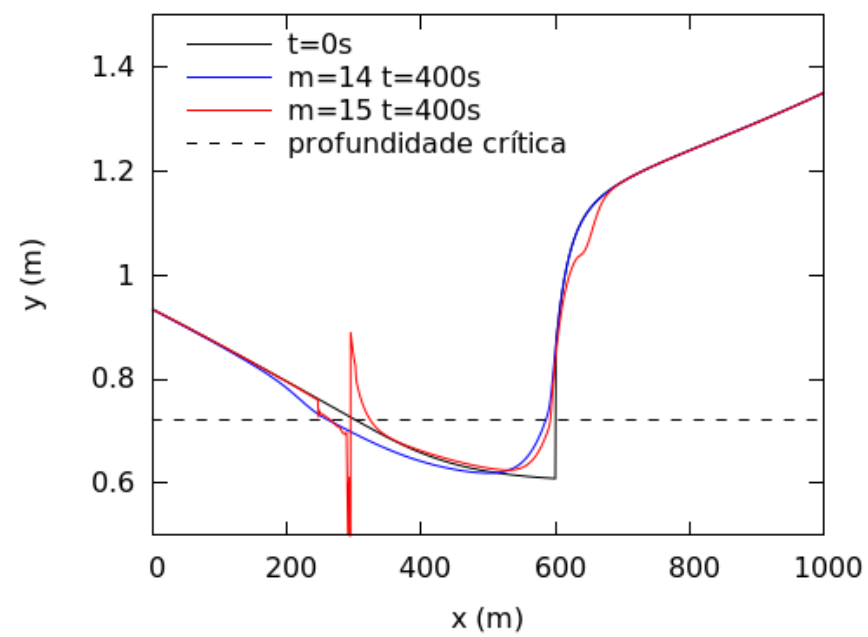

Figura 22 - Análise da influência do filtro LPI na solução e determinação do máximo valor de $m$, considerando $\Delta x=1 \mathrm{~m}$.

A Figura 39 apresenta a evolução da simulação com filtro LPI de $m=14$. Observase que, com o passar do tempo, a descontinuidade é suavizada e as linhas d'água apresentam uma característica ondular, que se estabilizam em torno do instante $t=400 \mathrm{~s}$. A vazão varia entre 15 e $23 \mathrm{~m}^{3} / \mathrm{s}$, estabilizando-se em $20 \mathrm{~m}^{3} / \mathrm{s}$ conforme a condição inicial.

A solução estabilizada ( $t=400 \mathrm{~s})$ é apresentada na Figura 40. Pode-se observar que o método não reproduziu exatamente a solução analítica. A descontinuidade foi amortecida com o passar da simulação. Isso provavelmente se deve à redução considerável da participação dos termos de inercia, consequente de uma valor ainda pequeno do termo $m$ do filtro LPI, que reduz a participação dos termos de inércia caracterizando uma simulação mais próxima da onda difusiva. No caso da discretização $\Delta x=10 \mathrm{~m}$ (Apêndice E), o valor ainda menor de $m$ resultou em um "descolamento" mais evidente da curva simulada 
em relação a curva analítica, principalmente na região do ressalto. Entretanto, o método foi capaz de fazer a simulação utilizando apenas a estrutura $1+1$ de condição de contorno e encontrar um ponto de estabilidade da solução, mesmo o problema apresentando os dois tipos de transição de escoamento.

Para uma solução mais próxima da analítica, seria necessário utilizar um método mais robusto de resolução de ressalto hidráulico, como os métodos de captura de choque (ver exemplo de resolução do mesmo problema em Freitag (2003)).
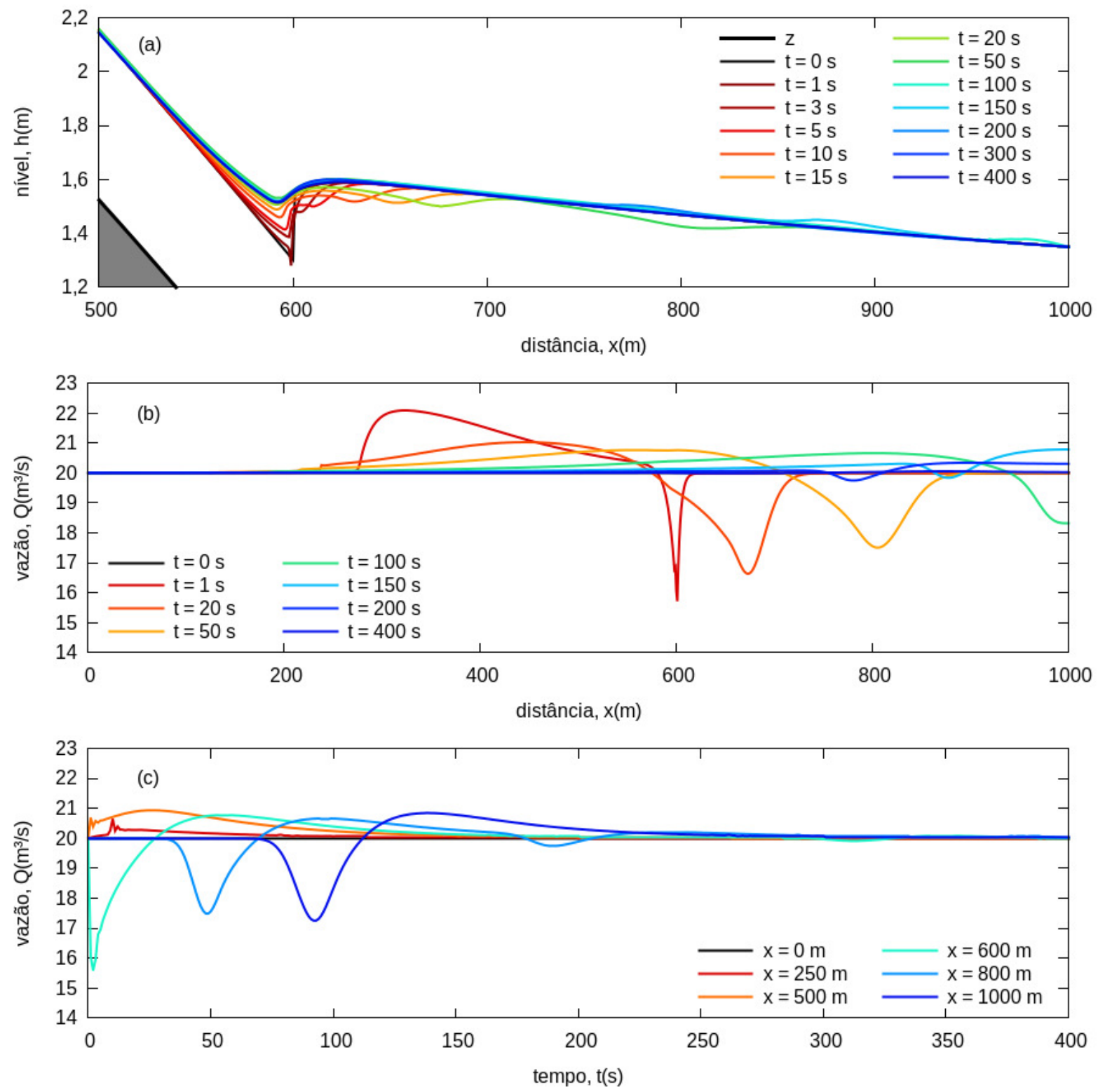

Figura 23 - Evolução da simulação com filtro LPI de $m=14$ e $\Delta x=1 \mathrm{~m}$. 

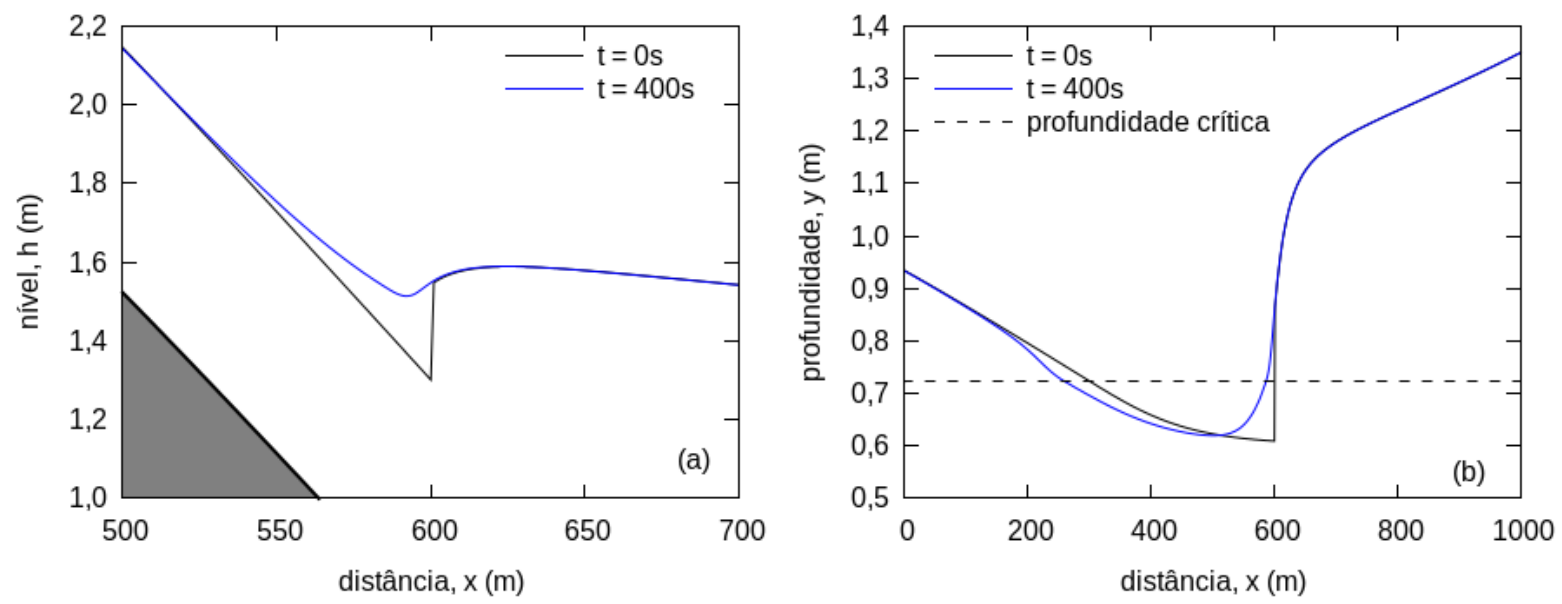

Figura 24 - Solução estabilizada para o filtro de $m=14$.

Para os objetivos iniciais da pesquisa, a simplicidade e facilidade do modelo utilizando filtro se apresentou suficiente ao propósido de estimação de vazão, visto que, o presente trabalho não pretende caracterizar exatamente um ressalto hidráulico - na verdade não se tem certeza se realmente ocorre ressalto hidráulico no trecho de canal analisado - mas entender melhor o escoamento no canal mesmo sem medições de vazão. Entretanto, para trabalhos futuros recomenda-se a utilização de métodos mais robustos para escoamento transcrítico.

\subsection{Simulação do Trecho do Córrego do Gregório}

Os limnigramas simulados para seção intermediária, considerando as duas representações adotadas para o fundo do canal, são comparados com os limnigramas observados nos Apêndices F e G para todos os eventos simulados. Por clareza, os limnigramas simulados de montante e de jusante não foram representados nos gráficos, visto que os mesmos fazem parte das condições de contorno, logo são coincidentes aos limnigramas observados.

Em uma primeira análise dos limnigramas, vale destacar que para os eventos obtidos pela instalação em tubos (eventos do ano de 2013) a simulação foi iniciada para profundidades maiores. Isso se deve ao rigoroso critério de seleção de eventos exigido para esse tipo de instalação. Recordando, o evento inicia quando as profundidades das três seções monitoradas são maiores que 0,6 m. Porém, para alguns eventos, a profundidade de montante apenas ultrapassa esse critério alguns instantes depois, quando as profundidades das demais seções já estão próximas do pico. Consequentemente, parte da informação registrada nas seções intermediária e de jusante não é utilizada. A Figura 25 ilustra um exemplo dessa perda de informação nos eventos do dia 02/04/2013. 


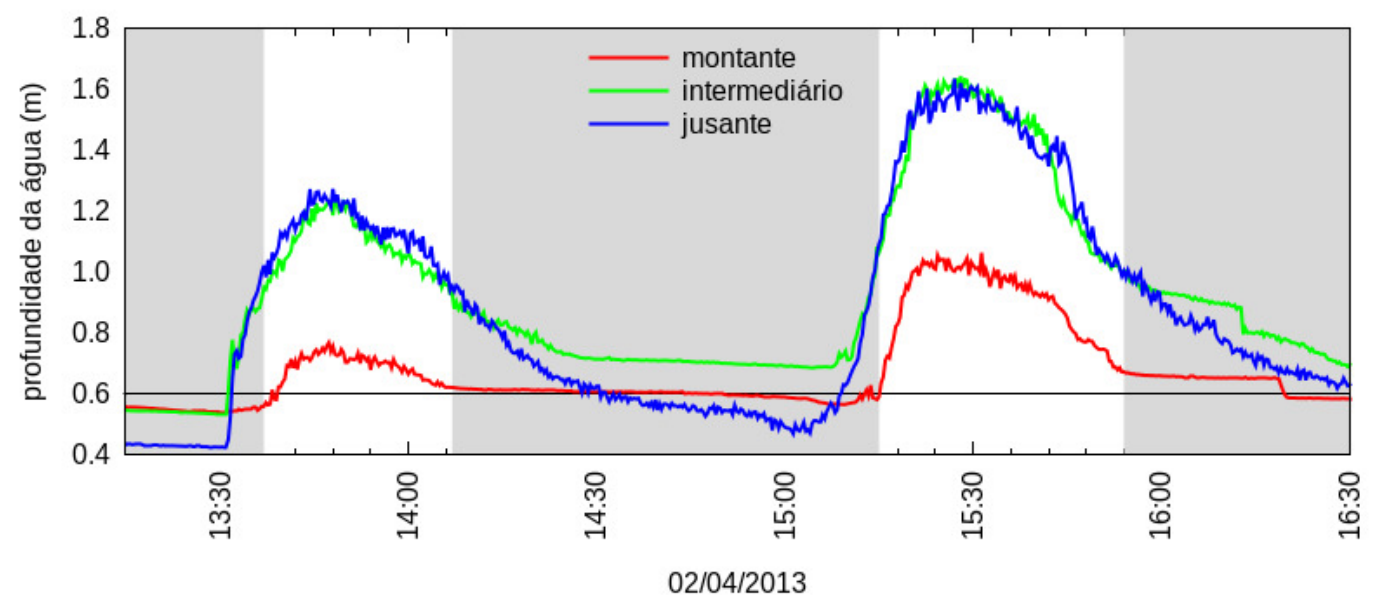

Figura 25 - Perda de informação na seleção de eventos registrados pela instalação em tubos. Os dados registrados que coincidem com as faixas cinzas, mesmo que consistentes, não participam da simulação.

Fazendo uma análise geral dos limnigramas (Apêndices $F$ e G), é notável que a simulação com fundo com degraus apresentou profundidades na seção intermediária maiores que a simulação com fundo simples para todos os eventos. Este fato deve-se, provavelmente, às menores inclinações de fundo entre os degraus.

O fato do fundo com degraus ser mais próximo da topografia, não significa que este tenha produziu melhores aproximação dos limnigramas observados na seção intermediária. $\mathrm{Na}$ verdade, pode-se considerar que ambos os fundos apresentaram boas aproximações, dependendo do evento. Para facilitar a análise dos resultados e a comparação entre as simulações de cada tipo de fundo, utilizou-se o Coeficiente de Eficiência de Nash-Sutcliff $(E N S)$, apresentados nas Tabelas 8 e 9.

O nível intermediário melhor simulado com o fundo simples corresponde ao evento do dia 12/12/2014, que atingiu $E N S=0,974$ e acompanhou adequadamente todas as etapas do evento (ascensão, pico e recessão). A simulação do mesmo evento utilizando o fundo com degraus superestimou as profundidades, porém, produziu um valor razoável para $E N S(=0,754)$. O maior valor de $E N S$ obtido pela simulação com o fundo com degraus corresponde ao evento do dia 26/01/2015 com ENS =0,921, contudo, para tal evento, ENS negativo foi produzido na simulação com fundo simples. O evento do dia 19/12/2014 também merece destaque por ter sido muito bem simulado por ambos os fundos, produzindo $E N S=0,958$ para o fundo simples e $E N S=0,917$ para o fundo com degraus. Os eventos dos dias 12/12/2014 e 19/12/2014 são muito significativos pois atingiram os maiores níveis registrados entre os anos de 2014 e 2015.

Continuando a análise dos valores $E N S$, é interessante notar que, a simulação com o fundo com degraus produziu melhores valores de $E N S$ que o fundo simples para quase todos os eventos de 2013, exceto um - justamente aquele de menores níveis registrados em 
2013 (ver Tabela 6). Apesar das simulações de 2013 apresentarem valores de ENS baixos e até mesmo negativos, os resultados sugerem que a simulação com fundo com degraus apresentou melhor desempenho na simulação de eventos registrados pela instalação em tubos, que são caracterizados por picos de grandes profundidades.

Tabela 8 - Coeficiente de Eficiência de Nash-Sutcliffe (ENS) resultantes das simulações dos eventos registrados com a instalação em tubos.

\begin{tabular}{crr}
\hline Data & $\begin{array}{c}\text { fundo } \\
\text { simples }\end{array}$ & $\begin{array}{c}\text { fundo com } \\
\text { degraus }\end{array}$ \\
\hline $27 / 02 / 201312 \mathrm{~h}$ & $-1,643$ & 0,623 \\
$28 / 02 / 201318 \mathrm{~h}$ & $-0,979$ & 0,800 \\
$09 / 03 / 201317 \mathrm{~h}$ & $-0,549$ & 0,356 \\
$09 / 03 / 201320 \mathrm{~h}$ & 0,295 & $-0,055$ \\
$10 / 03 / 201319 \mathrm{~h}$ & 0,630 & 0,862 \\
$25 / 03 / 201319 \mathrm{~h}$ & $-1,503$ & $-0,151$ \\
$02 / 04 / 201313 \mathrm{~h}$ & $-6,695$ & $-1,012$ \\
$02 / 04 / 201315 \mathrm{~h}$ & $-1,636$ & 0,048 \\
$28 / 05 / 201310 \mathrm{~h}$ & 0,064 & 0,602 \\
$04 / 10 / 201302 \mathrm{~h}$ & $-0,925$ & 0,449 \\
$04 / 11 / 201313 \mathrm{~h}$ & $-0,329$ & 0,622 \\
$16 / 11 / 201316 \mathrm{~h}$ & $-0,162$ & 0,583 \\
$17 / 11 / 201316 \mathrm{~h}$ & 0,143 & 0,767 \\
$29 / 11 / 201323 \mathrm{~h}$ & $-0,410$ & 0,497 \\
\hline
\end{tabular}

Já para os eventos de 2014 e 2015, ambos os fundos produziram resultados bons e ruins em proporções similares e de forma aparentemente aleatória. O fundo simples apresentou uma sequência de boas simulações nos meses de 11 e 12 de 2014, ao contrário do fundo com degraus. Já nos meses 1 e 2 de 2015 os melhores resultados foram obtidos com o fundo com degraus. No mês 3 de 2015 o fundo simples voltou a apresentar melhor desempenho. Entretanto, não se observou correlação direta entre os valores ENS e as profundidades máximas d'água.

Outra característica dos resultados é que as simulações de alguns eventos se iniciam depois e terminam antes dos dados observados, principalmente com a utilização do fundo com degraus. Isso ocorreu porque o modelo não foi capaz de estabelecer uma condição inicial, através da metodologia proposta, para níveis muito baixos - menores que 0,2 $\mathrm{m}$, no caso do fundo simples, e 0,3 m, no caso do fundo com degraus - e precisou iniciar a simulação em níveis um pouco maiores. Duas possíveis justificativas podem ser discutidas: (1) a invalidade da aproximação de seção retangular, adotada pelo modelo, e (2) a maior influência dos degraus para baixas profundidades. No caso da segunda justificativa, observa-se que, os níveis limites de simulação possuem a mesma ordem de grandeza do tamanho dos degraus (em torno de $30 \mathrm{~cm}$ ), consequentemente, a quebra de continuidade causada pelos degraus torna-se mais importante nessas situações. Entretanto, esses efeitos 
podem não estar sendo bem representados pelo modelo devido a aproximação grosseira adotada para os degraus, que contraria várias hipóteses das Equações de Saint Venant unidimensionais.

Tabela 9 - Coeficiente de Eficiência de Nash-Sutcliffe (ENS) resultantes das simulações dos eventos registrados com a instalação em suportes de fundo.

\begin{tabular}{|c|c|c|c|c|c|}
\hline Data & $\begin{array}{c}\text { fundo } \\
\text { simples }\end{array}$ & $\begin{array}{c}\text { fundo com } \\
\text { degraus }\end{array}$ & Data & $\begin{array}{c}\text { fundo } \\
\text { simples }\end{array}$ & $\begin{array}{c}\text { fundo com } \\
\text { degraus }\end{array}$ \\
\hline 01/11/2014 23h & 0,798 & 0,058 & $10 / 01 / 201517 \mathrm{~h}$ & 0,305 & 0,691 \\
\hline 02/11/2014 18h & 0,708 & $-0,469$ & $11 / 01 / 201516 \mathrm{~h}$ & 0,851 & 0,307 \\
\hline 04/11/2014 01h & 0,779 & $-0,120$ & 14/01/2015 17h & 0,623 & 0,832 \\
\hline $04 / 11 / 201416 \mathrm{~h}$ & 0,840 & $-0,445$ & $20 / 01 / 201523 \mathrm{~h}$ & 0,193 & 0,730 \\
\hline $07 / 11 / 201423 \mathrm{~h}$ & 0,904 & 0,439 & $22 / 01 / 201517 \mathrm{~h}$ & 0,554 & 0,689 \\
\hline $14 / 11 / 201404 h$ & 0,798 & $-0,042$ & $26 / 01 / 201519 \mathrm{~h}$ & $-0,142$ & 0,921 \\
\hline $26 / 11 / 201416 \mathrm{~h}$ & 0,234 & $-0,495$ & 29/01/2015 04h & 0,295 & 0,789 \\
\hline 09/12/2014 17h & 0,852 & $-2,943$ & $30 / 01 / 201517 \mathrm{~h}$ & 0,611 & 0,822 \\
\hline $12 / 12 / 201416 \mathrm{~h}$ & 0,974 & 0,754 & $31 / 01 / 201517 \mathrm{~h}$ & 0,337 & 0,865 \\
\hline $13 / 12 / 201409 \mathrm{~h}$ & 0,699 & $-1,517$ & 01/02/2015 16h & 0,307 & 0,825 \\
\hline $14 / 12 / 201415 \mathrm{~h}$ & 0,735 & $-0,222$ & $03 / 03 / 201515 \mathrm{~h}$ & 0,676 & 0,789 \\
\hline $19 / 12 / 201421 \mathrm{~h}$ & 0,952 & 0,917 & 04/02/2015 06h & 0,445 & 0,894 \\
\hline $21 / 12 / 201414 \mathrm{~h}$ & 0,527 & $-0,744$ & $05 / 02 / 201517 \mathrm{~h}$ & 0,407 & 0,817 \\
\hline $22 / 12 / 201422 \mathrm{~h}$ & 0,811 & 0,109 & $10 / 02 / 201514 \mathrm{~h}$ & $-0,138$ & 0,865 \\
\hline $23 / 12 / 201415 \mathrm{~h}$ & 0,780 & $-0,141$ & 10/02/2015 20h & $-0,598$ & 0,528 \\
\hline $28 / 12 / 201417 \mathrm{~h}$ & 0,533 & 0,790 & $15 / 03 / 201520 \mathrm{~h}$ & 0,795 & 0,789 \\
\hline $28 / 12 / 201419 \mathrm{~h}$ & 0,777 & 0,711 & 16/03/2015 16h & 0,954 & 0,861 \\
\hline $30 / 12 / 201417 \mathrm{~h}$ & 0,813 & 0,375 & $21 / 03 / 201516 \mathrm{~h}$ & 0,800 & $-0,261$ \\
\hline $30 / 12 / 201422 \mathrm{~h}$ & 0,495 & 0,296 & $27 / 03 / 201518 \mathrm{~h}$ & 0,709 & 0,176 \\
\hline $01 / 01 / 201518 \mathrm{~h}$ & 0,420 & 0,589 & 28/03/2015 18h & 0,611 & $-1,097$ \\
\hline 03/01/2015 20h & 0,411 & 0,847 & 29/03/2015 18h & 0,900 & 0,650 \\
\hline $05 / 01 / 201515 \mathrm{~h}$ & 0,804 & 0,815 & $30 / 03 / 201512 \mathrm{~h}$ & 0,699 & $-0,263$ \\
\hline 08/01/2015 17h & 0,579 & 0,705 & $05 / 04 / 201515 \mathrm{~h}$ & 0,757 & 0,550 \\
\hline 08/01/2015 19h & 0,693 & 0,783 & $05 / 04 / 201519 \mathrm{~h}$ & 0,390 & 0,755 \\
\hline
\end{tabular}

Uma análise detalhada dos limnigramas pode ser feita observando-se a Figura 26, em que foram apresentados os limnigramas simulados para algumas seções para o evento do dia 19/12/2014. Evento este escolhido por ter sido satisfatoriamente simulado para ambos os tipos de fundos.

Significativa diferença pode ser observada comparando-se a evolução dos limnigramas de fundo simples e de fundo com degraus. Os limnigramas de fundo simples evoluem seguindo uma ordem crescente da seção de montante até a seção de jusante. Já para o fundo com degraus, os limnigramas ascendem até a seção $x=200$, chegando a profundidades até mesmo maiores que as profundidades de jusante, depois descendem e ascendem novamente até atingir o limnigrama de jusante. Para melhor compreender tal comportamento, também foi analisada a evolução da linha d'água (Figura 27). 

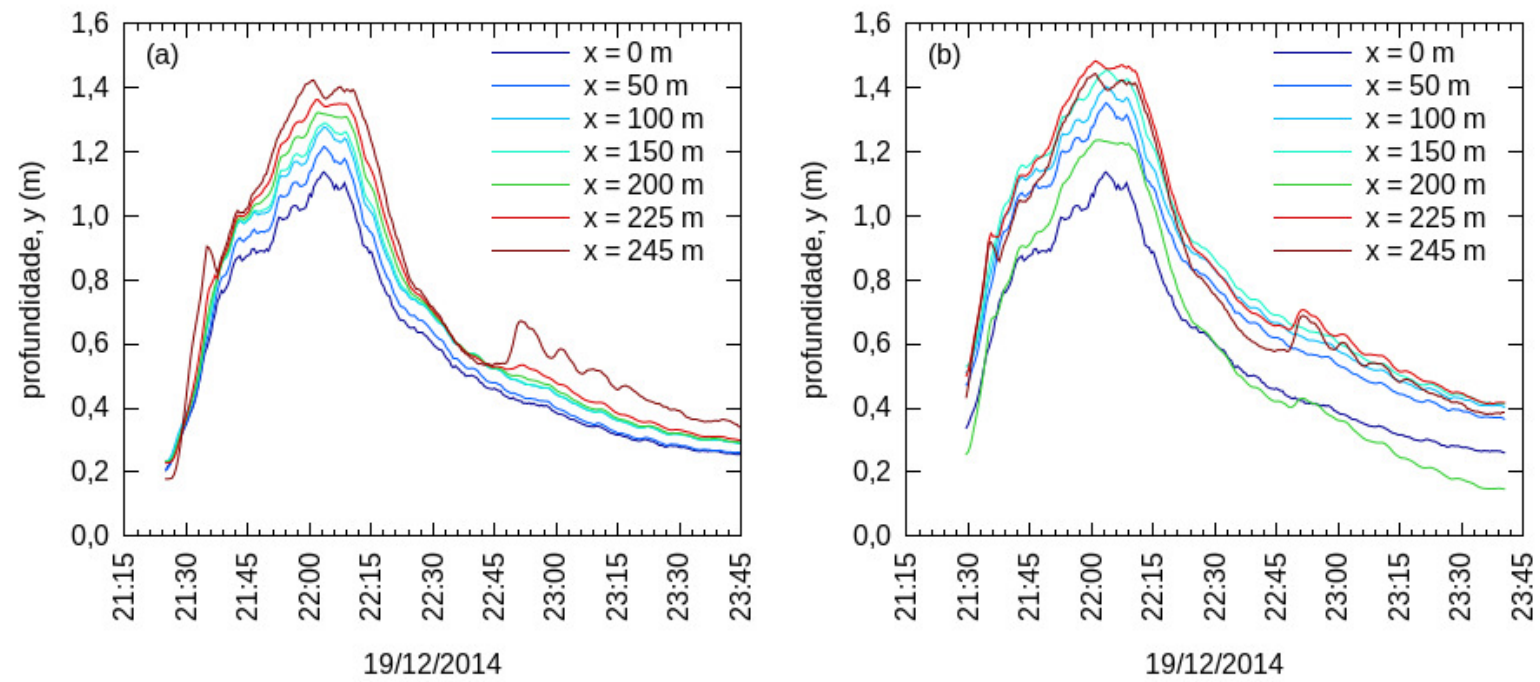

Figura 26 - Evolução dos limnigramas, com o passar das seções, simulados para o evento do dia 19/12/2014 21h para (a) fundo simples e (b) fundo com degraus.
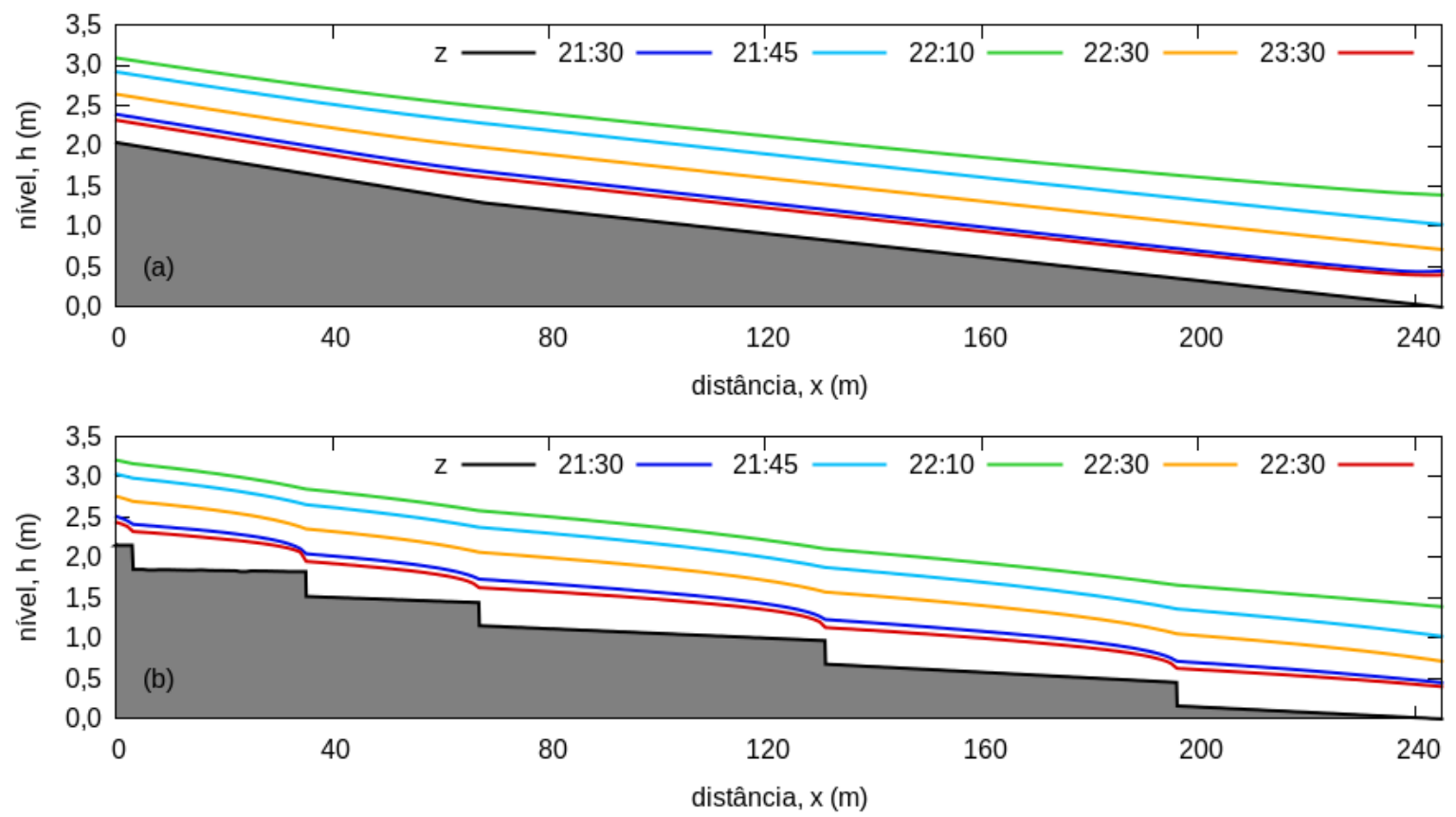

Figura 27 - Evolução da linha d'água simulada para o evento do dia 19/12/2014 para (a) fundo simples e (b) fundo com degraus.

A linha d'água simulada para o fundo simples varia de forma suave com o passar das seções e em todos os instantes de tempo mesmo com a mudança de declividade. No caso do fundo com degraus, fica perceptível o efeito dos degraus na linha d'água em profundidades menores. Como esperado, esse efeito é amenizado com o aumento das profundidades. Nota-se também que, a profundidade d'água diminui quando se aproxima 
dos degraus, esse comportamento fica mais evidente na Figura 28. Isso pode explicar o porquê dos limnigramas apresentados na Figura 26(b) não seguirem uma sequência crescente como na Figura 26(a).
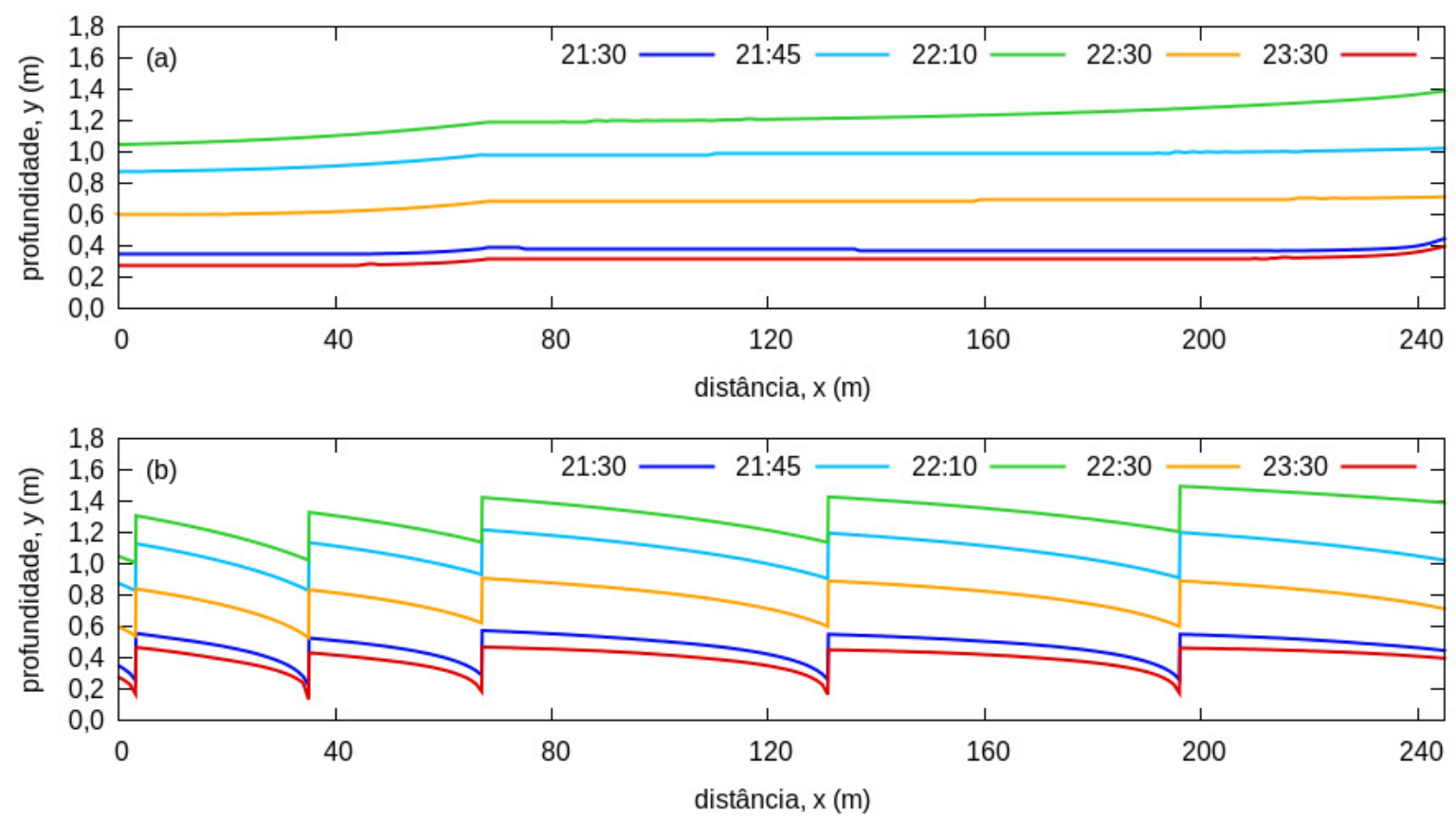

Figura 28 - Profundidade d'água simulada para o evento do dia 19/12/2014 para (a) fundo simples e (b) fundo com degraus.

Para a análise das vazões, os Apêndices H e I apresentam os hidrogramas simulados para todos os eventos. Verifica-se que todos os hidrogramas, tanto para o fundo simples como para o fundo com degraus são praticamente semelhantes para todas as seções e, se observados com cuidado, seguem o mesmo formato do limnigrama de montante.

Como o trecho simulado não é muito longo $(L=245 \mathrm{~m})$, não se esperava mesmo grande variação da vazão. A diferença dos resultados entre os tipos de fundos é apenas quantitativa em relação à vazão, sendo maior nas simulações do fundo com degraus.

Para facilitar a análise, serão discutidos os hidrogramas simulados para o evento do dia 19/12/2014. A Figura 29 compara os hidrogramas simulados com os hidrogramas obtidos pela Equação de Manning, aplicada aos dados observados e considerando as duas geometrias de fundo.

Observa-se que os hidrogramas simulados, apesar de muito semelhantes, são suavizados e discretamente amortecidos com o passar das seções. Como o trecho simulado não é muito longo ( $L=245 \mathrm{~m})$, não se esperava mesmo grande variação da vazão. Também pode ser observado que os hidrogramas de ambos os fundos são inesperadamente semelhantes ao hidrograma calculado pela Equação de Manning considerando os dados observados e os parâmetros de montante do fundo simples, ou seja com $S_{0}=0,0105$. Essa semelhança fica mais evidente na Figura 30. 

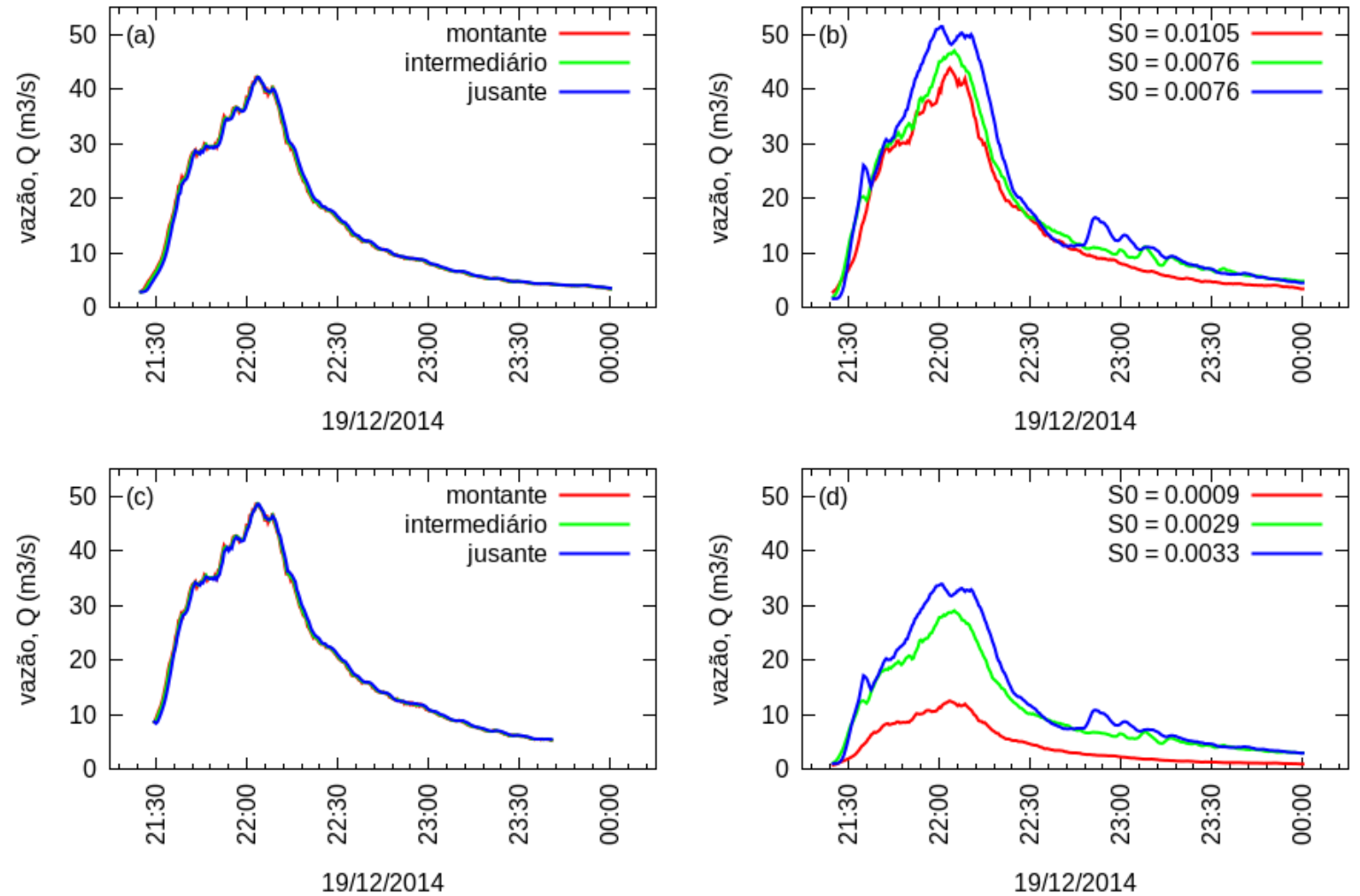

Figura 29 - Comparação dos hidrogramas simulados utilizando (a) fundo simples e (c) fundo com degraus com os hidrogramas obtidos pela Equação de Manning utilizando as declividades (b) do fundo simples e (d) do fundo com degraus.

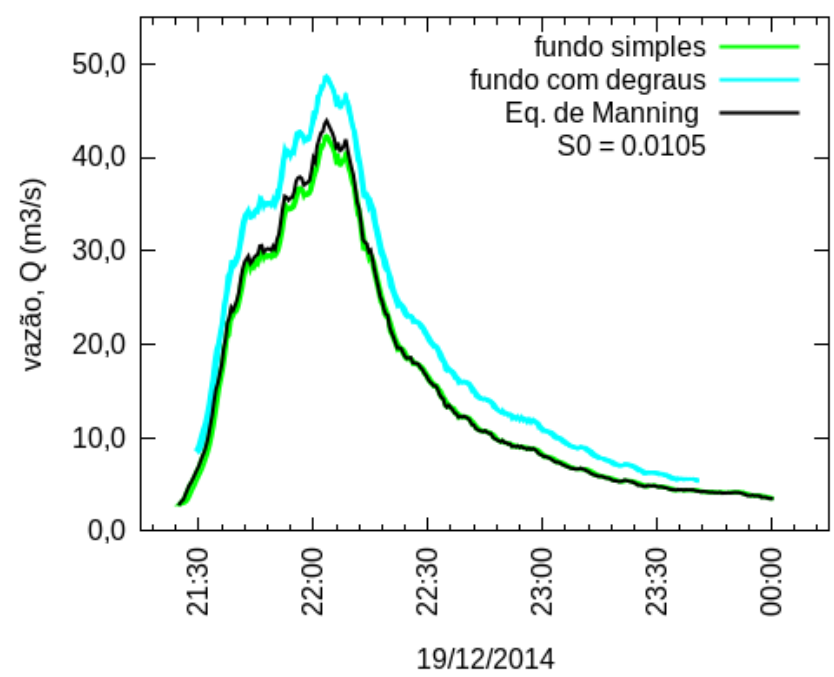

Figura 30 - Comparação dos hidrogramas simulados com o hidrograma obtido pela Equação de Manning considerando a geometria do fundo simples a montante.

As velocidades relacionadas às vazões simuladas variam entre 0,5 e $5 \mathrm{~m} / \mathrm{s}$ no caso do fundo simples e entre 1,5 e $6 \mathrm{~m} / \mathrm{s}$ no caso do fundo com degraus. A Figura 31 apresenta os intervalos dessas variações com o passar do tempo e das seções para todos os eventos simulados. 

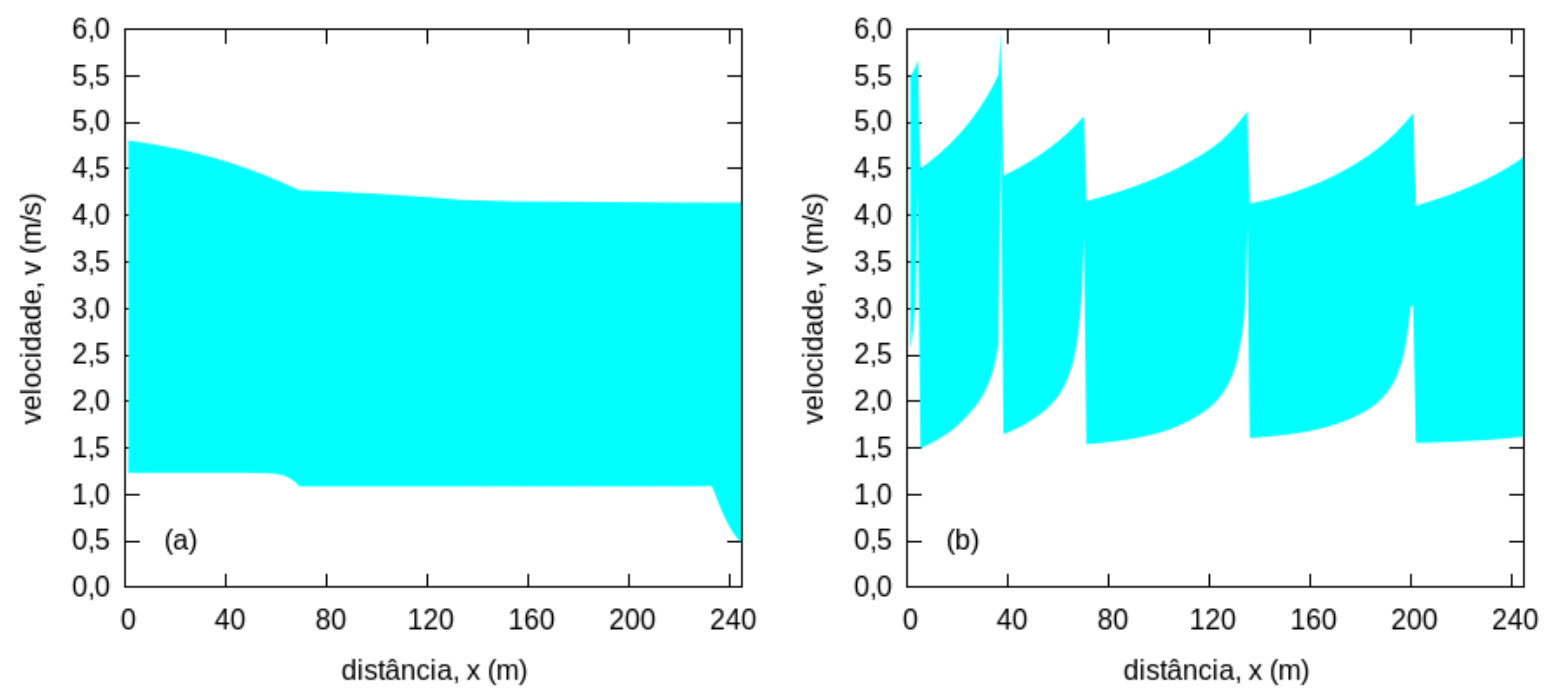

Figura 31 - Intervalo de variação da velocidade simulada considerando todos os eventos para (a) fundo simples e (b) fundo com degraus.

As velocidades atingem valores altos, assim como era esperado e observado em campo. Para uma análise mais detalhada, a Figura 32 apresenta a evolução da velocidade ao longo das seções e com o passar do tempo.
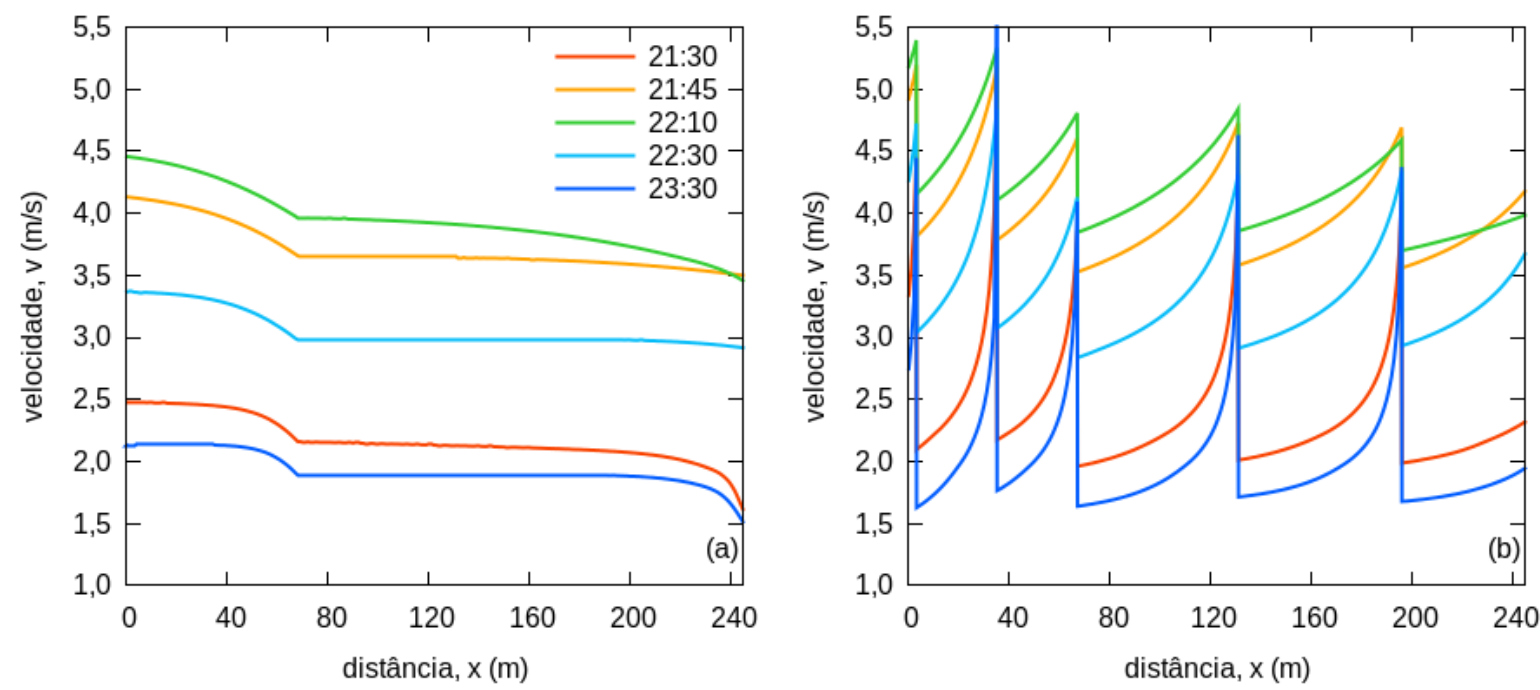

Figura 32 - Variação da velocidade simulada para o evento do dia 19/12/2014.

Para o fundo simples, as velocidades iniciam mais elevadas a montante e vão decaindo ao longo das seções, apresentam uma quebra de continuidade no ponto de mudança de declividade, evoluem praticamente constantes e decaem mais rapidamente nas próximidades da seção de jusante. Já no fundo com degraus, a presença dos degraus resultam em picos de velocidade que cessam instantaneamente. Este fato evidencia a grande influência da presença dos degraus, principalmente para menores profundidades. 
A evolução do número de Froude é outro resultado bastante interessante de ser analisado. Seu intervalo de variação durante as simulações considerando todos os eventos e instantes de tempo é representado pela Figura 33 .
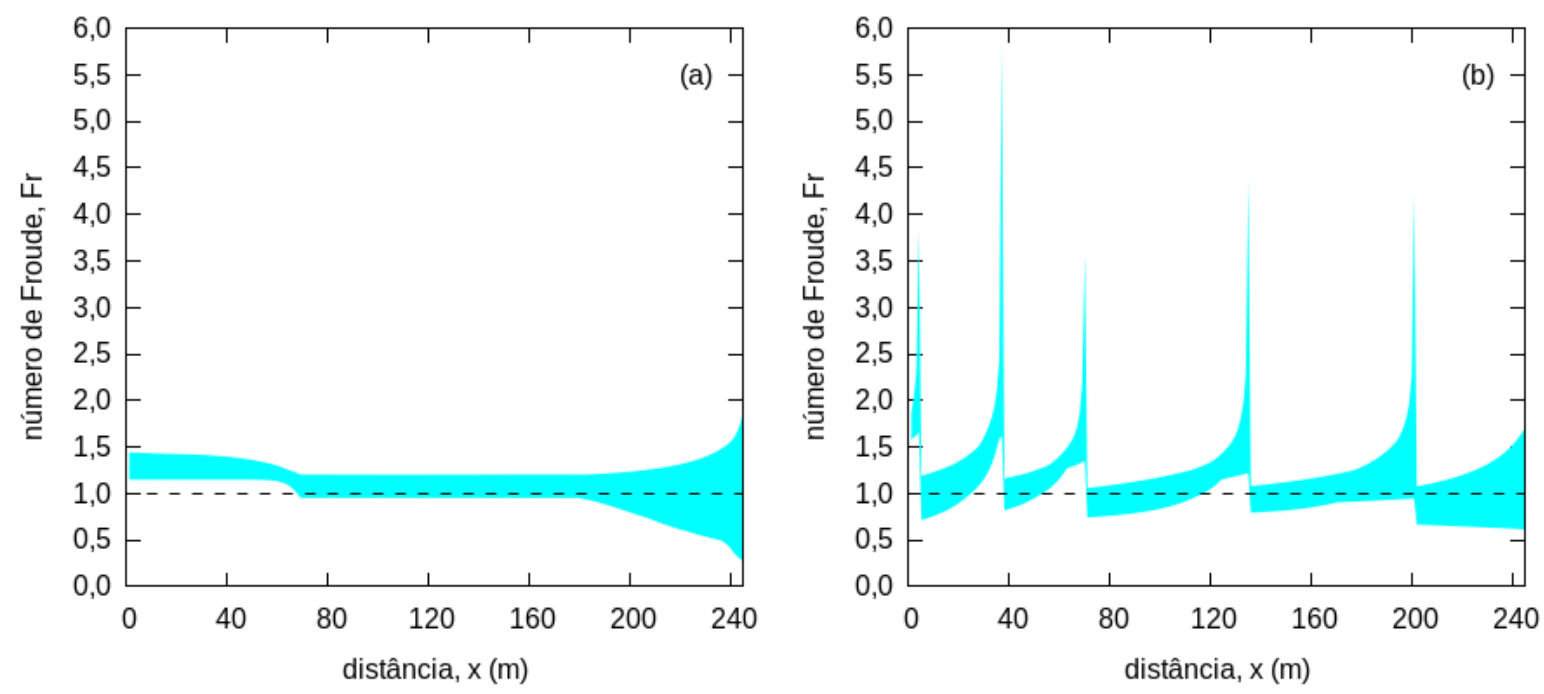

Figura 33 - Intervalo de variação do número de Froude considerando todos os eventos para (a) fundo simples e (b) fundo com degraus.

Para a simulação com fundo simples, na seção de montante, o escoamento é supercrítico, porém muito próximo ao crítico. Ao longo das seções, o número de Froude se aproxima ainda mais de um podendo passar para valores menores do que um caracterizando-se como escoamento subcrítico. Quanto mais o escoamento se aproxima da seção de jusante, maior é o intervalo de varição do número de Froude. Mesmo assim, pode-se considerar que o escoamento do rio é muito próximo do crítico em todas as seções com grande possibilidade de ocorrência de transição de regime. No caso da simulação com fundo com degraus, a descontinuidade do próprio degrau é evidente, levando o $\mathrm{Fr}$ a valores muito maiores que nas demais seções. Entretanto, também se observam valores de Froude próximos de um.

Para analisar com mais detalhes a evolução do número de Froude com o passar do tempo, a Figura 34 apresenta os valores obtidos para o evento do dia 19/12/2014 (os demais eventos apresentam comportamentos semelhantes).

No caso do fundo simples, nos primeiros instantes, o escoamento é sepercrítico em todas as seções. Esse comportamento muda rapidamente com o passar do tempo, principalmente na seção de jusante, que passa a ter valores menores do que um. A maior variação nas últimas seções $(x>200 \mathrm{~m})$ pode estar relacionada ao efeito de histerese da passagem de onda de cheia. Já no fundo com degraus, a mudança de supercrítico para subcrítico e vice versa ocorre em praticamente todos os intervalos entre degraus. Generalizando, o número de Froude realmente é muito próximo de um em boa parte do trecho e ao longo do tempo podendo transitar entre o escoamento supercrítico e subcrítico, 
o que caracteriza escoamento transcrítico. Essa transição de regime também é perceptível em campo, as velocidades na seção de jusante são visivelmente menores que as velocidades de montante.
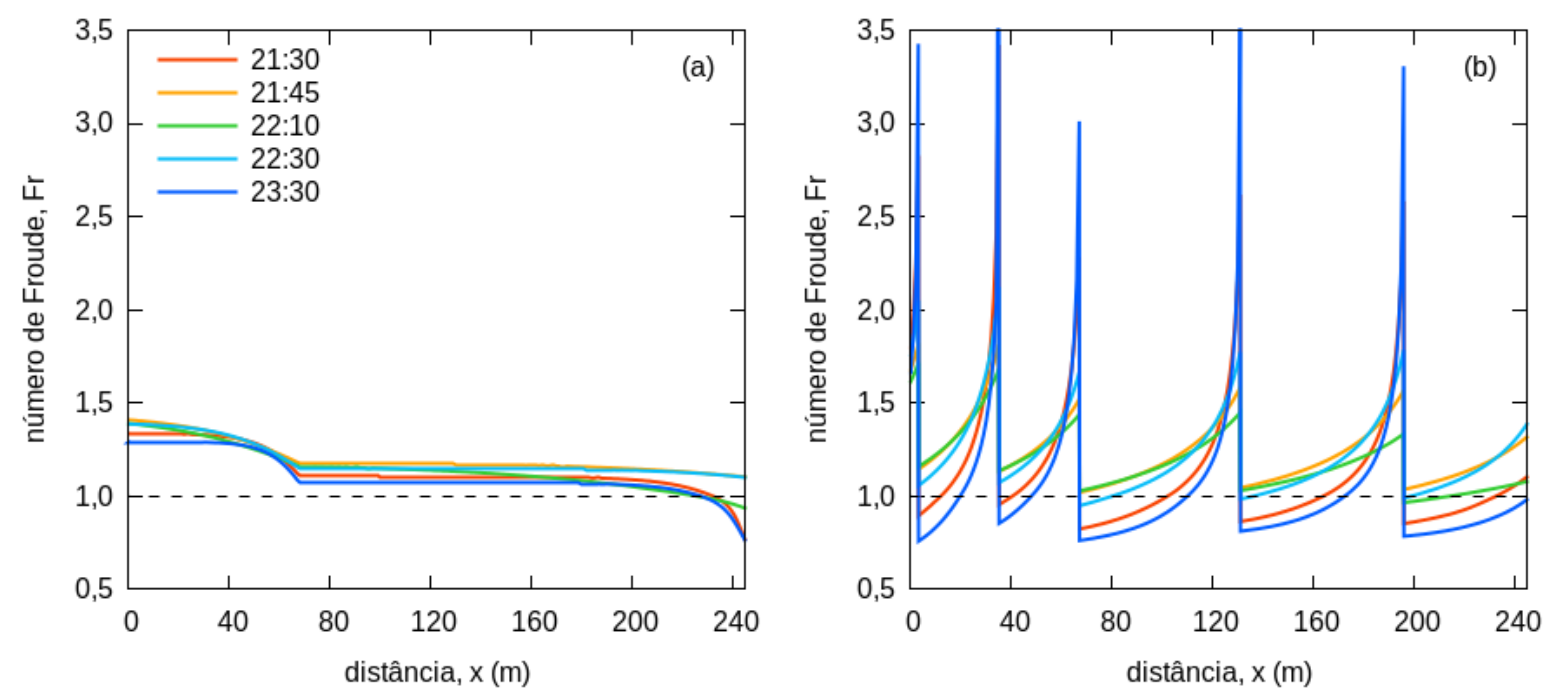

Figura 34 - Variação do número de Froude para a simulação do evento do dia 19/12/2014 $21 \mathrm{~h}$ para (a) fundo simples e (b) fundo com degraus..

As grandes variações da velocidade e do número de Froude observadas nas simulações que utilizaram o fundo com degraus (Figura 32(b) e 34(b)), levam a crer que essa aproximação de fundo não está sendo adequadamente representado pelas Equações de Saint Venant unidimensionais. Os grandes valores de velocidade e Froude são resultantes, provavelmente, das grandes declividades de fundo adotadas para a representação dos degraus ( $S_{0} \approx 2,9$ - ver Apêndice A). Ainda assim, as simulaçõs com fundo com degraus foram capazes de produzir bons resultados, dependendo do evento. Isso pode ser explicado pelo fato da seção intermediária de monitoramento estar localizada entre dois degraus, onde os efeitos não são muito significativos.

Os valores simulados foram utilizados ainda para relacionar vazões e níveis. Assim, como exemplo, a Figura 35 representa as curvas-chaves para o evento do dia 19/12/2014. Pode-se dizer que nas seções de montante e intermediária a relação profundidade-vazão possuem praticamente relação unívoca. Já para a seção de jusante, fica evidente um complexo efeito de histerese (HERSCHY, 1995). Observa-se que ambos os tipos de fundo apresentam as mesmas características, porém o fundo com degraus atinge maiores valores de vazão.

A Figura 36 apresenta, através de uma "nuvem" de pontos, a relação profundidadevazão para todos os eventos simulados, representando a região de relação entre as variáveis. Com o objetivo de melhor representar a curva-chave, destacou-se as simulações com $E N S>0,7$. Além disso, visando comparação, também foram plotadas as curvas obtidas pela Equação de Manning considerando a geometria da seção analisada. 

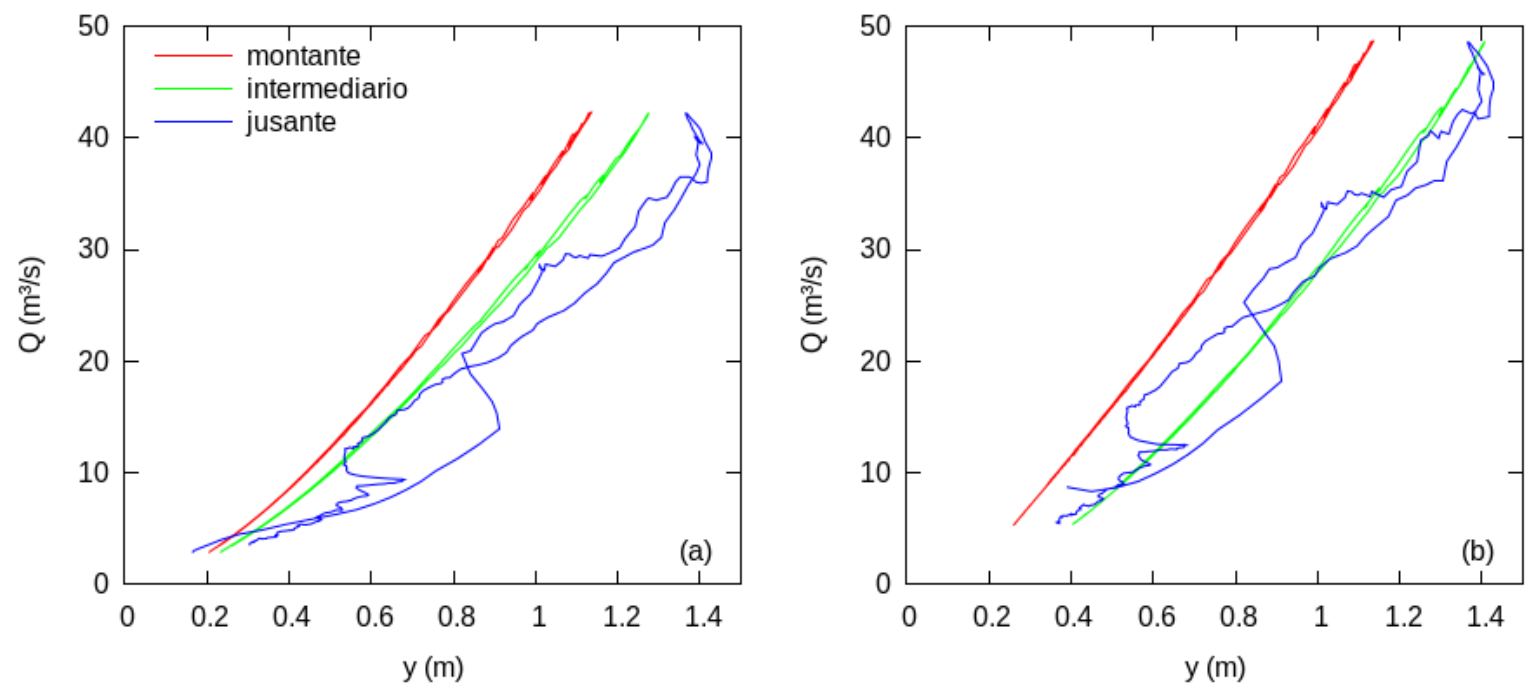

Figura 35 - Relações profundidade-vazão obtidas para a simulação do evento do dia 19/12/2014 para a aproximação de (a) fundo simples e (b) fundo com degraus.
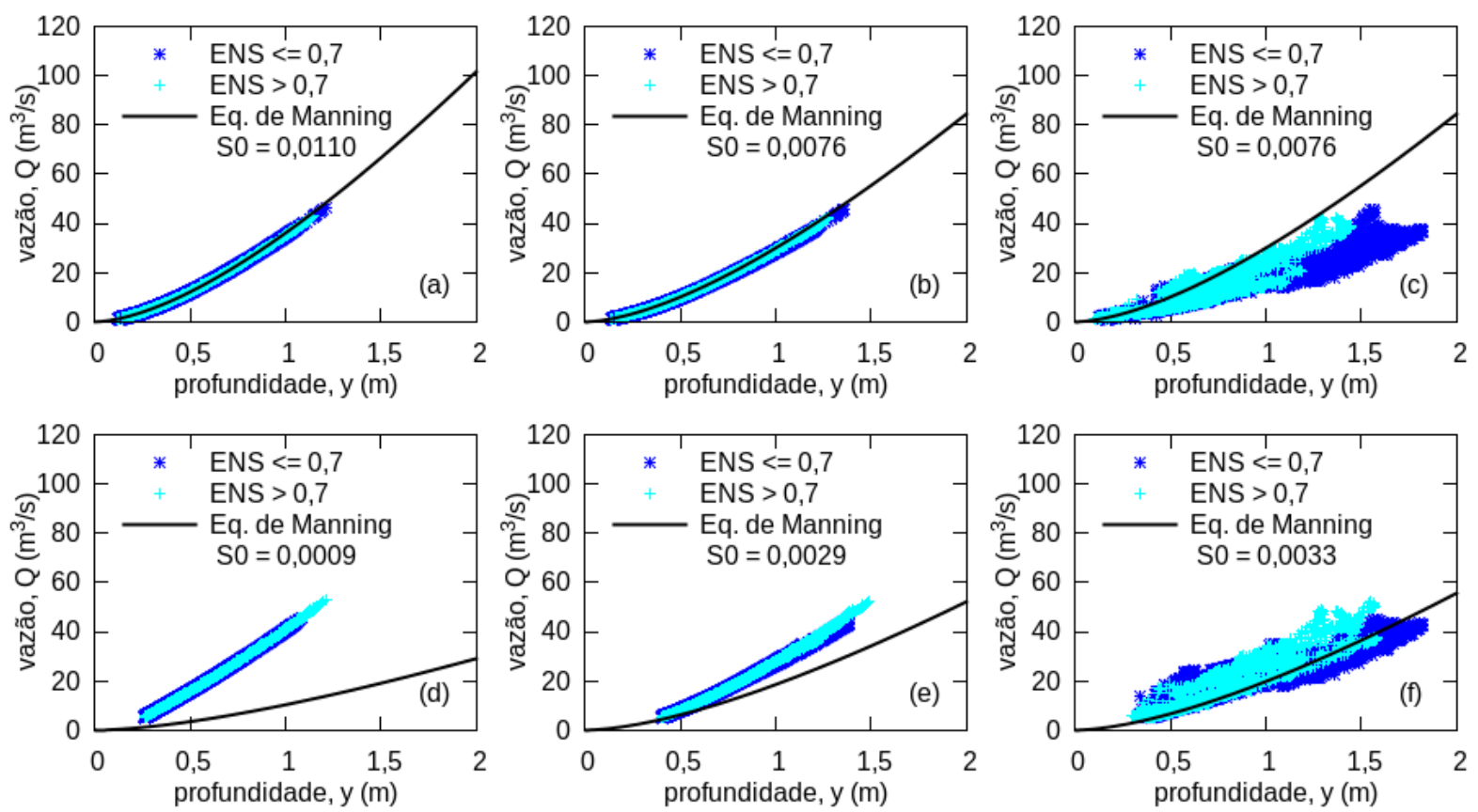

Figura 36 - Nuvem de pontos que relaciona profundidade-vazão para as seções (a) de montante, (b) intermediária e (c) de jusante, considerando fundo simples, e para a seção (d) de montante, (e) intermediária e (f) de jusante, considerando fundo com degraus.

Maior espalhamento dos pontos de relação profundidade-vazão é observado para a seção de jusante em ambos os tipos de fundo. Esse espalhamento é devido ao efeito de 
histerese, que foi observado no evento do dia 19/12/2014 e nos demais eventos. Também pode-se confirmar a relação unívoca do nível e vazão nas seções de montante e intermediária produzida para todos os eventos simulados. As simulações de fundo simples para a seção de montante e intermediária são muito próximas da Equação de Manning. Apesar da seção de jusante não estar muito próxima da curva, os eventos que obtiverem melhor simulação $(E N S>0.7)$ encontram-se mais próximos da Equação de Manning. Para o caso das simulações com fundo com degraus, as nuvens são bastante parecidas com as do fundo simples. Porém, pode-se observar que os eventos que atingiram altas vazões obtiveram melhores resultados $(E N S>0.7)$. As vazões calculadas pela Equações de Manning ficaram abaixo das simuladas devido ao baixo valor da declividade de fundo da geometria considerada. Já na seção de jusante, a curva é melhor envolvida pela nuvem de pontos.

Uma equação foi ajustada para as três seções considerando apenas os eventos que produziram ENS maior do que 0,7 e estão representadas na Figura 37. As curvas são muito parecidas para todas as seções e tipos de fundo. Isso comprova a semelhança de resultados entre os tipos de fundo, mesmo os melhores resultados não serem necessariamente produzidos para os mesmos eventos.
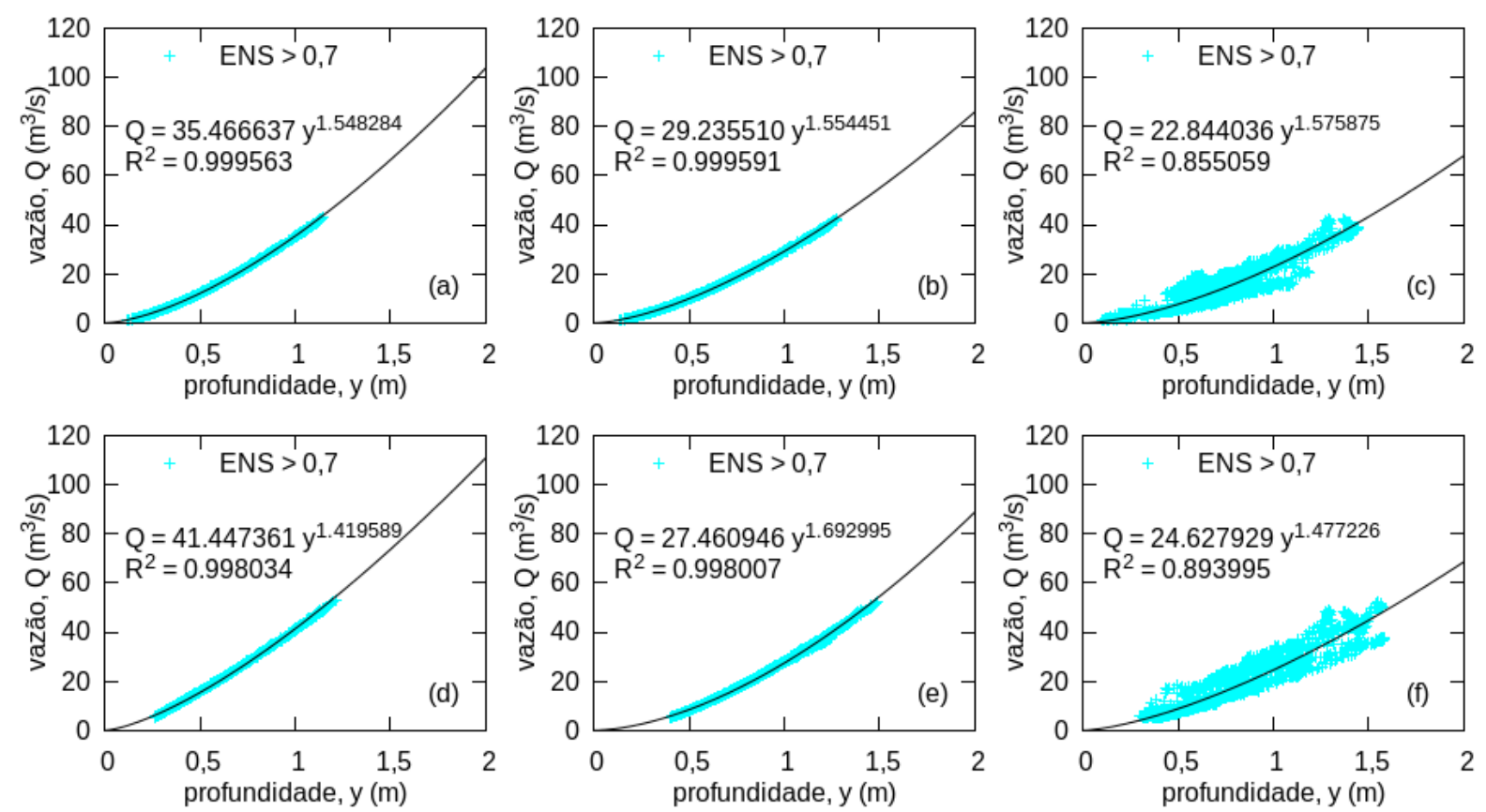

Figura 37 - Ajuste de curva-chave considerando a relação profundidade-vazão para as seções (a) de montante, (b) intermediária e (c) de jusante, considerando fundo simples, e para a seção (d) de montante, (e) intermediária e (f) de jusante, considerando fundo com degraus.

Apesar dos ajustes de curvas das relações profundidade-vazão terem sido realizados para as três seções, não se aconselha a definição de uma curva-chave unívoca para a seção de jusante, visto o efeito de histerese evidenciado nessa seção. Além disso, acredita- 
se que a seção de jusante também pode apresentar efeito de histerese, por ela apresentar limnigramas mais próximos dos limnigramas de jusante, apesar desse efeito não ser evidenciado nas simulações. Provavelmente, os eventos que não produziram bons valores de ENS $(E N S<0.7)$ foram justamente aqueles que apresentavam efeito de histerese. Portanto, também não se tem certeza se a equação ajustada pode ser representada como curva-chave da seção de jusante. Já no caso da seção de montante, o fato do escoamento ser mais torrencial justifica a relação unívoca e a curva-chave ajusta tem maior significado para essa seção. Com isso, conclui-se que as equações ajustadas para a seção de montante podem representar uma curva-chave para córrego do Gregório.

A Figura 38 permite a verificação da grande semelhança entre as curvas ajustadas e a Equação de Manning para as seções de montante e de jusante considerando o fundo simples. Entretanto, quando se considera as declividades mais próximas da topografia, a Equação de Manning subestima as vazões.
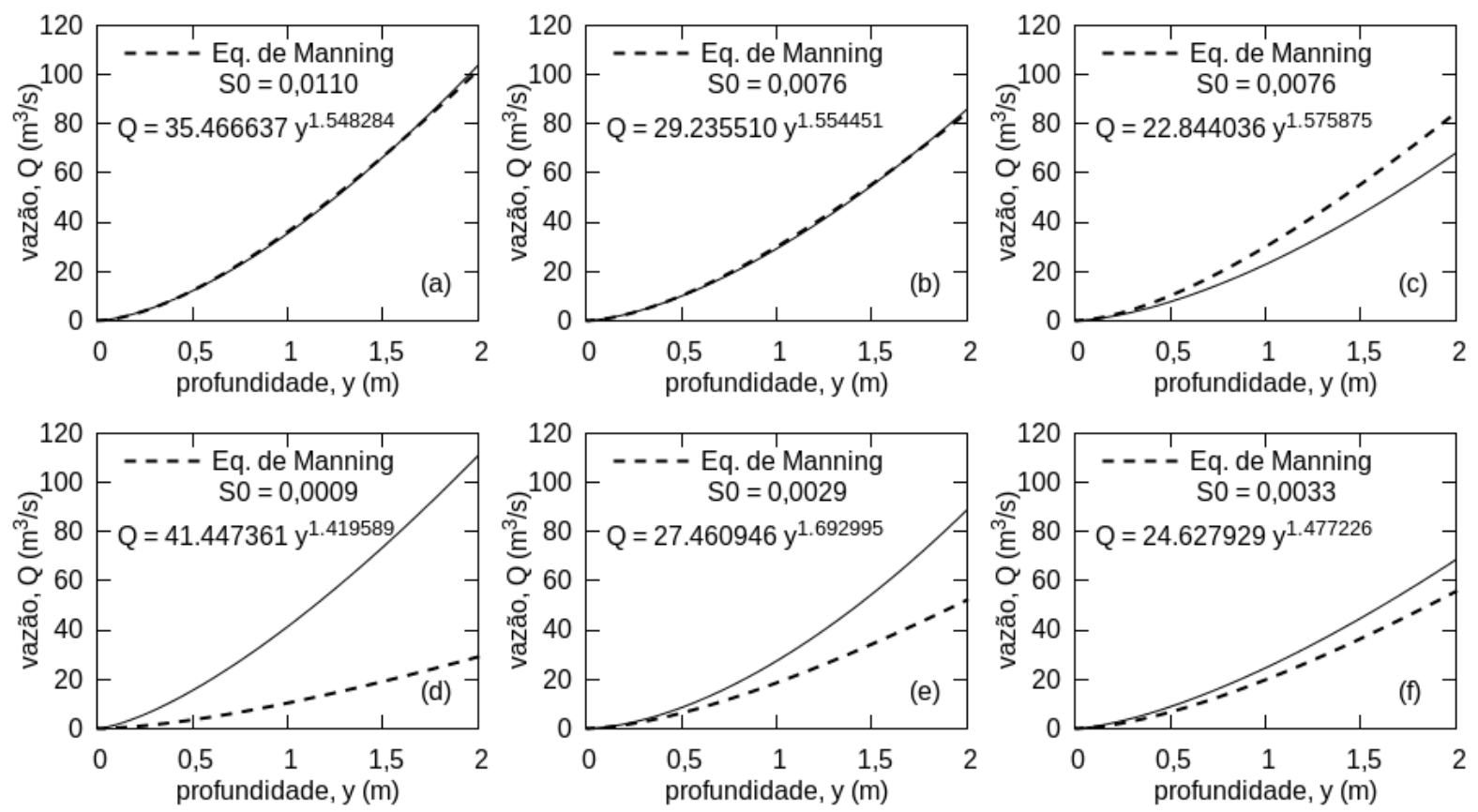

Figura 38 - Comparação entre as curvas-chave ajustada e a Equação de Manning calculada considerando as declividades das seções (a) de montante, (b) intermediária e (c) de jusante, considerando fundo simples, e das seções (d) de montante, (e) intermediária e (f) de jusante, considerando fundo com degraus.

\subsection{Observações em Relação à Escolha do Coeficiente de Rugosidade de Manning}

Os resultados apresentados até então foram obtidos fixando-se o coeficiente de rugosidade de Manning em $0,020 \mathrm{~s} / \mathrm{m}^{1 / 3}$. Entretanto, para verificar sua influência nos 
resultados, simulações utilizando $n=0,016 \mathrm{~s} / \mathrm{m}^{1 / 3}$ e $n=0,023 \mathrm{~s} / \mathrm{m}^{1 / 3}$ também foram realizadas. Para facilitar a comparação utilizou-se o coeficiente de Eficiência de NashSutcliffe ENS como apresentado nas Tabelas 10 e 11.

Tabela 10 - Coeficientes de Eficiência de Nash-Sutcliffe $(E N S)$ resultantes das simulações dos eventos registrados com a instalação em tubos para diferentes valores de rugosidade de Manning.

\begin{tabular}{|c|c|c|c|c|c|c|}
\hline \multirow[b]{2}{*}{ Data } & \multicolumn{3}{|c|}{ fundo simples } & \multicolumn{3}{|c|}{ fundo com degraus } \\
\hline & $\begin{array}{c}\mathrm{n}= \\
0,016\end{array}$ & $\begin{array}{c}\mathrm{n}= \\
0,020\end{array}$ & $\begin{array}{c}\mathrm{n}= \\
0,023\end{array}$ & $\begin{array}{c}\mathrm{n}= \\
0,016\end{array}$ & $\begin{array}{c}n= \\
0,020\end{array}$ & $\begin{array}{c}\mathbf{n}= \\
0,023\end{array}$ \\
\hline $27 / 02 / 201312 \mathrm{~h}$ & $-1,569$ & $-1,643$ & $-1,692$ & 0,620 & 0,623 & 0,644 \\
\hline $28 / 02 / 201318 \mathrm{~h}$ & $-0,911$ & $-0,979$ & $-1,026$ & 0,797 & 0,800 & 0,810 \\
\hline 09/03/2013 17h & $-0,450$ & $-0,549$ & $-0,611$ & 0,347 & & 0,378 \\
\hline 09/03/2013 20h & 0,298 & 0,295 & 0,283 & $-0,059$ & $-0,055$ & $-0,086$ \\
\hline $10 / 03 / 201319 \mathrm{~h}$ & 0,651 & & & & & 0,869 \\
\hline $25 / 03 / 201319 \mathrm{~h}$ & $-1,352$ & $-1,503$ & $-1,606$ & $-0,157$ & $-0,151$ & $-0,146$ \\
\hline 02/04/2013 13h & $-6,493$ & $-6,695$ & $-6,827$ & $-1,023$ & $-1,012$ & $-0,922$ \\
\hline $02 / 04 / 201315 \mathrm{~h}$ & $-1,457$ & $-1,636$ & $-1,750$ & 0,038 & 0,048 & 0,100 \\
\hline $28 / 05 / 201310 \mathrm{~h}$ & 0,118 & 0,064 & 0,026 & 0,576 & 0,602 & 0,609 \\
\hline 04/10/2013 02h & $-0,820$ & $-0,925$ & $-1,008$ & 0,414 & 0,449 & 0,449 \\
\hline 04/11/2013 13h & $-0,237$ & $-0,329$ & $-0,396$ & 0,618 & 0,622 & 0,621 \\
\hline $16 / 11 / 201316 \mathrm{~h}$ & $-0,117$ & $-0,162$ & $-0,193$ & 0,567 & 0,583 & 0,593 \\
\hline $17 / 11 / 201316 \mathrm{~h}$ & 0,207 & 0,143 & 0,061 & 0,758 & 0,767 & 0,775 \\
\hline $29 / 11 / 201323 \mathrm{~h}$ & $-0,319$ & $-0,410$ & $-0,472$ & 0,489 & 0,497 & 0,502 \\
\hline
\end{tabular}

Os resultados obtidos com $\mathrm{n}=0,016$ foram os que apresentaram maior número de melhorias quando comparados com os obtidos com $\mathrm{n}=0,020$. Entretanto, essas melhorias, foram menores do que 0,1 para a grande maioria dos eventos $(93 \%$ e $80 \%$ dos eventos simulados com fundo simples e fundo com degraus, respectivamente). Além disso, as maiores melhorias ocorrem para eventos que já não apresentaram bons resultados $(E N S<0,7)$ utilizando $n=0,020$. No caso da utilização de $n=0,023$ foi observada uma redução no valor de ENS para grande maioria dos eventos.

Considerando os valores de $E N S$, observou-se que não houve variação significativa nos resultados com as mudanças no coeficiente de rugosidade de Manning, por isso o valor de 0,020 foi mantido fixo nas simulações. 
Tabela 11 - Coeficientes de Eficiência de Nash-Sutcliffe $(E N S)$ resultantes das simulações dos eventos registrados com a instalação em suportes de fundo para diferentes valores de rugosidade de Manning.

\begin{tabular}{|c|c|c|c|c|c|c|}
\hline \multirow{2}{*}{ Data } & \multicolumn{3}{|c|}{ fundo simples } & \multicolumn{3}{|c|}{ fundo com degraus } \\
\hline & $\begin{array}{c}\mathrm{n}= \\
0,016\end{array}$ & $\begin{array}{c}n= \\
0,020\end{array}$ & $\begin{array}{c}n= \\
0,023\end{array}$ & $\begin{array}{c}n= \\
0,016\end{array}$ & $\begin{array}{c}n= \\
0,020\end{array}$ & $\begin{array}{c}n= \\
0,023\end{array}$ \\
\hline $01 / 11 / 201423 \mathrm{~h}$ & 0,791 & 0,798 & 0,795 & 0,182 & 0,058 & $-0,173$ \\
\hline 02/11/2014 18h & 0,693 & 0,708 & 0,654 & 0,524 & $-0,469$ & $-0,809$ \\
\hline 04/11/2014 01h & 0,799 & 0,779 & 0,775 & $-0,060$ & $-0,120$ & $-0,191$ \\
\hline $04 / 11 / 201416 \mathrm{~h}$ & 0,864 & 0,840 & 0,832 & $-0,453$ & $-0,445$ & $-0,466$ \\
\hline $07 / 11 / 201423 \mathrm{~h}$ & 0,919 & 0,904 & 0,903 & 0,434 & 0,439 & 0,423 \\
\hline 14/11/2014 04h & 0,799 & 0,798 & 0,797 & 0,375 & $-0,042$ & $-0,134$ \\
\hline 26/11/2014 16h & 0,235 & 0,234 & 0,233 & 0,131 & $-0,042$ & $-0,849$ \\
\hline 09/12/2014 17h & 0,826 & 0,852 & 0,822 & $-2,289$ & $-2,943$ & $-3,410$ \\
\hline $12 / 12 / 201416 \mathrm{~h}$ & 0,974 & 0,974 & 0,975 & 0,753 & 0,754 & 0,748 \\
\hline $14 / 12 / 201415 \mathrm{~h}$ & 0,724 & 0,735 & 0,705 & $-0,028$ & $-0,222$ & $-1,231$ \\
\hline $19 / 12 / 201421 \mathrm{~h}$ & 0,953 & 0,952 & 0,949 & 0,920 & 0,917 & 0,906 \\
\hline $21 / 12 / 201414 \mathrm{~h}$ & 0,530 & 0,527 & 0,504 & $-0,239$ & $-0,744$ & $-1,088$ \\
\hline $22 / 12 / 201422 \mathrm{~h}$ & 0,812 & 0,811 & 0,810 & 0,110 & 0,109 & 0,096 \\
\hline $23 / 12 / 201415 \mathrm{~h}$ & 0,783 & 0,780 & 0,777 & $-0,157$ & $-0,141$ & $-0,151$ \\
\hline 28/12/2014 17h & 0,537 & 0,533 & 0,530 & 0,799 & 0,790 & 0,766 \\
\hline $28 / 12 / 201419 \mathrm{~h}$ & 0,779 & 0,777 & 0,776 & 0,728 & 0,711 & 0,558 \\
\hline $30 / 12 / 201417 \mathrm{~h}$ & 0,807 & 0,813 & 0,748 & 0,428 & 0,375 & 0,235 \\
\hline $30 / 12 / 201422 \mathrm{~h}$ & 0,485 & 0,495 & 0,494 & 0,463 & 0,296 & 0,413 \\
\hline 01/01/2015 18h & 0,421 & 0,420 & 0,398 & 0,387 & 0,589 & 0,487 \\
\hline 03/01/2015 20h & 0,413 & 0,411 & 0,326 & 0,862 & 0,847 & 0,839 \\
\hline 05/01/2015 15h & 0,782 & 0,804 & 0,803 & 0,818 & 0,815 & 0,737 \\
\hline 08/01/2015 17h & 0,561 & 0,579 & 0,578 & 0,729 & 0,705 & 0,698 \\
\hline 08/01/2015 19h & 0,694 & 0,693 & 0,692 & 0,803 & 0,783 & 0,760 \\
\hline $10 / 01 / 201517 \mathrm{~h}$ & 0,280 & 0,305 & 0,302 & 0,706 & 0,691 & 0,514 \\
\hline $11 / 01 / 201516 \mathrm{~h}$ & 0,815 & 0,851 & 0,852 & 0,466 & 0,307 & 0,145 \\
\hline $14 / 01 / 201517 \mathrm{~h}$ & 0,625 & 0,623 & 0,577 & 0,846 & 0,832 & 0,816 \\
\hline $20 / 01 / 201523 \mathrm{~h}$ & 0,193 & 0,193 & 0,145 & 0,755 & 0,730 & 0,717 \\
\hline $22 / 01 / 201517 \mathrm{~h}$ & 0,558 & 0,554 & 0,550 & 0,705 & 0,689 & 0,413 \\
\hline $26 / 01 / 201519 \mathrm{~h}$ & $-0,140$ & $-0,142$ & $-0,143$ & 0,930 & 0,921 & 0,908 \\
\hline $29 / 01 / 201504 \mathrm{~h}$ & 0,296 & 0,295 & 0,134 & 0,803 & 0,789 & 0,755 \\
\hline $31 / 01 / 201517 \mathrm{~h}$ & 0,282 & 0,337 & 0,337 & $-102,589$ & 0,865 & 0,830 \\
\hline 01/02/2015 16h & 0,309 & 0,307 & 0,305 & 0,869 & 0,825 & 0,796 \\
\hline 03/03/2015 15h & 0,675 & 0,676 & 0,667 & 0,807 & 0,789 & 0,738 \\
\hline 04/02/2015 06h & 0,434 & 0,445 & 0,332 & 0,903 & 0,894 & 0,872 \\
\hline 05/02/2015 17h & 0,407 & 0,407 & 0,319 & 0,833 & 0,817 & 0,795 \\
\hline $10 / 02 / 201514 \mathrm{~h}$ & $-0,138$ & $-0,138$ & $-0,491$ & 0,877 & 0,865 & 0,839 \\
\hline $10 / 02 / 201520 \mathrm{~h}$ & $-0,598$ & $-0,598$ & $-0,599$ & 0,581 & 0,528 & 0,423 \\
\hline $15 / 03 / 201520 \mathrm{~h}$ & 0,798 & 0,795 & 0,798 & 0,796 & 0,789 & 0,766 \\
\hline $16 / 03 / 201516 \mathrm{~h}$ & 0,956 & 0,954 & 0,952 & 0,863 & 0,861 & 0,840 \\
\hline $21 / 03 / 201516 \mathrm{~h}$ & 0,816 & 0,800 & 0,783 & $-0,257$ & $-0,261$ & $-0,285$ \\
\hline $27 / 03 / 201518 \mathrm{~h}$ & 0,713 & 0,709 & 0,692 & 0,179 & 0,176 & 0,157 \\
\hline $28 / 03 / 201518 \mathrm{~h}$ & 0,614 & 0,611 & 0,608 & $-0,790$ & $-1,097$ & $-1,138$ \\
\hline $29 / 03 / 201518 \mathrm{~h}$ & 0,896 & 0,900 & 0,899 & 0,658 & 0,650 & 0,625 \\
\hline $30 / 03 / 201512 \mathrm{~h}$ & 0,652 & 0,699 & 0,698 & 0,208 & $-0,263$ & $-0,346$ \\
\hline 05/04/2015 15h & 0,759 & 0,757 & 0,755 & 0,655 & 0,550 & 0,397 \\
\hline 05/04/2015 19h & 0,341 & 0,390 & 0,389 & 0,796 & 0,755 & 0,628 \\
\hline
\end{tabular}




\section{Conclusões}

Neste trabalho apresentou-se o desenvolvimento de um modelo hidrodinâmico unidimensional, baseado nas equações completas de Saint Venant e capaz de resolver transição de regimes de escoamento. O modelo seguiu o esquema implícito de Preissmann, como apresentado por Akan (2006), adaptado por um filtro redutor dos termos de inércia da equação de momento, como proposto por Fread, Jin e Lewis (1996), e resolvido pelo Método de Iteração de Newton Generalizado e pelo Método da Dupla Varredura, como detalhado por Freitag (2003).

A simulação de um problema analítico de escoamento transcrítico, proposto por MacDonald et al. (1997), visando ao teste do modelo desenvolvido, confirmou a incapacidade de modelos de redução dos termos de inércia em caracterizar exatamente uma linha d'água descontínua, como a de um ressalto hidráulico. Entretanto, foi possível realizar a simulação do escoamento transcrítico sem a ocorrência de instabilidade.

Com o monitoramento de nível, através de transdutores de pressão instalados em três seções do córrego do Gregório, e a simulação de 60 eventos de passagem de onda de cheia, entre 2013 e 2015, pode-se concluir que, para monitorar ondas de cheia em rios urbanos, um intervalo de tempo de no máximo um minuto é necessário para se representar de forma detalhada o inicio da ascensão e o pico do limnigrama. Aconselha-se realizar o monitoramento dos primeiros eventos com intervalos de tempo menores. Dependendo das características da bacia monitorada e com a experiência adquirida na análise de alguns eventos, esse intervalo de tempo pode ser aumentado.

A mudança da instalação dos sensores, passando de tubos para os suportes de fundo, trouxe grandes benefícios, visto que profundidades menores passaram a ser monitoradas. Isso permitiu que os eventos fossem representados de forma mais completa, evitando-se perda de informação.

Apesar das tentativas de medição de vazão utilizando ADCP, não foi possível realizar medições durante a passagem de uma onda de cheia, mesmo com adaptações. A rápida resposta das bacias urbanas, a rápida ascensão dos níveis e as altas velocidades, vivenciadas no presente trabalho, são peculiaridades indiscutivelmente presentes na passagem de ondas de cheia. Essas características exigem adaptações das forma de medição de vazão clássicas, abordando temas, como o Método da Entropia, e novas tecnologias de medição, como os equipamento hidrosônicos, que ainda estão em pauta no meio científico.

As duas aproximações de fundo (fundo simples e fundo com degraus), consideradas nas simulações, produziram aproximações satisfatórias da profundidade intermediária para considerável quantidade de eventos $(36,7 \%$ do eventos simulados com fundo simples e $40 \%$ com fundo com degraus produziram valores de eficiência de Nash-Sutcliffe acima de 0,7 ), o que confirma a aplicabilidade do modelo para o problema real analisado. 
Foi observado que o modelo não é capaz de simular o escoamento para profundidades muito baixas. Essa dificuldade se deve às aproximações adotadas para o fundo do canal. A aproximação para seção retangular torna-se inválida para baixas profundidades. Além disso, no caso da representação mais próxima da topografia, a maior influência dos degraus sobre o escoamento não foi bem representada pelo modelo devido à aproximação grosseira dos degraus, que contraria as hipóteses das Equações de Saint Venant unidimensionais.

As vazões simuladas chegaram a valores de pico em torno de $50 \mathrm{~m}^{3} / \mathrm{s}$ e apresentam hidrogramas praticamente coincidentes para todas as seções, sendo apenas suavizados e levemente amortecidos com o passar das seções, o que já era esperado por se tratar de um trecho muito curto. As velocidades simuladas atingiram valores altos, em torno de $5 \mathrm{~m} / \mathrm{s}$, assim como previsto e observado em campo. O número de Froude manteve-se próximo de um durante as simulações, o que leva a concluir que o escoamento transcrítico realmente pode ocorrer durante a passagem de onde de cheia no canal estudado.

Analisando-se as relações profundidade-vazão obtidas pelas simulações, concluiuse que a seção de jusante possui forte efeito de histerese tendo relação nível-vazão bastante complexa. Apesar da relação nível-vazão produzidos para a seção intermediária apresentar comportamento unívoco, acredita-se que a seção intermediária também pode estar sob efeito de histerese, pois os limnigramas observados na seção intermediaria são mais próximos dos limnigramas observados a jusante na maioria dos eventos. Por isso, provavelmente, os eventos que apresentam tal comportamento são justamente aqueles que não produziram bons resultados na simulação. Já as relações na seção de montante podem ser representadas por uma curva-chave unívoca. Visto as problemáticas relacionadas com representação de fundo com degraus, propõem-se a curva-chave obtida pela aproximação de fundo simples como uma representação do escoamento do córrego do Gregório:

$$
Q=35,466637 y^{1,548284}
$$

Inesperadamente a Equação de Manning calculada utilizando as declividades do fundo simplificado ficaram muito semelhantes às curvas-chaves ajustadas para as seções de montante e intermediária, podendo a Equação de Manning, nessas condições, também ser considerada uma boa aproximação para a seção de montante. Entretanto, quando se consideram as declividades mais próximas da topografia existente, a Equação de Manning apresenta uma tendência de subestimar as vazões, principalmente para seção de montante. 


\section{Propostas para Trabalhos Futuros}

Em relação ao monitoramento:

- Instalação de câmeras que permitam a conferência através das réguas das medições realizadas pelos limnígrafos durante eventos de onda de cheia, para validar a precisão dos equipamentos;

- Instalação de câmera adequada em um ângulo que permita a visualização de potenciais flutuadores, que podem ser o próprio material suspenso carreado pelo rio. Dessa forma, pode ser possível acompanhar a evolução da velocidade superficial com o passar da onda de cheia através do tempo de vídeo;

- Analisar com maior cuidado a possibilidade de manter o ADP parado no meio do canal realizando medições em apenas uma vertical e a interpretação dos dados brutos disponibilizados pelo software. Comprovar a eficiência dessa metodologia através de testes em canais com vazões controláveis, fazendo comparações com a medição padrão;

- Investir em novas tecnologias e metodologias de medição de velocidade, como os radares sem contato com a superfície d'água, apresentado por Costa et al. (2006), e no método da Entropia, proposto por Chiu (1987).

Em relação à modelagem:

- Aplicar métodos de otimização visando calibrar o coeficiente de rugosidade de Manning para todos os eventos;

- Aplicar uma metodologia de resolução das Equações de Saint Venant que melhor descreva a transição de regime de escoamento, como por exemplo, o método de captura de choque utilizado por Freitag (2003);

- Representar de forma mais adequada o fundo do canal. As sugestões são as seguintes: (1) evitar a aproximação de seção retangular e representa-la de forma mais detalhada para melhor simular o escoamento de base; (2) representar, o mais próximo possível, a declividade real do fundo do canal e incluir uma perda localizada de energia nos degraus; e (3) detalhar a geometria do canal com os degraus e aplicar um modelo bidimensional, como apresentado por Saif e Hosoda (2012). 



\section{Referências}

ABEDINI, M. J.; HASHEMI, M. R. Effect of convective term suppression in numerical simulation of trans-critical open channel flow. Iranian Journal of Science 85 Technology, v. 30, n. B1, p. 85-96, 2006.

AGÊNCIA NACIONAL DE ÁGUAS. Orientações para operação das estações hidrométricas. [S.l.], 2012. Disponível em: < http://arquivos.ana.gov.br/infohidrologicas/ cadastro/OrientacoesParaOperacaoDeEstacoesHidrometricas-VersaoJun12.pdf $>$.

AKAN, A. O. Open Channel Hydraulics. Canada: Elsevier Ltd, 2006.

ALMEIDA, R. M. de. Estudo de Modelo Hidrodinâmico Unidimensional Aplicado a um Trecho de Canal do Córrego do Gregório em São Carlos, SP. Dissertação (Mestrado) Escola de Engenharia de São Carlos da Universidade de São Paulo, São Carlos, SP, 2013.

ARICÓ, C.; NASELLO, C.; TUCCIARELLI, T. Using unsteady-state water level data to estimate channel roughness and discharge hydrograph. Advances in Water Resources, v. 32, p. 1223-1240, 2009.

ARICÓ, C.; TUCCIARELLI, T. A marching in space and time (mast) solver of the shallow water equations. part i: The 1d model. Advances in Water Resources, v. 30, p. 1236-1252, 2007.

BALDASSARRE, G. D.; MONTANARI, A. Uncertainty in river discharge observations: a quantitative analysis. Hydrology and Earth System Sciences, v. 13, n. 6, p. 913-921, 2009. Disponível em: <http://www.hydrol-earth-syst-sci.net/13/913/2009/>.

BARBASSA, A. P. Simulação do Efeito da Urbanização Sobre a Drenagem Pluvial da Cidade de São Carlos, SP. Tese (Doutorado em Engenharia Hidráulica e Saneamento) Universidade de São Paulo - Escoala de Engenharia de São Carlos, São Carlos, SP, 1991.

BORGES, J. Q. O impacto da ocupação de fundos de vale em áreas urbanas. Caso: Córrego do Gregório - São Carlos (SP). Dissertação (Mestrado em Engenharia Hidráulica e Saneamento) - Universidade de São Paulo - Escoala de Engenharia de São Carlos, São Carlos, SP, 2006.

CASIER, F.; DECONINCK, H.; HIRSCH, C. A class of bidiagonal schemes for solving the Euler equations. AIAA Journal, v. 22, n. 11, p. 1556-1563, 1984.

CDCC. Centro de Divulgação Científica e Cultural da Universidade de São Paulo. Gregório: o córrego indomado. 1999. Vídeo. Disponível em: <http://www.ufscar.br/ aprender/aprender/2010/05/corrrego-do-gregorio/>. Acesso em: 16 dez. 2013.

CHAUDHRY, M. H. Open-Channel Flow. New Jersey: Prentice Hall, 1993.

CHIU, C.-L. Entropy and probability concepts in hydraulics. Journal of Hydraulic Engineering $A S C E$, n. 113, p. 583-600, 1987.

CHIU, C.-L.; HSU, S.-M.; TUNG, N.-C. Efficient methods of discharge measurements in rivers and streams based on the probability concept. Hidrological Processes, n. 19, p. 3935-3946, 2005. 
CHOW, V. T.; MAIDMENT, D. R.; MAYS, L. W. Applied Hydrology. [S.l.]: McGraw-Hill Series in Water Resources and Environmental Engineering, 1988.

CORATO, G.; MORAMARCO, T.; TUCCIARELLI, T. Discharge estimation combining flow routing and occasional measurements of velocity. Hydrology and Earth System Sciences, n. 15, p. 2979-2994, 2011.

COSTA, J. E. et al. Use of radars to monitor stream discharge by noncontact methods. Water Resources Research, v. 42, n. W07422, 2006.

CUI, H. Estimation of velocity distribution and suspended sediment discharge in open channels using entropy. Dissertação (Mestrado) — Texas A \& M University, 2011.

CUnGE, J. A.; HOLLY JR., F. M.; VERWEY, A. Pratical aspects of computational river hydraulics. London, UK: Pittman Publishing Ltd., 1980.

DECINA, T. G. T. Análise de medidas de controle de inundações a partir da avaliação de cenários de uso e ocupação do solo na bacia hidrográfica do Córrego do Gregório, São Carlos - SP. Dissertação (Mestrado em Engenharia Hidráulica e Saneamento) Universidade de São Paulo - Escoala de Engenharia de São Carlos, São Carlos, SP, 2012.

DJORDJEVIĆ, S. Matematicki model oticanja sa urbanih slivova interaktivnim tecenjem po povrsini i kroz mrezu podzemnih kolektora. Tese (doktorska) - Gradevinski fakultet Univerziteta u Beogradu, U Beogradu, 2002.

DJORDJEVIĆ, S.; PRODANOVIĆ, D.; WALTERS, G. A. Simulation of transcritical flow in pipe/channel networks. Journal of Hydraulic Engineering ASCE, n. 130, p. 1167-1178, 2004.

DOTTORI, F.; MARTINA, M. L. V.; TODINI, E. A dynamic rating curve approach to indirect discharge measurement. Hydrology and Earth System Sciences, v. 13, n. 6, p. 847-863, 2009. Disponível em: <http://www.hydrol-earth-syst-sci.net/13/847/2009/>.

FENTON, J. D. Calculating hydrographs from stage records. In: Proc. 28th IAHR Congress. Graz, Austria: [s.n.], 1999.

FREAD, D. L. NOAA Technical Memorandum NWS HYDRO-18: Numerical properties of implicit four-point finite difference equations of unsteady flow. Washington, DC, 1974.

FREAD, D. L. Computation of stage-discharge relationships affected by unsteady flow. Water Resources Bulletin, v. 11, n. 2, p. 213-228, 1975.

FREAD, D. L.; JIN, M.; LEWIS, J. M. An application of the lpi solution technique in the nws fldwav model. In: ASCE. North American Water and Environment Congress. 1996. Disponível em: <http://www.nws.noaa.gov/oh/hrl/hsmb/docs/hydraulics/papers before_2009/hl_342.pdf $>$. Acesso em: 19 dez. 2014.

FREITAG, M. Transcritical flow modelling with the Box Scheme. Dissertação (MSc in Modern Applications of Mathematics) - University of Bath - Department of Mathematical Sciences, Reino Unido, 2003.

FREITAG, M. A.; MORTON, K. W. The preissmann box scheme and its modification for transcritical flows. International Journal for Numerical Methods in Engineering, v. 70 , p. $791-811,2007$. 
FULTON, J.; OSTROWSKI, J. Measuring real-time streamflow using emerging technologies: Radar, hydroacoustics, and the probability concept. Journal of Hydrology, v. 357, p. 1-10, 2008.

HAVNO, K.; BRORSEN, M. Generalized mathematical modeling system for flood analysis and flood control design. In: BRITISH HYDRODYNAMICS RESEARCH ASSOC. International Conference on Hydraulics of Floods and Floods Control. Stevenage, UK, 1985.

HERSCHY, R. W. Streamflow Measurement. London, UK: E \& F N SPON, 1995.

JHONSON, T. C.; BAINES, M. J.; SWEBY, P. K. A box scheme for transcritical flow. International Journal for Numerical Methods in Engineering, v. 55, p. 895-912, 2002.

KRAUSE, P.; BOYLE, D. P.; BASE, F. Comparison of different efficiency criteria for hydrological model assessment. Advances in Geosciences, n. 5, p. 89-97, 2005.

KUTIJA, V. On the numerical modelling of supercritical flow. Journal of Hydraulic Research, v. 31, n. 6, p. 841-858, 1993.

KUTIJA, V.; HEWETT, C. J. Modelling of supercritical flow conditions revisited; newc scheme. Journal of Hydraulic Research, v. 40, n. 2, p. 145-152, 2002.

LABSIN. Laboratório de Simulação Numérica. Informações. 2015.

Disponível em: <http://www.shs.eesc.usp.br/informacao/laboratorios/

laboratorio-de-simulacao-numerica-labsin/> . Acesso em: 10 mai. 2015.

LOBO, G. de A. Medição de vazão em cheias de bacias urbanas e rurais com molinetes hidrométricos e flutuadores superficais. Tese (Doutorado em Engenharia) - Universidade de São Paulo - Escoala Politécnica, São Paulo, 2002.

LOPES, P. M. B. Modelo Numérico Misto: Superfície Livre / Pressão. Dissertação (obtenção de grau de Mestre em Engenharia Civil na Especialidade de Hidráulica, Recursos Hídricos e Ambiente) — Universidade de Coimbra, Coimbra, 2011.

MACDONALD, I. et al. Analytic benchmark solutions for open-channel flows. Journal of Hydraulic Engineering ASCE, v. 123, n. 11, p. 1041-1045, 1997.

MAROTTI, A. C. B. et al. Levantamento histórico e relatos de inundações do córrego do gregório na região central do município de são carlos - sp. Revista EIXO, v. 3, n. 1, p. 25-37, 2014.

MENDES, H. C.; MENDIONDO, E. M. Histórico da expansão urbana e incidência de inundaçcões: O caso da bacia do gregório, saão carlos - sp. RBRH - Revista Brasileira de Recursos Hídricos, v. 12, n. 1, p. 17-27, 2006.

MESELHE, E. A.; HOLLY JR., F. M. Invalidity of preissmann scheme for transcritical flow. Journal of Hydraulic Engineering, v. 123, n. 7, p. 652-655, July 1997.

MESELHE, E. A.; SOTIROPOUlOS, F.; HOLLY JR., F. M. Numerical simulation of transcritical flow in open channels. Journal of Hydraulic Engineering, v. 123, n. 9, p. 774-783, September 1997. 
MORIASI, D. N. et al. Model evaluation guidelines for systematic quantification of accuracy in watershed simulations. American Society of Agricultural and Biological Engineers, v. 50, n. 3, p. 885-900, 2007.

MORTON, K. W.; RUDGYARD, M. A.; SHAW, G. J. Upwind iteration methods for the cell vertex scheme in one dimension. Journal of Computational Physics, n. 114, p. 209-226, 1993.

MUELLER, D. S.; WAGNER, C. R. Techniques and methods 3-a22. In: U.S. GEOLOGICAL SURVEY. Virginia, USA: USGS, 2009. cap. Measuring Discharge with Acoustic Doppler Current Profilers from a Moving Boat. Disponível em: $<$ http://pubs.usgs.gov/tm/3a22/pdf/tm3a22_lowres.pdf $>$.

NASH, J. E.; SUTCLIFFE, I. V. River flow forecasting through conceptual models part i: A discussion of principles. Journal of Hydrology, n. 10, p. 282-290, 1970.

NATIONAL CENTER FOR COMPUTATIONAL HYDROSCIENCE AND ENGINEERING. CCHE2D User's Manual. [S.1.], 2005. Version 2.2.

NEGRÃO, A. C. et al. Adequacy proposals for hydrometric equipment setup to enable measurements of water stages and velocities in urban stream. In: 6th International Conference on Flood Management - ICFM. São Paulo, SP: [s.n.], 2014.

NIEMI, T. Development of a Hydraulic Model and its Application to a Small Urban Stream. Dissertação (MSc in Science) - Aalto University School of Science and Technology - Faculty of Engineering and Architeture, Espoo, 2010.

PERUMAL, M. et al. A methodology for discharge estimation and rating curve development at ungauged river sites. Water Resources Research, v. 43, n. W02412, p. $1-22,2007$.

PERUMAL, M.; RAJU, K. G. R. Variable-parameter stage-hydrograph routing method. i: Theory. ii: Evaluation. Journal of Hydrologic Engineering, v. 3, n. 2, p. 109-121, 1998.

PMSC. Prefeitura Municipal de São Carlos. Ministério das Cidades. Secretaria Nacional de Saneamento Ambiental. Programa de Drenagem Urbana Sustentável. 2007.

PORTO, R. de M. Hidráulica Básica. [S.l.]: EESC-USP, 2006.

POTSDAM INSTITUTE FOR CLIMATE IMPACT RESEARCH. SWIM - Soil and Water Integrated Model User Manual. [S.l.], 2000. Version 8.

SAIF, A.; HOSODA, T. Two-dimensional analysis of flow patterns around a single backward-facing step. International Journal of River Basin Management, v. 10, n. 2, p. 205-211, 2012.

SART, C. et al. Adaptation of preissmannś scheme for transcritical open channel flows. Journal of Hydraulic Research, n. 48 (4), p. 428-440, 2010.

SHAMAA, M. T.; KARKUR, H. M. Implicit numerical scheme for regulating unsteady flow in open channel. In: Fifteenth International Water Technology Conference IWTC-15. Alexandria, Egypt: [s.n.], 2011. 
SILVA, R. C. V. da; MASCARENHAS, F. C. B.; MIGUEZ, M. G. Hidráulica Fluvial. Rio de Janeiro: COPPE/UFRJ, 2003.

SOLINST. User Guide: Levelogger Series - Software Version 4. Canada, 2013.

SONTEK. Manual do Sistema RiverSurveyor S5/M9 - Versão de Software 1.0. San Diego, CA, 2009.

TUCCI, C. E. M. Modelos Hidrológicos. Porto Alegre, RS: UFRGS Editora, ABRH, 1998.

US ARMY CORPS OF ENGINEERS. HEC-RAS River Analysis System - User's Manual. [S.1.], 2010. Version 4.1. 

Apêndices 



\section{APÊNDICE A - Discretização espacial do trecho do córrego do Gregório}

Tabela 12 - Medidas obtidas a partir da topografia.

\begin{tabular}{ccc}
\hline \multicolumn{3}{c}{ Fundo Topográfico } \\
\hline & $\mathbf{x}$ & $\mathbf{z}$ \\
montante & 0,00 & 2,134 \\
& 2,62 & 2,163 \\
degrau 1 & 2,62 & 1,861 \\
& 34,73 & 1,831 \\
degrau 2 & 34,73 & 1,524 \\
& 66,89 & 1,446 \\
degrau 3 & 66,89 & 1,160 \\
intermediário & 96,07 & 1,117 \\
& 130,73 & 0,972 \\
degrau 4 & 130,73 & 0,681 \\
& 195,60 & 0,453 \\
degrau 5 & 195,60 & 0,162 \\
jusante & 244,97 & 0,000 \\
\hline
\end{tabular}

Tabela 13 - Discretização espacial utilizada na aproximação de fundo simples.

\begin{tabular}{|c|c|c|c|c|}
\hline \multicolumn{5}{|c|}{ Fundo Simples } \\
\hline \multirow{9}{*}{ mudança de declividade } & seção & $\mathrm{x}(\mathrm{m})$ & S0 & $\mathrm{z}(\mathrm{m})$ \\
\hline & 1 & 0 & 0,0110 & 2,0401 \\
\hline & 2 & 1 & 0,0110 & 2,0291 \\
\hline & 3 & 2 & 0,0110 & 2,0181 \\
\hline & $\ldots$ & $\ldots$ & $\ldots$ & $\ldots$ \\
\hline & 67 & 66 & 0,0110 & 1,3141 \\
\hline & 68 & 67 & 0,0110 & 1,3031 \\
\hline & 69 & 68 & 0,0073 & 1,2921 \\
\hline & 70 & 69 & 0,0073 & 1,2848 \\
\hline \multirow{5}{*}{ intermediário } & $\ldots$ & .. & $\ldots$ & $\ldots$ \\
\hline & 97 & 96 & 0,0073 & 1,0877 \\
\hline & $\cdots$ & $\ldots$ & & \\
\hline & 244 & 243 & 0,0073 & 0,0146 \\
\hline & 245 & 244 & 0,0073 & 0,0073 \\
\hline jusante & 246 & 245 & 0,0073 & 0,0000 \\
\hline
\end{tabular}


Tabela 14 - Discretização espacial utilizada na aproximação de fundo com degraus.

\begin{tabular}{|c|c|c|c|c|}
\hline \multicolumn{5}{|c|}{ Fundo com Degraus } \\
\hline \multirow{3}{*}{ montante } & seção & $\mathrm{x}(\mathrm{m})$ & S0 & $\mathrm{z}(\mathrm{m})$ \\
\hline & 1 & 0,0 & $-0,0097$ & 2,1270 \\
\hline & 2 & 1,0 & $-0,0097$ & 2,1367 \\
\hline \multirow{4}{*}{ degrau 1} & 3 & 2,0 & $-0,0097$ & 2,1464 \\
\hline & 4 & 3,0 & 3,0200 & 2,1561 \\
\hline & 5 & 3,1 & 0,0009 & 1,8541 \\
\hline & 6 & 4,0 & 0,0009 & 1,8533 \\
\hline \multirow{6}{*}{ degrau 2} & 37 & 350 & 700 & 254 \\
\hline & 38 & 35,1 & 0,0024 & 1,5184 \\
\hline & 39 & 36,0 & 0,0024 & 1,5162 \\
\hline & 40 & 37,0 & 0,0024 & 1,5138 \\
\hline & $\ldots$ & $\ldots$ & $\ldots$ & $\ldots$ \\
\hline & 69 & 66,0 & 0,0024 & 1,4442 \\
\hline \multirow{3}{*}{ degrau 3} & 70 & 67,0 & 2,8600 & 1,4418 \\
\hline & 71 & 67,1 & 0,0029 & 1,1558 \\
\hline & 72 & 68,0 & 0,0029 & 1,1532 \\
\hline \multirow[t]{3}{*}{ intermediário } & $\begin{array}{l}\ldots \\
100\end{array}$ & 96,0 & 0,0029 & 1,0720 \\
\hline & $\cdots$ & $\cdots$ & $\cdots$ & \\
\hline & 134 & 130,0 & 0,0029 & 0,9734 \\
\hline \multirow{3}{*}{ degrau 4} & 135 & 131,0 & 2,9100 & 0,9705 \\
\hline & 136 & 131,1 & 0,0035 & 0,6795 \\
\hline & 137 & 132,0 & 0,0035 & 0,6764 \\
\hline \multirow{7}{*}{ degrau 5} & $\ldots$ & $\ldots$ & $\ldots$ & $\ldots$ \\
\hline & 200 & 195,0 & 0,0035 & 0,4559 \\
\hline & 201 & 196,0 & 2,9100 & 0,4524 \\
\hline & 202 & 196,1 & 0,0033 & 0,1614 \\
\hline & 203 & 197,0 & 0,0033 & 0,1584 \\
\hline & $\ldots$ & & & \\
\hline & 250 & 244,0 & 0,0033 & 0,0033 \\
\hline jusante & 251 & 245,0 & 0,0033 & 0,0000 \\
\hline
\end{tabular}




\section{APÊNDICE B - Código do Modelo Hidrodinâmico 1D}





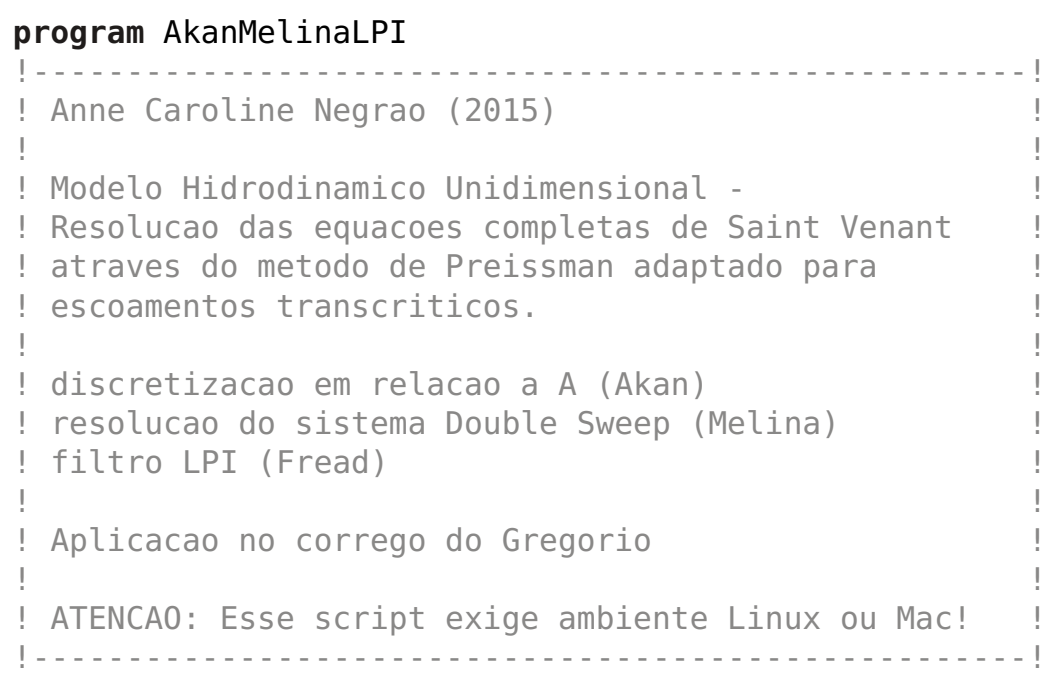

\section{implicit none}

integer: : $i, j, k, n, i t$

integer: : jj,nn,nit, infof, infop, jinter

integer: : problema, $m$, seg1, seg2

real: : g,long, $b, s, n M, d x, d t$, teta, tol, $Q \odot$

real: : AA, $P P$, inclinacao

real: : dAdt, dQdx, dQdt, dQ2Adx, Adhdx, ASf, rB, rBN

real, allocatable, dimension ( : , : ) : : h, y, A, dAdh, P, Q, Sf, dSfdQ, dSfdh, Fr, rC, rM

real, allocatable, dimension (: ) : : $x, S 0, z, d Q, d h$, rterm, norma, yup, yinter, ydown

real, allocatable: : $\operatorname{residuos}(:), \operatorname{Frmax}(:), \operatorname{Frmin}(:), \operatorname{vmax}(:), \operatorname{vmin}(:)$

real: : dPdh, dBdQ1, dBdh1,dBdQN, dBdhN, ENS

real, allocatable, dimension $(:,:):$ : W

real, allocatable, dimension ( : : : : : : dCdQ, dCdh, dMdQ, dMdh

logical: : more

character*200: : arq,arq_evento,dummy,temp,CI,fundo,processo,dir

character*10: : evento

character*10, allocatable, dimension (: ) : : amd,hms

10 format (i3, $4 f 8.2,2 f 8.1, f 8.2, f 8.1,3 f 14.7, f 9.3)$

11 format (f6.1,3f10.4)

write(*,*) "Leitura dos dados"

open $(1$, file="info_canal.txt", action="read" )

read $(1, *) g \quad$ ! aceleracao da gravidade

read $(1, *)$ long ! comprimento do canal

read $(1, *) b$ ! largura do fundo do canal

read $(1, *)$ s ! inclinacao daparede lateral

read $(1, *)$ nM ! rugosidade de Manning

read $(1, *)$ teta ! coef. temporal

read $(1, *)$ nit ! numero maximo de iteracoes

read $(1, *)$ tol ! tolerancia

read $(1, *)$ infof ! aproximacao para (1) fundo simples ou (2) fundo com degraus

read $(1, *)$ infop ! processo de (1) aquecimento ou (2) simulacao

$\operatorname{read}(1, *) \mathrm{m} \quad$ ! termo $m$ do filtro LPI

close (1)

! verificando a aproximacao de fundo

if ( infof $==1$ ) then

fundo = "fundo simples"

else if (infof $==2$ ) then

else

fundo = "fundo_degraus"

write $(*, *)$ "Codigo de aproximacao de fundo errado,"

write $(*, *)$ "verificar info_canal.txt ..." 
end if

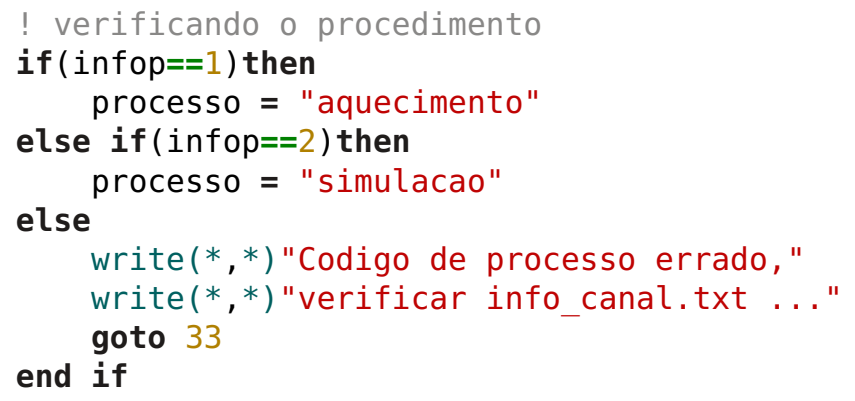

do

if ( processo=="aquecimento") then

read $\left(13,{ }^{\prime}(a)\right.$ ' , end $=97$ ) arq_evento

read (arq_evento, '( $17 x$, a10) ') evento 
else if (processo=="simulacao") then

end if

$\operatorname{read}\left(13,{ }^{\prime}(a, x, a)\right.$ ' , end=97) evento, arq_evento

write $(*, *)$ arq_evento

write(dir, ' (5a) ')"./", trim(fundo), "/", evento, "/"

!write $(*, *)$ dir

if $($ processo==" aquecimento" ) then

! criando diretorios:

write (arq, ' (2a) ') "mkdir ", trim (dir)

end if

call system(arq)

! tamanho do evento:

40 open $(1$, file=arq_evento, action="read" $)$

$\mathrm{nn}=0$

do

$\operatorname{read}(1, *$, end $=91)$

$\mathrm{nn}=\mathrm{nn}+1$

end do

91 rewind (1)

$\mathrm{nn}=\mathrm{nn}-1$

write $(*, *) " n n=", n n$

! read $(*, *)$

allocate $(h(\theta: n n, j j), y(\theta: n n, j j), A(\theta: n n, j j), P(\theta: n n, j j), Q(\theta: n n, j j), y u p(\theta: n n), y i n t e r(\theta: n n), y d$ own $(0: \mathrm{nn}))$

allocate $(S f(\theta: n n, j j), d S f d Q(\theta: n n, j j), d S f d h(\theta: n n, j j), d A d h(\theta: n n, j j), r C(j j, n i t), r M(j j, n i t), F r($ $0: \mathrm{nn}, \mathrm{j} j))$

allocate (residuos $(2 * j j), W(j j, 2), d Q(j j), \operatorname{dh}(j j), \operatorname{rterm}(j j), \operatorname{norma}(j j))$

allocate $(\mathrm{dCdQ}(j j, j j), \mathrm{dCdh}(j j, j j), \mathrm{dMdQ}(j j, j j), \mathrm{dMdh}(j j, j j))$

allocate (amd $(0: \mathrm{nn})$, hms $(0: \mathrm{nn}))$

! zerando as matrizes:

$\mathrm{h}=0 . ; \mathrm{y}=0 . ; \mathrm{A}=0 . ; \mathrm{P}=0 . ; \mathrm{Q}=0$.

$\mathrm{Sf}=0 . ; \mathrm{dSfdQ}=0 . ; \mathrm{dSfdh}=0$.

$\mathrm{dCdQ}=0 . ; \quad \mathrm{dCdh}=0 . ; \quad \mathrm{dMdQ}=0 . ; \mathrm{dMdh}=0$.

write $(*, *)$ "Lendo o arquivo do evento..."

do $\mathrm{n}=0, \mathrm{nn}$

end do

$\operatorname{read}(1, *) \operatorname{amd}(n), \operatorname{hms}(n), y u p(n), y i n t e r(n), y d o w n(n)$

close (1)

! obtendo $\mathrm{dt}$

$\operatorname{read}(\operatorname{hms}(0),)^{\prime}(6 x, i 2)$ ') seg1

read $(h m s(1), '(6 x, i 2) ')$ seg 2

$\mathrm{dt}=\operatorname{real}(\operatorname{abs}(\operatorname{seg} 1-\mathrm{seg} 2))$

write $(*, *) " d t=", d t$

if ( processo=="aquecimento") then

! calculo da vazao inicial como sendo a normal de montante

$A A=(b+y u p(\theta) * s) * y u p(0)$

$\mathrm{PP}=\mathrm{b}+2 . * \operatorname{yup}(\theta) * \operatorname{sqrt}(1 .+\mathrm{s} * * 2)$

$Q 0=A A^{*}(A A / P P) * *(2 . / 3). * \operatorname{sqrt}(S O(5)) / n M$

write(arq, ' (5a) ')"./",trim(fundo), "/", evento, "/h_y_obs.txt"

open $(1$, file $=$ arq, action="write" $)$

write $(1,10)$ int $(x(1)), z(1)+y u p(0), y u p(0)$

write $(1,10)$ int $(x(j$ inter $)), z(j$ inter $)+y i n t e r(0), y i n t e r(0)$

write $(1,10) \operatorname{int}(x(j j)), z(j j)+y d o w n(0), y d o w n(0)$

close (1) 
write $(*, 10) j, Q(n, j), z(j), y(n, j), h(n, j), A(n, j), d \operatorname{Adh}(n, j), P(n, j), d P d h, S f(n, j), d S f d Q(n, j), d S f d h($

$n, j), \operatorname{Fr}(n, j)$ end do

! Estimativa para o proximo instante (igualando ao instante atual)

$Q(n+1,:)=Q(n,:)$

$h(n+1,:)=h(n,:)$

call

canal_trapezoidal $(g, j j, z, h(n+1,:), b, s, Q(n+1,:), n M, A(n+1,:), \operatorname{dAdh}(n+1,:), P(n+1,:), \boldsymbol{\&}$ $\& d \operatorname{Pdh}, \operatorname{Sf}(n+1,:), d \operatorname{SfdQ}(n+1,:), d \operatorname{Sfdh}(n+1,:), \operatorname{Fr}(n+1,:))$

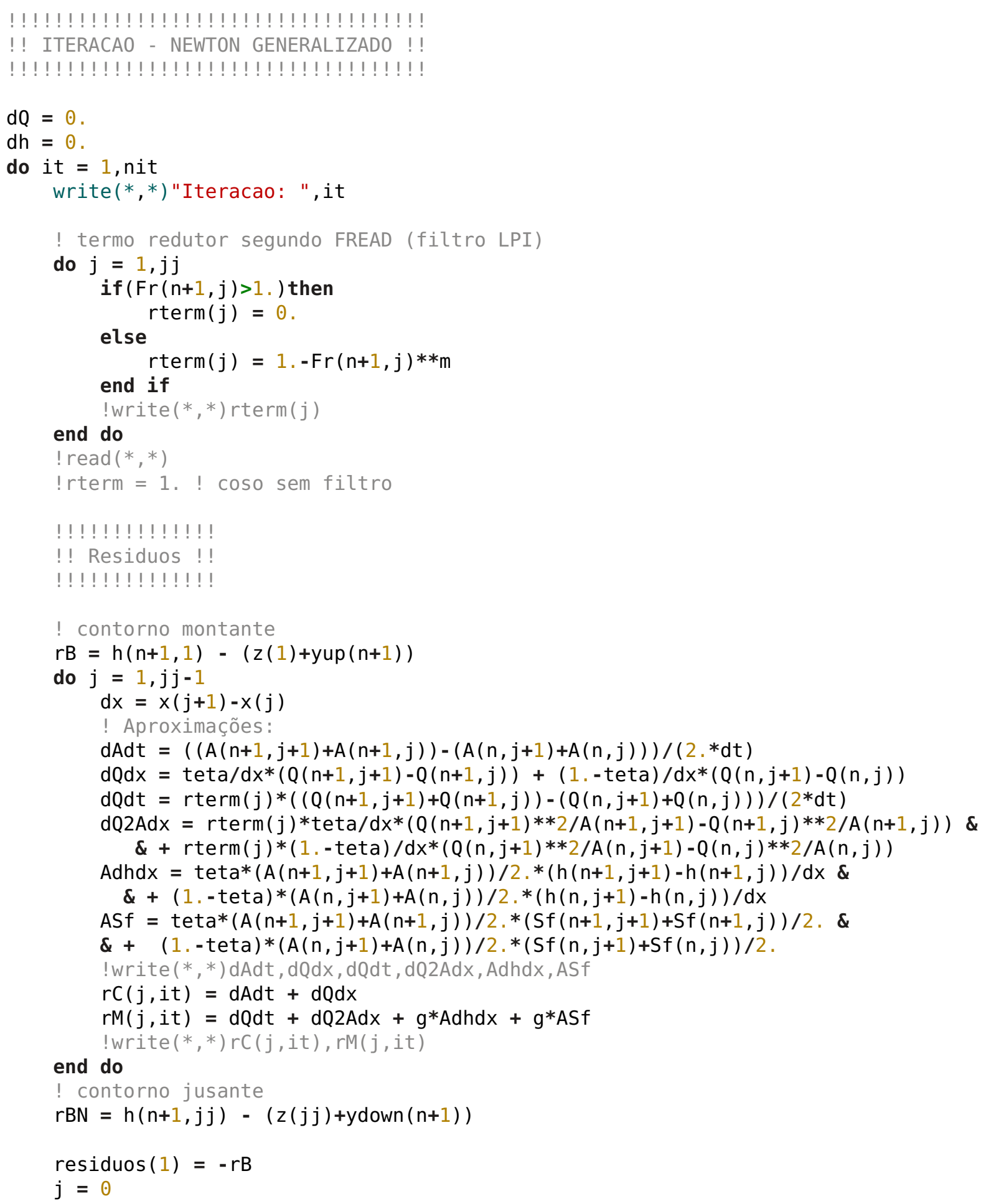


do $k=2,2 * j j-1$

if $(\bmod (k, 2)==0)$ then ! par

$\mathrm{j}=\mathrm{j}+1$

residuos $(k)=-r C(j, i t)$

else

$\operatorname{residuos}(k)=-r M(j, i t)$

end if

end do

$\operatorname{residuos}(2 * j j)=-r B N$
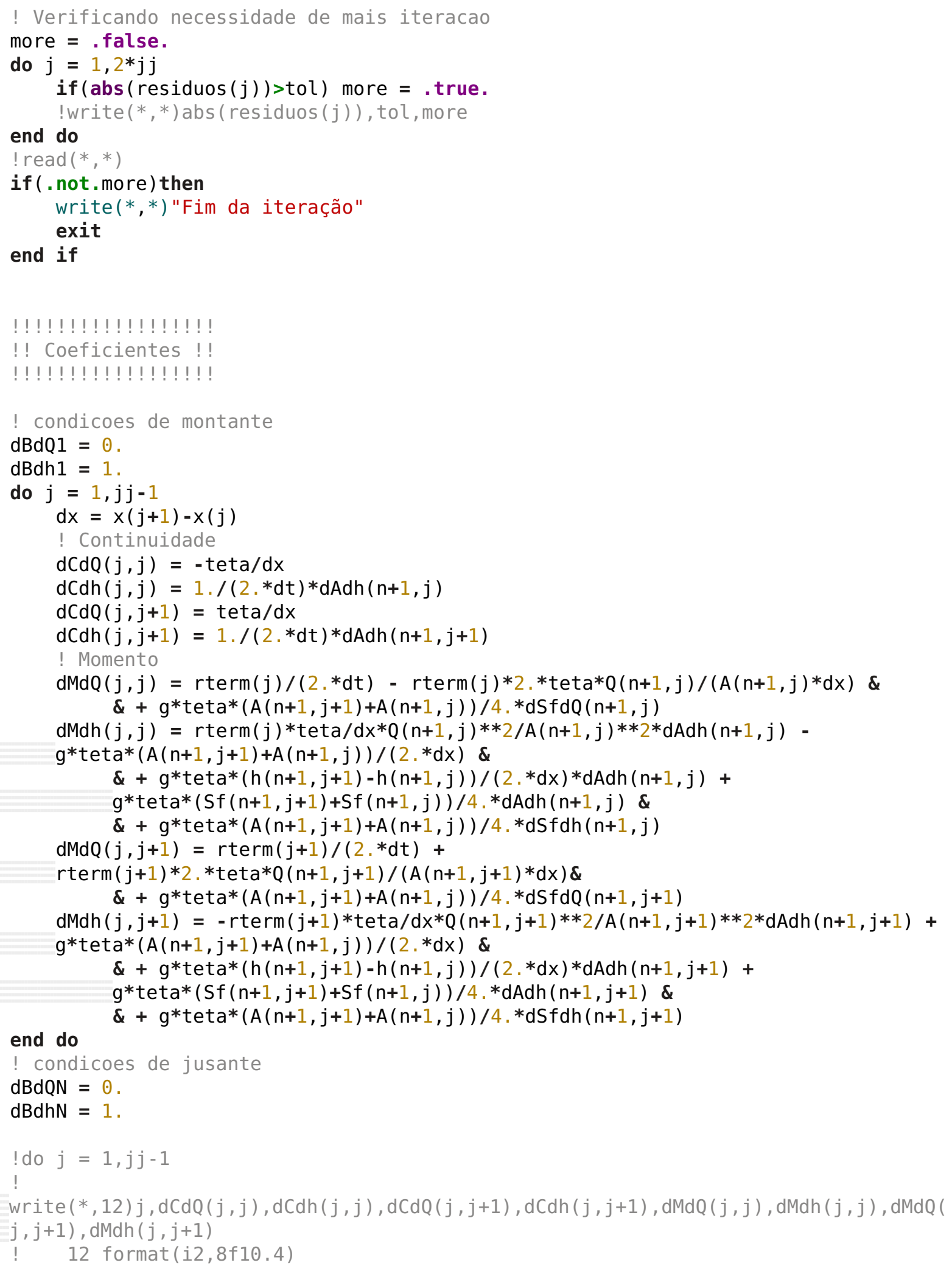
!end do

$! \operatorname{read}(*, *)$

!!!!!!!!!!!!!!!!!!!!

!! DOUBLE SWEEP !!

!!!!!!!!!!!!!!!!!!!

call double_sweep $(j \mathrm{j}, \mathrm{dBdQ1}, \mathrm{dBdh} 1, \mathrm{dBdQN}, \mathrm{dBdhN}, \mathrm{dCdQ}, \mathrm{dCdh}, \mathrm{dMdQ}, \mathrm{dMdh}$, residuos,$W$ )

do $j=1, j j$

$d Q(j)=W(j, 1)$

$\operatorname{dh}(j)=W(j, 2)$

end do

!write $(*, *) d Q(j), d h(j)$

! Atualizando valores

$Q(n+1,:)=Q(n+1,:)+d Q$

$h(n+1,:)=h(n+1,:)+d h$

!write(*, ' (10f8.4) ') Q ( $n+1$, : )

! write (*, ' (10f8.4) ') h $(n+1,:)$

$! \operatorname{read}(*, *)$

call

canal_trapezoidal $(g, j j, z, h(n+1,:), b, s, Q(n+1,:), n M, A(n+1,:), d A d h(n+1,:), P(n+1,:), \&$ $\& d \operatorname{Pdh}, \operatorname{Sf}(n+1,:), \operatorname{dSfdQ}(n+1,:), \operatorname{dSfdh}(n+1,:), \operatorname{Fr}(n+1,:))$

end do

if $($ processo=="aquecimento" ) then

! Controle de erro:

do $j=1, j j$

if $(i \operatorname{sinan}(h(n, j)))$ then

write(*,'(2a)')"Não foi possivel realizar o aquecimento do evento

$", \operatorname{trim}($ evento)

write $(*, *) "$ Os níveis iniciais são muito baixos.

write $(*, *)$ " 0 evento será cortado e o processo reniciado..."

write(arq,'(3a)')"sed -e 'ld' ",trim(arq_evento)," > temp"

call system(arq)

write(arq_evento, '(5a) ')"./",trim(fundo), "/eventos_cut/evento_",trim(even to),"_cut.txt"

write $(*, *)$ arq_evento

write (arq,'(2a) ') "mv temp ",trim(arq_evento)

call system(arq)

deallocate ( $h, y, A, P, Q$, yup, yinter, ydown, Sf, dSfdQ, dSfdh, dAdh, rC, rM, Fr)

deallocate ( residuos, W, dQ , dh, rterm, norma, dCdQ, dCdh, dMdQ , dMdh, amd , hms ) goto 40

end if

end do

end if

END DO

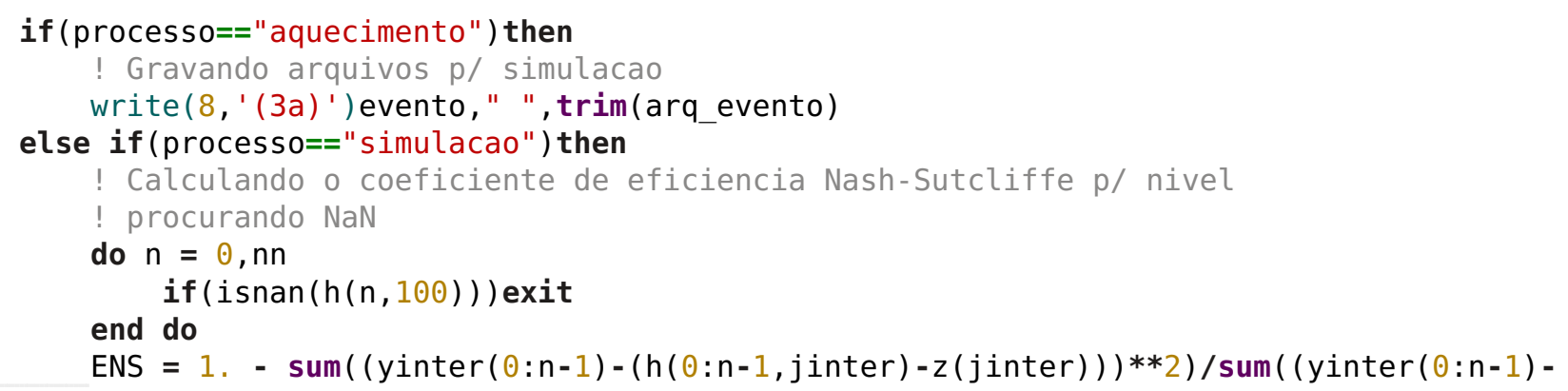


$\operatorname{sum}(\operatorname{yinter}(0: \mathrm{n}-1)) / \operatorname{real}(\mathrm{n})) * * 2)$

end if

write $(8$, ' (a10,f10.4) ') evento, ENS

! Impressao dos Resultados

if $($ processo=="aquecimento" ) then

write (arq, ' (2a)')trim(dir), "CI_aquecido.txt"

write $(*, *)$ arq

open $(1$, file=arq, action="write" $)$

write $(1, *) " Q \theta=", Q(n n, j j)$

do $j=1, j j$

end do $\operatorname{write}(1,11) \times(j), s \theta(j), z(j), h(n n, j)$

close (1)

write (arq, ' (2a) ') "cp linha.gnu ",trim(dir)

call system(arq)

else if (processo=="simulacao") then

write(arq, ' (2a) ')trim(dir), "res_xh.txt"

open $(1$, file $=a r q$, action="write" $)$

write(arq, ' (2a)')trim(dir), "res_xQ.txt"

open $(2$, file $=$ arq, action="write" $)$

write(arq, ' (2a) ') trim(dir), "res_xy.txt"

open $(3$, file $=a r q$, action="write" )

write(arq, ' (2a)')trim(dir), "res_xFr.txt"

open $(4$, file=arq, action="write" )

write(arq, ' (2a) ') trim(dir), "res_xv.txt"

open $(55$, file $=a r q$, action $=$ "write" $)$

do $j=1, j j$

$\operatorname{write}(1, *) x(j), z(j),(h(n, j), n=0, n n)$

write $(2, *) \times(j),(Q(n, j), n=0, n n)$

write $(3, *) x(j),(h(n, j)-z(j), n=0, n n)$

write $(4, *) \times(j),(\operatorname{Fr}(n, j), n=0, n n)$

write $(55, *) \times(j),(Q(n, j) / A(n, j), n=0, n n)$

end do

close(1); close(3); close(2); close(4) ; close(55)

write (arq, ' (2a) ')trim(dir), "res_tQ.txt"

open $(2$, file=arq, action="write" $)$

write(arq, ' (2a)')trim(dir), "res_ty.txt"

open $(3$, file $=a r q$, action="write" )

write(arq, '(2a)')trim(dir), "res_tfr.txt"

open $(4$, file=arq, action="write" )

write(arq, ' (2a)') trim(dir), "res_tv.txt"

open $(55$, file $=a r q$, action $=$ "write" $)$

do $\mathrm{n}=0, \mathrm{nn}$

write $(2, *)$ amd $(n), " \quad ", h m s(n),(Q(n, j), j=1, j j)$

write $(3, *)$ amd $(n), " n ", h m s(n),(h(n, j)-z(j), j=1, j j)$

write $(4, *)$ amd $(n), " \quad ", \operatorname{hms}(n),(\operatorname{Fr}(n, j), j=1, j j)$

end do

$\operatorname{write}(55, *)$ amd $(n), "$ ", hms $(n),(Q(n, j) / A(n, j), j=1, j j)$

close(2); close(3); close(4) ; close(55)

write (arq, ' (2a) ') trim (dir), "curva-chave.txt"

open $(1$, file=arq, action="write" )

do $\mathrm{n}=0, \mathrm{nn}$

write $(1, *) h(n, 1)-z(1), Q(n, 1), h(n, j$ inter $)-z(j$ inter $), Q(n, j$ inter $), h(n, j j)-$

end do $z(j j), Q(n, j j)$

close (1)

! procurando o valor maximo e minimo de Froude e velocidade para cada secao

Frmax $=-100000 . ;$ Frmin $=100000$.

$\operatorname{vmax}=-100000 . ; \operatorname{vmin}=100000$. 
do $\mathrm{n}=0, \mathrm{nn}$

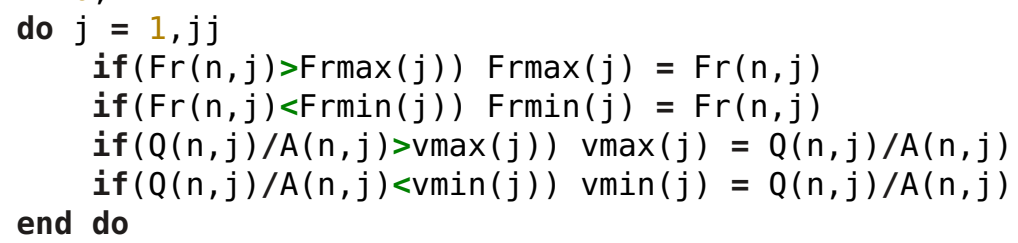

deallocate ( $h, y, A, P, Q, y u p$, yinter, ydown, $S f, d S f d Q, d S f d h, d A d h, r C, r M, F r)$

deallocate ( residuos , W, dQ , dh , rterm, norma, dCdQ , dCdh , dMdQ , dMdh , amd , hms )

end do

97 close(13)

close (8)

write $(*, *)$ "Fim!!! =D"

33 continue

end program

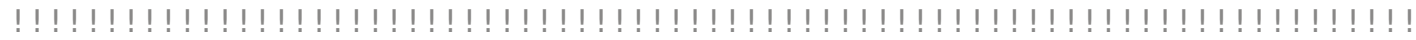

subroutine double_sweep $(\mathrm{n}, \mathrm{dBdQ} 1, \mathrm{dBdh} 1, \mathrm{dBdQN}, \mathrm{dBdhN}, \mathrm{dCdQ}, \mathrm{dCdh}, \mathrm{dMdQ}, \mathrm{dMdh}, \mathrm{res}, \mathrm{W})$

! Anne

! resolucao do sistema pelo metodo da dupla varredura

implicit none

integer: : $n, j, k$

real: : $\operatorname{res}(2 * n)$

real: : dBdQ1, dBdh1, dBdQN, dBdhN

real, dimension $(n, n)::$ dCdQ, dCdh, dMdQ, dMdh

real, dimension $(n, 2):$ : $Z, F, W$

real, dimension $(n, 2,2):: D, C, A, E$

real: : $\operatorname{MM}(2,2), \operatorname{iMM}(2,2), \operatorname{iD}(2,2)$

do $\mathrm{j}=1, \mathrm{n}$

do $k=1,2$

end do

$Z(j, k)=\operatorname{res}(2 * j-2+k)$

end do

do $j=1, n$

if $(j==1)$ then

$$
\begin{aligned}
& \mathrm{D}(j, 1,1)=\operatorname{dBdQ1} \\
& \mathrm{D}(j, 1,2)=\operatorname{dBdh} 1 \\
& \mathrm{D}(j, 2,1)=\operatorname{dCdQ}(j, j) \\
& \mathrm{D}(j, 2,2)=\operatorname{dCdh}(j, j)
\end{aligned}
$$

else if $(j==n)$ then

$D(j, 1,1)=\operatorname{dMdQ}(j-1, j)$

$D(j, 1,2)=\operatorname{dMdh}(j-1, j)$

$D(j, 2,1)=d B d Q N$

$D(j, 2,2)=d B d h N$

else 
end if

$D(j, 1,1)=\operatorname{dMdQ}(j-1, j)$

$D(j, 1,2)=\operatorname{dMdh}(j-1, j)$

$D(j, 2,1)=\operatorname{dCdQ}(j, j)$

$D(j, 2,2)=\operatorname{dCdh}(j, j)$

if $(j==1)$ then

else

$A(j,:,:)=0$.

$A(j, 1,1)=\operatorname{dMdQ}(j-1, j-1)$

$A(j, 1,2)=\operatorname{dMdh}(j-1, j-1)$

$A(j, 2,1)=0$.

end if

$A(j, 2,2)=0$.

if $(j==n)$ then

else

$C(j,:,:)=0$.

$C(j, 1,1)=0$.

$C(j, 1,2)=0$.

$C(j, 2,1)=\operatorname{dCdQ}(j, j+1)$

end if

$C(j, 2,2)=\operatorname{dCdh}(j, j+1)$

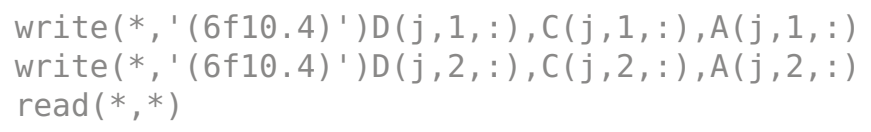

! ! ! ! ! ! ! ! ! ! ! ! ! ! ! ! ! ! ! ! ! ! ! ! ! ! ! ! ! ! ! ! ! ! ! ! ! ! ! ! ! ! ! ! ! ! ! ! ! ! ! ! ! ! ! ! ! ! ! ! 
! ! ! ! ! ! ! ! ! ! ! ! ! ! ! ! ! ! ! ! ! ! ! ! ! ! ! ! ! ! ! ! ! ! ! ! ! ! ! ! ! ! ! ! ! ! ! ! ! ! ! ! ! ! ! ! ! ! ! ! !

subroutine matriz_inversa_adj_2x2(A,B)

! Anne 05/01/2015

! Inversão de matriz atraves da matriz adjunta

! considerando APENAS matrizes $2 \times 2$

! entrada: $A=$ matriz $2 \times 2$ que se deseja obter a inversa

! saída: $B$ = matriz invertida

implicit none

integer: : $i, j$

real: : det

real, dimension $(2,2):$ : A, B, Acof , Adj

$\operatorname{Acof}(1,1)=(-1) * *,(1+1) * A(2,2)$

$\operatorname{Acof}(1,2)=(-1) * *,(1+2) * A(2,1)$

$\operatorname{Acof}(2,1)=(-1) * *,(2+1) * A(1,2)$

$\operatorname{Acof}(2,2)=(-1) * *.(2+2) * A(1,1)$

$\operatorname{Adj}=$ Acof

do $i=1,2$

do $j=1,2$

if $(i /=j)$ then

end if

$\operatorname{Adj}(i, j)=\operatorname{Acof}(j, i)$

end do

end do

$\operatorname{det}=\operatorname{Adj}(1,1) * \operatorname{Adj}(2,2)-\operatorname{Adj}(1,2) * \operatorname{Adj}(2,1)$

$B=A d j /$ det

return

end subroutine

! ! ! ! ! ! ! ! ! ! ! ! ! ! ! ! ! ! ! ! ! ! ! ! ! ! ! ! ! ! ! ! ! ! ! ! ! ! ! ! ! ! ! ! ! ! ! ! ! ! ! ! ! ! ! ! ! ! ! ! ! ! ! ! ! !

!! ! ! ! ! ! ! ! ! ! ! ! ! ! ! ! ! ! ! ! ! ! ! ! ! ! ! ! ! ! ! ! ! ! ! ! ! ! ! ! ! ! ! ! ! ! ! ! ! ! ! ! ! ! ! ! ! ! ! ! ! ! !

subroutine canal_trapezoidal $(g, n, z, h, b, s, Q, n M, A, d A d h, P, d P d h, S f, d S f d Q, d S f d h, F r)$

! Anne

! calculo das propriedades do canal trapezoidal

! $\mathrm{s}=$ declividade da parede do canal

implicit none

integer, intent(in): : $\mathrm{n}$

integer: : i

real, intent(in):: $\mathrm{g}, \mathrm{b}, \mathrm{s}, \mathrm{nM}$

real: : ka

real, intent (out) : : dPdh

real, dimension( $(n)$, intent (in): : $z, h, Q$

real, dimension( $n$ ), intent (out) : : A,P, Sf, dSfdQ, dSfdh, dAdh, Fr

real,dimension(n): : y

if $(g>10$.$) then$

ka $=1.49$ ! unidades britanicas

$\mathrm{ka}=1 . \quad$ ! SI

end if

$y=h-z$

$A=(b+y * s) * y$

$\mathrm{dAdh}=\mathrm{b}+2 . * \mathrm{~s} *(\mathrm{~h}-\mathrm{z})$ 
$\mathrm{P}=\mathrm{b}+2 . * \mathrm{y} * \operatorname{sqrt}(1,+\mathrm{s} * * 2)$

$\mathrm{dPdh}=2 . * \operatorname{sqrt}(1 .+\mathrm{s} * * 2)$

$\mathrm{Sf}=(\mathrm{nM} * * 2 * \mathrm{P} * *(4 . / 3). * \mathrm{Q} * \mathrm{abs}(\mathrm{Q})) /(\mathrm{ka} * * 2 * A * *(10 . / 3)$.

$\mathrm{dSfdQ}=(2 * n \mathrm{nM} * 2 * \mathrm{p} * *(4 . / 3) * a b s.(\mathrm{Q})) /(\mathrm{ka} * * 2 * A * *(10 . / 3)$.

$\mathrm{dSfdh}=(\mathrm{nM} * * 2 * \mathrm{Q} *$ abs $(\mathrm{Q}) /(\mathrm{ka} * * 2 * A * *(20, / 3))) *$,

\& $(4, / 3, * \mathrm{P} * *(1, / 3). * \mathrm{dPdh} * A * *(10, / 3)-10,, / 3, * A * *(7, / 3), * \mathrm{dAdh} * \mathrm{P} * *(4, / 3)$,

$\mathrm{Fr}=\mathrm{Q} / \mathrm{A} / \mathrm{sqrt}(\mathrm{g} * \mathrm{~A} / \mathrm{dAdh})$

return

end subroutine

! ! ! ! ! ! ! ! ! ! ! ! ! ! ! ! ! ! ! ! ! ! ! ! ! ! ! ! ! ! ! ! ! ! ! ! ! ! ! ! ! ! ! ! ! ! ! ! ! ! ! ! ! ! ! ! ! ! ! ! ! ! ! 


\section{APÊNDICE C - Limnigramas obtidos com a instalação em tubos}
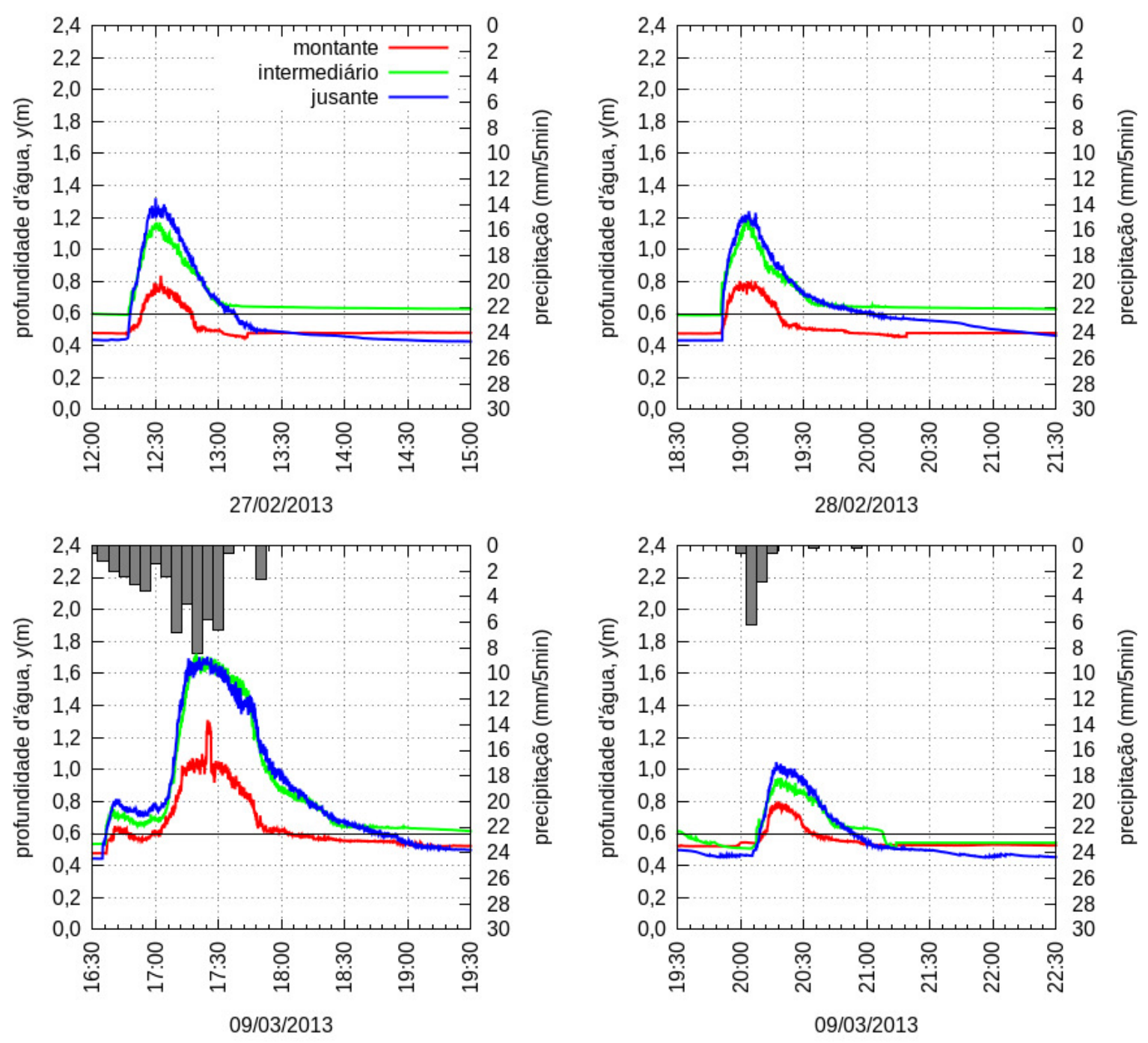

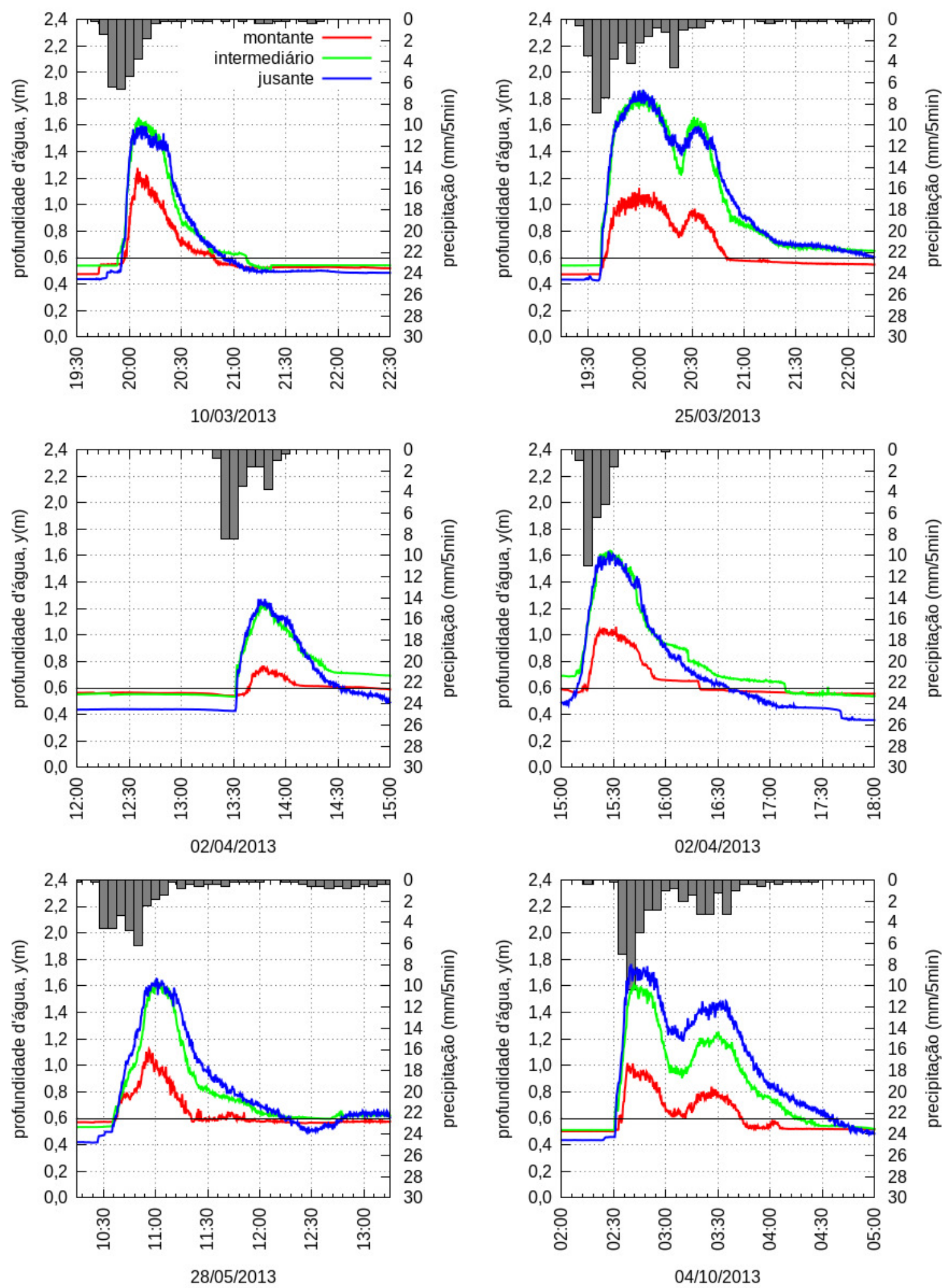

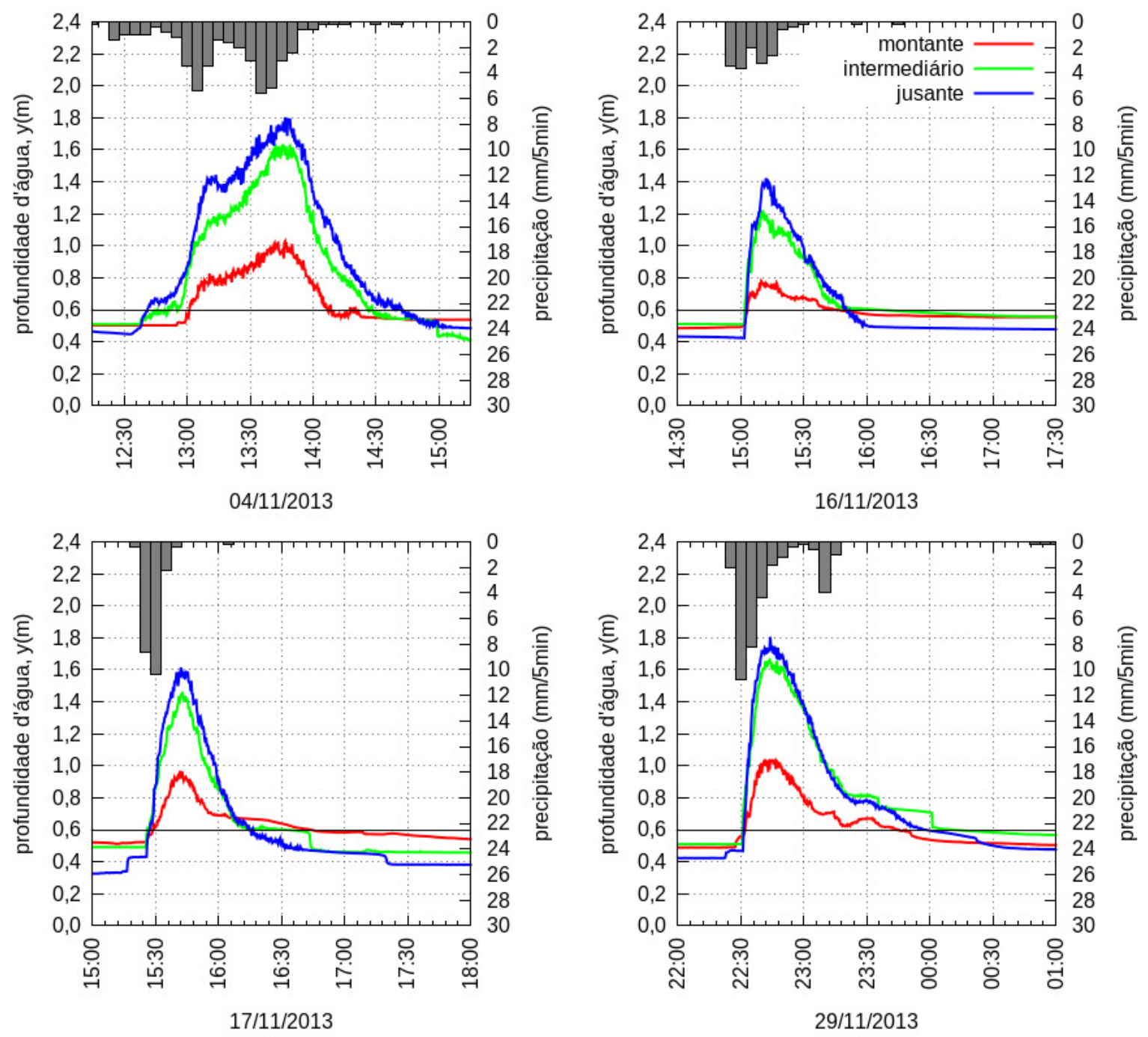



\section{APÊNDICE D - Limnigramas obtidos com a instalação em suportes de fundo}
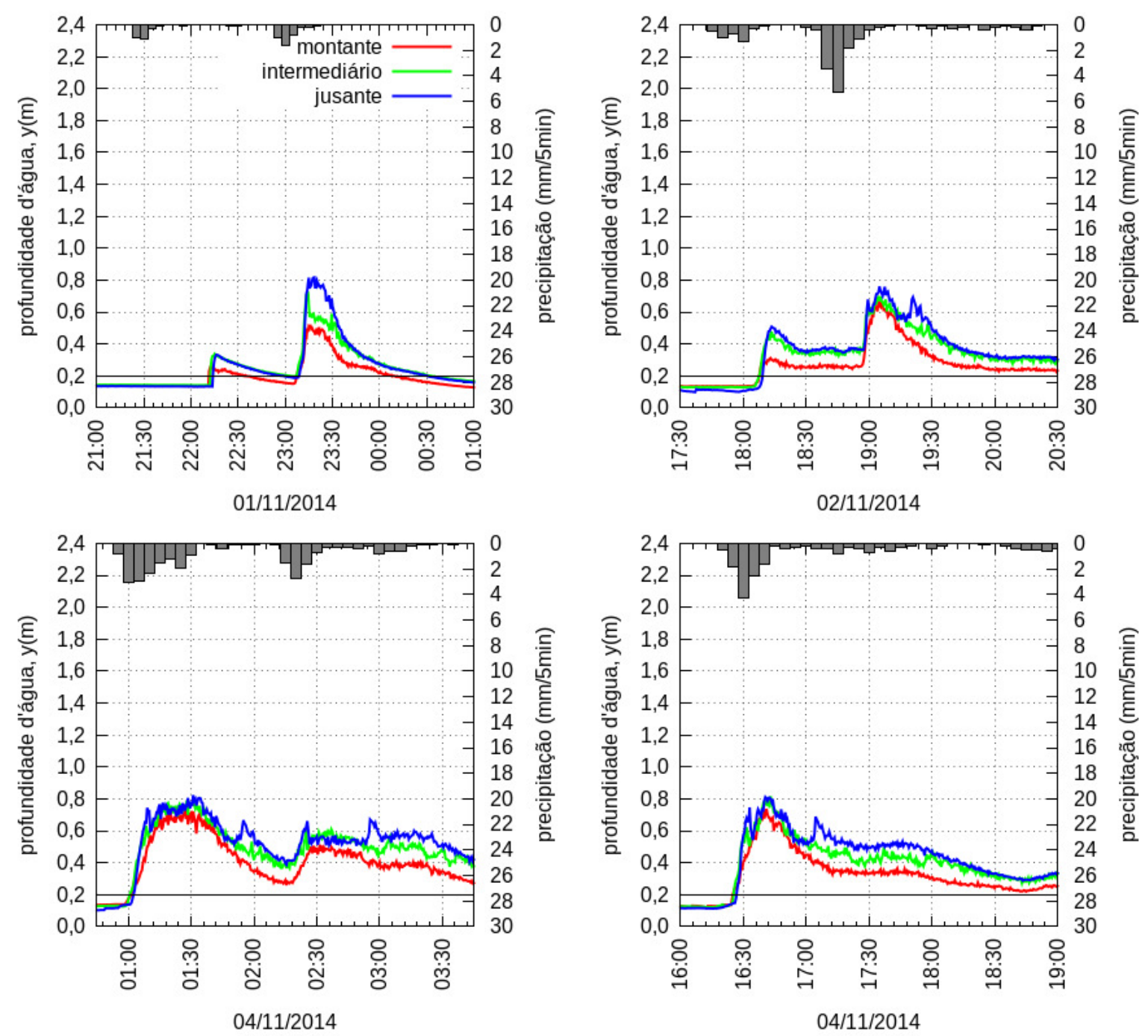

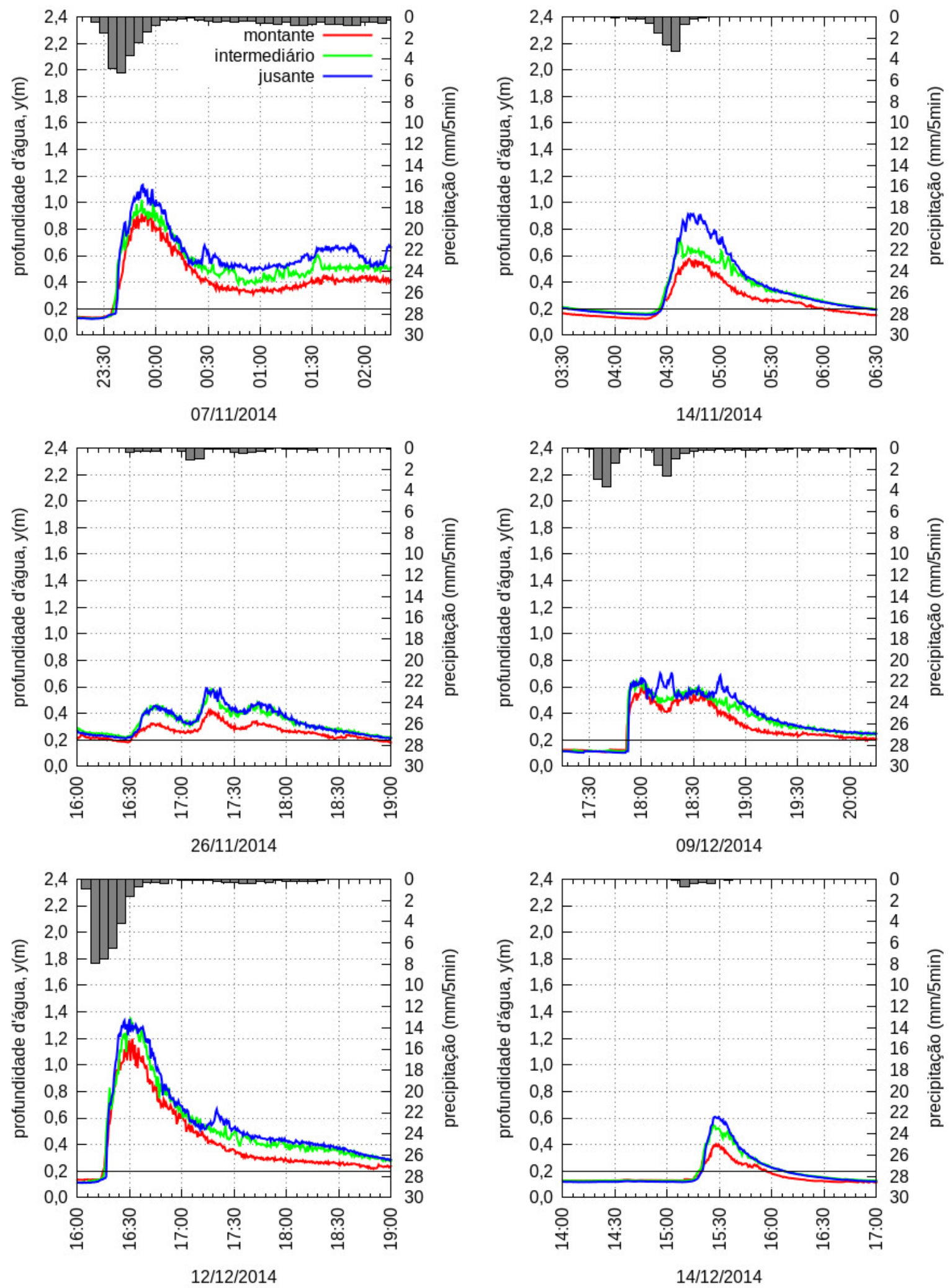

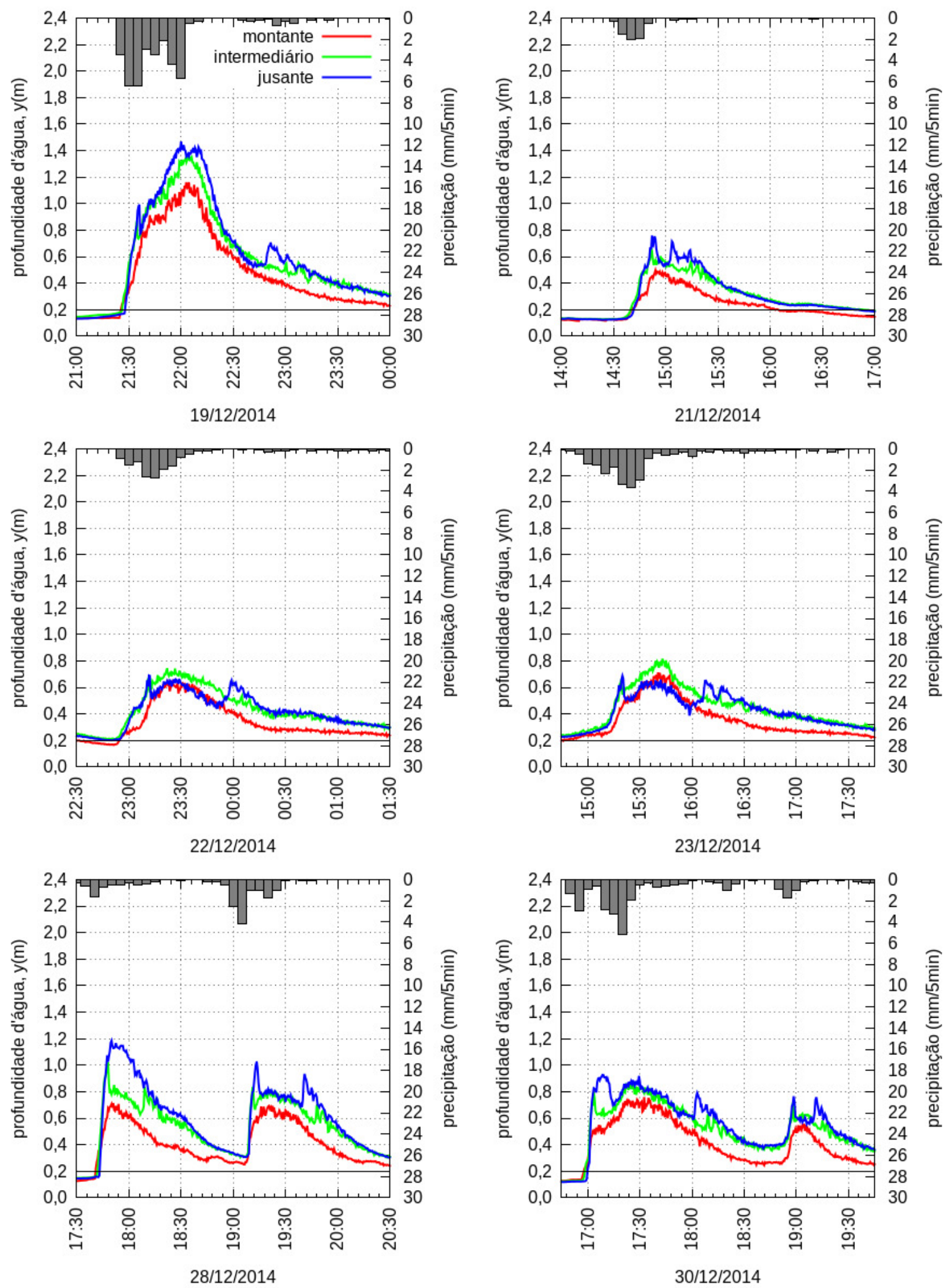

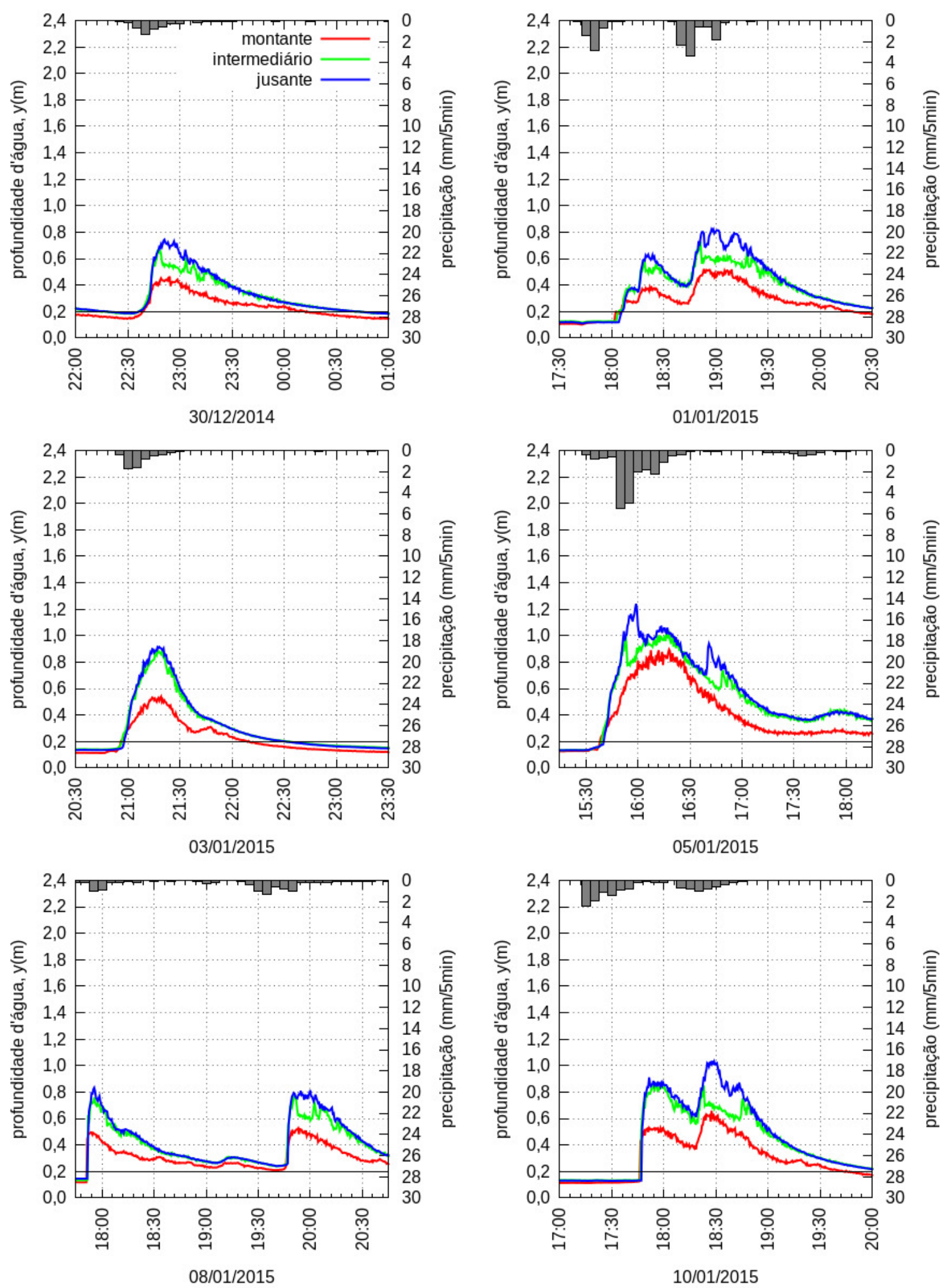

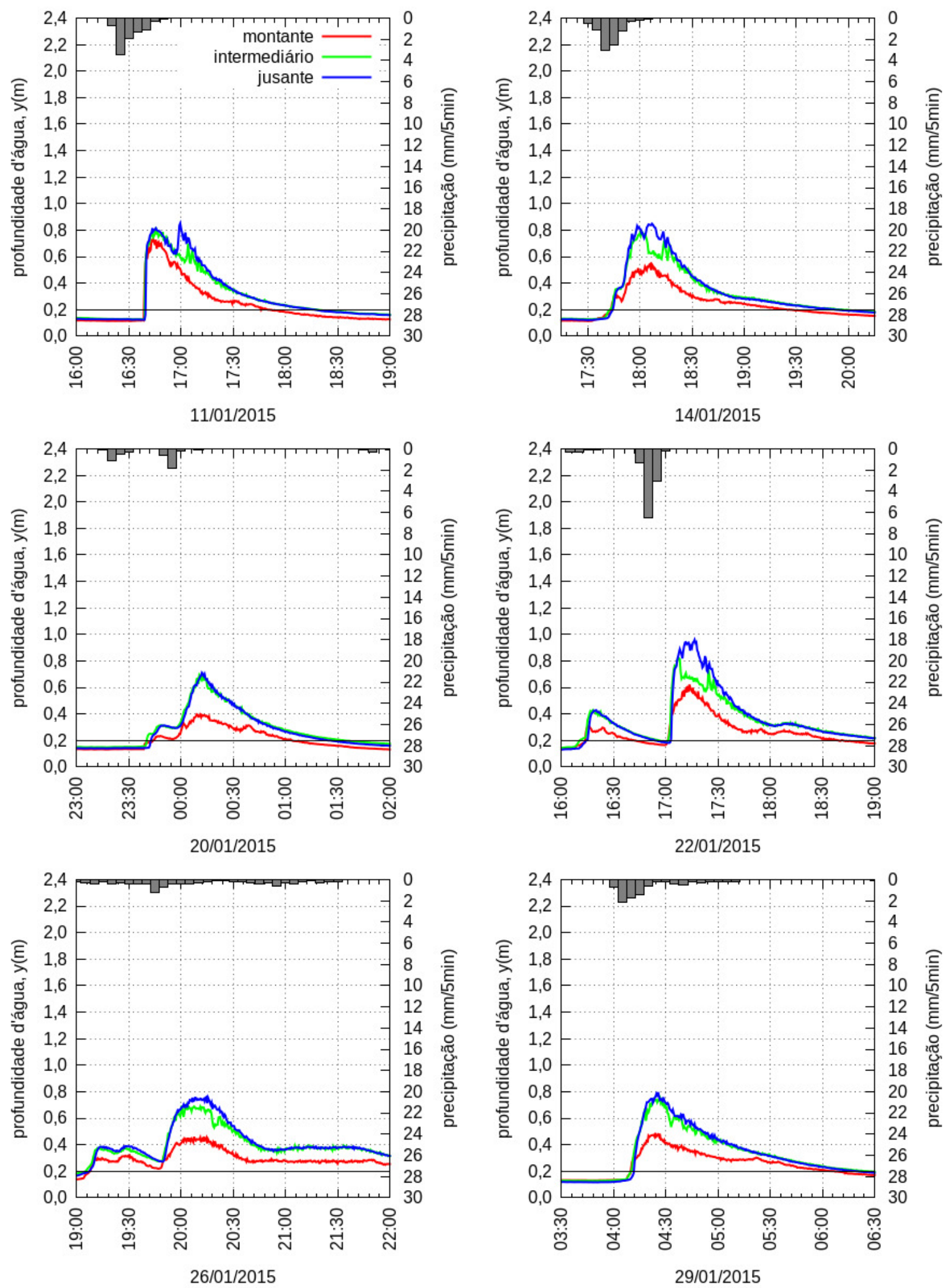

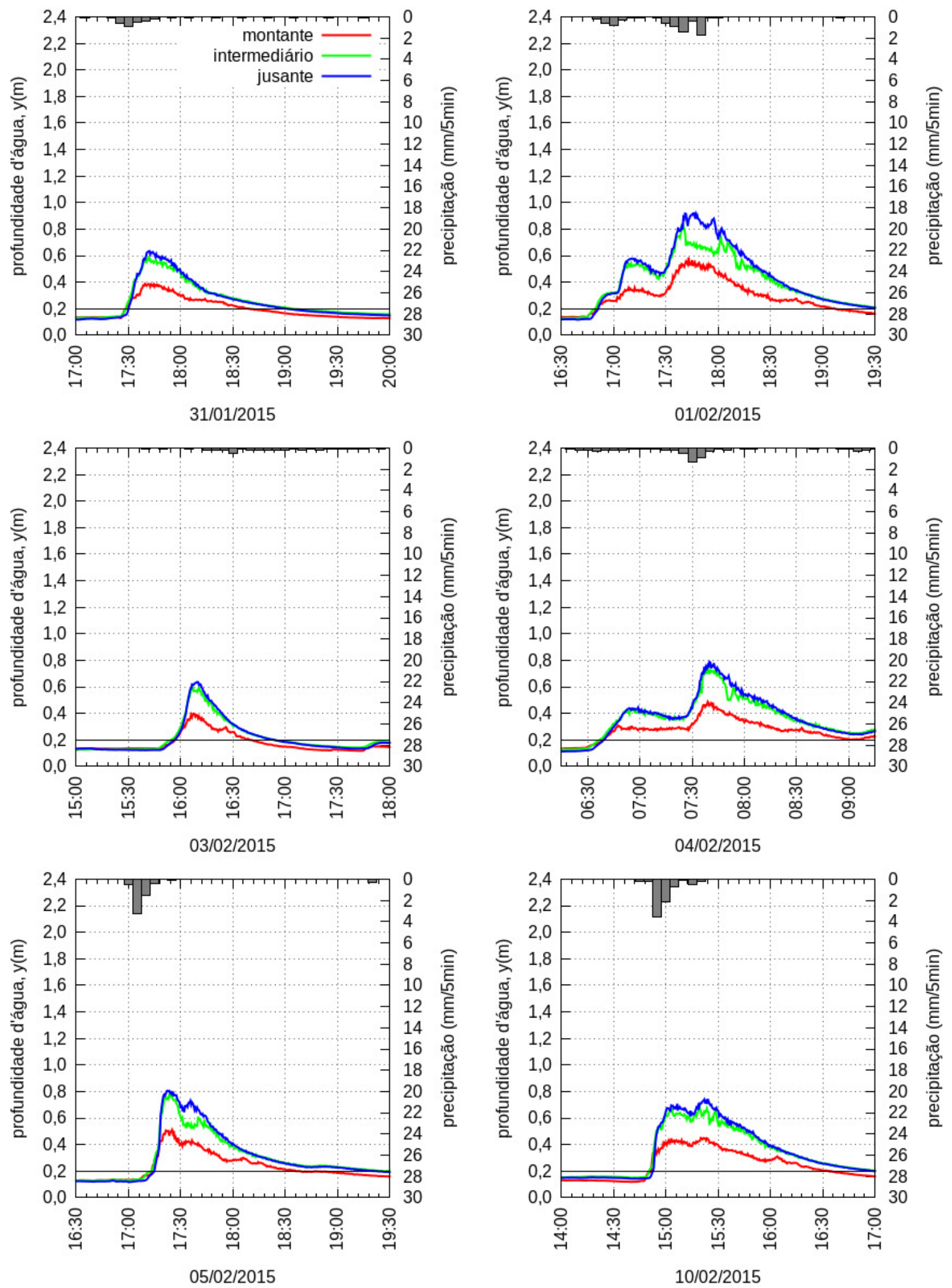

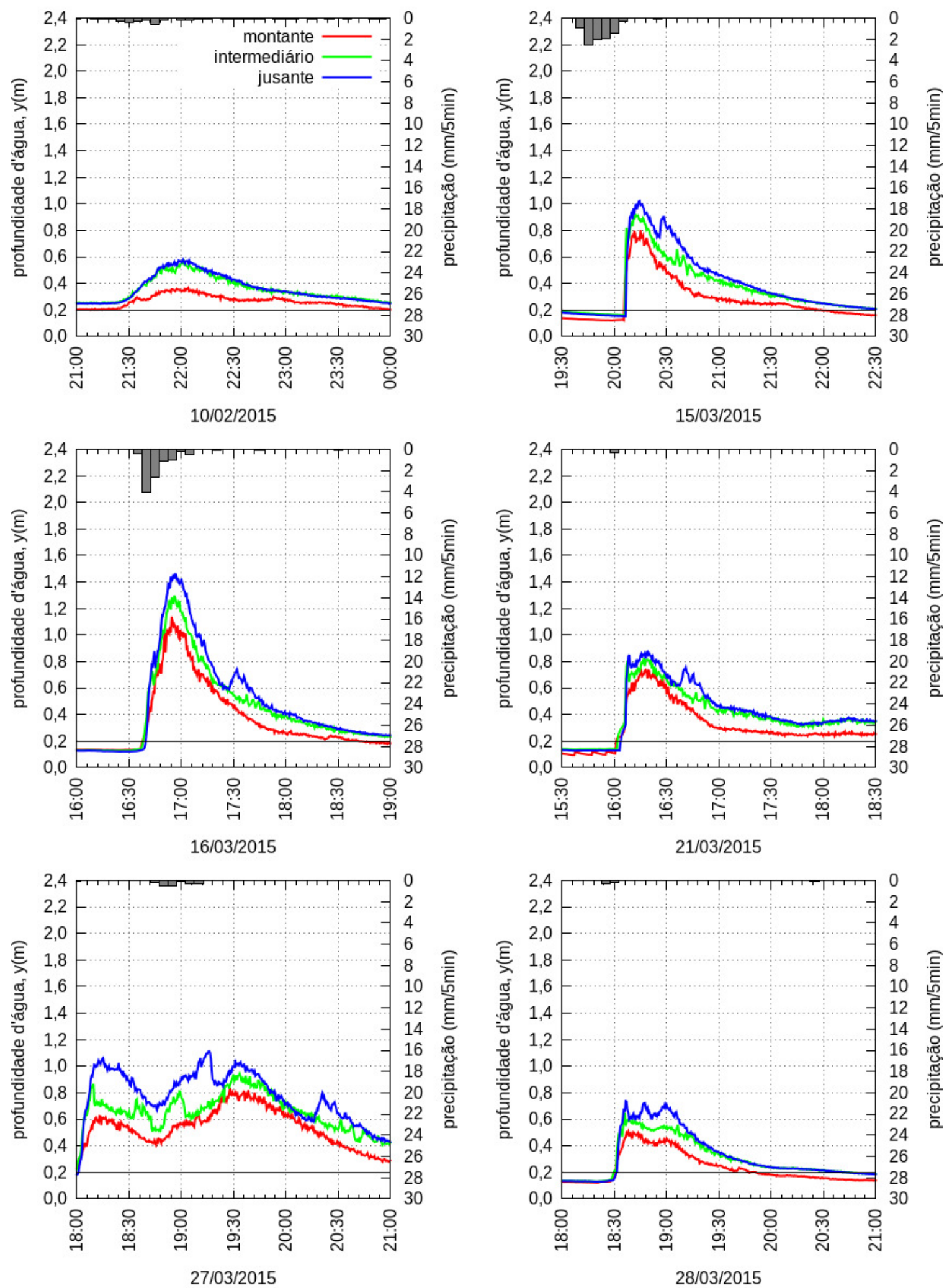

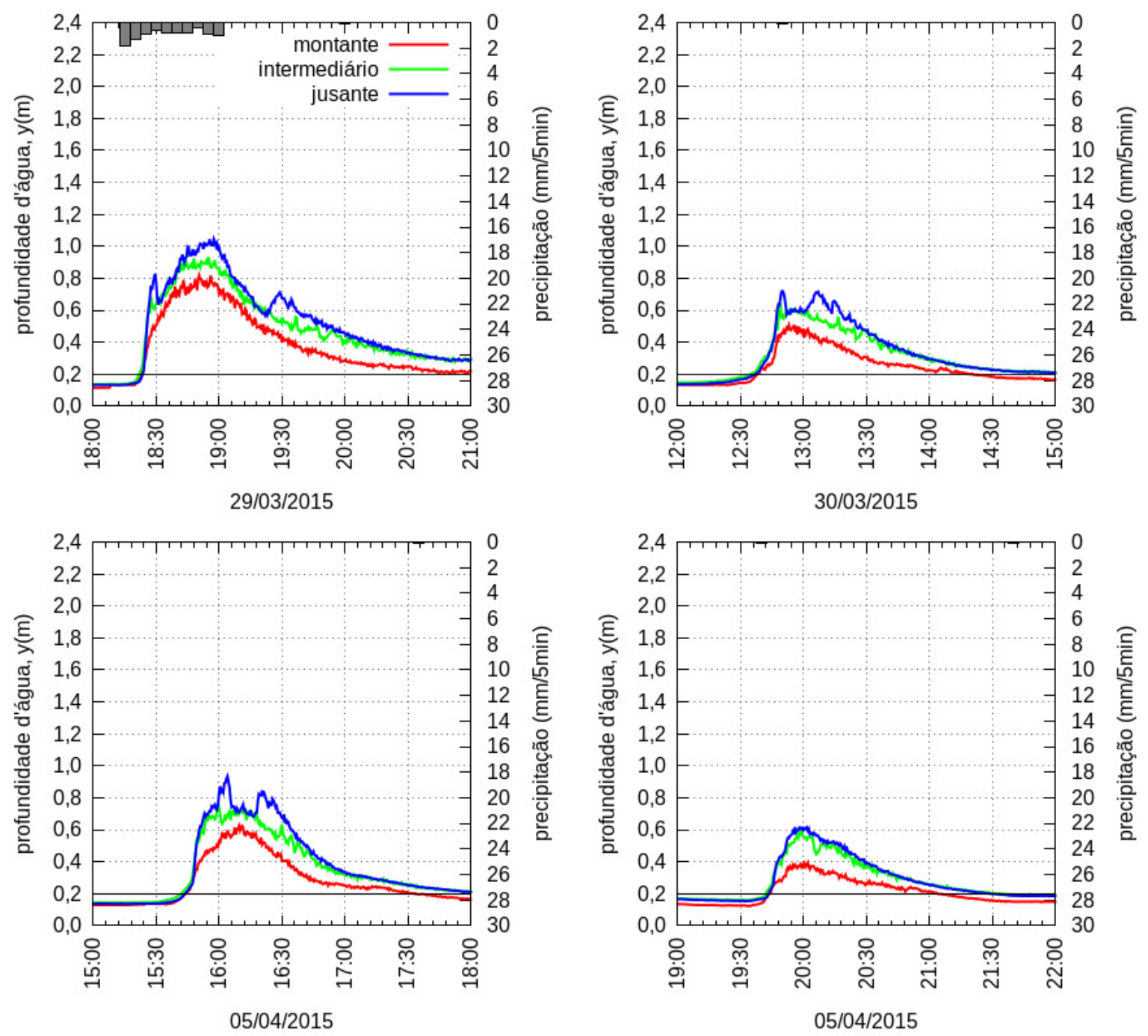


\section{APÊNDICE E - Resultados do Problema} Teste para a discreteização de $\Delta x=10 \mathrm{~m}$
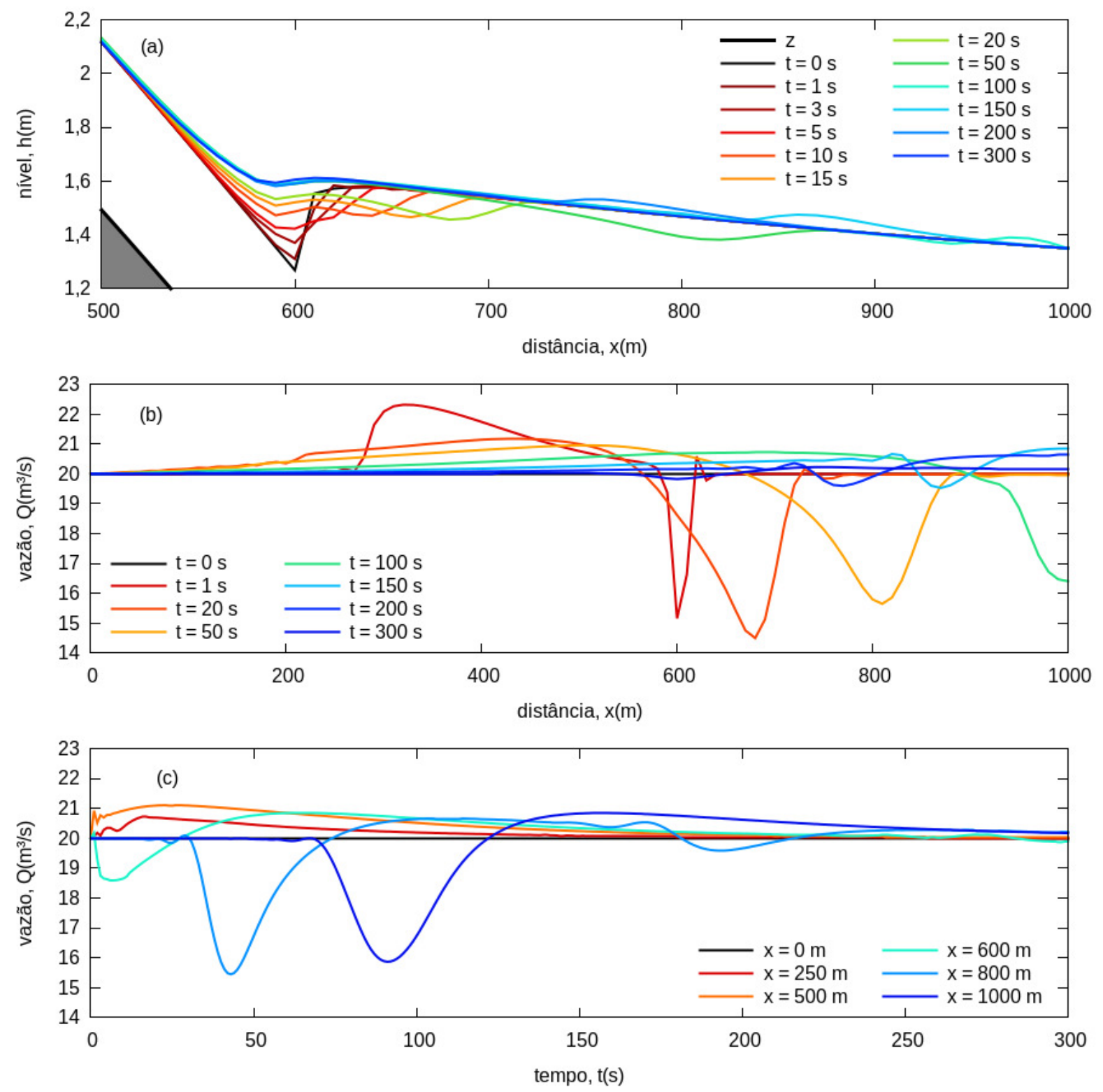

Figura 39 - Evolução da simulação com filtro LPI de $m=5$ e $\Delta x=10 \mathrm{~m}$. 

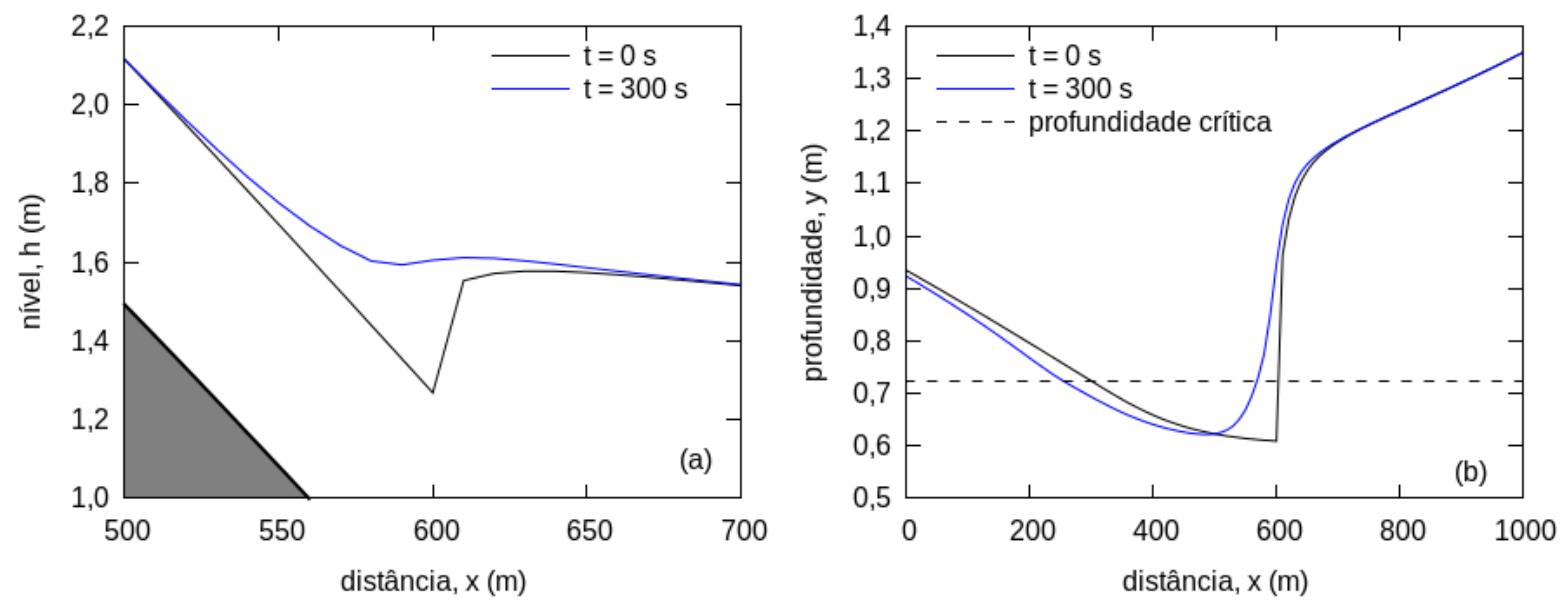

Figura 40 - Solução estabilizada para o filtro de $m=5$ e $\Delta x=10 \mathrm{~m}$. 


\section{APÊNDICE F - Limnigramas simulados dos eventos obtidos com a instalação em tubos}
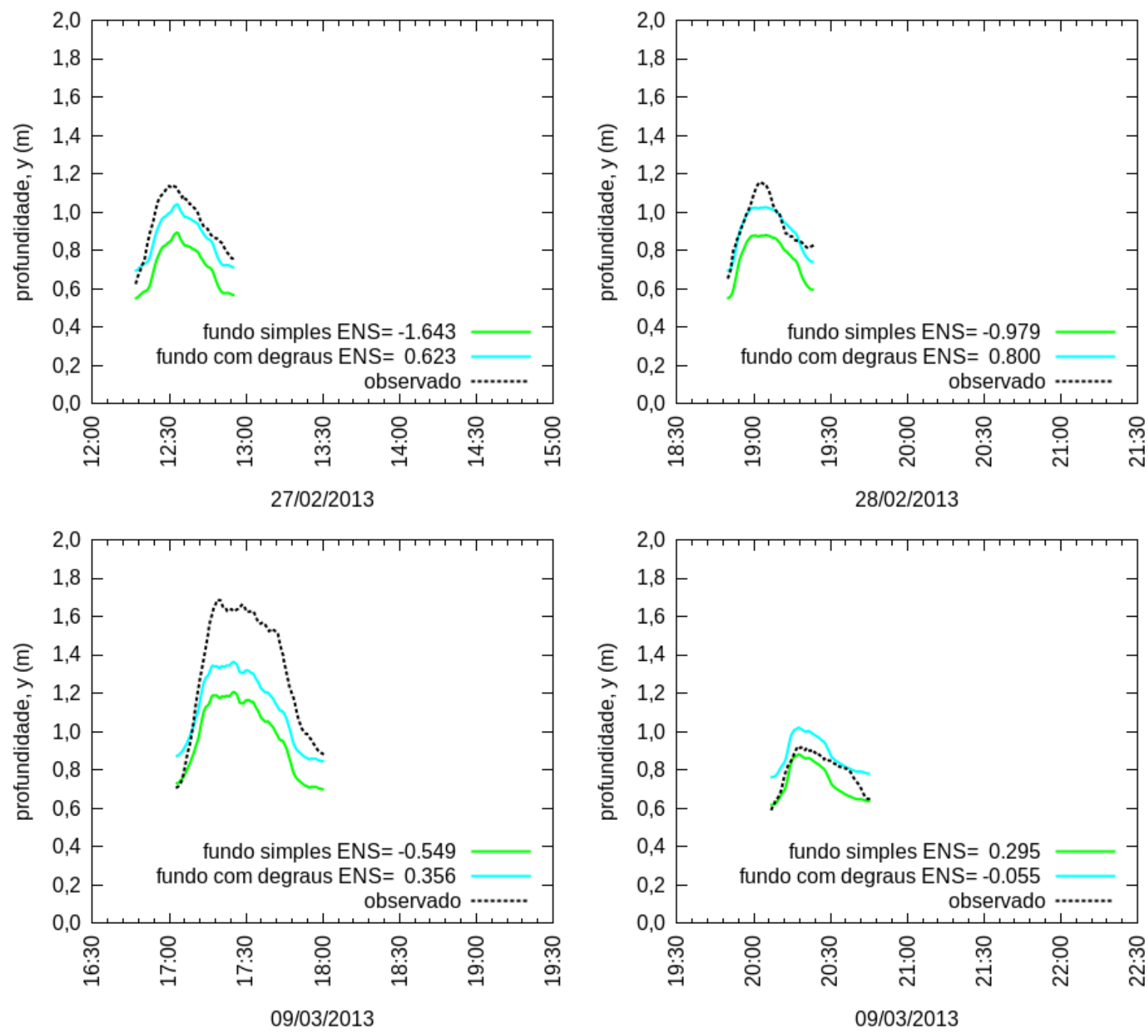

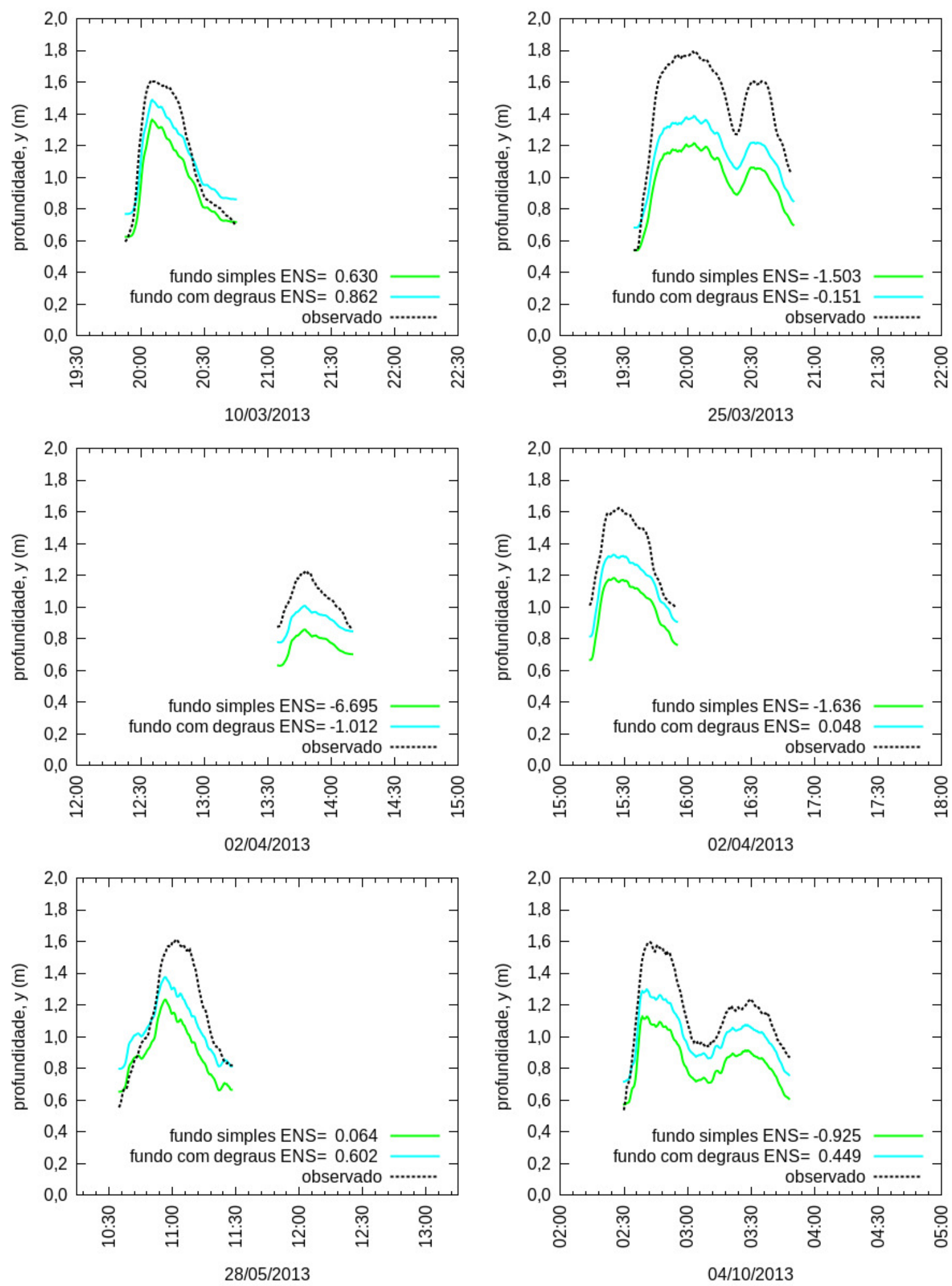

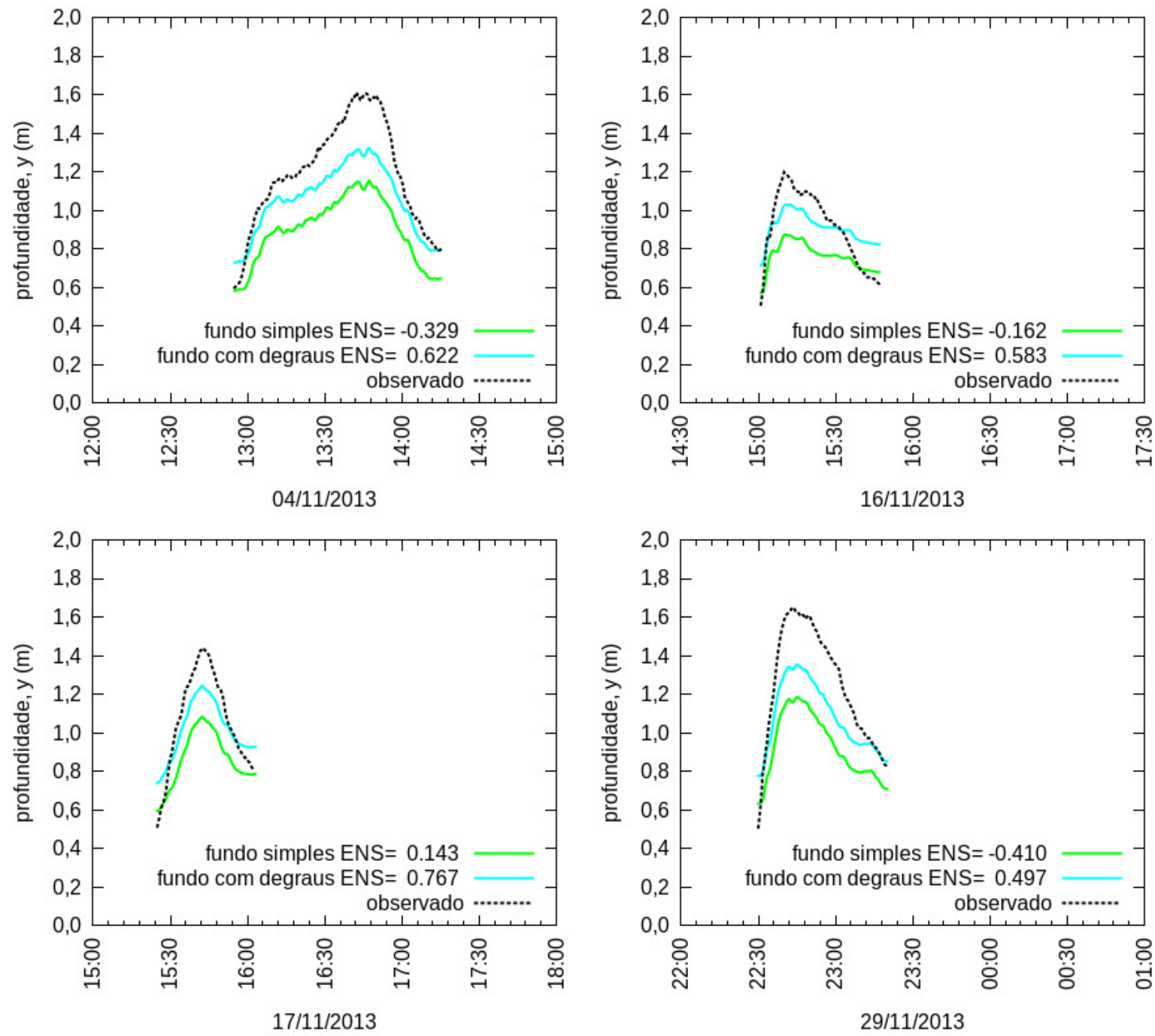



\section{APÊNDICE G - Limnigramas simulados dos eventos obtidos com a instalação em suportes de fundo}
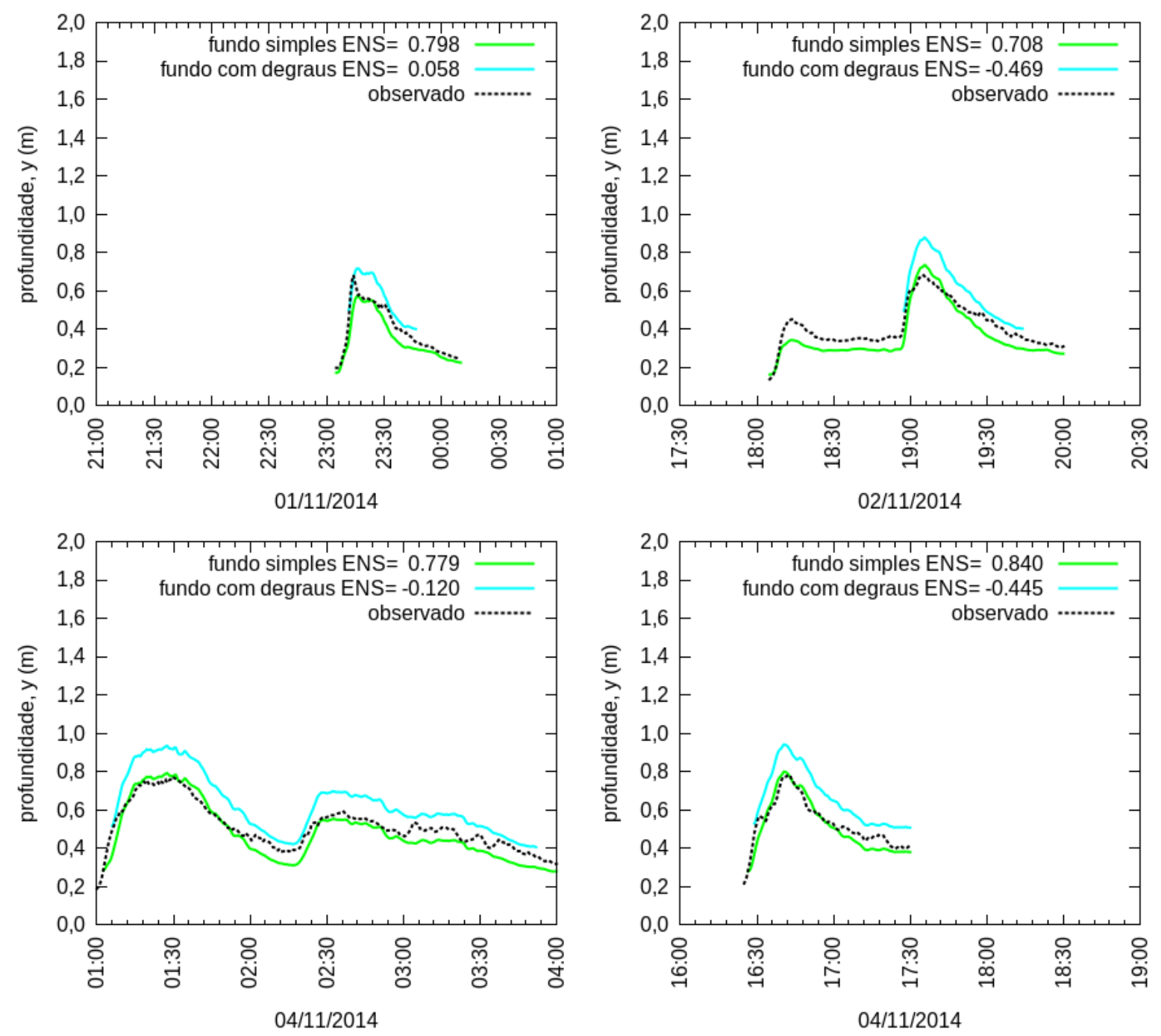

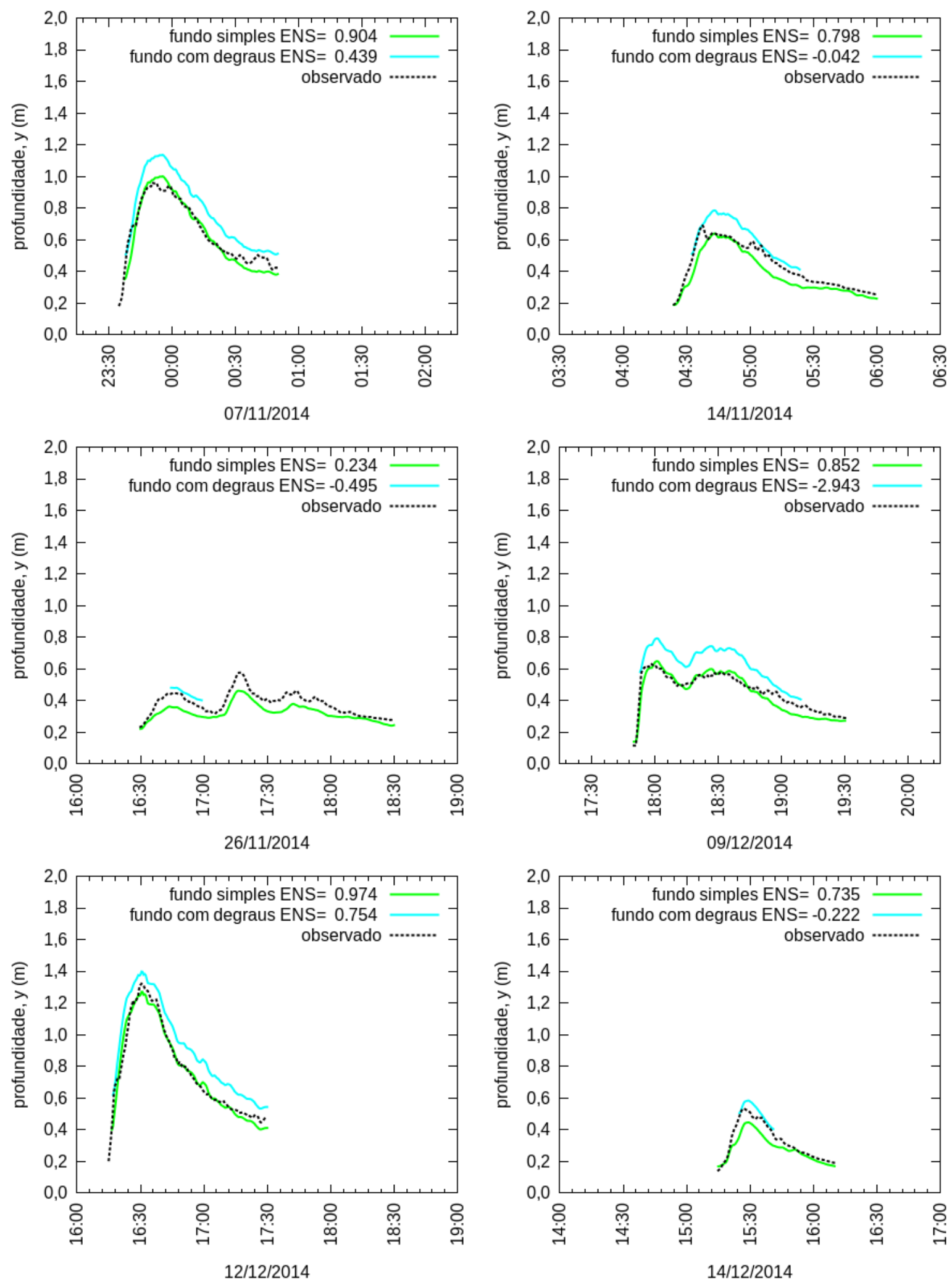

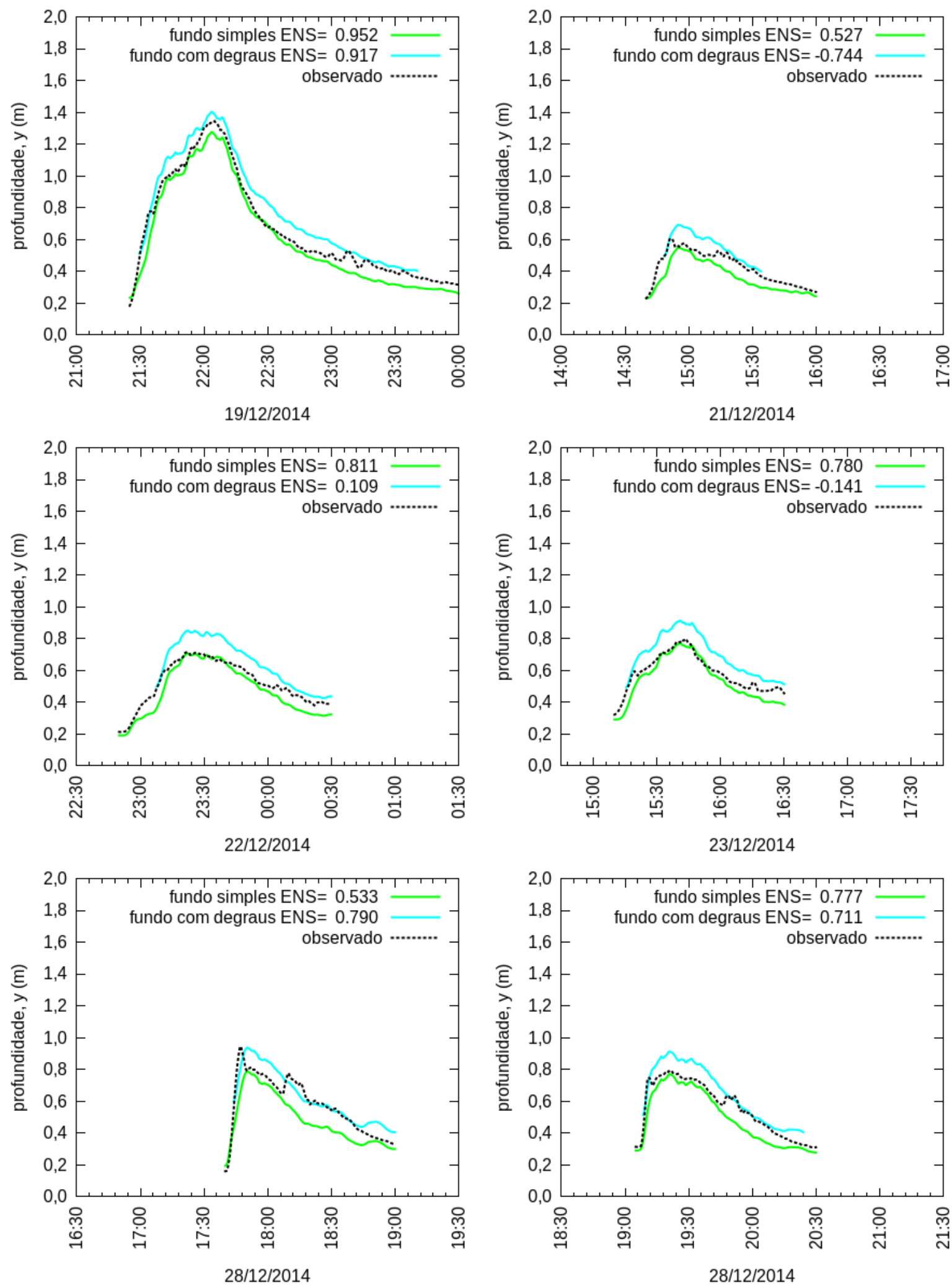

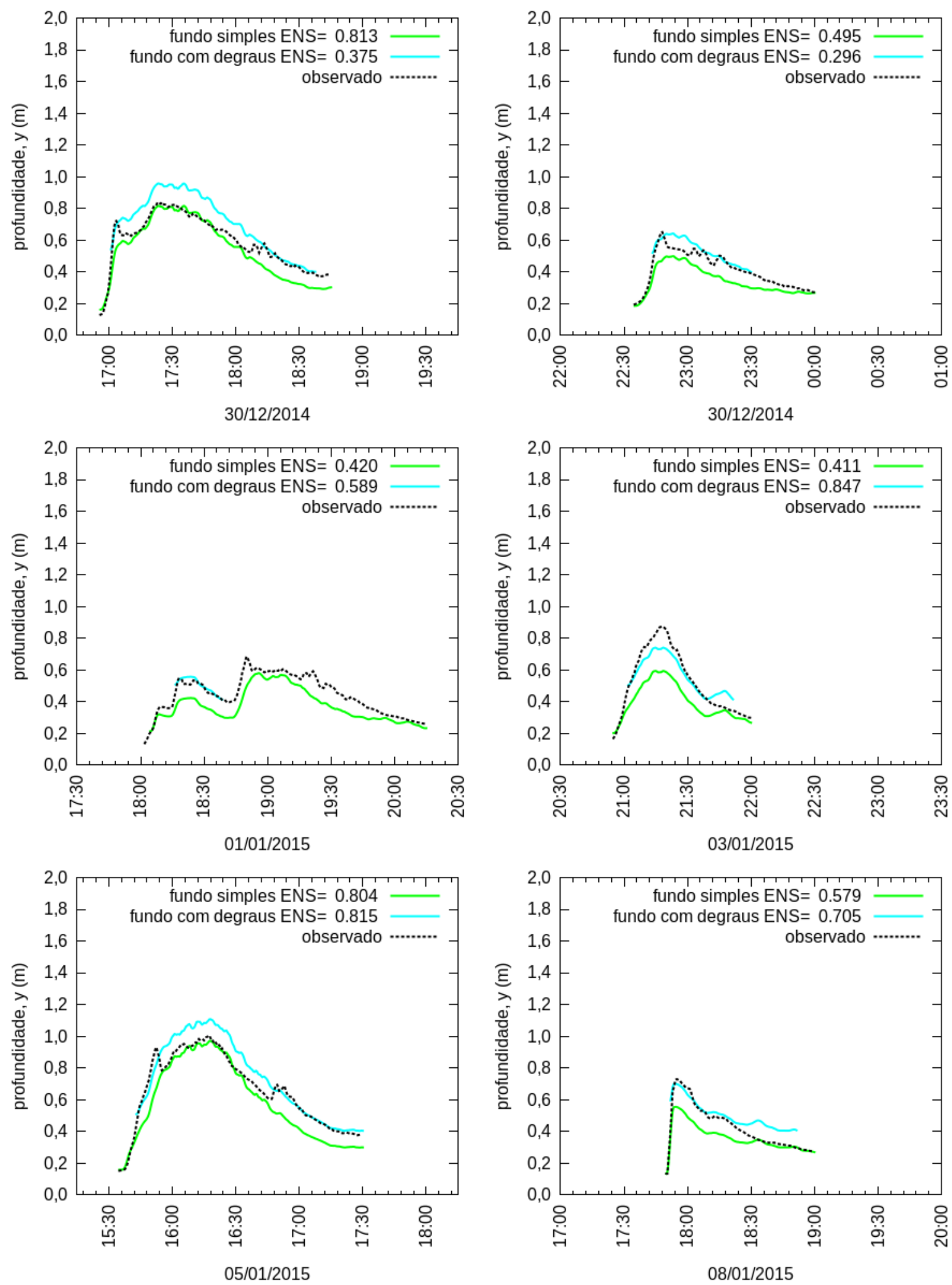

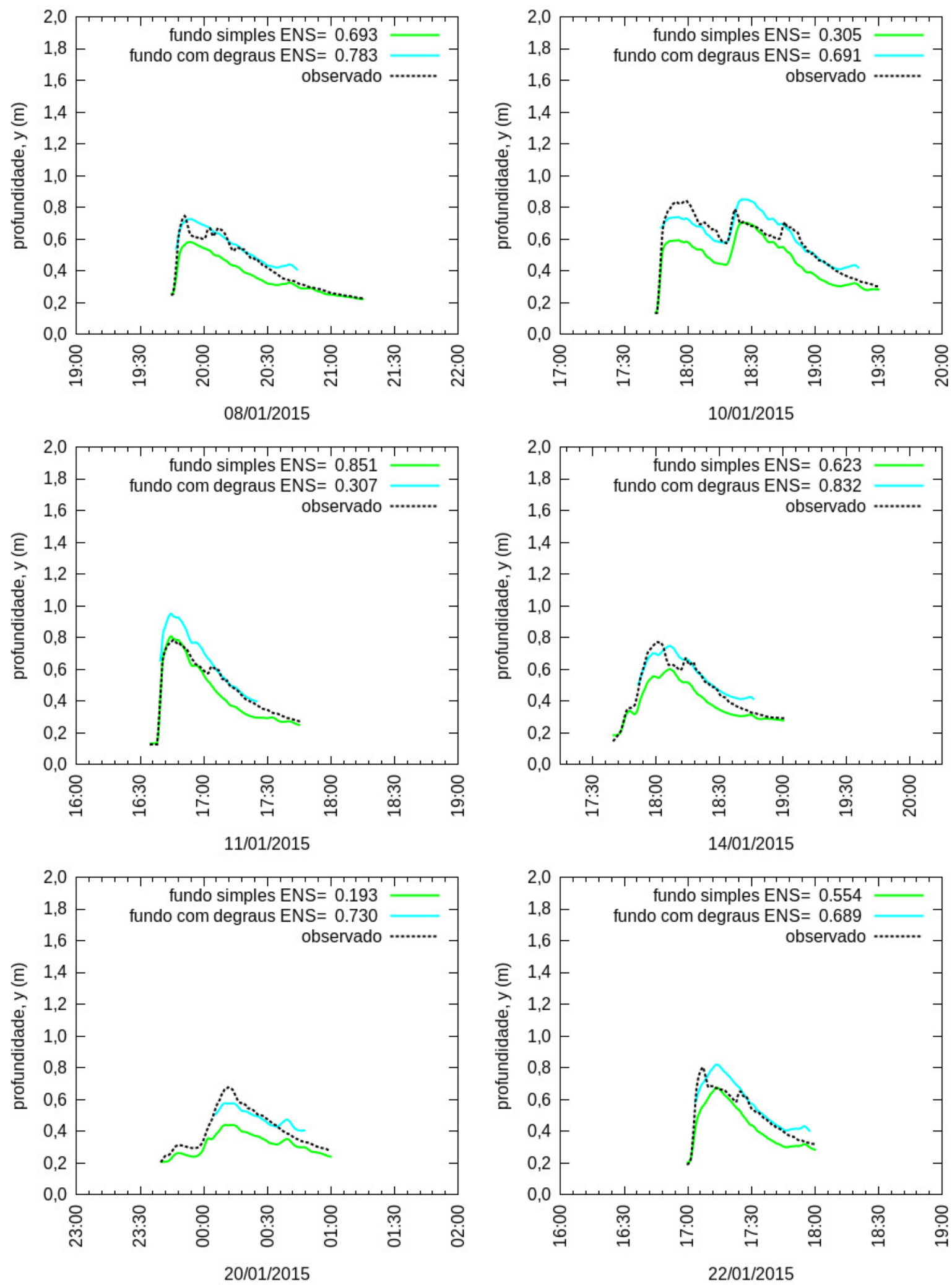

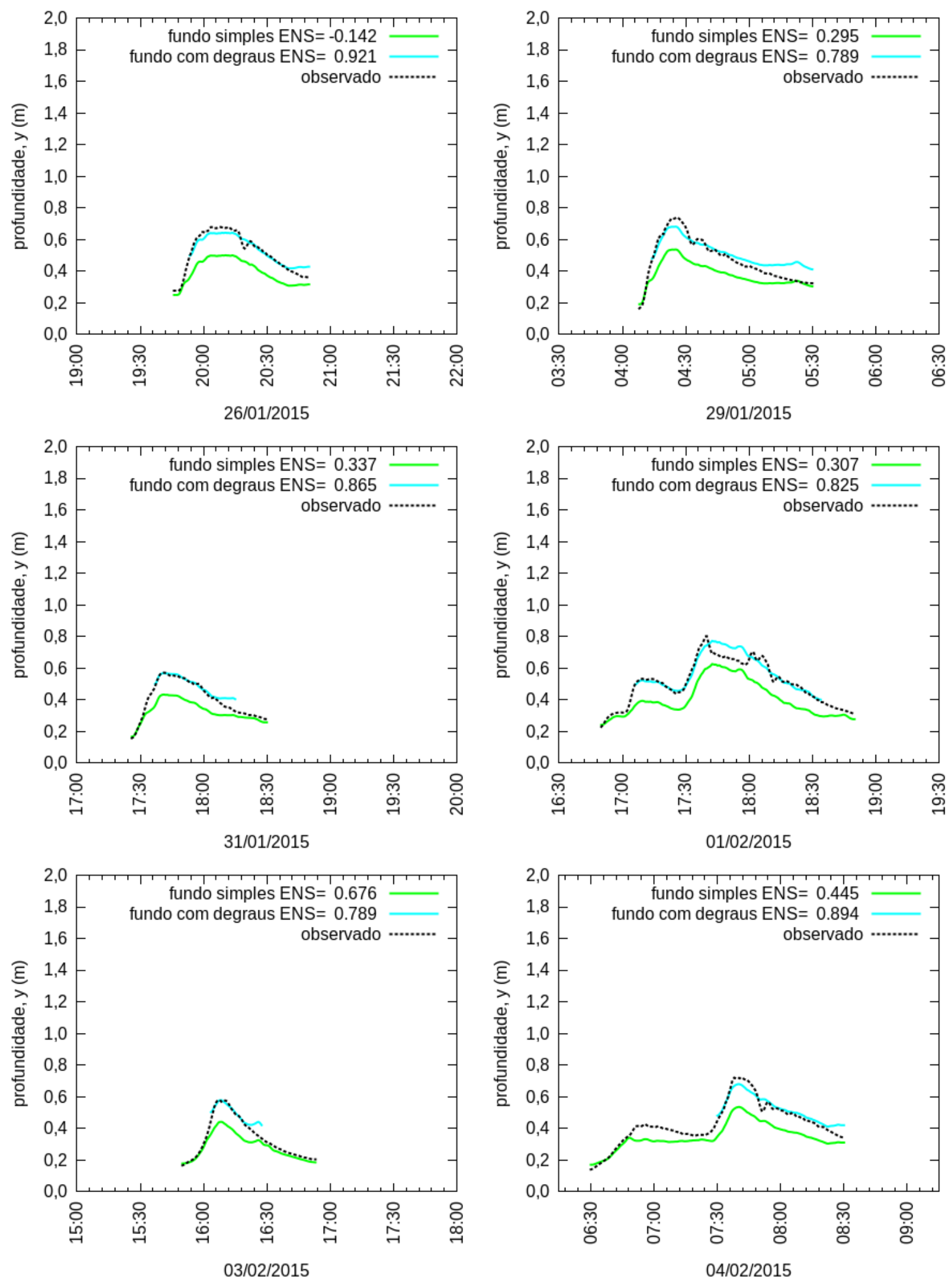

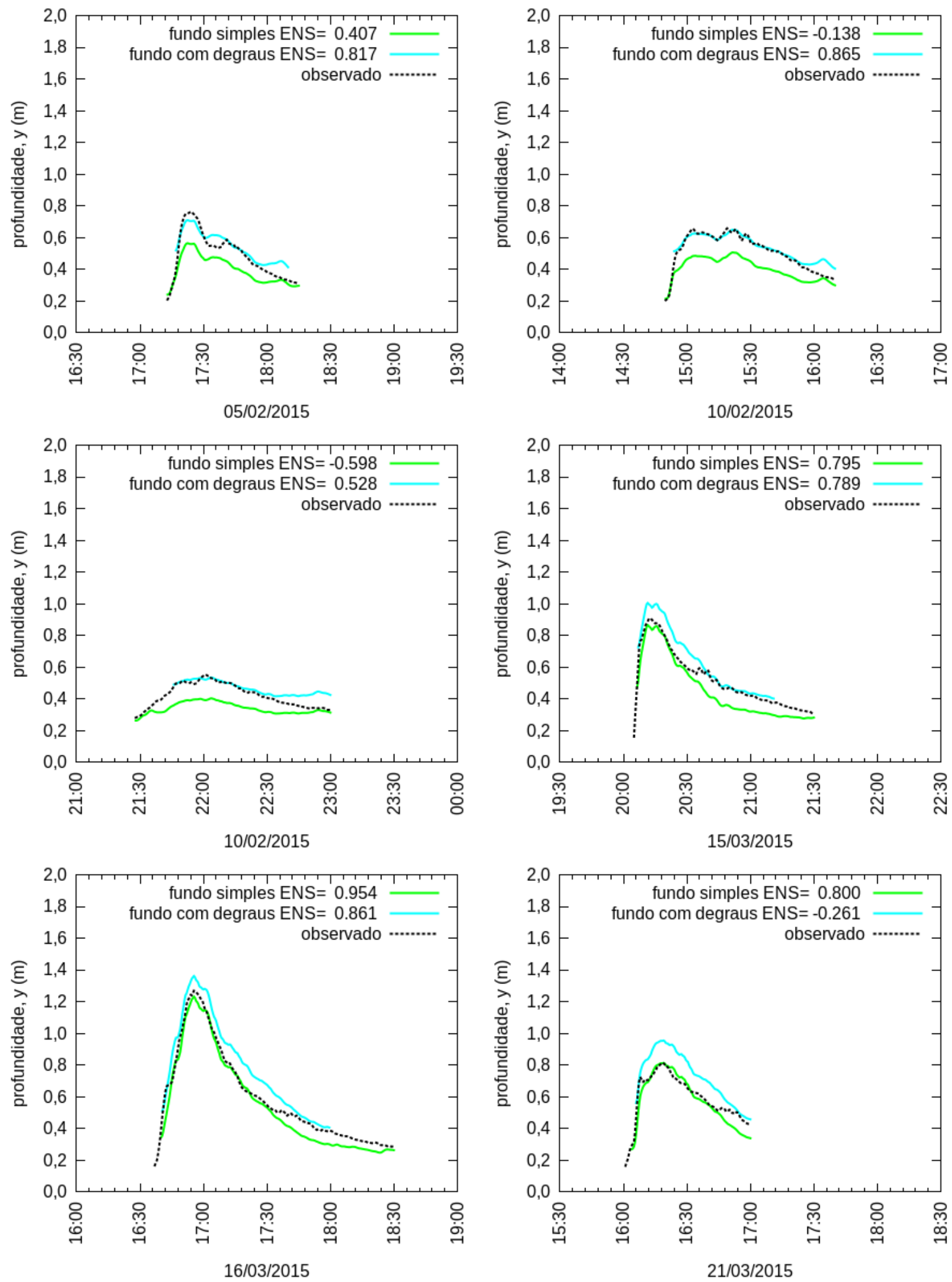

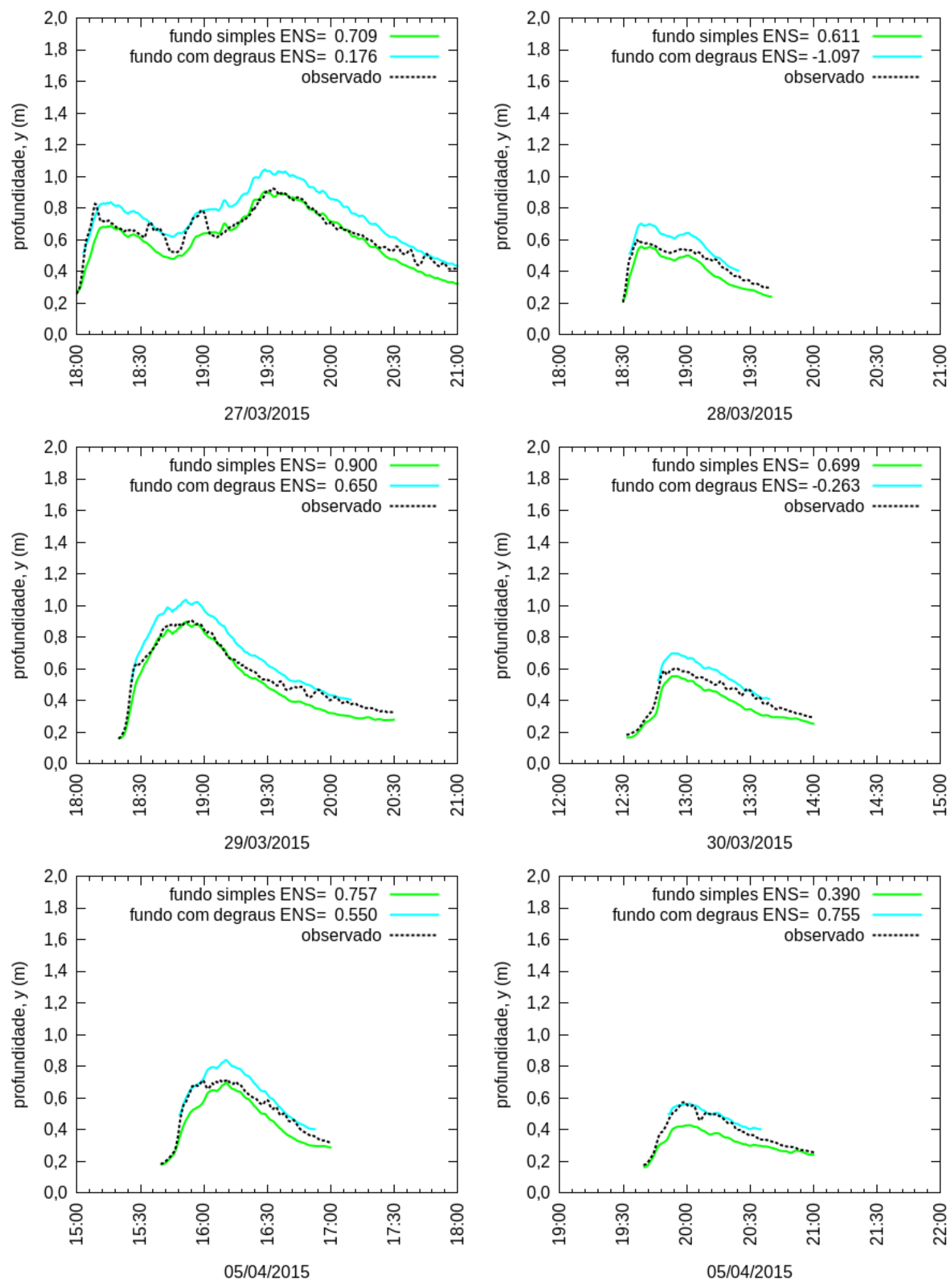


\section{APÊNDICE $\mathrm{H}$ - Hidrogramas simulados dos eventos obtidos com a instalação em tubos}
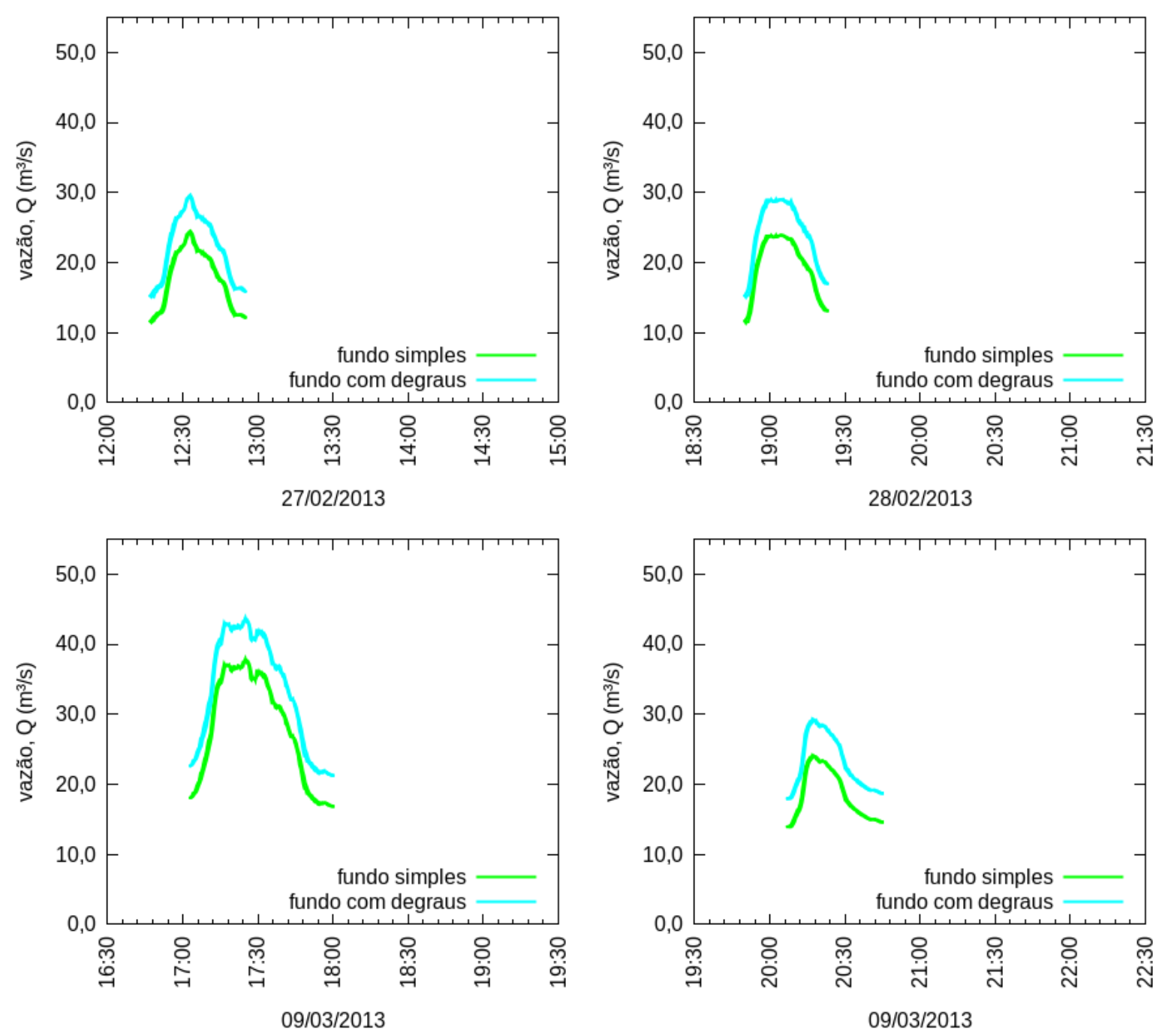

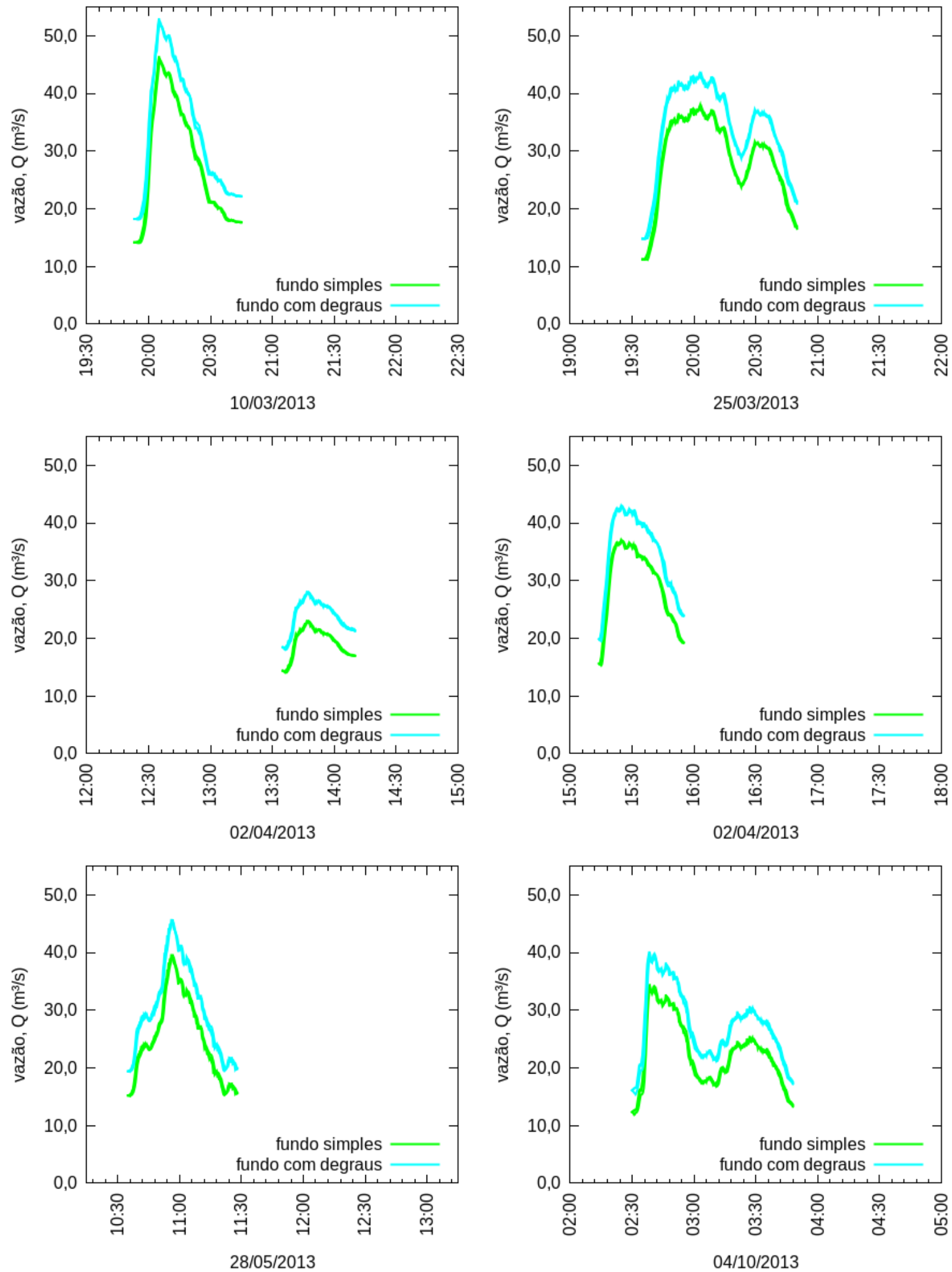

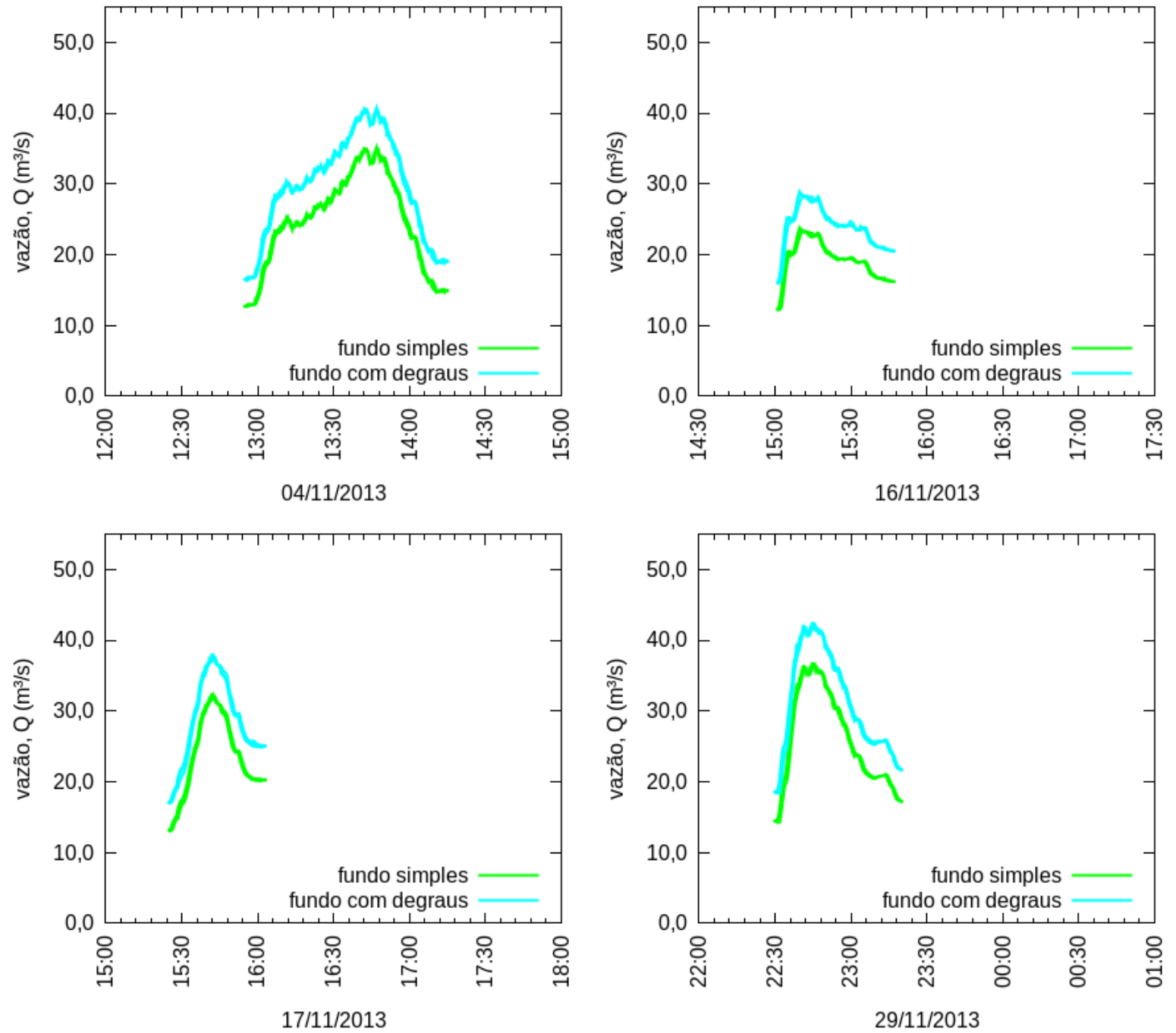



\section{APÊNDICE I - Hidrogramas simulados dos eventos obtidos com a instalação em suportes de fundo}
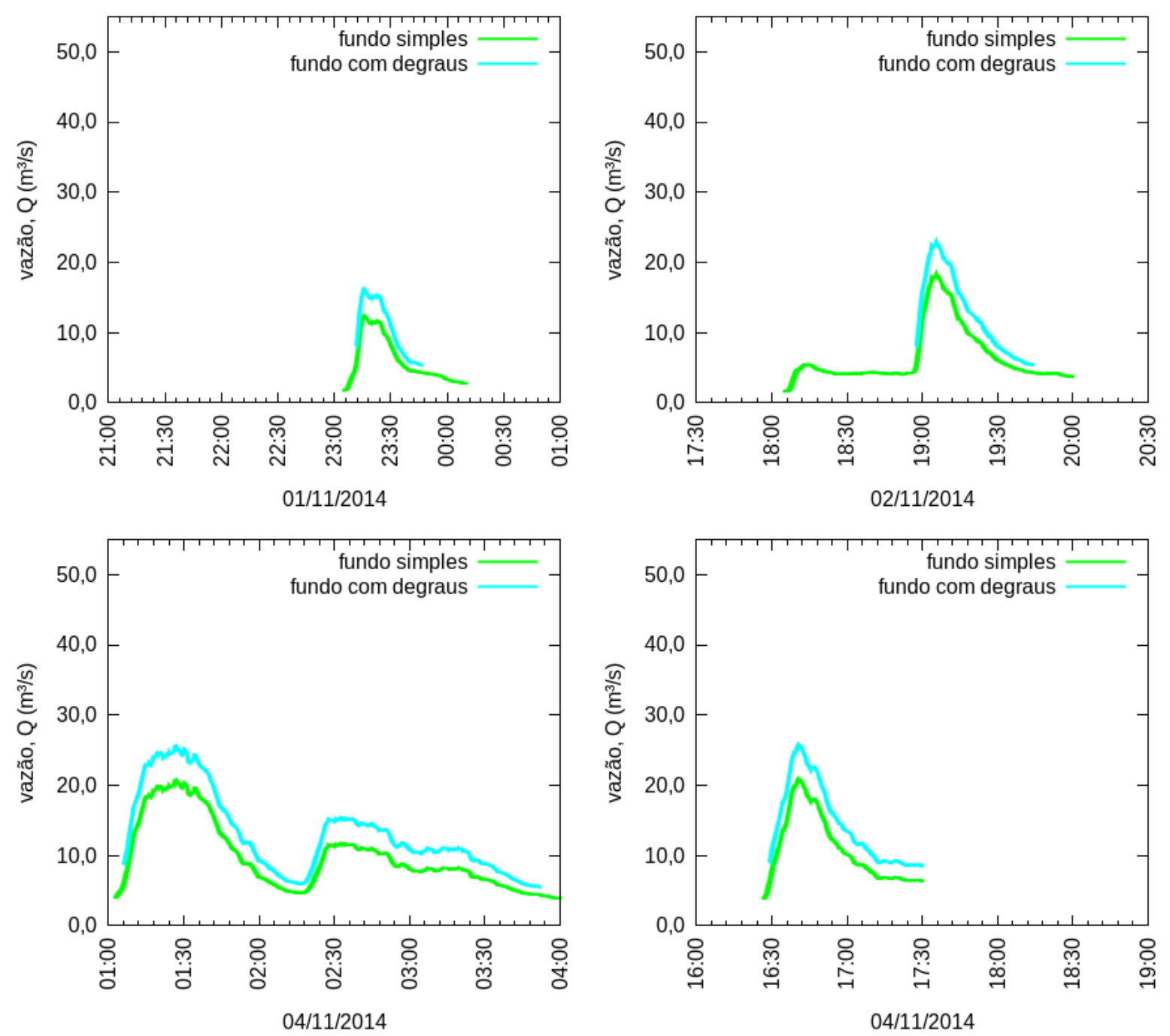

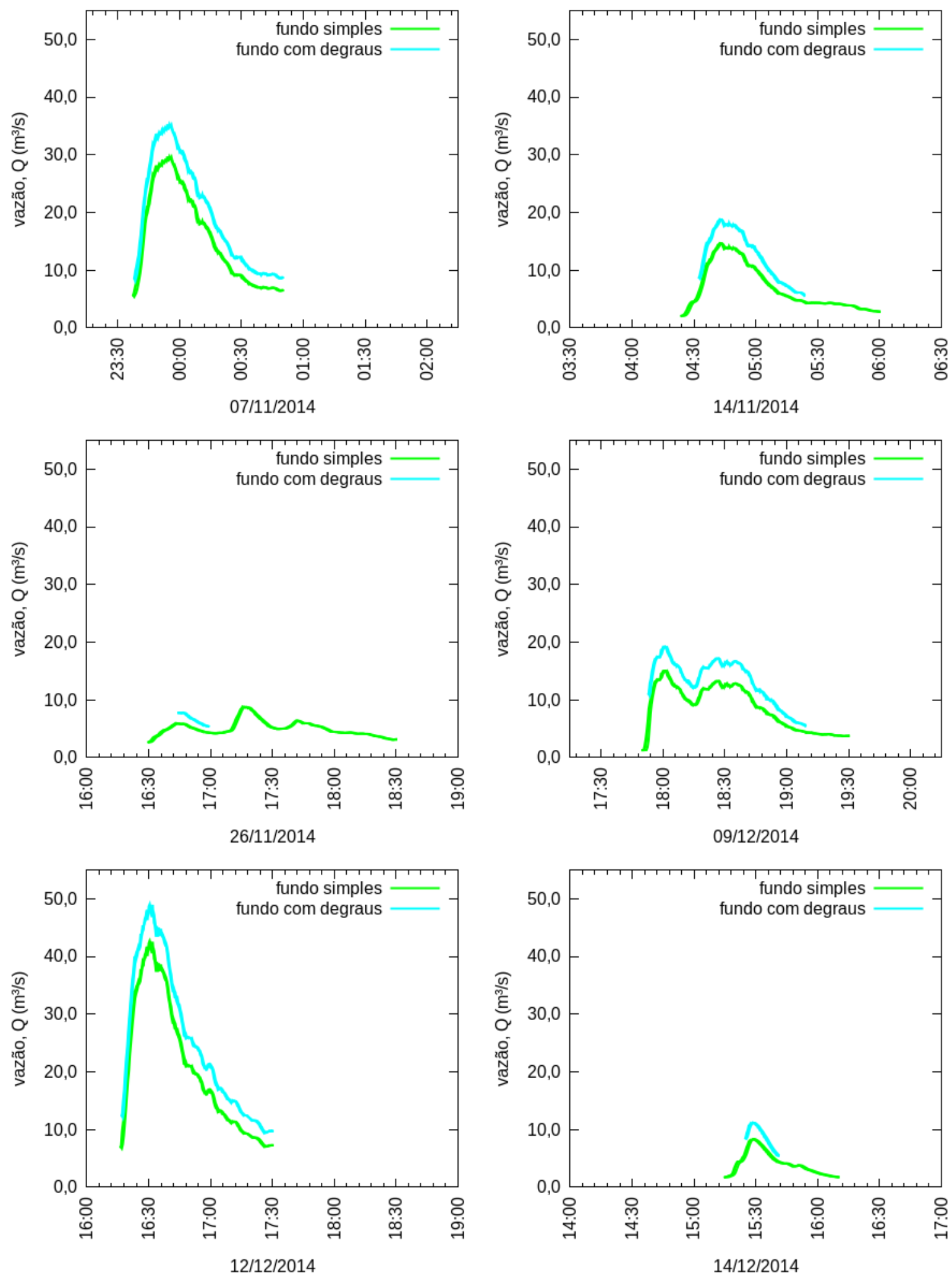

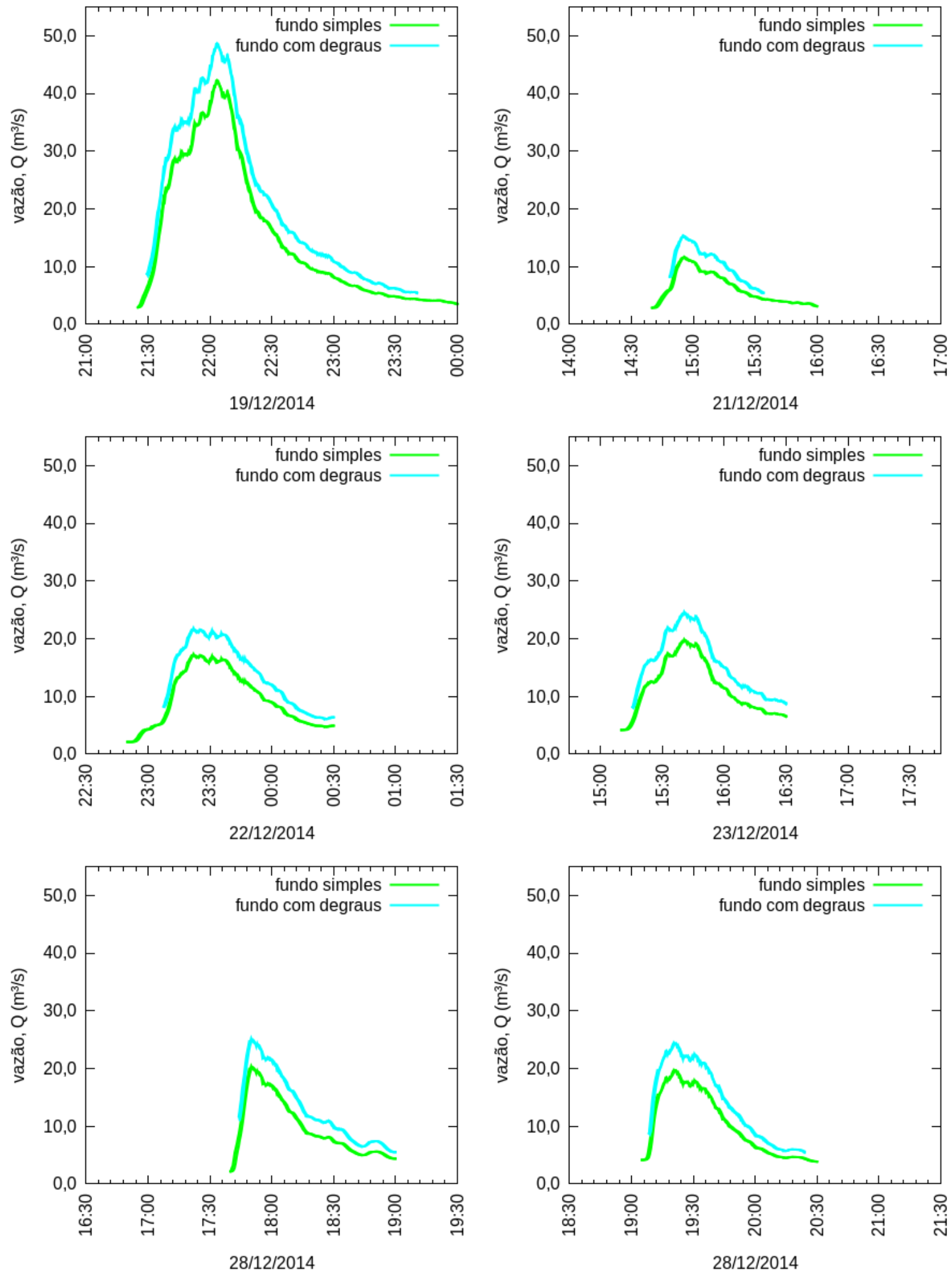

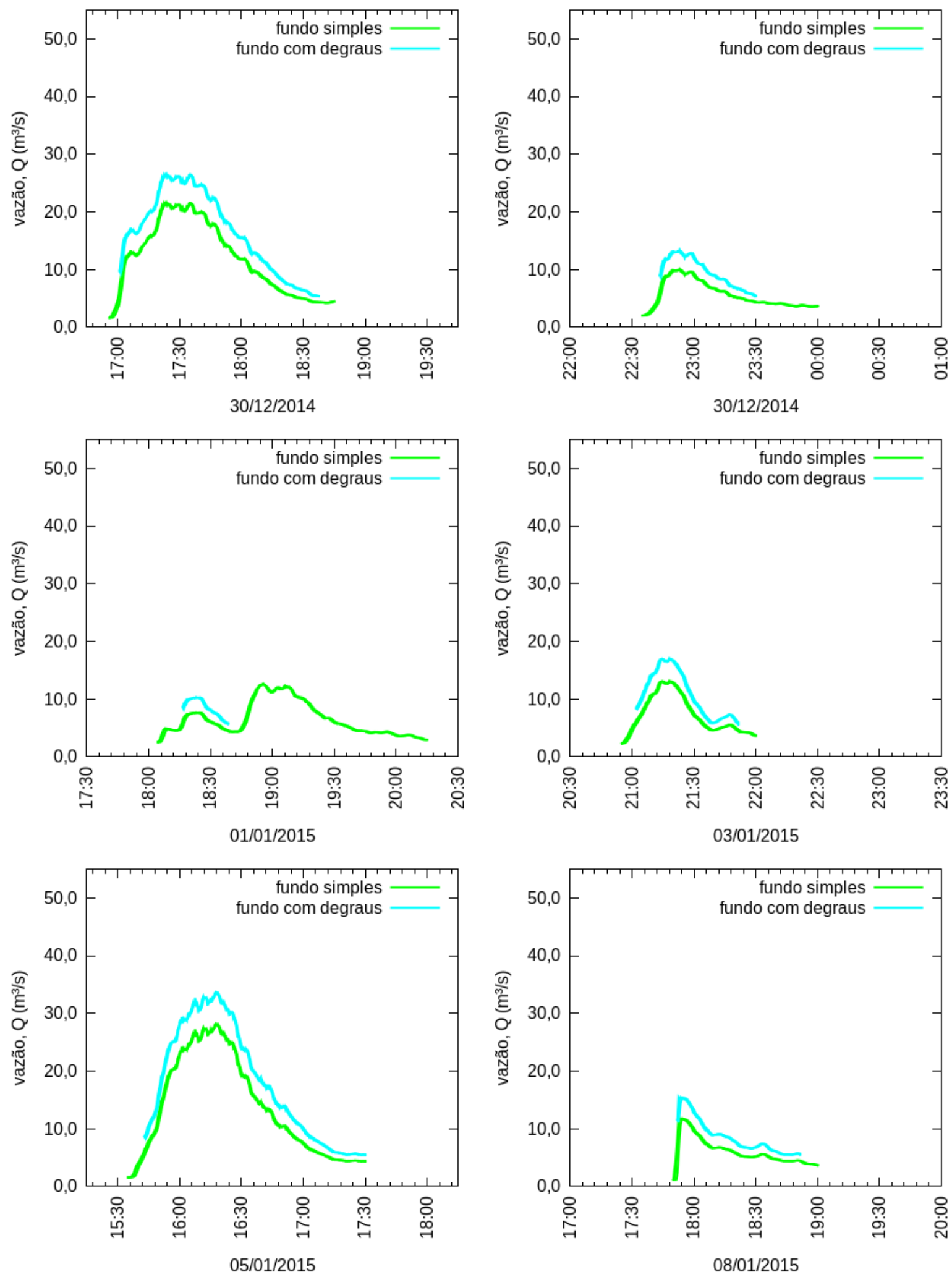

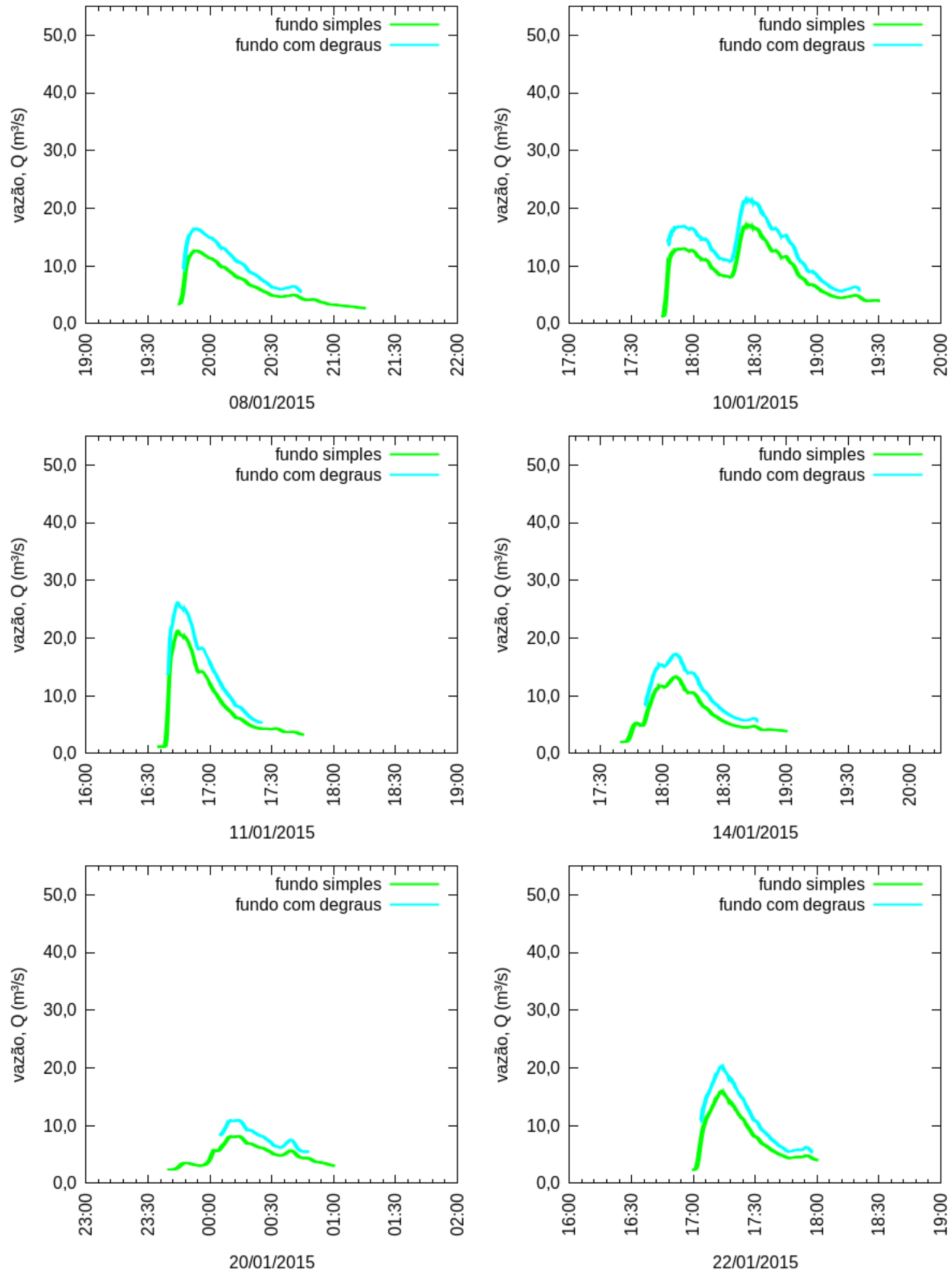

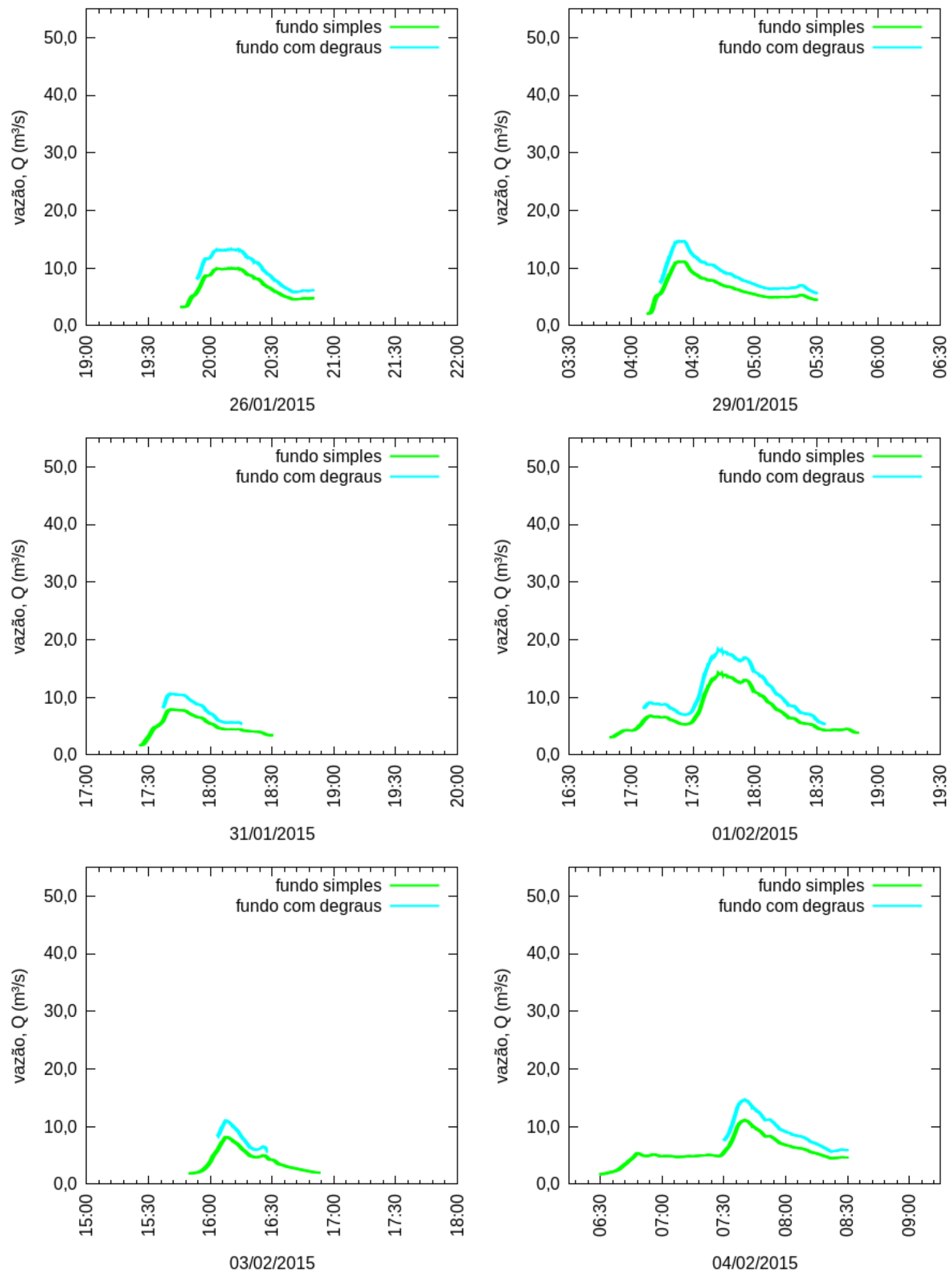

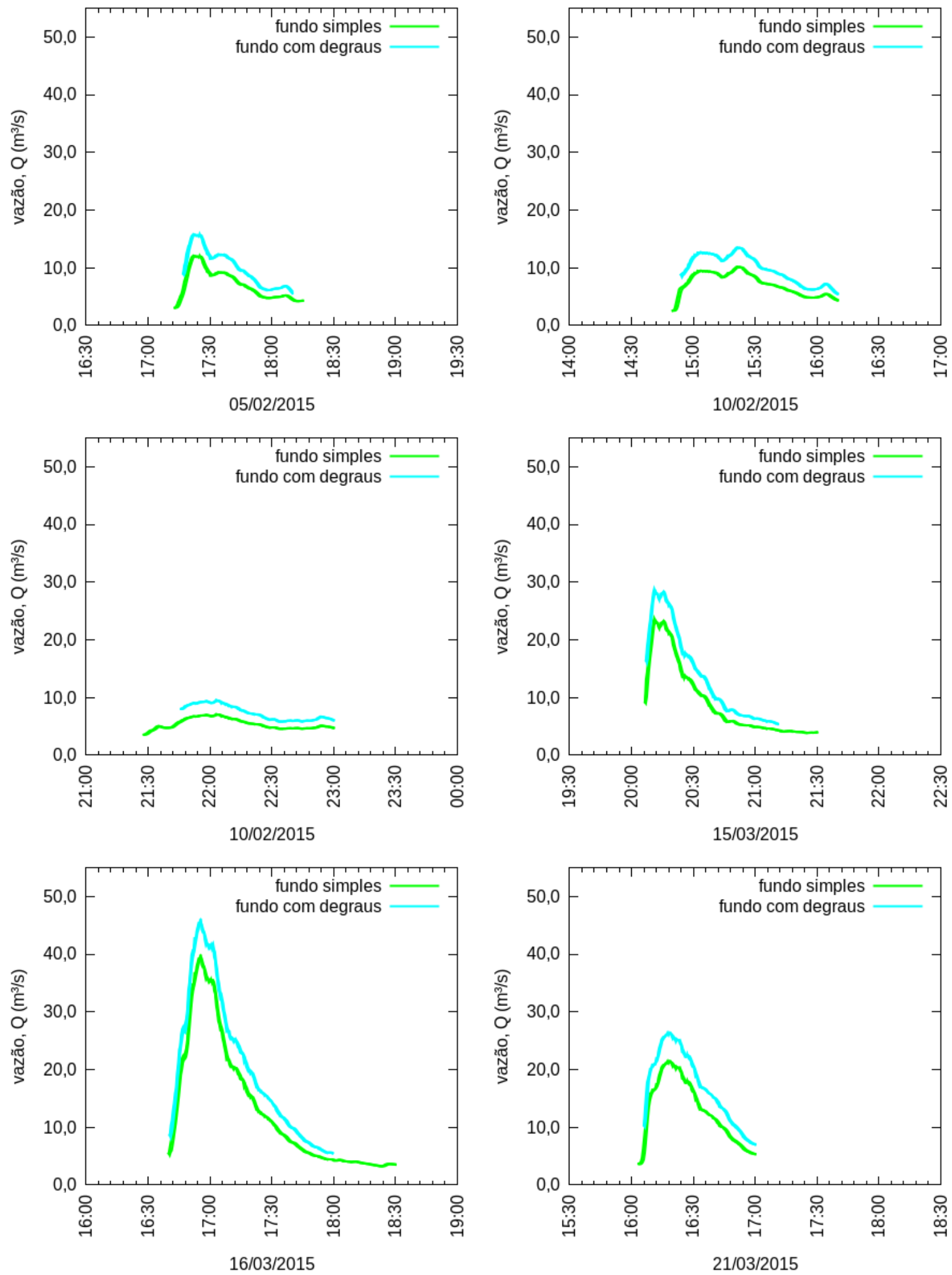

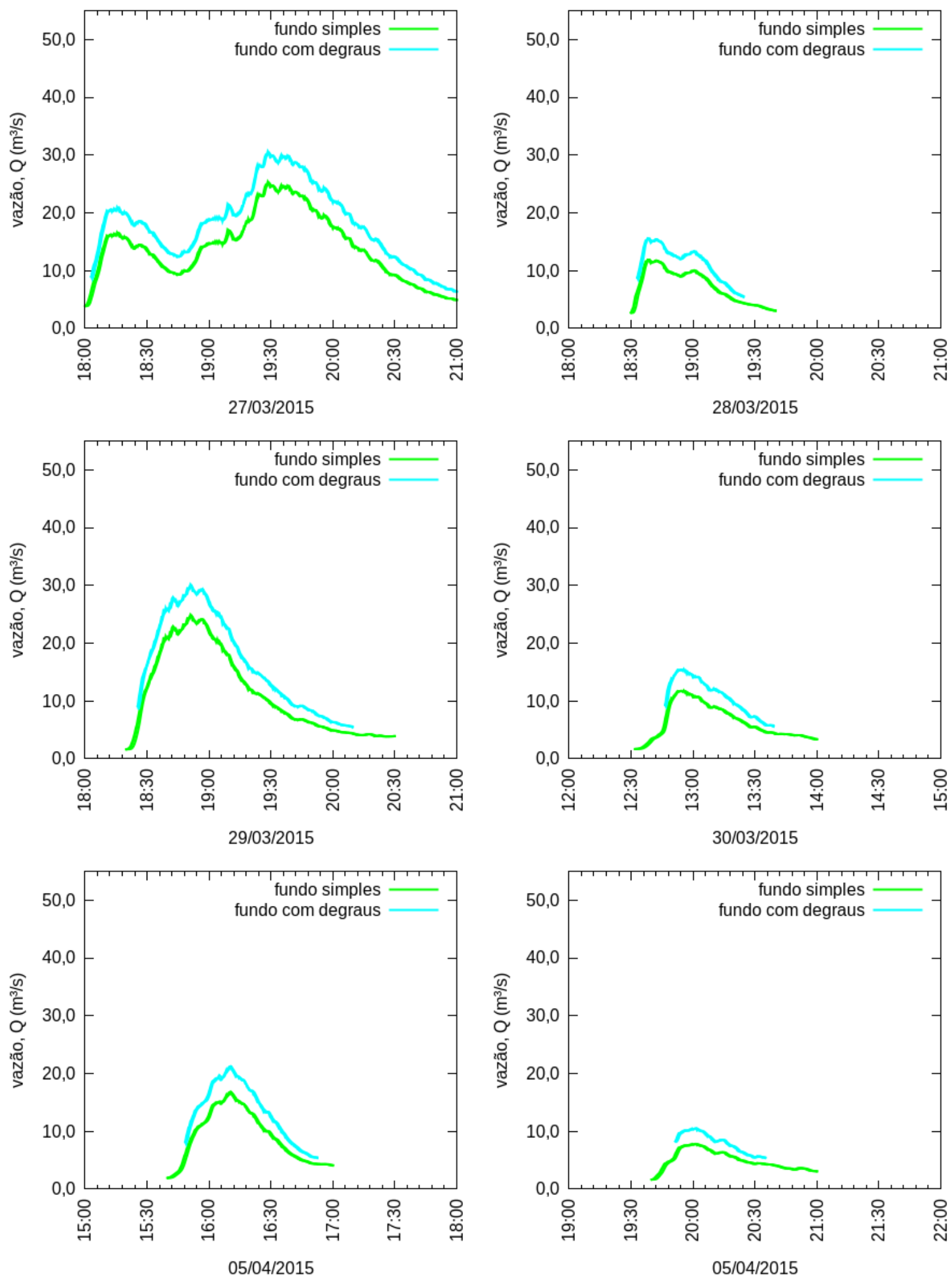
Anexos 



\section{ANEXO A - Rede de Hidrometria}

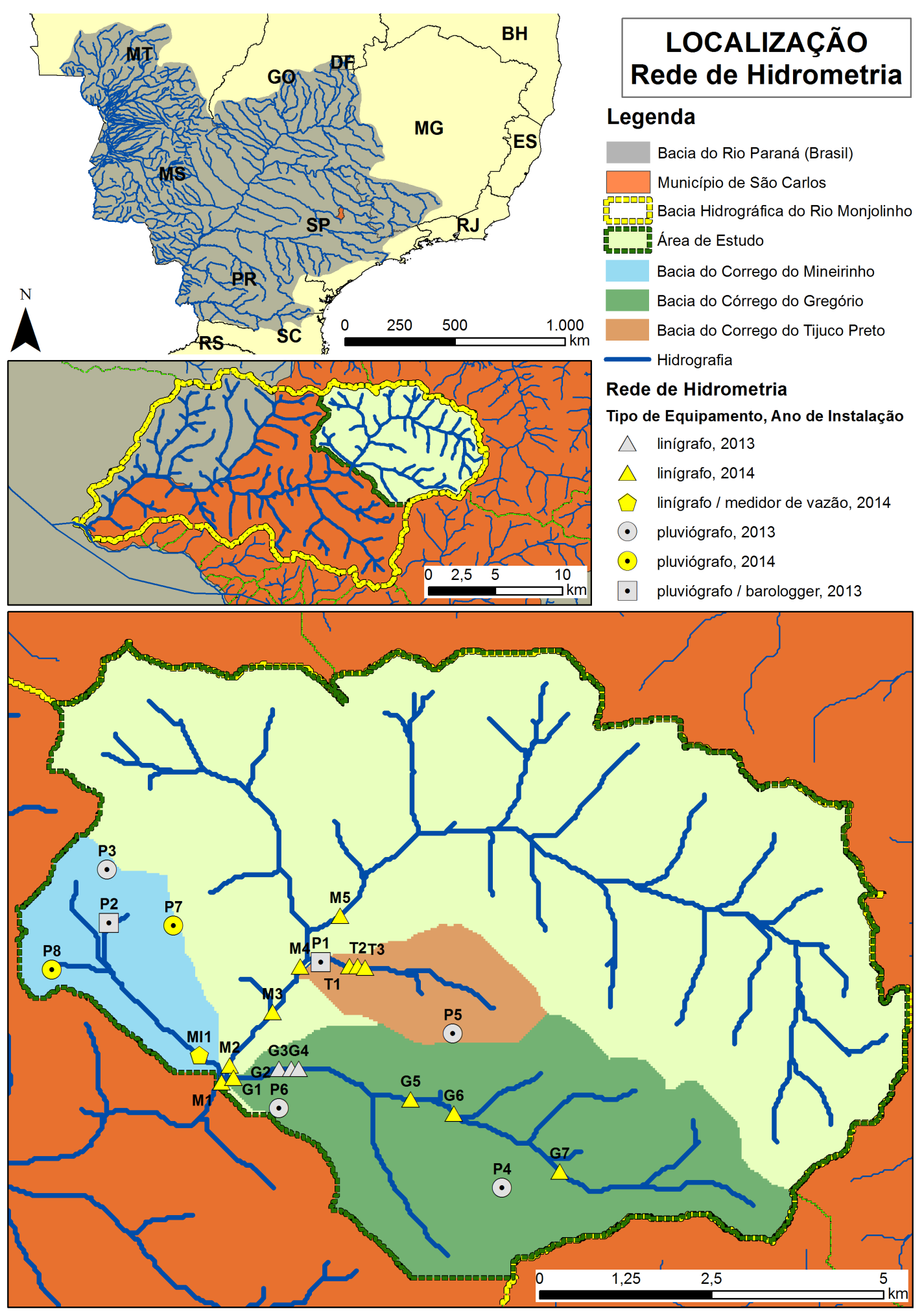

